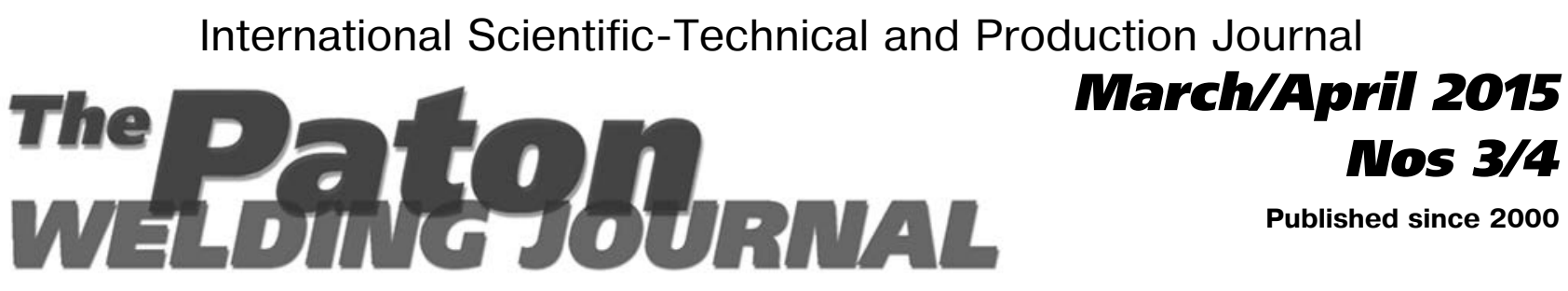

English translation of the monthly «Avtomaticheskaya Svarka» (Automatic Welding) journal published in Russian since 1948

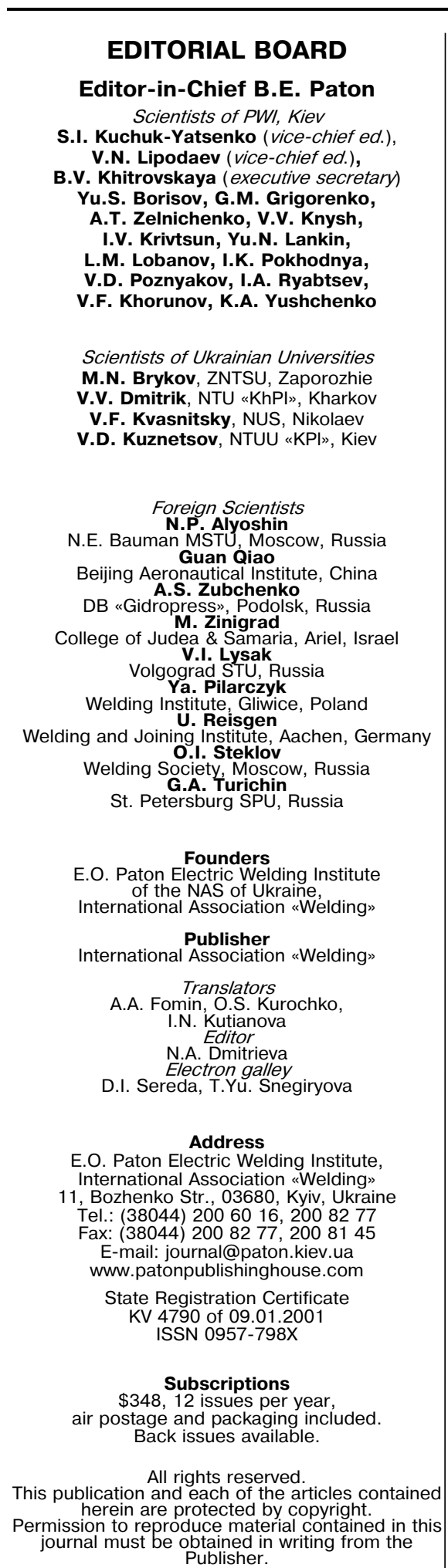

\title{
CONTENTS
}

Evgeny O. Paton, the outstanding scientist in the field of welding and bridge construction (on the occasion of the 145th birthday anniversary)

\section{SCIENTIFIC AND TECHNICAL}

Krivstun I.V., Krikent I.V., Demchenko V.F., Reisgen U., Zabirov A.F. and Mokrov O.A. Interaction of $\mathrm{CO}_{2}$-laser radiation beam with electric arc plasma in hybrid (laser + TIG) welding

Rybakov A.A., Filipchuk T.N. and Kostin V.A. Peculiarities of microstructure and impact toughness of metal of welded joints of pipes of high-strength steel with niobium and molybdenum

Makhlin N.M. and Korotynsky A.E. Asynchronous exciters and stabilizers of welding arc. Analysis and design procedure.

Part 1

Gulyaev I.P., Gulyaev P.Yu., Korzhik V.N., Dolmatov A.V., Iordan V.I., Krivtsun I.V., Kharlamov M.Yu. and Demianov A.I. Experimental investigation of process of plasma-arc wire spraying

Shelyagin V.D., Saenko V.Ya., Polishko A.A., Ryabinin V.A., Bernatsky A.V., Stepanyuk S.N. and Klochkov I.N. Laser welding of commercial arc slag remelted titanium VT1-0 hardened by nitrogen

\section{INDUSTRIAL}

Lyuty A.P. Contribution of Professor Evgeny O. Paton to the development of welding materials science and production of high-quality steel

Kapustyan A.E. Manufacture of long-length semi-products from sintered titanium alloys using friction welding

Khokhlov M.A. and Ishchenko D.A. Structural superlight porous metals (Review)

Tikhy V.G., Gusev V.V., Potapov A.M., Shevtsov E.I., Gusarova I.A., Manko T.A. and Falchenko Yu.V. Thermal protection tile structures of shuttlecraft with different external load-carrying elements

Bryzgalin A.G., Dobrushin L.D., Shlensky P.S., Lavrenko I.G.

and Romashko I.M. Manufacture of coaxial copper-aluminium rods using explosion welding and drawing

Pantelejmonov E.A. and Pismenny A.A. Inductor for continuous heating in hardening of railway rail head

\section{NEWS}

Meeting of Boris E. Paton, President of the NAS of Ukraine, with Carlos Moedas, EU Commissioner 


\section{EVGENY O. PATON, THE OUTSTANDING SCIENTIST IN THE FIELD OF WELDING AND BRIDGE CONSTRUCTION (on the occasion of the 145th birthday anniversary)}

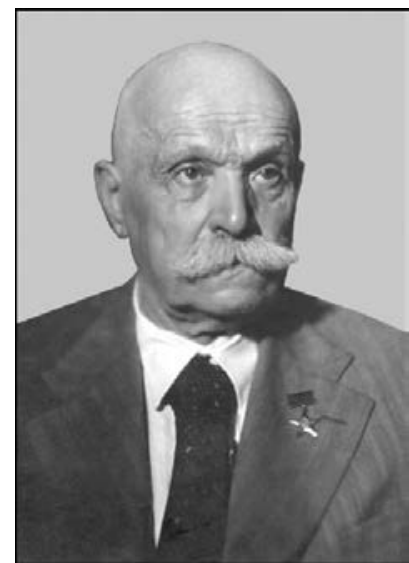

Academician E.O. Paton
Evgeny Oscarovich $\mathrm{Pa}-$ ton went down in history of science and engineering as a scientist, engineer, organizer of production, public figure, founder of scientific schools of bridge construction and welding. His publications became the basis of many scientific directions, which retain actuality until now. His life and activity are described in «Reminiscences», in articles and narratives of colleagues, associates, literary men, historians.

Activity, deeds, decisions taken by Evgeny O. Paton, expressed thoughts did not often coincide with existing standards and formed circumstances, due to which they were not always perceived at once even by the colleagues. He had to live and work in hard and troubled periods of history, to experience the change in political regime and two World Wars, to undergo risk and to fight for his work, to stand up for ideas and to establish a justice. However, he was

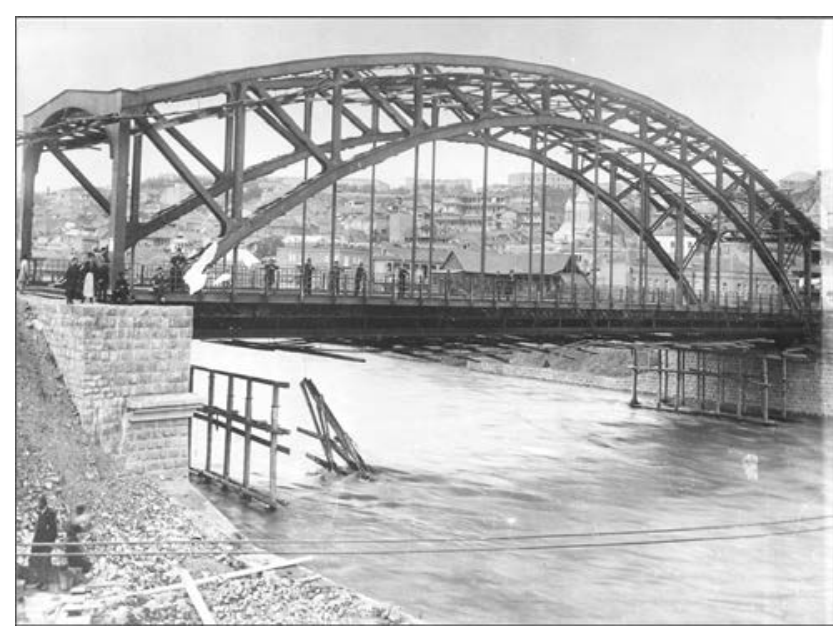

Mukhransky bridge across the Kura river, connecting two regions of Tbilisi in 1911. Evgeny Paton designed the bridge with arch single-span structure instead of ordered three-span structure always, not thinking, governed by such principles as a love to homeland, labor, honesty in everything, strictness to himself and pupils, colleagues, attention to people, calm attitude to awards. Fortunately, his works in the field of bridge construction and welding production solved the large-scale problems on the way of scientific-technical progress, made a great contribution to the governmental programs of industrialization, armament production, after-war reconstruction of the economy. Pedagogical, organizational and social activity of E.O. Paton was highly appreciated by the government and recognized abroad.

Evgeny Paton was born on March 4, 1870 in the family of Oscar Paton, the Russian diplomat, former military engineer. In 1884, he finished the engineering-building faculty of Royal Saxon Higher School of Technology in Dresden. But to work in Russia, Evgeny Paton had to pass exams and defend the projects in Petersburg Institute of Engineers of Communications. In 1896, he received the diploma of engineer, designed bridges, had teaching activity in Petersburg and Moscow. In 1901, he defended the thesis. In 1904, Professor Paton was invited to head the chair of bridges in Kiev Polytechnic Institute. He combined successfully the pedagogical and scientific work with designing and supervision of bridges construction. He made a great contribution to the creation of fundamentals of designing the span structures of bridges, the technology of their construction and test methods. According to the projects of Paton E.O., more than 40 bridges of unique designs were constructed, among which is the Mukhransky bridge across the Kura river in Tbilisi, bridges in Kiev across the Dnieper river and Petrovskaya alley, over- and underpasses in Moscow, roofing structures of halls of Kiev Polytechnic Institute and hotel «Metropol». At the beginning of the World War I, Paton E.O. developed the design of split bridges, won a victory over J. Eiffel, the French engineer, at the international competition.

In 1929, E. O. Paton was elected the academician of the All-Ukrainian Academy of Sciences (AUAS, now NAS of Ukraine) and that year became as a new stage in his creative activity. 


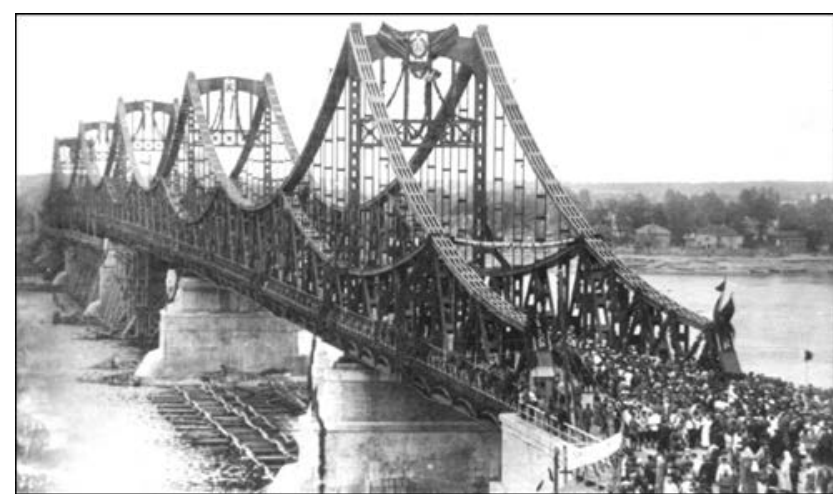

In 1927, the bridge after Eugenia Bosh joined Kiev with worker's settlements and all the left-bank part of Ukraine. E.O. Paton had to solve the unique problems, such as to repeat contours of Nikolaevsky chain bridge, bombed during the war, which was liked by the kievites, and «to tie» the beams of its dismountable bridges of the war-period to the retained supports of the chain bridge

Paton E.O. inspired the idea to apply welding instead of riveting in construction of bridges. Intuition of scientist and experience of engineer suggested to him that the further progress in bridge construction and many other branches of industry on the base of riveting is impossible. On May 2, 1929 the Presidium of AUAS took a decision, by the suggestion of E.O. Paton, about organizing the Electric Welding Laboratory, and the government of the Ukr.SSR allocated the money for its development. The scientist widened the investigations on serviceability of welded structures, works of development of covered electrodes and investigation of process of metal melting in welding, designed the rational types of welded structures, rendered assistance in designing and implementation of welding at the enterprises. In 1931, E.O. Paton faced one more problem: to automate the process of arc welding. The volume of scheduled research investigations and industrial ordered works was rapidly widened.

It should be noted that in the mentioned period the laboratories of companies and higher-educational institutions were also dealing with separate problems of welding production. In 1932, E.O. Paton expressed the idea for the first time in the world about the integrated approach to the solution of welding problems taking place in metallurgical, electric engineering and many other branches of knowledge and establishment of institution, where it would be possible to solve independently all the problems occurring on the way of development of the new technologies. He worked out the structure of the institution, which included research departments, design bureau, workshops, experimental and implementation groups. In 1933, the establishment of the institute was approved by the AUAS Presidium. On January 3, 1934 the first in the world specialized research-design organization in the field of welding production received an official status

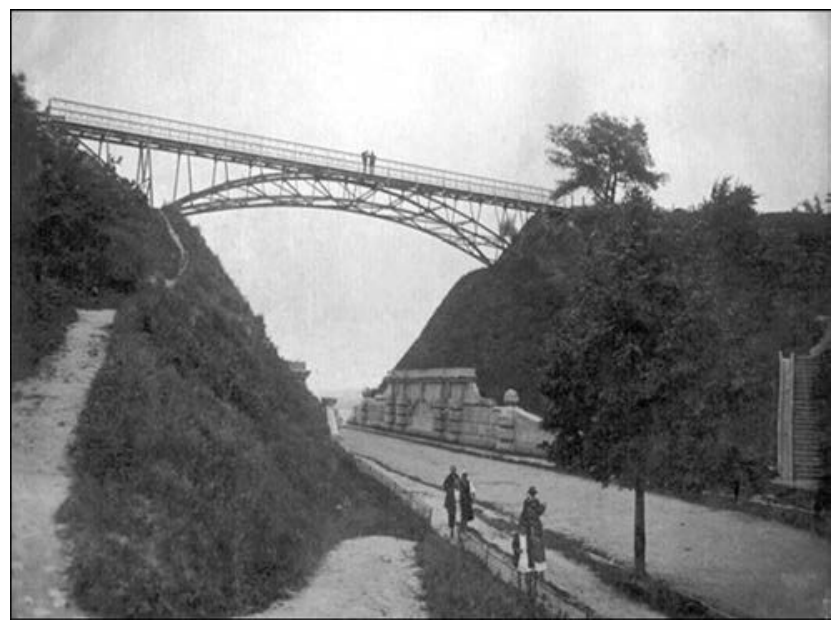

In 1909, E.O. Paton, participating in the competition, suggested to make alley in the Tsarsky garden and to construct the arch bridge. In accordance with his project the bridge was constructed on land and with readiness the ground was dug, structure was lowered and mounted on the prepared supports. Bridge became a decoration of Kiev

by the resolution of the government - Electric Welding Institute. E.O. Paton was the director and scientific supervisor of the Institute until his last days of life. In 1935, the scientist organized the Chair of Welding in the Kiev Polytechnic Institute and headed it until 1939.

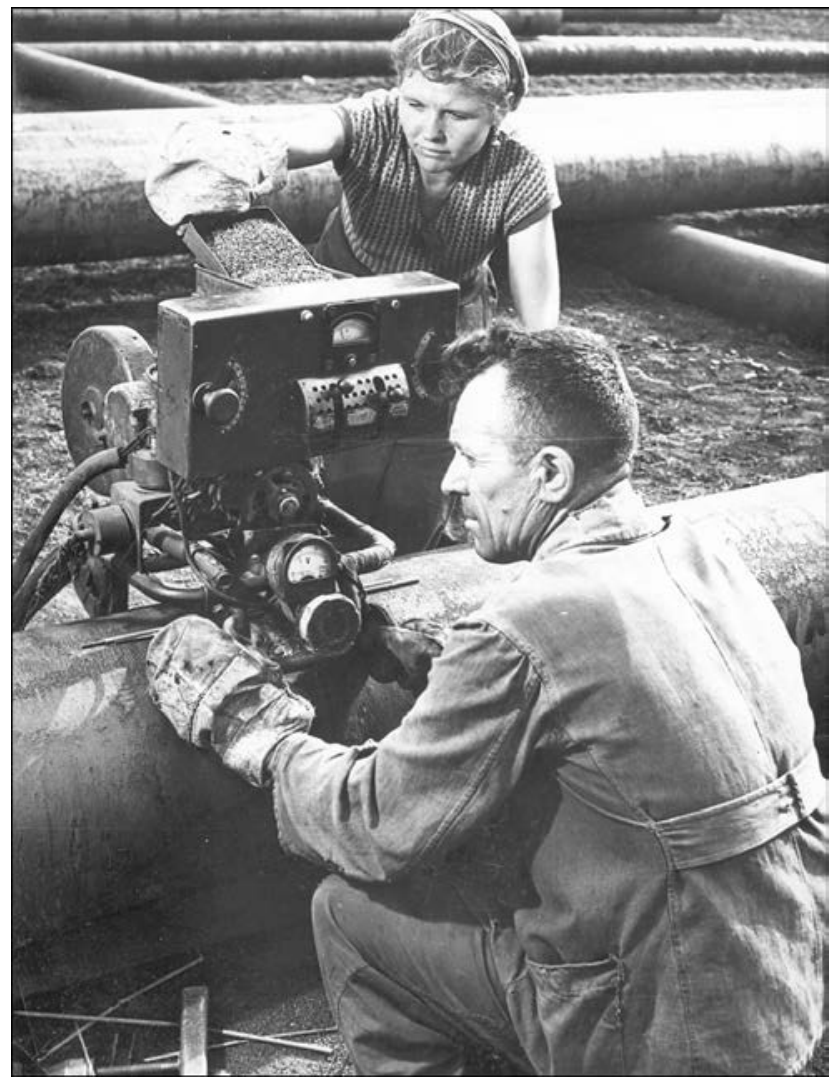

In 1947 , in order to accelerate and make the construction of gas pipeline Dashava-Kiev-Bryansk-Moscow less expensive Paton E.O. suggested to create the field stations, where separate pipes could be joined into sections using the submerged arc welding 


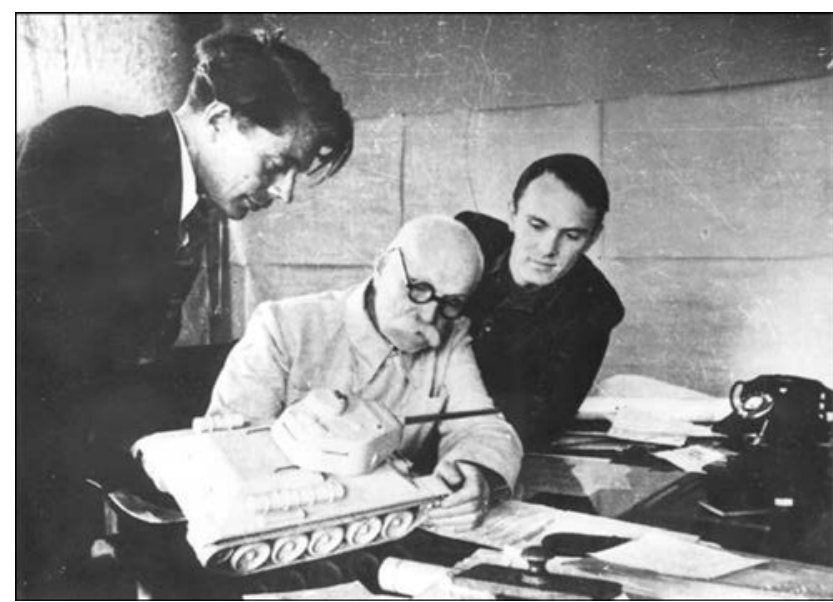

Evgeny O. Paton and his sons Vladimir and Boris with model of tank-34

At the end of the 1930s the associates of the Electric Welding Institute developed the domestic method of submerged arc welding under supervision of the scientist. Taking into consideration the great importance of the new progressive technology, the government issued the special resolution in December, 1940 about implementation of the submerged arc welding at the 20 largest enterprises of the country.

E.O. Paton was appointed the Adviser of Government on machine building. In March, 1941 Paton E.O. was awarded the State Prize of the first degree for the development of method and equipment for high-speed submerged arc welding.

At the beginning of the Great Patriotic War the Electric Welding Institute was evacuated by the initiative of the director to the Urals, to Nizhny Tagil. There, the plant and design bureau from Kharkov, the creators of tank-34, the best mediumweight tank of the World War II, were evacuated to the territory of «Uralvagonzavod». For the first time in the world the problem of automatic welding of armor steels was solved under supervision of E.O. Paton, technology and equipment for welding of tank bodies, artillery armament, ammunition

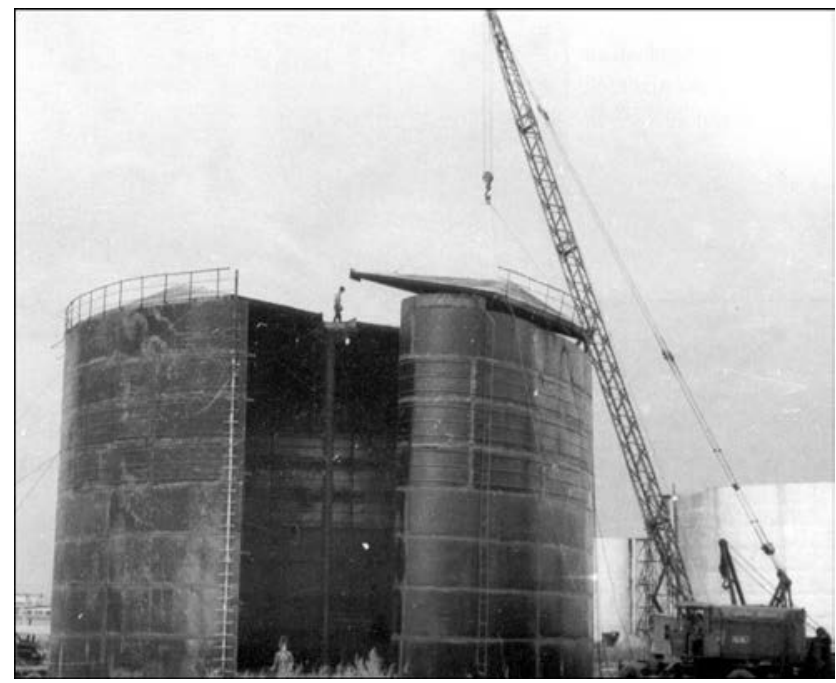

Erection of large-size tank (1948) were developed, the mass production of tanks was arranged. The efficiency of the automatic welding of armor bodies was 10 times higher than that of manual welding, the net volume of products from the unit of industrial area was several times increased. At the beginning of 1945 the submerged arc welding was widely used at 52 plants of the country. On March 2, 1943 E.O. Paton was the first one among the Ukrainian academicians who was awarded the title of Hero of Social Labor.

In April, 1944 the Institute returned to Kiev. In the post-war years E.O. Paton concentrated efforts of associates for the solution of problem of restoration and development of the country national economy. Under his supervision and direct participation the planned implementation of submerged arc welding in industry, construction and transport was beginning, technology and equipment for automatic and semi-automatic submerged arc welding were developed, the production lines were manufactured.

It was managed for the first time in the world to solve the problem of submerged arc welding of vertical welds. The Institute made a great contribution to the development of new industrial methods of manufacture of pipes, ships, railway cars, mine cars, construction of main pipelines, oversized tanks, blast furnace structures and other objects. Application of new technologies of assembly-welding works contributed to the complete restoration of fuelenergy complex and mining-metallurgical industry of Pridneprovie, Donbass and other regions. Invention of a new type of joining at the Institute, i.e. electroslag welding, solved the problem of manufacture of structures of semi-products of unlimited thickness.

At the same time, Paton E.O. began to widen the scope of research works. The Institute was enlarging, new advanced equipment was designed and purchased for a successful work of laboratories, young highly-skilled specialists were recruited for operation in this equipment. In that period the leading scientific directions were formed. Physical-metallurgical and thermal fundamentals of welding, scientific bases of mechanization and automation

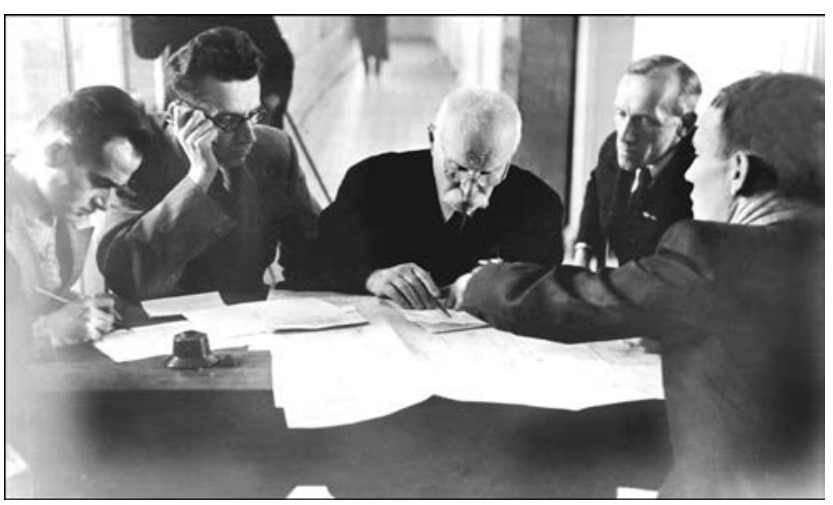

Evgeny O. Paton with associates 


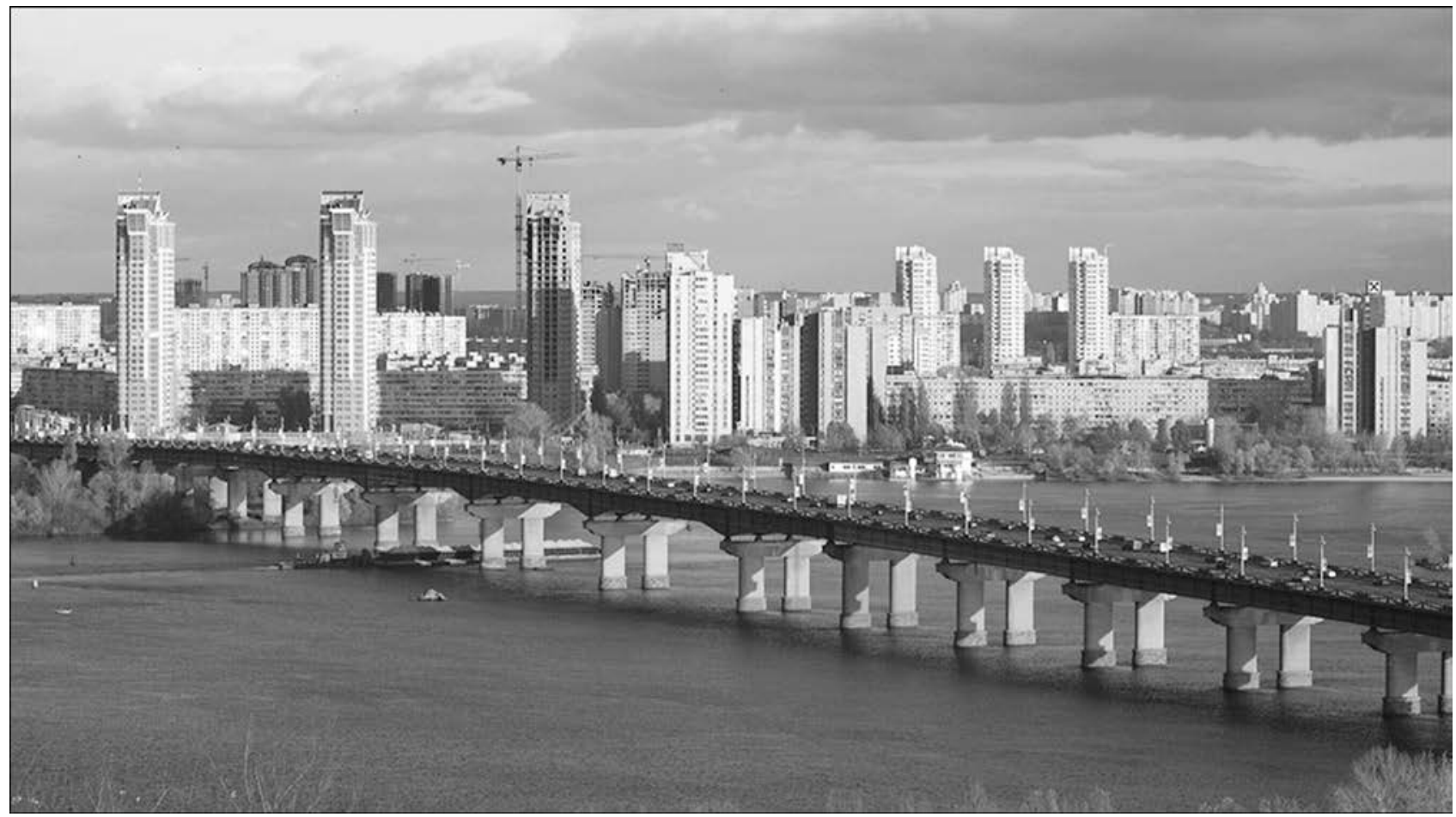

The E.O. Paton bridge across the Dnieper river in Kiev

of welding processes were developed, theory of strength of welded structures and joints was created. With participation of Paton E.O. and under his supervision the fundamental works were published on different aspects of welding science and technology. More than 300 published works belong to E.O. Paton.

Dealing with the problems of permanent joining of metals, Paton E.O. continued to work in the field of bridge construction. In 1953, the traffic was open in Kiev along the all-welded road bridge across the Dnieper river, having the length of more than $1500 \mathrm{~m}$, which was named after E.O. Paton. This road bridge was constructed completely, for the first time in the world, by applying the automatic (up to $90 \%$ ) and semi-automatic welding.

Evgeny O. Paton died on August 12, 1953, less than three months before the gala opening of this bridge. The American Welding Society has recognized the bridge as an outstanding welded structure of the XX century. At present the bridge is under service at a load, 10 times exceeding the design one. In the project of his last bridge Paton E.O. applied completely the potentialities of technologies, developed under his supervision, without using arch, lattice or suspended structures.

The writer Shulgin V.V., the political figure, remarked: «The Paton bridge is a great achievement in the field of bridge construction. Its beauty is in the fact that the bridge even does not exist at all. It is as if one of Kiev streets is throwing over magically from the right to left bank».
The peculiar feature of all the activity of E.O. Paton was the continuous attempt to strengthen universally the cooperation of science with industry, to implement widely the scientific achievements into the national economy. He has excellently joined the talent of outstanding scientist and engineer in himself.

E.O. Paton participated actively in the social life of the country. For the prominent scientific, pedagogical and social activity E.O. Paton was awarded with the title of Honored Worker of Science and Technology, orders and medals. He was twice elected the Vice-President of the Academy of Sciences of the Ukr.SSR.

Occupying different positions, he personally contributed greatly to strengthening of cooperation of institutes of the Academy of Sciences of the Ukr.SSR with industry, widening not only fundamental, but also applied investigations, having a great importance for the solution of actual problems of formation and development of the national economy. E.O. Paton was the founder and editor-inchief of journal «Avtomaticheskaya Svarka» («Automatic Welding»).

The Electric Welding Institute, founded by $\mathrm{Pa}-$ ton E.O., today is also the powerful scientific-technical complex, the largest center in the field of welding, protective and strengthening coatings and special electrometallurgy, which includes, except the scientific and designing departments, the pilot plants, engineering and training centers. 


\title{
INTERACTION OF CO2-LASER RADIATION BEAM WITH ELECTRIC ARC PLASMA IN HYBRID (LASER + TIG) WELDING*
}

\author{
I.V. KRIVSTUN ${ }^{1}$, I.V. KRIKENT ${ }^{1}$, V.F. DEMCHENKO ${ }^{1}$, U. REISGEN ${ }^{2}$, A.F. ZABIROV ${ }^{2}$ and O.A. MOKROV ${ }^{2}$ \\ ${ }^{1}$ E.O. Paton Electric Welding Institute, NASU \\ 11 Bozhenko Str., 03680, Kiev, Ukraine. E-mail: office@paton.kiev.ua \\ ${ }^{2}$ Welding and Joining Institute, Aachen University \\ 49 Pontstrasse, Germany. E-mail: reisgen@isf.rwth-aachen.de
}

\begin{abstract}
Self-consistent mathematical model was proposed for the processes of energy-, mass- and charge transfer in the plasma of the column and anode region of electric arc with refractory cathode, running in inert gas, and exposed to a focused beam of $\mathrm{CO}_{2}$-laser radiation, propagating along the arc column. Mathematical description of the processes running in such a system uses single-temperature model of arc plasma, allowing for additional plasma heating due to laser radiation absorption, as well as its multicomponent nature, associated with metal evaporation from cathode surface. Influence of laser beam power and anode surface temperature on thermal and electromagnetic characteristics of plasma of the column and anode region of argon arc on refractory cathode was analyzed. It is shown that as a result of additional local heating of arc plasma by laser radiation, its temperature in the paraxial zone of arc column can rise by 5000-10000 K, compared to the respective arc in TIG welding. This leads to an essential restructuring of spatial distributions of electric potential and density of electric current in the arc column near-anode region, as well as density of thermal flow applied by the arc to the anode, thus changing the distributed and integral characteristics of its thermal and dynamic impact on the metal being welded. It is established that the impact of a focused laser beam on arc plasma leads to the effect of electric current contraction in the center of the region of anode binding of the arc and respective increase of the density of heat flow, applied by the arc to the anode, in hybrid ( $\mathrm{CO}_{2}$-laser + TIG) welding. This promotes an increase of the energy applied to the metal, which is consumed in its melting and, therefore, an increase of penetrability of laser-arc heat source. It is shown that anode metal evaporation leads to a certain weakening of the effect of electric current contraction in the arc near-anode region, which is exposed to a focused laser beam. The influence of laser radiation absorption and refraction in arc plasma on the characteristics of laser beam interacting with it and its thermal impact on the surface of metal being welded under the conditions of hybrid $\left(\mathrm{CO}_{2}\right.$-laser + TIG) welding was studied. It is shown that laser beam absorption in arc plasma leads to a certain decrease of radiation power, reaching the anode surface. The size of beam focusing spot on the above surface practically does not change, i.e. beam refraction in arc plasma turns out to be insignificant. 11 Ref., 1 Table, 14 Figures.
\end{abstract}

Keywords: hybrid ( $\mathrm{CO}_{2}$-laser + TIG) welding, electric arc, refractory cathode, arc column, anode region, evaporating anode, arc plasma, laser beam, simulation

Hybrid laser-arc processes performed by simultaneous action of a focused laser beam and electric arc on the item being welded (within a common heating zone) have become widely accepted over the last decades [1, 2]. At practical implementation of hybrid welding processes a consumableelectrode arc is the most often used (laser + MIG/MAG) [2]. On the other hand, of considerable practical interest are hybrid processes, based on a nonconsumable-electrode arc (laser + TIG), as well as plasma arc (laser + plasma) [1].
Here not only the type of welding arc used in the hybrid process, but also laser beam characteristics, primarily the radiation wave length $\lambda$, are of essential importance. This is associated with a strong dependence of the coefficient of volume absorption of laser radiation in arc plasma $\kappa_{\omega}$ on its wave length. At application of shortwave radiation of solid-body or fiber-optic lasers $(\lambda \approx 1 \mu \mathrm{m})$ in the hybrid process, laser beam absorption in arc plasma is insignificant $\left(\kappa_{\omega} \sim\right.$ $\sim 1 \mathrm{~m}^{-1}$ [1]).

In this case, intensive evaporation of metal from weld pool surface occurs under the impact of high-energy density source of laser heating, which has a significant influence of the compo-

\footnotetext{
* By material of Proceedings of the 7th International Conference «Mathematical Modelling and Information Technologies in Welding and Related Processes» (September 15-9, 2014, Odessa, Ukraine).
} 
sition, thermal, gas-dynamic and electromagnetic properties of arc plasma and, consequently, leads to a change of its thermal and dynamic interaction with the metal being welded. At application of $\mathrm{CO}_{2}$-lasers $(\lambda=10.6 \mu \mathrm{m})$ in hybrid processes both the interaction mechanisms turn out to be significant, namely, laser radiation absorption in arc column plasma $\left(\kappa_{\omega} \sim 100 \mathrm{~m}^{-1}[1]\right)$ and metal evaporation from melt surface under the impact of focused laser beam.

Combining laser and arc heat sources in hybrid $\left(\mathrm{CO}_{2}\right.$-laser + TIG) welding can lead to appearance of synergetic effect, which is manifested in disturbance of additivity of the beam and arc thermal impact on the metal being welded, as well as intensification of the dynamic impact of welding current on the metal pool. As a result, the energy, used for metal melting in hybrid welding, can more than 2 times exceed the sum of the respective energies in welding by each of the heat sources taken separately [1]. Physical factors causing such a synergetic effect are still undisclosed, and should be studied with application of mathematical modeling methods.

Problem definition. The objective of this work is a theoretical study and mathematical modeling of the processes of direct interaction of focused laser radiation with arc plasma. An atmospheric pressure stationary argon arc on refractory tungsten cathode and, in the general case, on evaporating anode from low-carbon steel (iron is the evaporating element) was selected as the object of study, to which a Gaussian beam of continuous $\mathrm{CO}_{2}$-laser radiation focused by an optical system, is applied as shown in Figure 1. As the object, which is the result of such a combination of the laser beam and electric arc, does not have any axial symmetry, we will take the following assumptions to simplify its mathematical model. Let us assume that starting from a certain distance from the anode $\left(z=z_{0}\right)$ the arc column is axially symmetric, and arc plasma characteristics are close to the respective characteristics for an arc on a refractory cathode, located normal to the anode surface. We will also assume that the interaction of the laser beam with the arc plasma proceeds only at $z>z_{0}$. Accordingly, we will introduce a cylindrical system of coordinates $(r, z)$ and will select the calculated areas for arc plasma $\Omega_{\mathrm{p}}=\left\{0 \leq r \leq R_{\mathrm{p}}\right.$, $0 \leq z \leq L\}$ and laser beam $\Omega_{\mathrm{b}}=\left\{0 \leq r \leq R_{\mathrm{b}}, z_{0} \leq\right.$ $\leq z \leq L\}$ (see Figure 1).

Basic equations. We will use the equations of single-temperature model of arc plasma for mathematical description of the processes of energy-, mass- and charge transfer in such a model

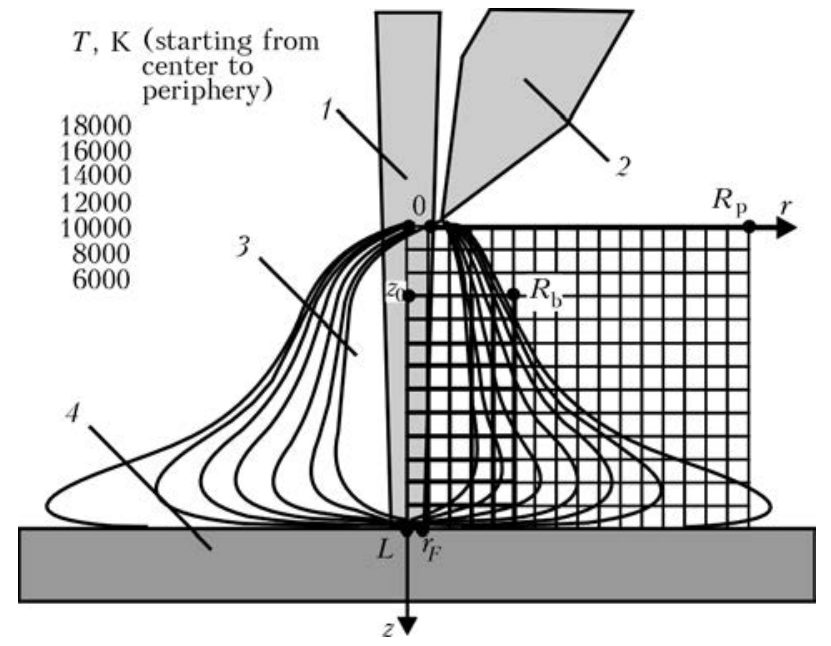

Figure 1. Schematic of combining in the hybrid process a focused laser beam and an electric arc with refractory cathode, as well as temperature isolines for $150 \mathrm{~A}$ argon arc interacting with $1500 \mathrm{~W}$ beam of $\mathrm{CO}_{2}$-laser radiation: 1 laser beam; 2 - refractory cathode; 3 - arc column; 4 metal being welded (anode)

(axially symmetric) system [3, 4]. The respective system of equations should be improved, allowing for the specifics of the studied object and stationarity of the considered processes. Equations of continuity and plasma motion, as well as equations of arc current electromagnetic field are unchanged [3], whereas the equation of energy allowing for additional heating of arc plasma by a focused laser beam should be written as follows [1]:

$$
\begin{gathered}
\rho C_{\mathrm{p}}\left(v \frac{\partial T_{\mathrm{p}}}{\partial r}+u \frac{\partial T_{\mathrm{p}}}{\partial z}\right)=\frac{1}{r} \frac{\partial}{\partial r}\left(r \chi \frac{\partial T_{\mathrm{p}}}{\partial r}\right)+ \\
+\frac{\partial}{\partial z}\left(\chi \frac{\partial T_{\mathrm{p}}}{\partial z}\right)+\frac{k_{\mathrm{B}}}{e}+ \\
+\left\{j_{r} \frac{\partial\left[(5 / 2-\delta) T_{\mathrm{p}}\right.}{\partial r}+j_{z} \frac{\partial\left[(5 / 2-\delta) T_{\mathrm{p}}\right.}{\partial z}\right\}+ \\
+\frac{j_{r}^{2}+j_{z}^{2}}{\sigma}+\kappa_{\omega} S-\psi,
\end{gathered}
$$

where $\rho$ is the plasma mass density; $C_{\mathrm{p}}$ is the specific heat capacity of plasma, allowing for ionization energy; $v, u$ are the radial and axial components of plasma velocity; $T_{\mathrm{p}}$ is the plasma temperature; $\chi$ is the coefficient of plasma temperature conductivity; $k_{\mathrm{B}}$ is the Boltzmann constant; $e$ is the electron charge; $j_{r}, j_{z}$ are the radial and axial components of electric current density in the plasma; $\delta$ is the constant of electron thermodiffusion; $\sigma$ is the specific electric conductivity of plasma; $\psi$ are the energy losses for inherent radiation in the approximation of optically thin plasma. 
In equation (1) energy evolution in arc plasma column due to laser radiation absorption is allowed for by $\kappa_{\omega} S$ term in the right-hand part (where $\kappa_{\omega}$ is the coefficient of volume (back-Bremstrahlung) absorption of laser radiation by arc plasma; $S$ is the spatial distribution of radiation intensity in the laser beam, interacting with plasma).

Let us consider the equation, describing radiation intensity distribution $S(r, z)$ in the laser beam, allowing for its absorption and refraction in non-uniform arc plasma. Assuming that relative change of plasma parameters at distances of the order of laser radiation wave length is small, and that laser radiation reflected from anode surface is absent, quasi-optical approximation was used to describe beam propagation in arc plasma. In this case, the equation for the amplitude of laser beam field assumed to be Gaussian (axially symmetric), can be expressed as follows [1]:

$$
-2 i k \frac{\partial A_{\omega}}{\partial z}=\frac{1}{r} \frac{\partial}{\partial r}\left(r \frac{\partial A_{\omega}}{\partial r}\right)+k^{2}\left(\varepsilon_{\omega}-1\right) A_{\omega},
$$

where $k \equiv k_{z}=2 \pi / \lambda$ is the wave vector of laser radiation; $A_{\omega}^{z}$ is the complex amplitude of laser beam electric field; $\varepsilon_{\omega}=\varepsilon_{\omega}^{\prime}+i \varepsilon_{\omega}^{\prime \prime}$ is the complex dielectric permeability of arc plasma at laser radiation frequency $\omega$.

Sought value $S$ is a time-averaged value of axial component of the density of beam electromagnetic energy flow, and it is related to complex amplitude of electric field $A_{\omega}$ by the relationship [1]

$$
S(r, z)=\frac{1}{2} \sqrt{\frac{\varepsilon^{0}}{\mu^{0}}}\left|A_{\omega}\right|^{2},
$$

where $\varepsilon^{0}$ is the dielectric permeability of vacuum; $\mu^{0}$ is the universal magnetic constant.

To assign the initial distribution of $A_{\omega}\left(r, z_{0}\right)$, let us assume that at $z=z_{0}$ a focused Gaussian laser radiation beam is applied to arc plasma, which in the absence of plasma has minimum radius $r_{F}$ on the anode surface (see Figure 1). Spatial distribution of complex amplitude of an electric field of such a beam at $z \leq z_{0}$ is given by the following expression [1]:

$$
A_{\omega}=A_{\omega F} \frac{r_{F}}{r_{z}} \exp \left[-\frac{r^{2}}{r_{z}^{2}}+i\left(k \frac{r^{2}}{2 R_{z}}-\varphi_{z}\right)\right],
$$

where

$$
\begin{gathered}
r_{z}^{2}=r_{F}^{2}\left[1+\frac{(z-L)^{2}}{z_{F}^{2}}\right] ; \\
R_{z}=(z-L)\left[1+\frac{z_{F}^{2}}{(z-L)^{2}}\right] ; \quad \varphi_{z}=\operatorname{arctg}\left(\frac{z-L}{z_{F}}\right) .
\end{gathered}
$$

Constant $A_{\omega F}$ in (4) is found from integral relationship for the total power of laser radiation in the beam cross-section:

$$
Q(z)=2 \pi \int_{0}^{R_{\mathrm{b}}} S(r, z) r d r,
$$

that allowing for (3) yields

$$
A_{\omega F}=\sqrt{\frac{4 Q^{0}}{\pi r_{F}^{2}}\left(\frac{\mu^{0}}{\varepsilon^{0}}\right)^{1 / 2}},
$$

where $Q_{0}=Q\left(z_{0}\right)$ is the power of initial laser beam.

At numerical simulation of the processes of transfer of energy, pulse, mass and charge in the studied system, let us consider two characteristic variants of the anode, namely, water-cooled (non-evaporating) anode with surface temperature $T_{\mathrm{s}}=500 \mathrm{~K}$ and diffusion-induced evaporating anode. In the latter case we will assume that within the region of the arc anode binding the anode surface temperature $T_{\mathrm{s}}=T_{\mathrm{s}}(r)$ varies by the exponential law [4] and reaches $3000 \mathrm{~K}$ in the center of this region, i.e. does not exceed iron boiling temperature, at which evaporation changes into convective mode. Having thus assigned the anode surface temperature distribution, in order to allow for the multicomponent nature of arc plasma, associated with diffusioninduced evaporation of anode material, the considered model should be complemented by the equation of convective diffusion of ionized metal vapour, describing the transport of neutral atoms, single- and double-charged ions of metal into arc column plasma [4]:

$$
\times c \begin{gathered}
\frac{1}{r} \frac{\partial}{\partial r}\left(r n_{m} v\right)+\frac{\partial}{\partial z}\left(n_{m} u\right)=\frac{1}{r} \frac{\partial}{\partial r} \times \\
\left.r\left[\begin{array}{l}
G_{0} \frac{\partial\left\{n_{m} T_{\mathrm{p}}\right\}}{\partial r}+\bar{G}_{1} \frac{\partial\left\{K_{1} n_{m} T_{\mathrm{p}}\right\}}{\partial r}+ \\
+\bar{G}_{2} \frac{\partial\left\{K_{2} n_{m} T_{\mathrm{p}}\right\}}{\partial r}+\left\{b_{1} K_{1}+b_{2} K_{2}\right\} n_{m} \frac{\partial \varphi}{\partial r}
\end{array}\right]\right)+
\end{gathered}
$$

$$
+\frac{\partial}{\partial z}\left(\left[\begin{array}{l}
G_{0} \frac{\partial\left[n_{m} T_{\mathrm{p}}\right]}{\partial z}+\bar{G}_{1} \frac{\partial\left[K_{1} n_{m} T_{\mathrm{p}}\right]}{\partial z}+ \\
+\bar{G}_{2} \frac{\partial\left[K_{2} n_{m} T_{\mathrm{p}}\right]}{\partial z}+\left\{b_{1} K_{1}+b_{2} K_{2}\right\} n_{m} \frac{\partial \varphi}{\partial z}
\end{array}\right]\right) .
$$

Here, $n_{m}+n_{m 1}+n_{m 2}$ is the total concentration of metal vapour particles in arc plasma; 


$$
\begin{gathered}
\bar{G}_{1}=G_{1}-G_{0} ; \quad \bar{G}_{2}=G_{2}-G_{0} ; \\
K_{1}=\frac{n_{m 1}}{n_{m}} ; \quad K_{2}=\frac{n_{m 2}}{n_{m}} ; \\
G_{Z}=\frac{D_{Z}}{T_{\mathrm{p}}}\left(1-n_{m Z} \frac{M_{m}-\bar{M}_{m Z}}{\rho}\right) ; \quad \bar{M}_{m Z}=\frac{\rho-M_{m} n_{m Z}}{n_{0}-n_{m Z}},
\end{gathered}
$$

$(Z=0,1,2) ; D_{Z}$ are the coefficients of diffusion of atoms $(Z=1)$, of single- $(Z=1)$ and doublecharged $(Z=2)$ metal ions in multicomponent plasma; $M_{m}$ is the metal atom mass; $n_{0}$ is the total concentration of particles in arc column plasma; $b_{Z}=\left(e Z / k_{\mathrm{B}}\right) G_{Z}$ are the mobilities of metal ions $(Z=1,2)$ in the electric field; $\varphi$ is the scalar potential of electric field in arc column.

Equation (8) describes the following kinds of metal vapour particles transfer in arc plasma: convective transfer, concentration diffusion, thermodiffusion, as well as vapour ion drift in the electric field.

Numerical realization of the described model of the processes of transfer of energy, pulse, mass and charge requires assigning the thermodynamic, transport and optical properties of multicomponent arc plasma, depending on its temperature, composition and pressure. For isothermal argon plasma at atmospheric pressure, data given in work [5] were used. Dependencies of thermodynamic and transport properties of $\mathrm{Ar}-$ Fe plasma of different composition were determined by the procedure proposed in [6]. The respective dependencies of energy losses for inherent radiation, coefficient of volume absorption and complex dielectric permeability of arc plasma were calculated as described in [1].

Boundary conditions. We will define the boundary conditions for plasma velocity vector $\vec{V}=\{v, 0, u\}$, its temperature $T_{\mathrm{p}}$, electric field potential $\varphi$, metal vapour particle concentration $n_{m}$ and laser beam field amplitude $A_{\omega}$ as follows. In the initial section of the calculated region we will assign for arc column plasma (plane $z=0$ ) the boundary conditions for values $v, u, T_{\mathrm{p}}, \varphi$ and $n_{m}$ similarly to what was done in $[3,4]$ for an arc with a refractory cathode located normal to the anode surface. In particular, for velocity vector components we will take that

$$
\left.v\right|_{z=0}=0 ;\left.\quad u\right|_{z=0}=u_{0},
$$

where $u_{0}$ value is determined by shielding gas flow rate and diameter of its feed nozzle.

For temperature and electric potential in nearcathode zone of arc column we will assign the following conditions:

$$
\left.T_{\mathrm{p}}\right|_{z=0}=T_{\mathrm{c}}(r) ;\left.\quad \sigma \frac{\partial \varphi}{\partial z}\right|_{z=0}=j_{\mathrm{c}}(r)
$$

where distribution of plasma temperature $T_{\mathrm{p}}(r)$ and electric current density near the cathode $j_{c}(r)$ are selected according to recommendations of [7]. In the zone of shielding gas feed we will take that

$$
\left.T_{\mathrm{p}}\right|_{z=0}=T_{0} ;\left.\quad \frac{\partial \varphi}{\partial z}\right|_{z=0}=0,
$$

where $T_{0}$ is the ambient temperature.

Considering the earlier assumption that laser beam interaction with arc plasma starts at $z=z_{0}$ in equation (1) in region $z<z_{0}$ we will assume that $S=0$, and we will assign the initial condition for equation (2) on the upper boundary of calculated region $\Omega_{\mathrm{b}}$, i.e. at $z=z_{0}$ (see Figure 1 ), as described above.

As regards equation (8), here allowing for the direction of movement of shielding gas and plasma in the near-cathode zone of arc column, we will assume that the particles of evaporated anode metal do not reach plane $z=0$, i.e. on upper boundary of calculated region $\Omega_{\mathrm{b}}$ (see Figure 1) we will take

$$
\left.n_{m}\right|_{z=0}=0 .
$$

For water-cooled (non-evaporating) anode «sticking» conditions are assigned on its surface (plane $z=L$ ), i.e. radial and axial components of plasma flow velocity are taken to be zero. For evaporating anode the near-anode plasma flow, resulting from evaporation of metal atoms from the anode surface and diffusion of ionized metal vapour into the arc column, should be taken into account. Results of calculation performed in [4] show that at $T_{\mathrm{s}}(0)=3000 \mathrm{~K}$, the axial component of the velocity of motion of multicomponent arc plasma near the anode, which is due to diffusioninduced evaporation of its material, can reach the value of the order of $10 \mathrm{~m} / \mathrm{s}$. This requires correction of the boundary condition for normal to anode surface component of plasma velocity vector on anode layer boundary, which in case of diffusion of evaporating anode becomes [4]

$$
\begin{gathered}
\left.u\right|_{z=L}= \\
=\frac{M_{m}\left[Y_{m 0}(r, L)+Y_{m 1_{2}}(r, L)+Y_{m 2_{z}}(r, L)\right]}{\rho(r, L)-M_{m}\left[n_{m 0}(r, L)+n_{m 1}(r, L)+n_{m 2}(r, L)\right.} .
\end{gathered}
$$

Here $Y_{m Z_{z}}(r, L)$ are the radial distributions of axial components of the densities of diffusion flows of metal atoms and ions, being present in the charged state $Z$, on the boundary of the column with anode region of the arc.

On the boundary of column plasma of the arc with the anode layer taken to be infinitely thin 
[8], we can write the following condition of energy balance:

$-\left.\chi \frac{\partial T_{\mathrm{p}}}{\partial z}\right|_{z=L}+j_{\mathrm{a}} \frac{k_{\mathrm{B}}}{e}\left(\frac{5}{2}-\delta\right) T_{\mathrm{pa}}+\Delta \varphi_{\mathrm{a}} j_{\mathrm{a}}+q_{\mathrm{a}}-j_{\mathrm{a}} \bar{\varphi},(14)$

where $j_{\mathrm{a}}=j_{z} \|_{z=L}$ is the absolute value of electric current density on the anode; $\tau_{\mathrm{pa}}=\left.T_{\mathrm{p}}\right|_{z=L}$ is the temperature of arc column on the boundary with the anode region; $\Delta \varphi_{\mathrm{a}}$ is the difference of potential of arc plasma on the outer boundary of the anode layer and potential of anode surface; $q_{\mathrm{a}}$ is the heat flow applied by the arc to the anode; $\bar{\varphi}$ is the work function of anode metal. With good approximation the electric potential of anode surface can be considered to be constant and selected equal to zero, then the boundary condition for plasma potential on the boundary of arc column with the anode layer can be written as [3]

$$
\left.\varphi\right|_{z=L}=\Delta \varphi_{\mathrm{a}} .
$$

To calculate values $\Delta \varphi_{\mathrm{a}}$ and $q_{\mathrm{a}}$ included into boundary conditions (14) and (15), we will use the model of the arc anode region, proposed in [8]. This model allows calculation of radial distributions of heat flow $q_{\mathrm{a}}$, applied by the arc to the anode, as well as a node drop of potential $U_{\mathrm{a}}=-\Delta \varphi_{\mathrm{a}}$ in the region of anode binding of the arc, depending on radial distributions of electric current density on the anode $j_{\mathrm{a}}$ and plasma temperature on anode layer boundary $T_{\mathrm{pa}}$ to be determined.

On the boundary of arc column plasma with anode layer (at $z=L$ ) boundary condition for $n_{m}=n_{m 0}+n_{m 1}+n_{m 2}$ can also be determined according to the model of anode region of the arc with evaporating anode [8], depending on local values of near-anode plasma temperature, anode surface temperature and its evaporation mode.

In the considered diffusion mode of evaporation it can be assumed with sufficient accuracy that local values of partial pressure of atoms and ions of plasma metal component $p_{\mathrm{m}}$ on the mentioned boundary are equal to the pressure of saturated vapour of anode metal at the respective value of its surface temperature $T_{\mathrm{s}}$ :

$$
p_{\mathrm{m}} \mathrm{l}_{z=L}=p_{0} \exp \left\{\frac{\lambda_{\mathrm{v}}}{k_{\mathrm{B}}}\left[\frac{1}{T_{B}}-\frac{1}{T_{\mathrm{s}}(r)}\right]\right\},
$$

where $p_{0}$ is the atmospheric pressure; $\lambda_{\mathrm{v}}$ is the energy spent for transition of one metal atom from the liquid into the vapour phase; $T_{B}$ is the anode metal boiling temperature.

On the system axis of symmetry (at $r=0)$ the boundary conditions for velocity, temperature, plasma electric potential and concentration of metal vapour particles, as well as amplitude of laser beam electric field, assumed to be Gaussian, are assigned in the standard manner (see, for instance, $[1,3,4]$ ):

$$
\begin{gathered}
\left.v\right|_{r=0}=0 ;\left.\quad \frac{\partial u}{\partial r}\right|_{r=0}=0 ;\left.\quad \frac{\partial T_{\mathrm{p}}}{\partial r}\right|_{r=0}=0 ; \\
\left.\frac{\partial \varphi}{\partial r}\right|_{r=0}=0 ;\left.\quad \frac{\partial n_{m}}{\partial r}\right|_{r=0}=0 ;\left.\quad \frac{\partial A_{\omega}}{\partial r}\right|_{r=0}=0 .
\end{gathered}
$$

On the outer boundary of calculated region for plasma (at $r=R_{\mathrm{p}}$ ) we will express boundary conditions for velocity and electric potential as follows:

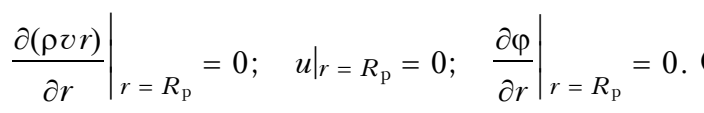

We will determine boundary conditions for temperature and concentration of metal vapour particles at $r=R_{\mathrm{p}}$, depending on the direction of plasma flow motion [3, 4]:

$$
\begin{aligned}
& \left.T_{\mathrm{p}}\right|_{r=R_{\mathrm{p}}}=T_{0} ;\left.\quad n_{m}\right|_{r=R_{\mathrm{p}}}=0 \text { at }\left.\vartheta\right|_{r=R_{\mathrm{p}}} \leq 0 ; \\
& \left.\frac{\partial T_{\mathrm{p}}}{\partial r}\right|_{r=R_{\mathrm{p}}}=\left.\frac{\partial n_{m}}{\partial r}\right|_{r=R_{\mathrm{p}}}=0 \text { at }\left.v\right|_{r=R_{\mathrm{p}}}>0 .
\end{aligned}
$$

Finally, assuming that the transverse dimension of the laser beam is essentially smaller than the radius of the respective calculated region $R_{\mathrm{b}}$, we will write

$$
\left.A_{\omega}\right|_{r=R_{\mathrm{b}}}=0 .
$$

System of diffusion equations, which describe the transfer of energy, pulse, mass and charge in multicomponent arc plasma, exposed to a focused laser beam, with the above-mentioned boundary conditions, was solved numerically, using a combined Lagrangian-Eulerian method [9, 10], adapted to the conditions of a compressible medium. Parabolic equation (2) for complex amplitude of laser beam field was solved by the method, described in detail in [1].

Modeling results. Numerical modeling of the characteristics of plasma column and anode region of electric arc with tungsten cathode and steel anode, exposed to a focused beam of $\mathrm{CO}_{2}{ }^{-}$ laser radiation, was conducted at the following system parameters: length of interelectrode gap $L=4 \mathrm{~mm}$; arc current $I=150 \mathrm{~A}$; shielding gas was argon, pressure was atmospheric; initial laser beam power $Q^{0}$ was varied in the range of 500$1500 \mathrm{~W}$; beam radius in the focusing plane $(z=$ $=L) r_{F}=0.2 \mathrm{~mm}$; distance from cathode to the 


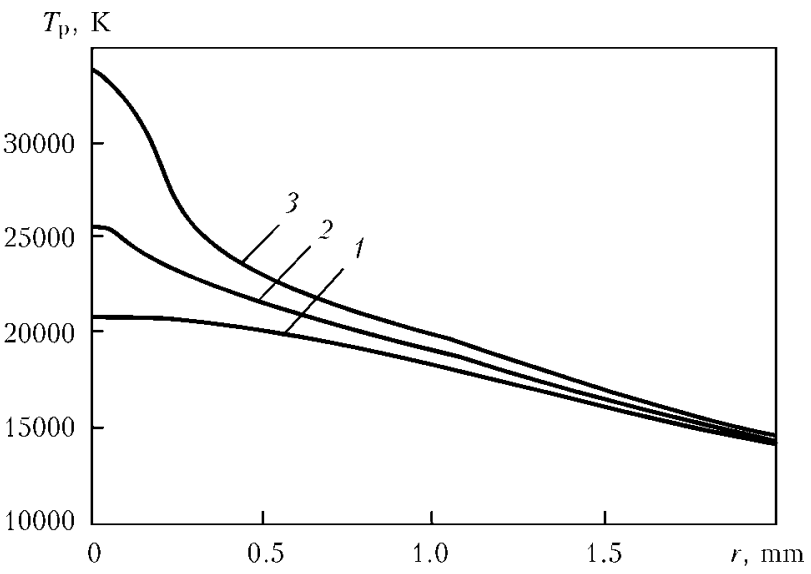

Figure 2. Radial distributions of plasma temperature in the cross-section $z=2.5 \mathrm{~mm}$ of arc column at $T_{\mathrm{S}}=500 \mathrm{~K}: 1-$ $Q^{0}=0 ; 2-500 ; 3-1500 \mathrm{~W}$

plane, where the interaction of the laser beam with arc plasma begins, $z_{0}=1 \mathrm{~mm}$ was selected.

Arc plasma. Let us first consider the influence of laser radiation absorption by arc plasma on the thermal and electric characteristics of the column and anode region of the studied arc. Under the impact of the focused beam of $\mathrm{CO}_{2}$-laser radiation a high-temperature region localized near the beam axis forms in the arc column ( $\mathrm{Fi}^{-}$ gure 2), in which the maximum plasma temperature increases with the increase of laser beam power. Here, the radius of the above-mentioned region is equal to a value of the order of $0.5 \mathrm{~mm}$. So, on the axis of $150 \mathrm{~A}$ arc (at $z=2.5 \mathrm{~mm}$ ) plasma temperature in the absence of laser impact, is equal to $20,700 \mathrm{~K}$, whereas under the impact of laser beam of power $Q^{0}=500$ and $1500 \mathrm{~W}$ it increases up to 25,100 and $32,800 \mathrm{~K}$, respectively.

The effect of local laser heating of arc plasma is manifested right up to the boundary of the column with the arc anode region, leading to a noticeable increase of axial values of near-anode plasma temperature. Influence of arc plasma heating by the laser beam on its temperature distribution along the axis of arc column (laser beam axis) is shown in Figure 3. Note that the anode surface temperature (its material evaporation) practically does not influence the spatial distribution of plasma temperature in the arc column that is in keeping with the conclusions of [4].

Change of spatial distribution of arc plasma temperature under the impact of focused laser beam radiation causes a noticeable redistribution of electric current density in the discharge. Figure 4 gives the distributions of absolute value of axial component of current density along the arc axis, exposed to the impact of $\mathrm{CO}_{2}$-laser radiation beam of different power (curve $1-Q^{0}=$ $=1500 \mathrm{~W} ; 2-500 \mathrm{~W}$ ), compared to the respec-
$T_{\mathrm{p}}, \mathrm{K}$

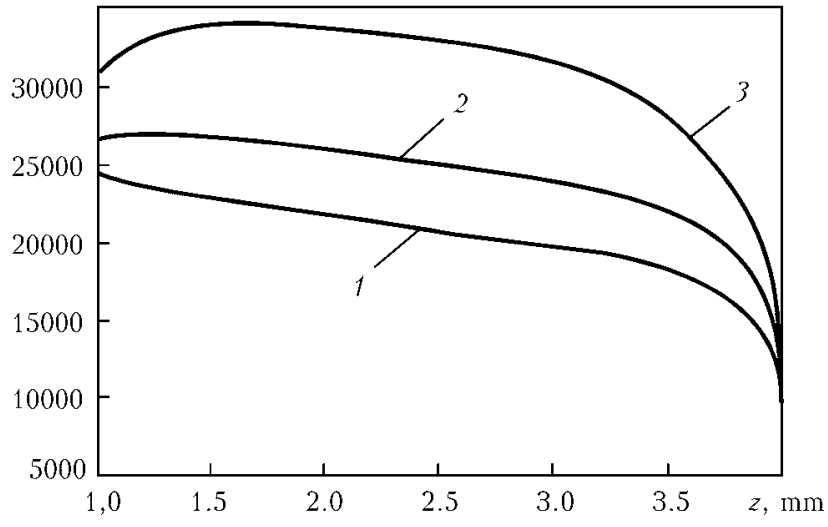

Figure 3. Axial distributions of plasma temperature on the axis of arc column at $T_{\mathrm{S}}=500 \mathrm{~K}: 1-Q^{0}=0 ; 2-500$; $3-1500 \mathrm{~W}$

tive distribution $\left|j_{z}(0, z)\right|$ for the regular arc (curve 3).

Despite the fact that plasma temperature in the axial zone of the arc column rises significantly under the impact of laser radiation (Figures 2 and 3), electric current density on the discharge axis in the initial sections of the region of laserarc interaction $(0<z<3 \mathrm{~mm})$ remains practically the same as for the regular arc. Influence of laser heating of arc plasma on current density distribution in the arc column starts to be manifested closer to the anode. In the near-anode zone of the column value $j_{z}(0, z) \mid$ for an arc exposed to laser radiation, increases significantly, the maximum value of current density on the arc axis rising with increase of initial beam power (see Figure 4). As a result, for instance, at the impact of $1500 \mathrm{~W}$ laser beam on $150 \mathrm{~A}$ arc, current density in the center of the region of anode binding of the arc can more than 3 times exceed the respective value for the regular arc at other conditions being equal (Figure 5).

Heat flow $q_{\mathrm{a}}$ applied by the arc to the anode, essentially depends on the density of electric cur-

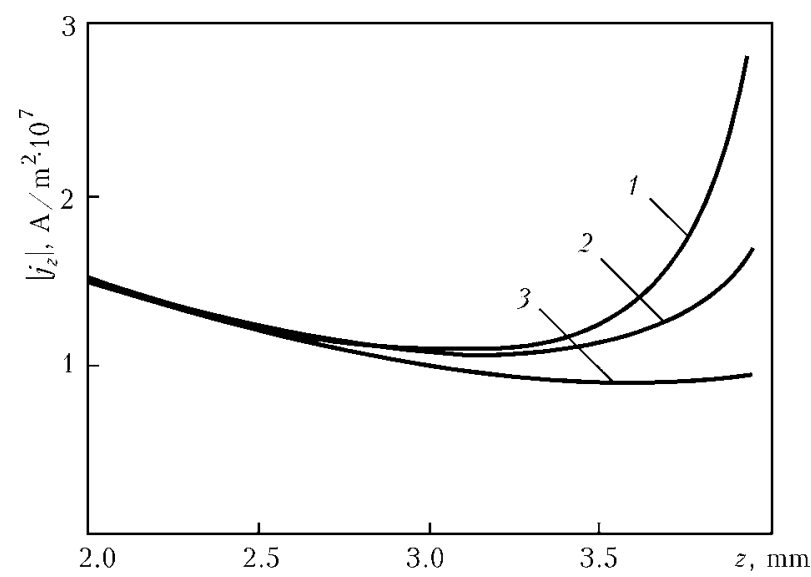

Figure 4. Distributions of absolute value of axial component of electric current density on the arc axis along its column at $T_{\mathrm{S}}=500 \mathrm{~K}$ (for $1-3$ see the text) 


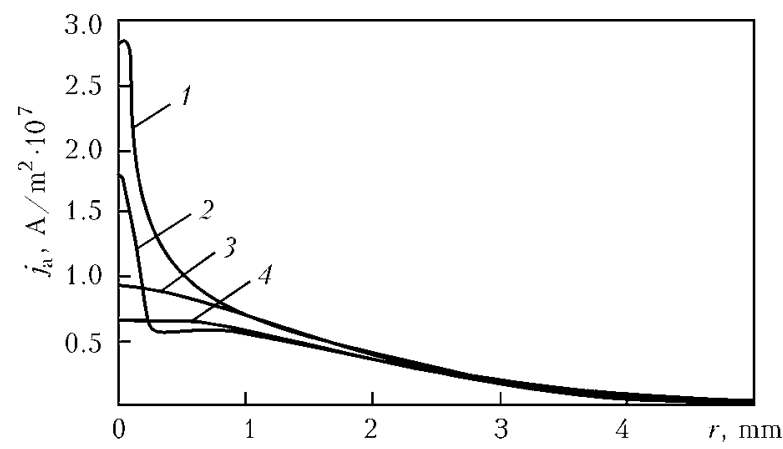

Figure 5. Distributions of electric current density on the anode: $1-Q^{0}=1500 \mathrm{~W}, T_{\mathrm{s}}=500 \mathrm{~K} ; 2-Q^{0}=1500 \mathrm{~W}$, $T_{\mathrm{S}}(0)=3000 \mathrm{~K} ; 3-Q^{0}=0, T_{\mathrm{S}}=500 \mathrm{~K} ; 4-Q^{0}=0$, $T_{\mathrm{S}}(0)=3000 \mathrm{~K}$

rent on the anode [3, 4], therefore, the nature of $q_{\mathrm{a}}(r)$ distribution, given in Figure 6, is similar to distribution of current density on the anode (see Figure 5). So, at the impact of $1500 \mathrm{~W}$ laser beam on $150 \mathrm{~A}$ arc, axial value of density of the heat flow, applied by the arc to the anode, increases almost 4 times. At increase of anode temperature (allowing for its evaporation) the effect of contraction of electric current and density of heat flow on the anode, respectively, becomes somewhat weaker, remaining, however, significant compared to an arc, not exposed to laser radiation (see Figures 5 and 6).

To analyze the effect of arc contraction near the anode surface, we will consider radial distributions of near-anode plasma temperature $T_{\mathrm{pa}}$ (Figure 7) and drops of electric field potential $\Delta \varphi_{\mathrm{a}}$ on the anode layer (Figure 8) for an arc exposed to a laser beam of power $Q^{0}=1500 \mathrm{~W}$ (curves 1) and for a regular arc (curves 2 in the Figure).

It is known [8] that anode voltage $\operatorname{drop} U_{\mathrm{a}}=$ $=-\Delta \varphi_{\mathrm{a}}$ is negative, dependent on density of current on the anode, anode and near-anode plasma temperatures, and in such a way that potential jump $\Delta \varphi_{\mathrm{a}}$ rises noticeably with increase of plasma temperature near the anode and weakly decreases at increase of current density on the anode. At $Q^{0}=1500 \mathrm{~W}$ the axial temperature of plasma on

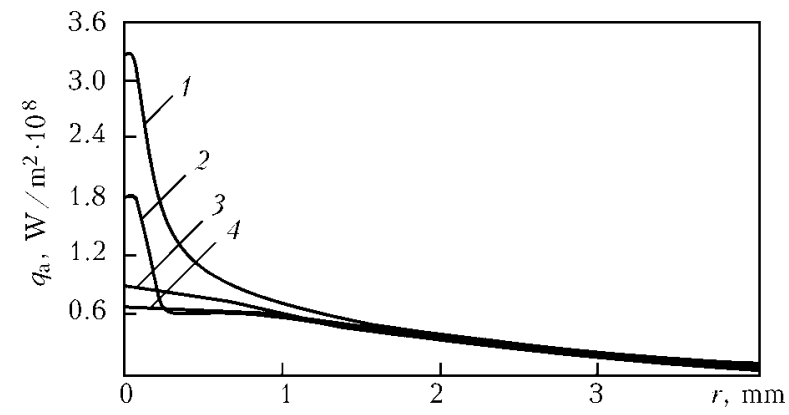

Figure 6. Distributions of heat flow contributed by arc to the anode over its surface: $1-Q^{0}=1500 \mathrm{~W}, T_{\mathrm{s}}=500 \mathrm{~K}$; $2-Q^{0}=1500 \mathrm{~W}, T_{\mathrm{S}}(0)=3000 \mathrm{~K} ; 3-Q^{0}=0, T_{\mathrm{S}}=$ $=500 \mathrm{~K} ; 4-Q^{0}=0, T_{\mathrm{s}}(0)=3000 \mathrm{~K}$

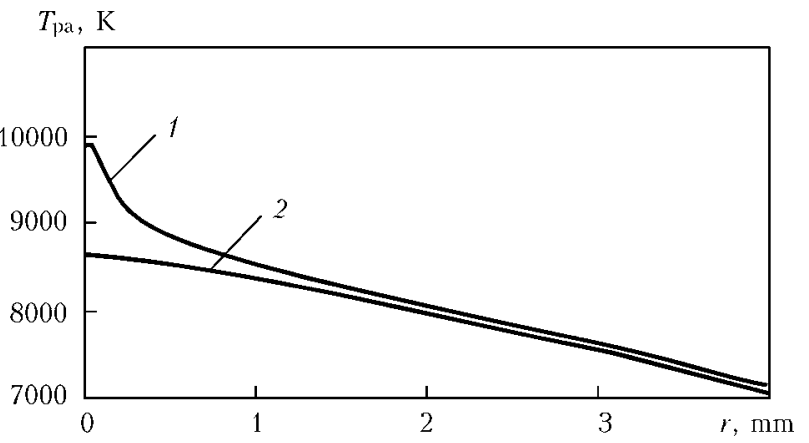

Figure 7. Radial distributions of plasma temperature on the anode layer boundary at $T_{\mathrm{S}}=500 \mathrm{~K}$ (for 1,2 see the text)

the anode layer boundary for an arc with a nonevaporating anode rises by almost $1200 \mathrm{~K}$, compared to a regular arc (see Figure 7). It results in increase of axial values of plasma potential on the above boundary and appearance of a pronounced maximum near the arc axis in $\Delta \varphi_{\mathrm{a}}(r)$ distribution (see Figure 8, curve 1). An abrupt change of $\Delta \varphi_{\mathrm{a}}$ along the anode surface leads to deformation of equal potential lines in paraxial zone of near-anode plasma, resulting in appearance of a significant radial component of electric field intensity vector and respective radial component of current density. Alongside increase of temperature (plasma electric conductivity), as well as axial component of electric field intensity in the above zone, it leads to an essential contraction of electric current in the region of anode binding of the arc exposed to a laser beam (see Figure 5), compared to a regular arc.

The above features of the influence of radial distribution of anode drop of potential on electric current distribution in the plasma near the anode, are illustrated in Figures 9 and 10, which give the equipotential lines and vector fields of current density in near-anode plasma for a regular arc and for an arc, exposed to focused laser radiation. Note that in the case of an anode evaporating under the impact of diffusion $\left(T_{\mathrm{s}}(0)=\right.$ $=3000 \mathrm{~K})$ plasma temperature on the boundary with the arc anode region decreases compared to water-cooled (non-evaporating) anode both in

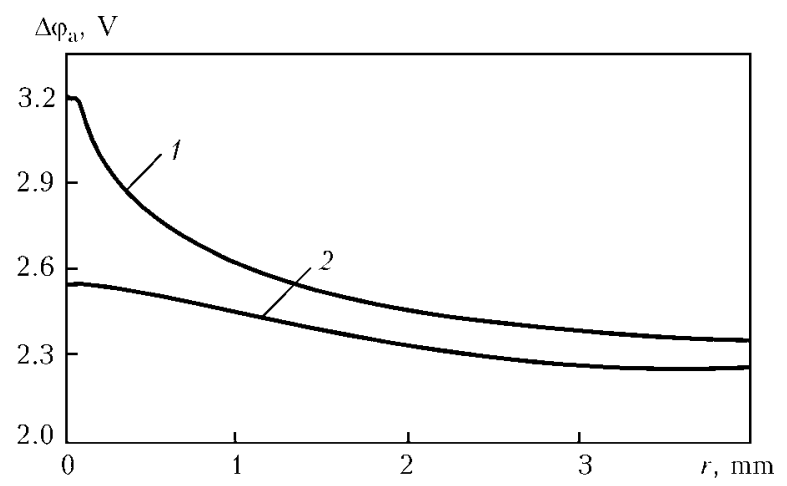

Figure 8. Radial distributions of electric potential drop in the arc anode layer at $T_{\mathrm{s}}=500 \mathrm{~K}$ (for 1,2 see the text) 


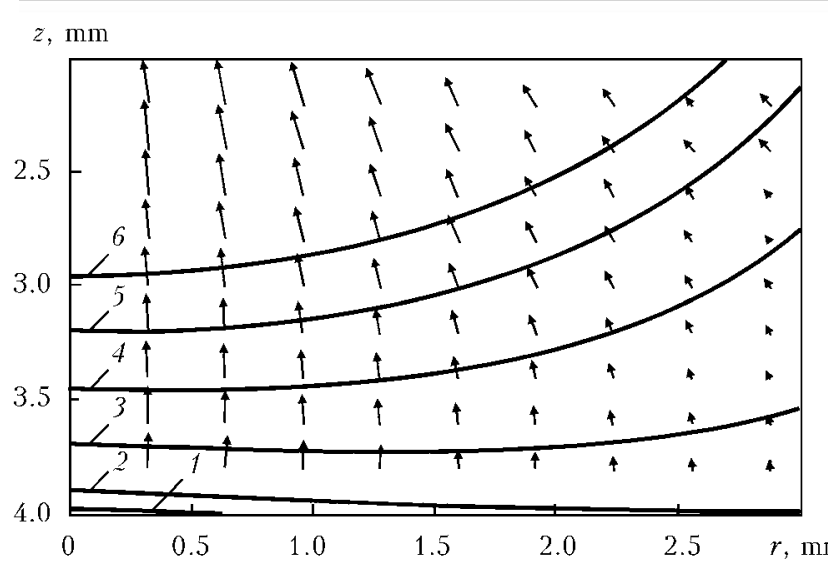

Figure 9. Equal potential lines and vector field of electric current densities in near-anode plasma of regular arc at $T_{\mathrm{S}}=$ $500 \mathrm{~K}: 1-\varphi=2.5 ; 2-2.25 ; 3-2 ; 4-1.75 ; 5-$ $1.5 ; 6-1.25 \mathrm{~V}$

the presence, and in the absence of laser impact. As a result, the effect of arc current contraction under the laser beam impact becomes less noticeable (see Figure 5).

Laser beam. Let us consider the influence of arc column plasma on the laser beam interacting with it. Let $\zeta(z)=Q(z) / Q^{0}$ be the coefficient of beam weakening due to its absorption in arc plasma, where $Q(z)$ is the laser beam power in the section of the arc with axial coordinate $z$, calculated by formula (6). Because of beam absorption in arc column, about $74 \%$ of laser beam power reaches the anode surface (Figure 11). This value only slightly depends on initial beam power and anode surface temperature for the selected parameters of the laser beam and the arc.

The power applied by laser beam to the anode $Q_{\mathrm{b}}=\Gamma Q(L)$ can be assessed, knowing the power of radiation $Q(L)$, which has reached the anode, and the coefficient of laser radiation absorption by its surface $\Gamma$. Assuming that the anode is watercooled, made from low-carbon steel, and select-

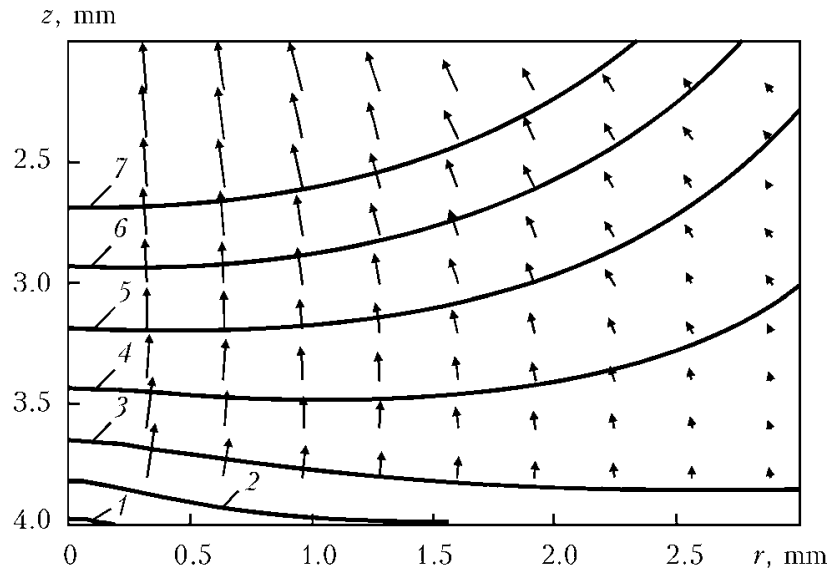

Figure 10. Equal potential lines and vector field of electric current densities in near-anode plasma of regular arc $\left(T_{\mathrm{S}}=\right.$ $=500 \mathrm{~K})$, exposed to laser beam of $1.5 \mathrm{~kW}$ power: 1 $\varphi=3 ; 2-2.5 ; 3-2.25 ; 4-2 ; 5-1.75 ; 6-1.5$; $7-1.25 \mathrm{~V}$

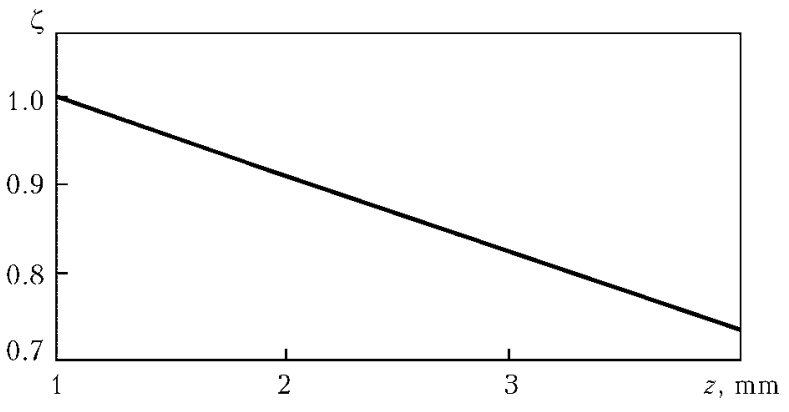

Figure 11. Change of coefficient of laser radiation weakening in arc plasma along the arc length

ing $\Gamma=0.1$ [11], we obtain $Q_{\mathrm{b}}=110 \mathrm{~W}$ at $Q^{0}=$ $=1500 \mathrm{~W}$. Note that melting and intensive laser-induced evaporation of the anode metal can lead to formation of a vapour-gas channel, which can absorb practically all the laser radiation power reaching the anode surface. Here the power, applied to the anode by the laser beam at $Q^{0}=1500 \mathrm{~W}$, can reach value $Q_{\mathrm{b}}=1105 \mathrm{~W}$ and can be commensurate with the power imparted to such an anode by the arc.

Distribution of radiation intensity along the axis of focused laser beam, interacting with arc plasma, compared to the respective distribution for the initial beam, is shown in Figure 12. Unlike laser beam propagating in air (in the absence of the arc), at propagation in arc plasma the intensity of laser radiation on beam axis $S_{0}=S(0, z)$ decreases when coming closer to the anode surface.

As follows from calculated dependencies, given in Figures 11 and 12, interaction of the focused laser beam with arc plasma under the considered conditions is mainly reduced to absorption of beam energy by the plasma, here the role of its refraction in non-uniform arc plasma turns out to be insignificant. This is also indicated by the dependence of effective beam radius $r_{\mathrm{b}}(z)$ (Figure 13), determined as distance from its axis, at which radiation intensity is equal to $1 \%$ of the respective $S(0, z)$ value. Effective radius of the laser beam, interacting with plasma, practically does not differ from initial beam radius in

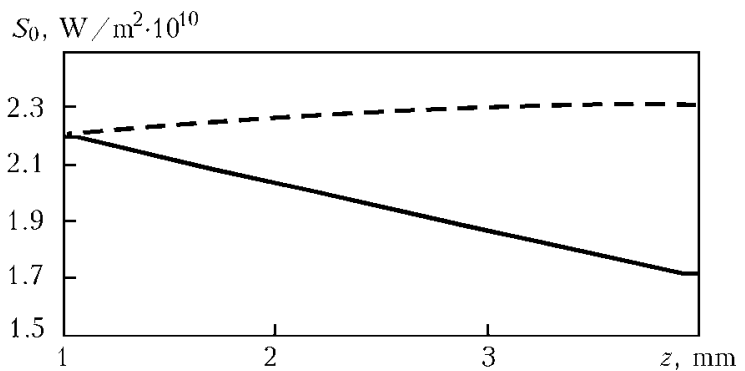

Figure 12. Distribution of radiation intensity on the axis of focused laser beam of $1500 \mathrm{~W}$ power propagating in arc plasma (solid curve), and for initial beam (hatched) 


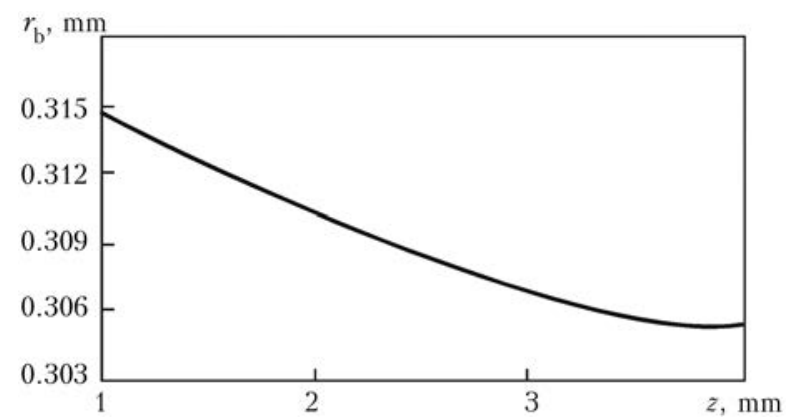

Figure 13. Distribution of laser beam effective radius along its length

the respective section, and for conditions considered in this work, it does not depend on its power.

Discussion. The predicted by mathematical modeling effect of contraction of electric current on the anode and heat flow to the anode, respectively, arising under the impact of focused beam of $\mathrm{CO}_{2}$-laser radiation on argon arc with refractory cathode, can have important technological consequences. Under the impact of $1500 \mathrm{~W}$ laser beam on $150 \mathrm{~A}$ arc, axial values of the above characteristics increase by more than 3 times. Thus, laser impact on the considered arc makes it a higher energy density source of thermal and dynamic impact on the metal. Calculations show that additional laser heating of arc plasma also causes a marked increase of total power applied by the arc to the anode $Q_{\mathrm{a}}=2 \pi \int_{0}^{R_{\mathrm{p}}} q_{\mathrm{a}} r d r$ (the

Table), and with increase of laser beam power the total heat flow contributed by the arc to the anode increases both for the water-cooled anode and for the anode evaporating through diffusion.

Now let us consider the mechanism of synergetic effect arising at combining of laser and arc heat sources under the conditions of hybrid $\left(\mathrm{CO}_{2}\right.$ laser + TIG) welding. This effect is manifested in disturbance of additivity of thermal impact of the laser beam and arc plasma on the metal being welded, which may result in the energy used for metal melting in hybrid welding, being more than 2 times greater than the sum of the respective

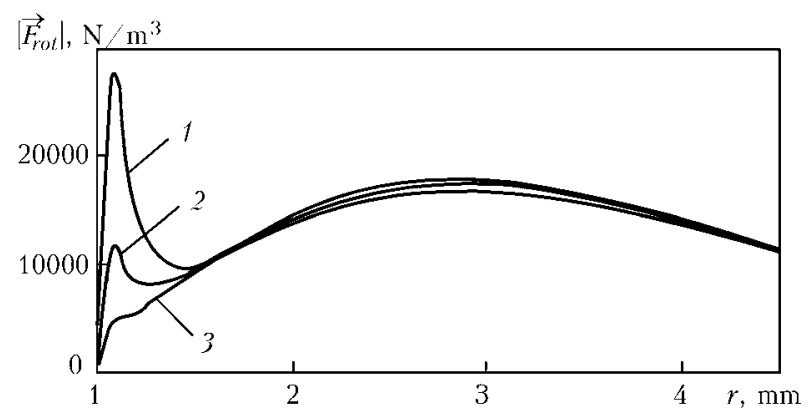

Figure 14. Distribution of eddy component of Lorentz force over the anode surface at $T_{\mathrm{S}}=500 \mathrm{~K}: 1-Q^{0}=1500 ; 2-$ $500 \mathrm{~W} ; 3$ - regular arc
Total heat flow into the anode from the arc depending on laser radiation power and thermal state of anode surface

\begin{tabular}{|c|c|c|}
\hline$T_{\mathrm{s}}(0), \mathrm{K}$ & $Q^{0}, \mathrm{~W}$ & $Q_{\mathrm{a}}, \mathrm{W}$ \\
\hline 500 & 0 & 1431.8 \\
\hline 500 & 500 & 1494.0 \\
\hline 500 & 1500 & 1564.4 \\
\hline 3000 & 0 & 1478.6 \\
\hline 3000 & 500 & 1526.1 \\
\hline 3000 & 1500 & 1579.7 \\
\hline
\end{tabular}

energies in welding by each individually taken heat source [1].

It is known that in an axially symmetric magnetic field of arc current, molten metal motion under the impact of the Lorentz force is excited by its eddy component $\vec{F}_{\text {rot }}$ having centripetal direction. Magnitude of this force is maximum on weld pool surface and decreases at electric current spreading in the volume of metal being welded. The thus arising pressure gradient causes a descending melt flow transporting the overheated metal from the pool surface to the melting front. At intensive flow of the melt towards the weld pool bottom part, the effectiveness of consumption (use for metal melting) of thermal power, applied to the anode by both the heat sources is increased, and the molten metal volume becomes greater, respectively. Let us approximately evaluate the influence of laser-arc interaction on distribution of eddy component of electromagnetic force on the surface of anode molten metal, assuming it to be undeformable. Arc contraction, which is expressed in an essential increase of electric current density on the metal surface near the center of the region of arc anode binding (see Figure 5), leads to an abrupt increase of the centripetal component of the Lorentz force in the above-mentioned zone ( $\mathrm{Fi}^{-}$ gure 14). The dynamic effect due to contraction of arc current on the anode surface, turns out to be the higher, the greater the laser radiation power.

The conducted approximate evaluation of electromagnetic force applied to the weld pool metal, requires further precising, primarily aimed at studying the thermal, electromagnetic and gasdynamic processes at arcing on the surface of molten anode metal, deformed under the impact of a high energy density laser source.

\section{Conclusions}

1. Additional local heating of arc plasma by a focused laser beam results in formation in the arc column of a high-temperature region localized 
near the beam axis, in which the maximum plasma temperature rises with the increase of laser radiation power. It is anticipated that formation of such a rigidly coupled with the laser beam axis, high-temperature region of arc plasma, having a high conductivity, will increase the spatial stability of the arc under the conditions of the hybrid process $\left(\mathrm{CO}_{2}\right.$-laser + TIG) that is particularly important at large welding speeds.

2. Redistribution of electric potential in arc plasma, occurring due to variation of spatial distribution of its temperature under the impact of the focused laser beam, leads to an essential increase of current density in near-anode plasma, as well as density of heat flow, applied by the arc to the anode, making such an arc a higher energy density source of thermal and electromagnetic impact on the metal being welded. Total power, applied by the arc to the metal in hybrid $\left(\mathrm{CO}_{2}\right.$-laser + TIG) welding, exceeds the power contributed by the respective arc under the conditions of regular nonconsumable-electrode welding. The effect predicted by the computational experiment of arc current contraction in hybrid welding may lead to a significant increase of the Lorentz force, transporting overheated metal from the center of the region of arc anode binding on the weld pool surface to its bottom, that should lead to increase of the power fraction of each of the used heat sources, which is consumed for melting of the metal being welded.

3. Interaction of the focused beam of $\mathrm{CO}_{2}$-laser radiation with plasma of the argon arc with refractory cathode leads to a certain decrease of the power of radiation, reaching the anode surface, as a result of partial absorption of laser radiation in the arc column plasma. Here, refraction of the beam in nonuniform arc plasma turns out to be negligible. The power applied by the laser beam to the metal, being welded in hybrid $\left(\mathrm{CO}_{2}\right.$-laser + TIG $)$ welding, can be both greater and smaller than the power applied to the metal in laser welding, depending on the conditions of absorption of laser radiation reaching the metal surface, determined, for instance, by the possibility of formation of a vapour-gas channel in the weld pool, which more effectively absorbs laser radiation than the flat surface of the melt.

This work was performed under Joint Project RE-2755/20-1 «Self-consistent modeling of hybrid (laser-TIG) and (laser-plasma) welding in the heat-conductivity penetration mode» funded by the German Research Society (DFG). The authors express their gratitude to DFG for financial support of these studies.

1. Seyffarth, P., Krivtsun, I.V. (2002) Laser-arc processes and their applications in welding and material treatment. Vol. 1. London: Taylor and Francis Books.

2. Dilthey, U. (2002) Laser arc hybrid welding - An overview. Arc welding processes and production systems: IIW Doc. XII-1710, 243-248.

3. Krikent, I.V., Krivtsun, I.V., Demchenko, V.F. (2012) Modelling of processes of heat-, mass- and electric transfer in column and anode region of arc with refractory cathode. The Paton Welding J., 3, $2-6$.

4. Krikent, I.V., Krivtsun, I.V., Demchenko, V.F. (2014) Simulation of electric arc with refractory cathode and evaporating anode. Ibid., 9, 17-24.

5. Boulos, M.I., Fauchais, P., Pfender, E. (1997) Thermal plasmas: Fundamentals and applications. Vol. 1. New York, London: Plenum Press.

6. Krivtsun, I.V., Porytsky, P., Demchenko, V. et al. (2010) On the application of the theory of Lorentzian plasma to calculation of transport properties of multicomponent arc plasmas. Europ. Phys. J. $D, \mathbf{5 7}, 77-85$.

7. Wendelstorf, J., Simon, G., Decker, I. et al. (1997) Investigation of cathode spot behaviour of atmospheric argon arcs by mathematical modeling. In: Proc. of 12th Int. Conf. on Gas Discharges and Their Applications (Germany, Greifswald, 1997), Vol. 1, 62-65.

8. Krivtsun, I.V., Demchenko, V.F., Krikent, I.V. (2010) Model of the processes of heat, mass and charge transfer in the anode region and column of the welding arc with refractory cathode. The Paton Welding J., 6, 2-9.

9. Lyashko, I.I., Demchenko, V.F., Vakulenko, S.A. (1981) Version of the method of splitting equations of uncompressible viscous fluid dynamics on Lagrangian-Eulerian networks. Doklady AN UkrSSR, Series A, 7, 43-47.

10. Demchenko, V.F., Lesnoj, A.B. (2000) LagrangianEulerian method of numerical solution of multidimensional problems of convective diffusion. Dopovidi NANU, 11, 71-75.

11. Gladush, G.G., Smurov, I. (2011) Physics of laser materials processing: Theory and experiment. Berlin, Heidelberg: Springer.

Received 19.01.2015 


\title{
PECULIARITIES OF MICROSTRUCTURE AND IMPACT TOUGHNESS OF METAL OF WELDED JOINTS OF PIPES OF HIGH-STRENGTH STEEL WITH NIOBIUM AND MOLYBDENUM
}

\author{
A.A. RYBAKOV, T.N. FILIPCHUK and V.A. KOSTIN \\ E.O. Paton Electric Welding Institute, NASU \\ 11 Bozhenko Str., 03680, Kiev, Ukraine. E-mail: office@paton.kiev.ua
}

\begin{abstract}
The work describes the results of investigation of microstructure and impact toughness of metal of welded joints of gas-and-oil pipeline pipes of steel category X65-X80 with different content of niobium and molybdenum. Investigated were welded joints of longitudinal pipes of 820-1420 mm diameter with 17.5$36.0 \mathrm{~mm}$ wall thickness, manufactured by using the traditional technology with applying the double-sided submerged multiarc welding. Optical and electron scanning metallography, as well as standard impact bend tests were used. The negative effect of increased content of niobium on structural characteristics of metal of HAZ and weld was found, which was intensified in the presence of molybdenum. Taking into account the niobium susceptibility to segregation at the grain boundaries, the additional alloying with molybdenum, decreasing the temperature of transformation, leads to the formation of unfavorable structural constituents and phases in the metal of welded joints, and also their clustering along the grain boundaries, in particular in reheating regions. To provide high impact toughness and crack resistance of welded joints of pipes of high-strength microalloyed steel, it is necessary to limit in it, in addition to carbon, the content of niobium $( \pm 0.05 \%)$ and molybdenum $( \pm 0.20 \%)$, as well as to use the welding consumables, providing the mass share of molybdenum in weld of not more than $0.30 \%$. Results of the work were applied in industrial production of pipes of category X65-X80 at pipe welding enterprises of Ukraine and Russia. 8 Ref., 2 Tables, 6 Figures.
\end{abstract}

$\boldsymbol{K} \boldsymbol{e} \boldsymbol{y} \boldsymbol{w} \boldsymbol{o r d} \boldsymbol{s}:$ gas-and-oil pipeline pipes, microalloyed steel, welded joint, weld metal, heat-affected zone, microstructure, impact toughness

In construction of modern main gas-and-oil pipelines the pipes of strength class K60, K65 (category X65, X80) of microalloyed steel, produced by using the thermomechanical treatment, including controllable rolling and accelerated cooling, are mainly used. These steels contain, as a rule, $0.05-0.10 \% \mathrm{C}, 1.5-2.0 \% \mathrm{Mn}$ and elements increasing the austenite stability, such as $\mathrm{Ni}, \mathrm{Cr}$, Mo in the amount of up to $0.3 \%$ each. A complex microalloying with carbonitride-forming elements $(\mathrm{Ti}, \mathrm{V}, \mathrm{Nb})$, which total content usually is within $0.12-0.15 \%$, is also used [1-4]. The definite chemical composition of pipe steel, providing the required complex of properties, is determined by the applied technology of its production and technical characteristics of metallurgical and rolling equipment. For example, the limited potentiality of optimizing the cooling of strip after rolling is compensated by the higher alloying with carbide-forming elements and elements decreasing the temperature of $\gamma \rightarrow \alpha$ trans-

(c) A.A. RYBAKOV, T.N. FILIPCHUK and V.A. KOSTIN, 2015 formation. As a result, in steel of the same class of different producers the content of carbon and microalloying elements, first of all, niobium and molybdenum, can change within rather wide ranges reaching limiting values allowable by standards, in particular for steel K65.

It is generally accepted that the increase in level of alloying can lead to deterioration of steel weldability, in particular, the risk is increased for formation of regions with a lower toughness in welded joint metal and, as a consequence, the probability of brittle fracture developed in these regions is increased.

Some authors outline the negative effect of increased niobium content on the structural state and impact toughness of HAZ metal of welded joints of pipe steel, in particular, in zones of the repeated heating in multipass welding [5-7]. In our investigations the negative role of niobium increased significantly with increase in amount of molybdenum in steel. Results of these investigations are described in the present article. The data on structure and properties of weld metal of pipes of steel with increased molybdenum and niobium content are also given. 
Welded joints of longitudinal gas-and-oil pipeline pipes of $820-1420 \mathrm{~mm}$ diameter and $17.5-36.0 \mathrm{~mm}$ wall thickness, made of highstrength steel with different content of molybdenum and niobium, were investigated at a number of domestic and foreign pipe welding plants by traditional technology using a double-sided submerged multiarc welding [8]. The longitudinal welds of pipes were welded inside (internal weld, four-arc welding) and outside (external weld, five-arc welding) the pipe. The energy input of welding processes was within the ranges of $4-7 \mathrm{~kJ} / \mathrm{mm}$.

Content of main alloying elements and admixtures in steel for investigated pipes were in the following ranges, \%: $0.05-0.07 \mathrm{C}$; $0.242-$ $0.281 \mathrm{Si} ; 1.64-1.72 \mathrm{Mn} ; 0.13$ (in one melting -
$0.02)-0.22 \mathrm{Ni} ; 0.01-0,03 \mathrm{~V} ; 0.014-0.016 \mathrm{Ti}$; $0.027-0.035 \mathrm{Al} ; \mathrm{S} \leq 0.007 ; \mathrm{P} \leq 0.011$. Amount of $\mathrm{Nb}$ in steel changed from 0.040 up to 0.076 , and Mo changed from 0.01 up to $0.27 \%$. For comparison, the data on properties and structure of welded joint metal of pipe of steel of X65 category with minimum amount of $\mathrm{Nb}(0.017 \%)$ and almost absence of Mo $(<0.03 \%)$ are also considered.

The test pipes were given the conditional letter designations (Table 1). The base metal (BM) of pipes A and B represented steel of category X80 with increased content of molybdenum $(0.27$ and $0.18 \%$ ) and niobium ( 0.068 and $0.076 \%$ ). Total mass share of carbonitride-forming elements $(\mathrm{Nb}$, $\mathrm{V}$ and $\mathrm{Ti}$ ) in this metal was, respectively, 0.109 and $0.103 \%$. Steel of category X80, from which the pipe $\mathrm{C}$ was manufactured, refers to the same

Table 1. Typical chemical composition of base metal and metal of internal and external welds of investigated welded joints of pipes

\begin{tabular}{|c|c|c|c|c|c|c|c|}
\hline \multirow{2}{*}{$\begin{array}{l}\text { Conditional code of pipes } \\
\text { (category, thickness of BM) }\end{array}$} & \multirow{2}{*}{ Zone of inspection } & \multicolumn{6}{|c|}{ Elements, wt.\% } \\
\hline & & $\mathrm{C}$ & $\mathrm{Si}$ & $\mathrm{Mn}$ & $\mathrm{P}$ & $\mathrm{S}$ & $\mathrm{Ni}$ \\
\hline \multirow[t]{3}{*}{$\mathrm{A}(\mathrm{X} 80,22 \mathrm{~mm})$} & $\mathrm{BM}$ & 0.051 & 0.242 & 1.69 & 0.006 & 0.007 & 0.22 \\
\hline & Internal weld & 0.053 & 0.344 & 1.68 & 0.012 & 0.010 & 0.15 \\
\hline & External weld & 0.054 & 0.433 & 1.67 & 0.013 & 0.010 & 0.14 \\
\hline \multirow[t]{3}{*}{$\mathrm{B}(\mathrm{X} 80,17.5 \mathrm{~mm})$} & $\mathrm{BM}$ & 0.050 & 0.281 & 1.64 & 0.008 & 0.002 & 0.20 \\
\hline & Internal weld & 0.050 & 0.452 & 1.64 & 0.010 & 0.006 & 0.24 \\
\hline & External weld & 0.050 & 0.474 & 1.66 & 0.010 & 0.006 & 0.21 \\
\hline \multirow[t]{3}{*}{$\mathrm{C}(\mathrm{X} 80,27.7 \mathrm{~mm})$} & BM & 0.070 & 0.270 & 1.67 & 0.007 & 0.002 & 0.20 \\
\hline & Internal weld & 0.060 & 0.305 & 1.46 & 0.016 & 0.004 & 0.20 \\
\hline & External weld & 0.055 & 0.327 & 1.45 & 0.015 & 0.003 & 0.19 \\
\hline \multirow[t]{3}{*}{$\mathrm{D}(\mathrm{X} 65,36 \mathrm{~mm})$} & BM & 0.062 & 0.096 & 1.74 & 0.011 & 0.002 & 0.13 \\
\hline & Internal weld & 0.056 & 0.181 & 1.72 & 0.012 & 0.006 & 0.10 \\
\hline & External weld & 0.059 & 0.177 & 1.70 & 0.013 & 0.006 & 0.09 \\
\hline \multirow[t]{3}{*}{$\mathrm{E}(\mathrm{X} 80,17.5 \mathrm{~mm})$} & BM & 0.050 & 0.250 & 1.72 & 0.011 & 0.003 & 0.02 \\
\hline & Internal weld & 0.051 & 0.425 & 1.69 & 0.012 & 0.006 & 0.08 \\
\hline & External weld & 0.051 & 0.434 & 1.68 & 0.013 & 0.006 & 0.09 \\
\hline
\end{tabular}

Table 1 (cont.)

\begin{tabular}{|c|c|c|c|c|c|c|c|}
\hline \multirow{2}{*}{$\begin{array}{l}\text { Conditional code of pipes } \\
\text { (category, thickness of BM) }\end{array}$} & \multirow{2}{*}{ Zone of inspection } & \multicolumn{6}{|c|}{ Elements, wt.\% } \\
\hline & & Mo & $\mathrm{V}$ & $\mathrm{Ti}$ & $\mathrm{Nb}$ & $\mathrm{Al}$ & B \\
\hline \multirow[t]{3}{*}{$\mathrm{A}(\mathrm{X} 80,22 \mathrm{~mm})$} & $\mathrm{BM}$ & 0.27 & 0.030 & 0.014 & 0.068 & 0.027 & $\mathrm{~N} / \mathrm{D}$ \\
\hline & Internal weld & 0.35 & 0.029 & 0.016 & 0.045 & 0.020 & 0.0010 \\
\hline & External weld & 0.35 & 0.027 & 0.019 & 0.039 & 0.019 & 0.0013 \\
\hline \multirow[t]{3}{*}{$\mathrm{B}(\mathrm{X} 80,17.5 \mathrm{~mm})$} & $\mathrm{BM}$ & 0.18 & 0.012 & 0.015 & 0.076 & 0.035 & $\mathrm{~N} / \mathrm{D}$ \\
\hline & Internal weld & 0.28 & 0.008 & 0.014 & 0.043 & 0.023 & 0.0010 \\
\hline & External weld & 0.29 & 0.007 & 0.018 & 0.047 & 0.023 & 0.0015 \\
\hline \multirow[t]{3}{*}{$\mathrm{C}(\mathrm{X} 80,27.7 \mathrm{~mm})$} & $\mathrm{BM}$ & 0.15 & 0.020 & 0.014 & 0.045 & 0.036 & $\mathrm{~N} / \mathrm{D}$ \\
\hline & Internal weld & 0.25 & 0.019 & 0.019 & 0.022 & 0.022 & 0.0025 \\
\hline & External weld & 0.25 & 0.019 & 0.020 & 0.022 & 0.021 & 0.0030 \\
\hline \multirow[t]{3}{*}{$\mathrm{D}(\mathrm{X} 65,36 \mathrm{~mm})$} & $\mathrm{BM}$ & $<0.03$ & 0.020 & 0.015 & 0.017 & 0.031 & $\mathrm{~N} / \mathrm{D}$ \\
\hline & Internal weld & 0.05 & 0.020 & 0.018 & 0.011 & 0.017 & 0.0038 \\
\hline & External weld & 0.05 & 0.020 & 0.015 & 0.011 & 0.015 & 0.0040 \\
\hline \multirow[t]{3}{*}{$\mathrm{E}(\mathrm{X} 80,17.5 \mathrm{~mm})$} & $\mathrm{BM}$ & 0.01 & 0.010 & 0.016 & 0.040 & 0.027 & $\mathrm{~N} / \mathrm{D}$ \\
\hline & Internal weld & 0.10 & 0.006 & 0.013 & 0.021 & 0.018 & 0.0020 \\
\hline & External weld & 0.13 & 0.005 & 0.017 & 0.021 & 0.018 & 0.0028 \\
\hline
\end{tabular}


system of alloying ( $\mathrm{Mn}-\mathrm{Nb}-\mathrm{Mo}-\mathrm{V}-\mathrm{Ni}-\mathrm{Ti})$, however, it contains the lower amount of molybdenum and niobium $(0.15$ and $0.045 \%$, respectively), but here $\mathrm{Nb}+\mathrm{V}+\mathrm{Ti}=0.079 \%$. Pipes $\mathrm{D}$ and $\mathrm{E}$ are manufactured of steel of category X65 and X80 with minimum alloying: mass share of niobium was 0.017 and $0.040 \%$, there was no almost molybdenum, and $\mathrm{Nb}+\mathrm{V}+\mathrm{Ti}$ was equal to 0.052 and $0.066 \%$, respectively.

During investigations the impact toughness of metal was evaluated at negative temperatures on specimens with a sharp notch, made in different zones of the pipe welded joint. Structure of metal of welded joints was investigated by using optical microscopy, scanning electron microscopy and fractography.

It is known that in the HAZ of welded joints of high-strength pipes the zone of a coarse grain (ZCG) is most problematic, that is caused by a significant growth of austenite grain, formation of the coarse packets of plate-like ferrite and upper bainite, as well as the presence of MACphase, in particular of a lath morphology. It is considered that the minimum toughness is characterized by the zone of local embrittlement, formed due to reheating region of coarse grain of the first (internal) pass in welding of the second (external) pass, except of ZCG in HAZ, adjacent to the fusion line of internal and external longitudinal welds [5]. By this reason, when carrying out of metallographic examinations of HAZ the main attention was paid to structuralphase characteristics of metal of these regions in particular.

In metal of investigated welded joints of pipes at the ZCG of HAZ of internal and external welds a microstructure of the same type is formed, represented mainly by rather coarse packets of the bainite type structure: it is the ferrite with an ordered second phase of the lath morphology (Figure 1). The regions with the ordered and disordered second phase of granulated morphology are also observed. The formation of polygonal hypoeutectic ferrite along the boundaries of the former austenite grain in welded joint metal of investigated pipes was completely suppressed, with the exception of pipes $\mathrm{D}$ and $\mathrm{E}$ with minimum content of molybdenum and niobium, where the boundary precipitation of this structural component was found (Figure 1,c). Value of grains in HAZ metal, adjacent directly to the fusion line of external and internal welds, inde-

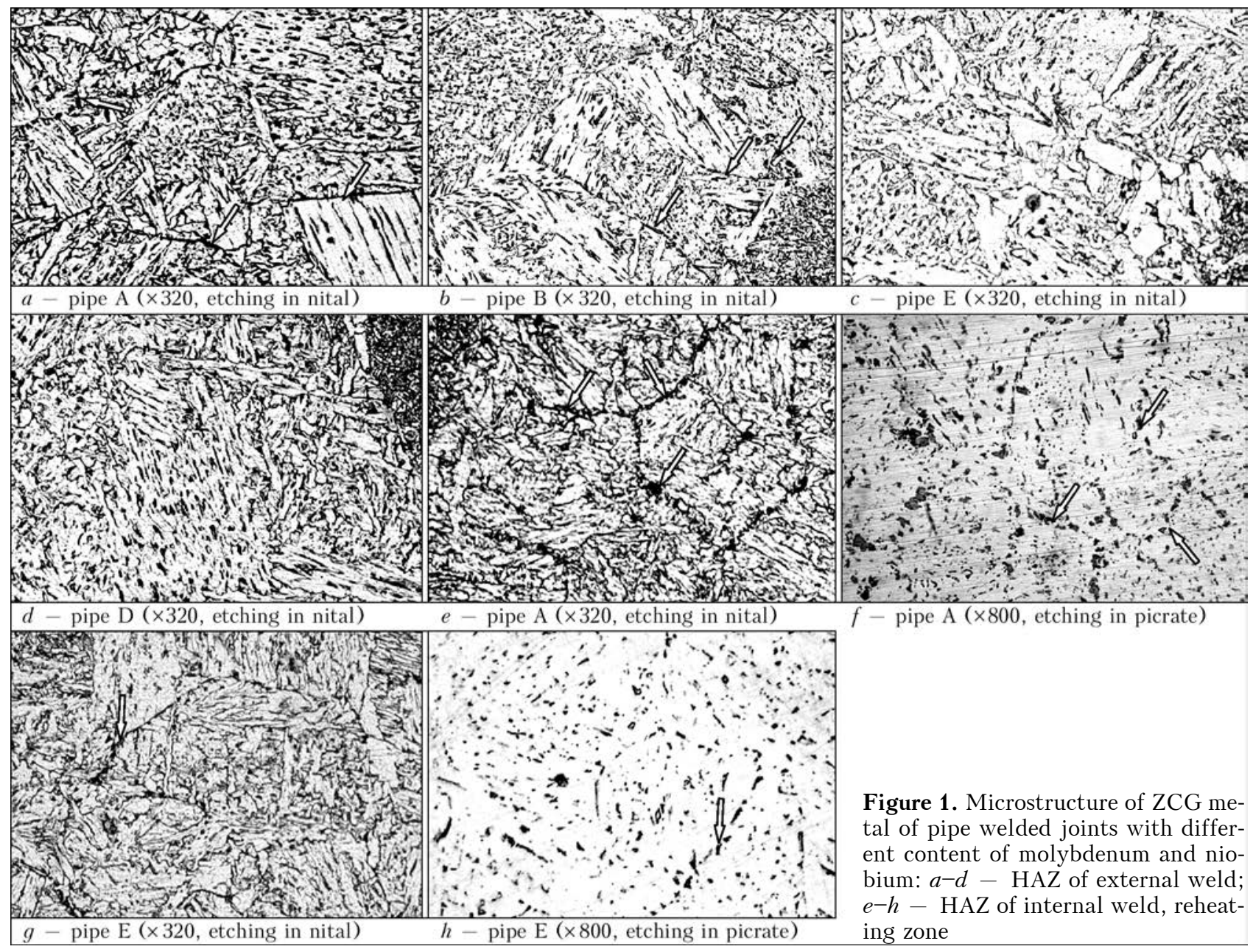




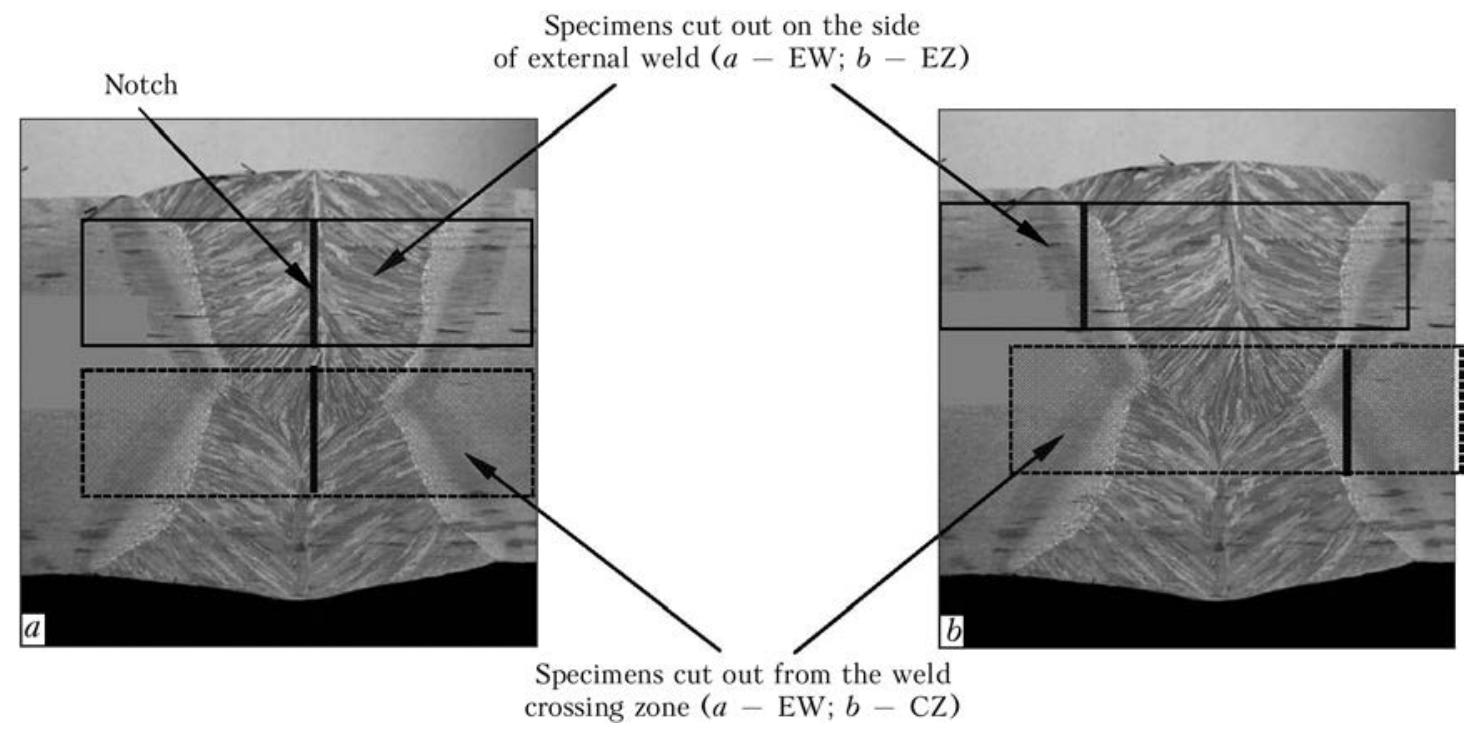

Figure 2. Scheme of cutting out of specimens and making a notch at impact bent test of weld $(a)$ and HAZ (b) metal

pendently of changing the mass share of molybdenum and niobium in the investigated limits, amount mainly to $54-108 \mu \mathrm{m}$, that corresponds to number 5-4 (by GOST 5639). Single larger grains of number 3 (of sizes up to $137 \mu \mathrm{m}$ ), revealed mainly in the fusion zone of external welds (in their apex), were also found, moreover, the large grains, as a rule, were fragmented into the finer subgrains.

As is seen from Figure 1, with increase in amount of niobium and molybdenum in steel (pipes A and B) the share of regions of brittle structure with similar oriented carbon phase (MAC-phase) of the lath morphology, as well as sizes (length and width) of precipitates of this phase are increased. The increase in the mass share of the mentioned elements in steel has the more negative effect on the state of boundaries of the metal grains in the examined zone. Thus, in metal of ZCG of external weld of pipes A and $B$ with high content of niobium and molybdenum, unlike the other examined welded joints of pipes, the carbon formations, such as MACphases and carbides, are precipitated intensively along the boundaries of the former austenite grain (shown by arrows in Figure 1, $a, b$ ). In metal of ZCG of internal welds in regions, subjected to repeated heating in making the external weld, the mentioned grain-boundary carbon precipitation was observed almost in all the examined welded joints, with exception of pipe D with minimum amount of niobium. Moreover, at the higher content of niobium these precipitates are coarser (see arrows in Figure 1).

The impact toughness of HAZ metal was evaluated on specimens cut out at the region of external weld (Figure 2, specimen EZ) and in the zone of crossing the external and internal welds (Figure 2, specimen CZ). It is known that under conditions of structurally heterogeneous welded joint the determination of tough characteristics of metal and, first of all, HAZ by using impact tests of specimens of standard sizes $(10 \times$ $\times 10 \mathrm{~mm}$ ) is not quite correct, as the obtained values of impact toughness depend to a great extent on specimen disposition and place of a notch. It follows from Figure 2 that in making a notch in HAZ metal of external weld in accordance with GOST 6996-66 the notch section includes only ZCG small area adjacent to the fusion line. The larger share of ZCG is observed in the notch section of specimens cut out from the place of welds crossing. In such specimens the region of reheating of internal weld zone with the most unfavorable structure can also be present.

Results of some tests of specimens with a notch along the fusion line are given in Table 2. The observed large scattering of $K C V$ values at such making of the notch is predetermined by the additional effect of weld shape on impact toughness values. The effect of weld shape on HAZ toughness values is a subject of independent investigations and will be described by us in other publications. Here, we shall only note that the recommended GOST rules of making the notch in HAZ for welds with conditionally good shape factor limit greatly the ZCG share (local zone of brittleness) in the examined section of the impact test specimen.

At the same time, in spite of the observed scattering of test results, the data of Table 2 allow making an adequate conclusion that increase in mass share of niobium in steel for more than $0.05 \%$ leads to decrease in HAZ impact toughness values, in particular in cutting out of specimens in the zone of crossing of internal and external welds. The most noticeable decrease in 
Table 2. Impact toughness of welded joints of pipes investigated $K C V_{-40}, \mathrm{~J} / \mathrm{cm}^{2}$

\begin{tabular}{|c|c|c|c|c|}
\hline \multirow{2}{*}{$\begin{array}{l}\text { Conditional } \\
\text { code of } \\
\text { pipes } \\
\text { (category, } \\
\text { thickness of } \\
\text { BM) }\end{array}$} & \multicolumn{2}{|c|}{ Notch in the weld centre } & \multicolumn{2}{|c|}{ Notch along the fusion line } \\
\hline & $\begin{array}{c}\text { EW } \\
\text { specimens }\end{array}$ & $\begin{array}{c}\mathrm{CW} \\
\text { specimens }\end{array}$ & $\begin{array}{c}\text { EZ } \\
\text { specimens }\end{array}$ & $\begin{array}{c}\mathrm{CZ} \\
\text { specimens }\end{array}$ \\
\hline $\begin{array}{l}\text { A }(X 80, \\
22 \mathrm{~mm})\end{array}$ & $\frac{56-110}{92}$ & $\frac{42-93}{56}$ & $\frac{56-141}{114}$ & $\frac{21-95}{46}$ \\
\hline $\begin{array}{l}\mathrm{C}(\mathrm{X} 80, \\
27.7 \mathrm{~mm})\end{array}$ & $\frac{112-195}{165}$ & $\frac{88-121}{105}$ & $\frac{80-197}{140}$ & $\frac{58-142}{81}$ \\
\hline $\begin{array}{l}\mathrm{D}(\mathrm{X} 65, \\
36 \mathrm{~mm})\end{array}$ & $\frac{185-197}{192}$ & $\frac{152-177}{160}$ & $\frac{290-320}{300}$ & $\frac{100-287}{198}$ \\
\hline \multicolumn{5}{|c|}{$\begin{array}{l}\text { Notes. 1. Numerator indicates minimum and maximum values of } \\
\text { impact toughness, denominator }- \text { mean values of } 6-12 \text { tests. } 2 \text {. } \\
\text { Schemes of cut out of specimens and making a notch are given in } \\
\text { Figure } 2 \text {. }\end{array}$} \\
\hline
\end{tabular}

impact toughness is observed at maximum content of molybdenum, niobium and manganese (pipe A) in steel in the investigated limits, when the least favorable microstructure is formed in ZCG metal.

Investigations after etching of fracture surface of impact test specimens of welded joints with a

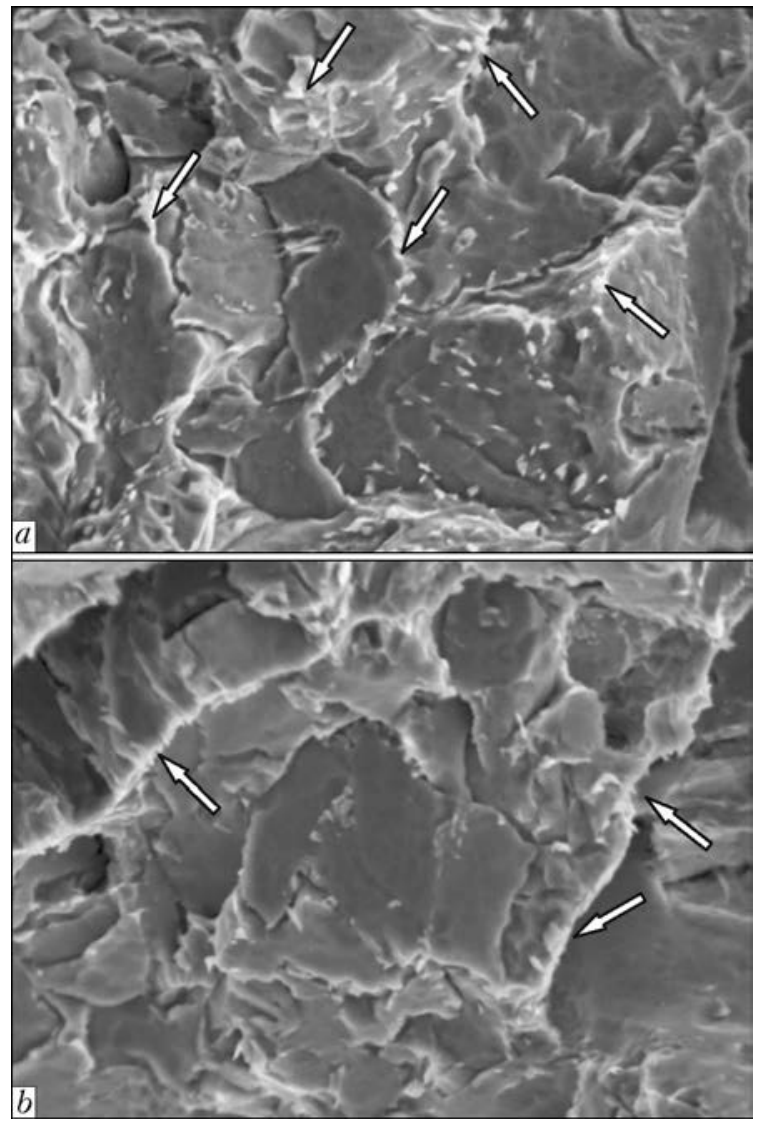

Figure 3. Fractoograms of quasi-brittle regions of fracture of specimens of pipe A $(a)$ and $\mathrm{B}(b)$ with a notch along the fusion line, fractured at temperature $-40{ }^{\circ} \mathrm{C}(\times 2000$, etching in nital) notch along the fusion line confirmed that in weld metal of pipes A and B with high content of niobium and molybdenum at the regions of quasi-brittle fracture along the boundaries of facets the segregations of carbon formations are revealed (they are shown in Figure 3 with light arrows). There are no such formations along the boundaries of the facets in HAZ metal with limited alloying with niobium (for example, pipes $\mathrm{D}$ and $\mathrm{E}$ ).

Similar effect has the increased content of niobium and molybdenum on structural-phase characteristics of the weld metal. In arc welding of large-diameter pipes for main pipelines the niobium is transferred, as is known, into weld metal mainly from the pipe steel. The share of molybdenum in weld metal is determined by its content in steel and welding wire and can be regulated within definite limits by changing of its amount in the latter. Moreover, to increase the tough characteristics the metal of pipe welds is often microalloyed with titanium and boron. Thus, the weld metal represents a rather complexly-alloyed system.

It was found that due to increase in the mass share of niobium up to $0.039-0.047 \%$ and molybdenum up to $0.28-0.35 \%$, because of the higher content of these elements in steel at mass share of manganese of $1.64-1.68 \%$, in weld metal of pipes $\mathrm{A}$ and $\mathrm{B}$ a rather non-homogeneous structure is formed with the formation of constituents of different strength and toughness. The higher content of elements in metal of such welds, actively reducing the temperature of $\gamma \rightarrow \alpha$ transformation ( $\mathrm{Mo}, \mathrm{Mn}, \mathrm{Nb})$, leads also to the formation of regions of the upper bainite, except of the main structure of acicular ferrite ( $75 \%)$ (Figures $4, b$ and 5, $a$ ). MAC-phase is often represented essentially by martensite-austenite complexes with increased content of carbon, but not with products of bainite-martensite transformation (the same as at smaller alloying). Such structural constituent is poorly etched and at examination in the scanning microscope it is revealed as smooth, unstructured light formations (in Figure $5, a, b$ they are shown by light arrows). In addition, the susceptibility to formation of segregations of MAC-phase is distinctly expressed at the boundaries of acicular and grain-boundary polygonal ferrite (Figures 4, $c$ and 5, $a$ ). Due to a limited alloying with titanium and boron, realized by welding wire, the formation of grainboundary polygonal ferrite in weld metal of pipes $\mathrm{A}$ and $\mathrm{B}$ was not suppressed completely ( $\mathrm{Fi}-$ gure $4, a$ ). And though the share of interlayers of hypoeutectic polygonal ferrite is not very high (not more than $10 \%$ even at the periphery regions of weld), the enrichment of their boundaries with 

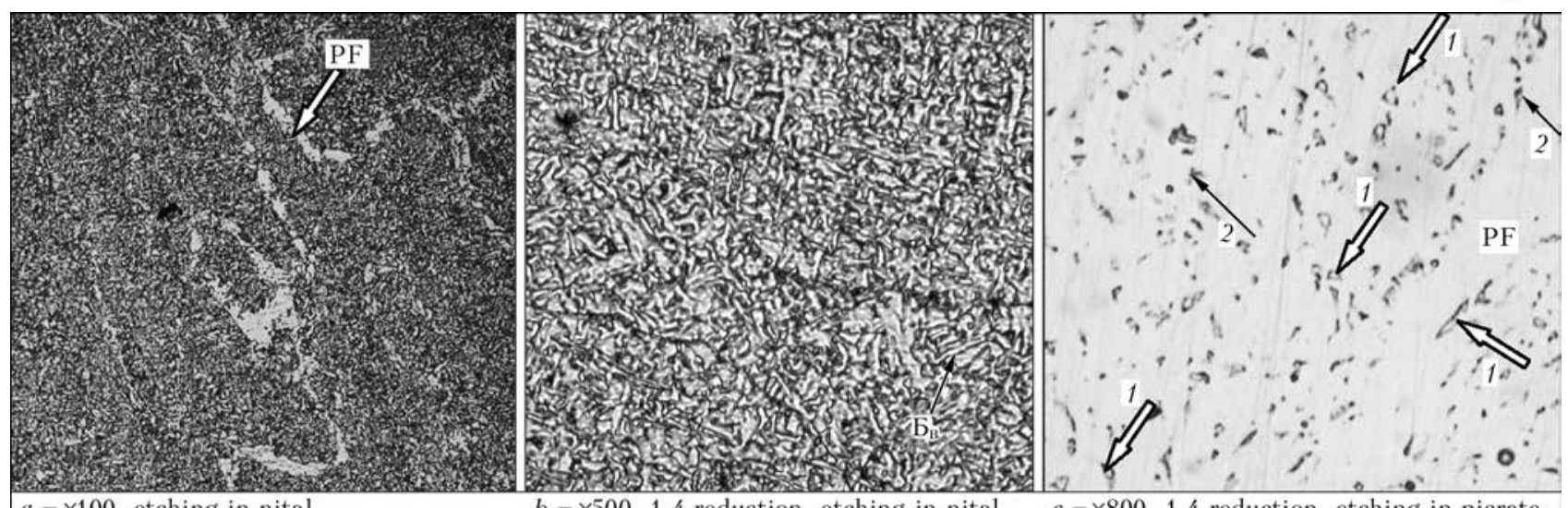

\section{$a-\times 100$, etching in nital}

$b-\times 500,1.4$ reduction, etching in nital
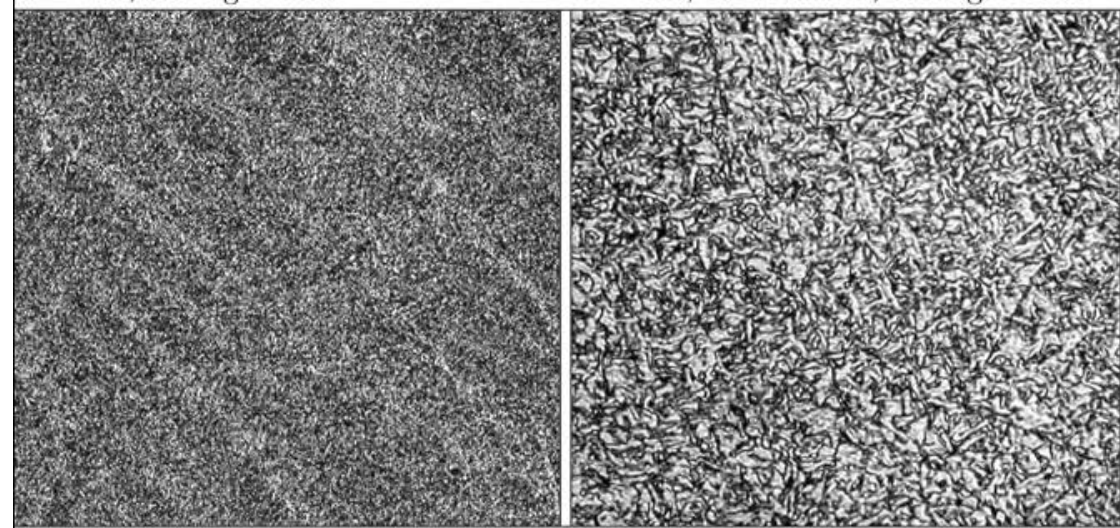

$c-\times 800,1.4$ reduction, etching in picrate

$d-\times 100$, etching in nital

$e-\times 500,1,4$ reduction, etching in nital
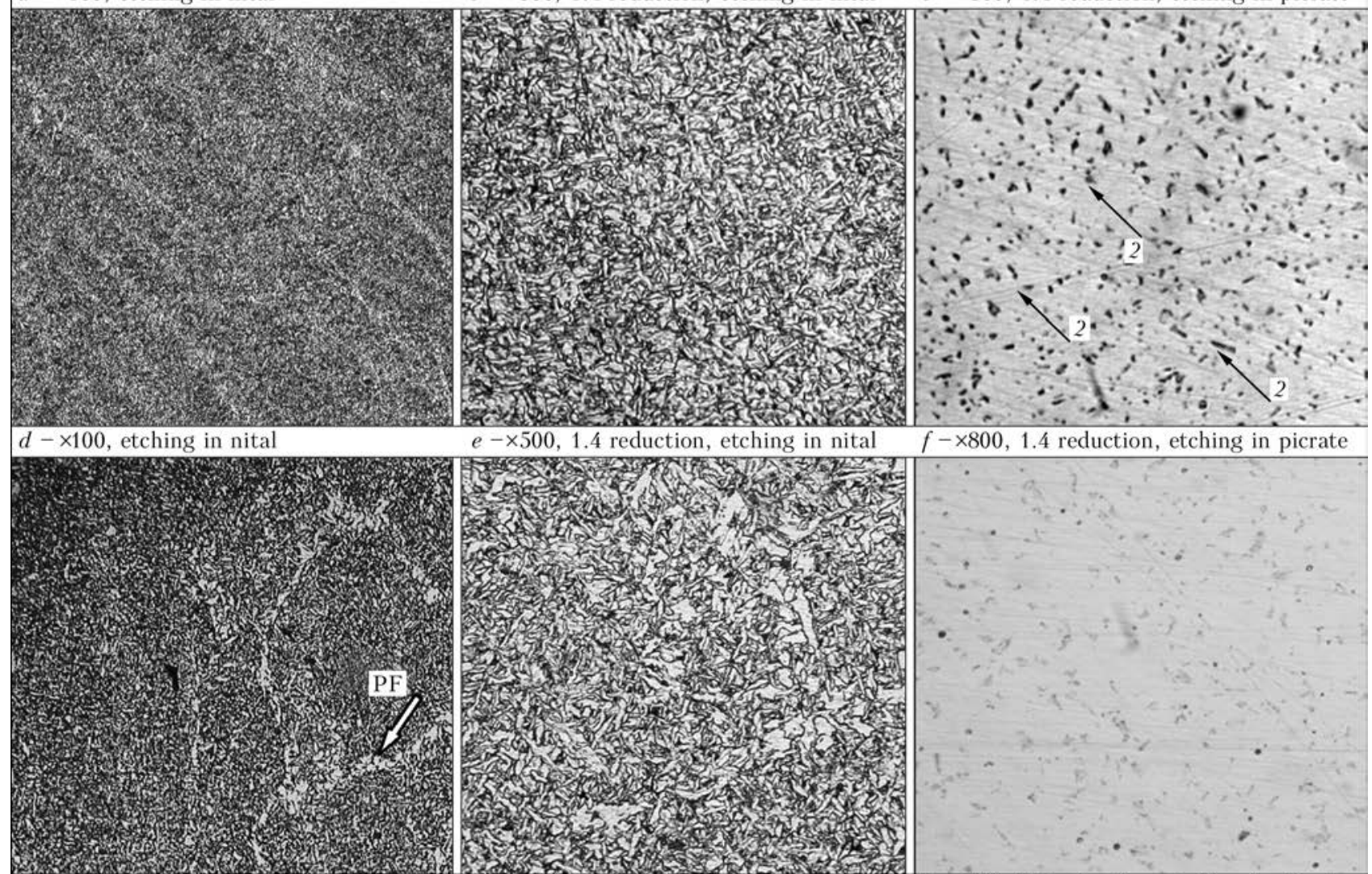

$f-\times 800,1.4$ reduction, etching in picrate

$g-\times 100$, etching in nital

$h-\times 500,1.4$ reduction, etching in nital

Figure 4. Microstructure of metal of external welds with different content of molybdenum and niobium (optic metallography): $a-c-$ pipe A; $d-f-$ pipe $\mathrm{C} ; g-i-$ pipe D; $1-$ martensite-austenite complex; $2-$ MAC-phase

formations of MAC-phase (Figure 4,c), possessing sufficiently high strength, is a negative factor, promoting the fracture initiation. Maximum segregations of carbon phases and structural constituents (MAC-phase, carbides) are observed along the boundaries of crystallites in metal of internal weld at the regions of reheating ( $\mathrm{Fi}^{-}$ gure $6, a, b)$. The developed system of polygonal boundaries, often decorated with MAC-phase precipitates, was also revealed (see Figure $4, b$ ).

The mentioned structural peculiarities cause the higher susceptibility of metal of such welds to the formation of cracks, that is confirmed by the presence of separate relatively large cracks in ferrite interlayers, fringed by MAC-phase, and net of microcracks, localized along the secondary (polygonal) boundaries in one of examined specimens of welded joints of pipe A.

Microstructure of weld metal of pipe $\mathrm{C}$, moderately alloyed with $\mathrm{Nb}(0.022 \%)$, Mo $(0.25 \%)$ and $\mathrm{Mn}$ (about $1.46 \%$ ) is more homogeneous and represented mainly by the dispersed acicular ferrite $(\sim 90 \%)$. The elongated grains of acicular ferrite of 3-4 × 5-15 $\mu \mathrm{m}$ size are disoriented for a large angle (see Figure $4, e$ ). Due to optimum ratio of titanium and boron in weld metal $(0.020$ and $0.003 \%$, respectively) the formation of grain-boundary polygonal ferrite was almost suppressed (only in weld root, $1-3 \%$ of this structural constituent was observed). Negligible struc- 


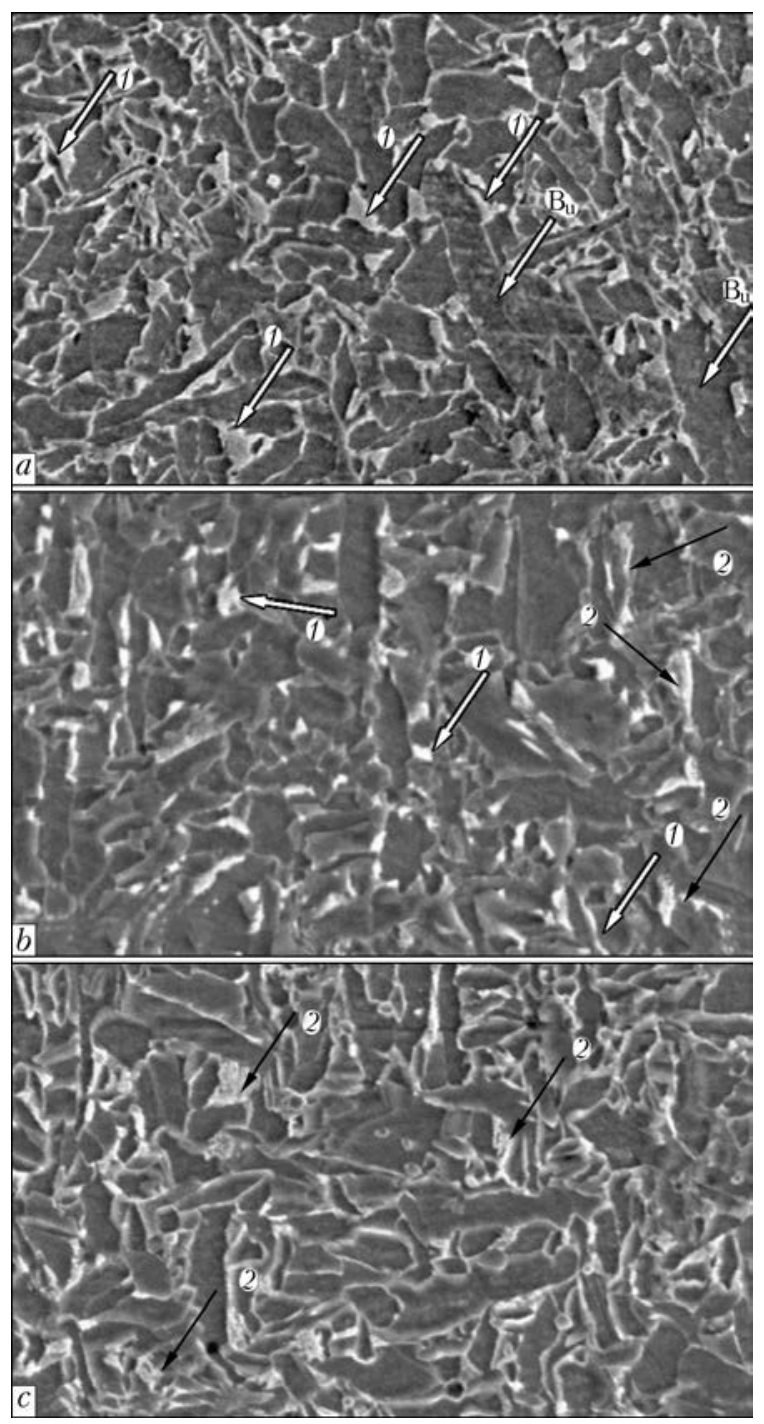

Figure 5. Morphology and topography of MAC-phase in metal of external welds with different content of molybdenum and niobium ( $\times 3000$, scanning microscopy): $a-$ pipe $\mathrm{A} ; b-$ pipe $\mathrm{C} ; c-$ pipe $\mathrm{D} ; 1$ - martensite-austenite complex (light arrows); 2 - MAC-phase (dark arrows)

tural heterogeneity is appeared along the boundaries of crystallites in the form of grains of acicular ferrite of some larger size (Figure $4, d, e$ ). Dispersed MAC-phase, including mainly the products of bainite transformation, is distributed quite uniformly (Figure 4, $f$ ). Clusters of carbon phases and structural constituents along the boundaries of crystallites, including the reheating zone of internal weld, are almost absent (see Figure $6, c, d)$. Polygonal boundaries in such weld are poorly developed (Figure $4, e$ ).

The typical feature of the microstructure of weld metal of pipe D of lower strength (X65) with minimum content of molybdenum $(0.05 \%)$ and niobium $(0.011 \%)$ in weld at mass share of $\mathrm{Mn}$ at the level of $1.70-1.72 \%, \mathrm{Ti}-0.015-$ $0.018 \%$ and $\mathrm{B}-0.0038-0.0040 \%$ is the fact that, in spite of the presence of sufficiently wide layers of grain-boundary polygonal ferrite (6-
$12 \%$, at the periphery - up to $15 \%$ ), except acicular ferrite (about $80 \%$ ), the precipitation of MAC-phase at their boundary, including regions of reheating of internal weld, are absent (Figure 4, $g-i$ ) Grains of the acicular ferrite are close in most cases to equiaxial ones (with shape factor $\chi=1.1-1.5)$. The more elongated $(\chi=$ $=7-8$ ) ferrite grains, present in a small number, are disoriented, therefore, the regions of metal with similar orientation of structures are quite infrequent (see Figure 5, c). Close nature of microstructure is typical of weld metal of pipe E of steel X80, in which the mass share of molybdenum is within the ranges of $0.010-0.13 \%$, and niobium is contained in the amount of $0.021 \%$.

Table 2 gives results of tests of specimens of pipe welded joints with a notch in the weld centre, cut out from the external weld, made finally (EW specimens), and from the zone of crossing the external and internal welds (CW). Scheme of cutting out of specimens and making of notches is given in Figure 2, $a$. As is seen from Table 2, the level of impact toughness of weld metal of test pipes is sufficiently high in general. This is due, in the first turn, to application of advanced welding consumables: agglomerated aluminate flux of low basicity and welding wires with Mo, $\mathrm{Ni}, \mathrm{Ti}$ and B. Optimum combination of these elements provides the preferable formation of acicular ferrite structure with high tough characteristics in weld metal (see Table 2, pipes C, D). At the same time, the excessive alloying of weld of pipe A with molybdenum $(0.35 \%)$ and $\mathrm{Nb}(0.039 \%)$, accompanied, as was noted, by the appearance in structure of regions of upper bainite and segregations of carbon phases along the boundaries of crystallites, decreases the values of impact toughness (see Table 2, pipe A, EW specimens).

The higher decrease in tough characteristics is noted in the case when the test section of impact test specimen of pipe A with increased content of $\mathrm{Mo}$ and $\mathrm{Nb}$ includes the region of metal of internal weld with unfavorable structure, subjected to reheating in welding of external weld (Table 2, CW specimen). For welds with lower share of molybdenum and niobium (Table 2, pipes $\mathrm{C}$ and $\mathrm{D}$ ) the decrease in impact toughness at testing of these specimens is appeared to a much less extent.

Fractographic investigations of fracture surface of impact test specimens with a notch along the axis of weld showed that the weld metal at increased content of $\mathrm{Mo}, \mathrm{Nb}$ and $\mathrm{Mn}$ (pipe A) even at temperature $-10{ }^{\circ} \mathrm{C}$ is fractured mainly by a quasi-brittle mechanism, here, the elongated smooth (quasi-brittle) regions, corresponding to 


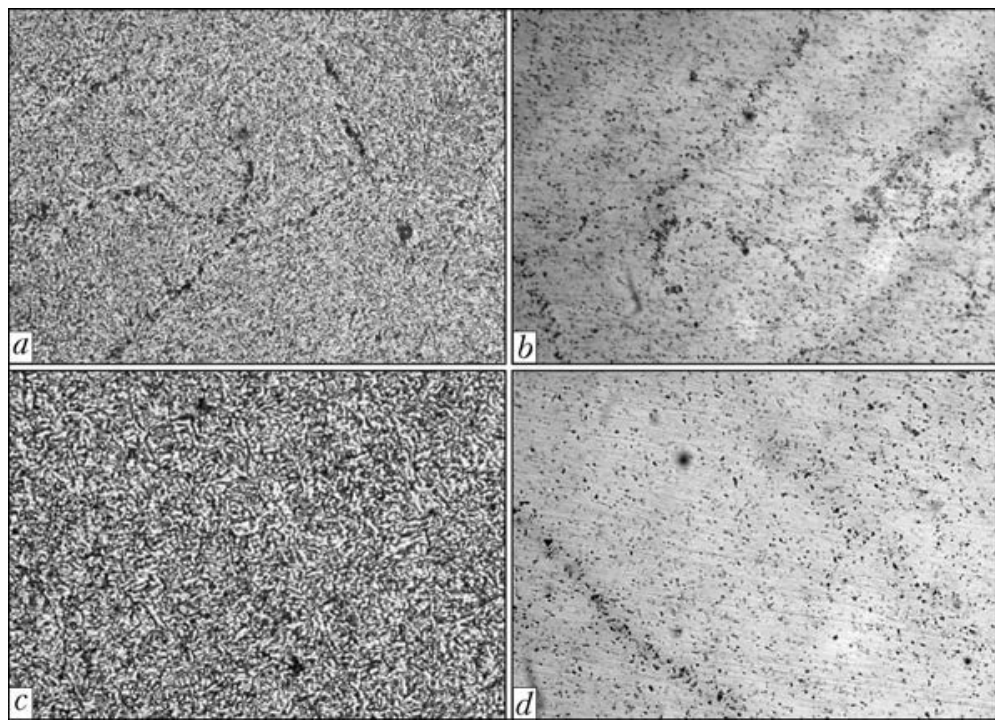

Figure 6. Typical microstructure of metal of internal weld in the zone of reheating of welded joint of pipe A $(a, b)$ and pipe $C(c, d)$ of steel with different content of niobium and molybdenum

interlayers of hypoeutectic grain-boundary polygonal ferrite with boundaries enriched with carbon precipitates, revealed earlier in study of results of metallographic examinations, were observed at small tough areas of the fracture surface. In case of limited alloying of weld metal (pipes $\mathrm{C}$ and $\mathrm{D}$ ) the share of areas of tough fracture at $-40{ }^{\circ} \mathrm{C}$ is within the limits from 10 up to $50 \%$. In this case the tough regions are located under the notch of impact test specimens, and their length is not less than $2 \mathrm{~mm}$, that predetermines the high values of the impact toughness.

Thus, the results of carried out investigations confirmed the negative effect of increased content of niobium (in steel of more than $0.05 \%$ and more than $0.03 \%$ in weld), which is intensified in the presence of molybdenum, on structural characteristics of weld metal and HAZ. Taking into account the susceptibility of niobium, similarly to sulfur, to segregation, the additional alloying with molybdenum, reducing the temperature of transformation, leads to the formation of unfavorable structural constituents and phases, as well as to their clustering along the grain boundaries in metal of the welded joints. At such amount of niobium and molybdenum in ZCG metal the packets of bainite structure are formed with coarser carbon phase of the lath morphology, and clusters of MAC-phase and carbides are precipitated along the boundaries of former austenite grains, in particular in the reheating zones.

In weld metal containing the mass share of Mo of more than $0.3 \%$ and $\mathrm{Nb}$ of more than $0.03 \%$, at $\mathrm{Mn}$ on the level of $1.6 \%$ and higher, the regions of the upper bainite are formed, length of polygonal boundaries and amount of MAC-phase precipitates along the grain boundaries are increased, and also the share of martensite in the composition of this structural constituent is increased. These structural changes of weld metal, as also in HAZ metal, are appeared to a larger extent in the reheating zones.

By this reason, to provide the high impact toughness and crack resistance of metal of joints in welding of pipes of high-strength microalloyed steel it is necessary to limit the content of niobium $(\leq 0.05 \%)$ and molybdenum $(\leq 0.20 \%)$, as well as to apply the welding consumables, providing the mass share of molybdenum in weld of not more than $0.30 \%$.

1. Morozov, Yu.D., Efron, L.I. (2006) Steels for pipes of main pipelines: State-of-the-art and tendencies of developments. Metallurg, 5, 54-56.

2. Efron, L.I., Nastich, S.Yu. (2006) State of the manufacturing of sheet products and coiled stock for spirally welded pipes of strength category up to X100. «Chermetinformatsiya». Bull. Chyorn. Metallurgiya, 11, 68-81.

3. Morozov, Yu.D., Matrosov, M.Yu., Nastich, S.Yu. et al. (2008) High-strength pipe steels of new generation with ferrite-bainite structure. Metallurg, 8, 39-42.

4. De Moor, E., Gibbs, P.J., Speer, J.G. et al. (2010) Strategies for third-generation advanced highstrength steel development. Iron and Steel Techn., 11, 133-144.

5. Hamada, M., Fukada, Y., Komizo, Y. (1995) Microstructure and precipitation behavior in heat affected zone of $\mathrm{C}-\mathrm{Mn}$ microalloyed steel containing $\mathrm{Nb}, \mathrm{V}$ and Ti. ISIJ Int., 35(10), 1196-1201.

6. Graf, M., Niederhoff, K. (1990) Toughness behavior of the heat-affected zone (HAZ) in submerged-arc welded large-diameter pipe. In: Proc. of Pipeline Technology Conf. (Oostende, Belgium, 15-18 Oct. 1990), 131-139.

7. Li, Y., Crowther, D.N., Green, M.J.W. et al. (2001) The effect of vanadium and niobium on the properties and microstructure of the intercritically reheated coarse grained heat affected zone in low carbon microalloyed steels. ISIJ Int., 41(1), 46-55.

8. Rybakov, A.A. (2009) Current state of manufacturing of large diameter pipes for main pipelines. In: Proc. of Sci.-Techn. Seminar on Service Reliability Control of Pipeline Transportation Systems (Kiev, 10-11 June 2009), 48-52. 


\title{
ASYNCHRONOUS EXCITERS AND STABILIZERS OF WELDING ARC. ANALYSIS AND DESIGN PROCEDURE. Part 1
}

\author{
N.M. MAKHLIN ${ }^{1}$ and A.E. KOROTYNSKY ${ }^{2}$ \\ ${ }^{1}$ SE REC Welding Control in Power Engineering of E.O. Paton Electric Welding Institute, NASU \\ 11 Bozhenko Str., 03680, Kiev, Ukraine. E-mail: electro@paton.kiev.ua \\ ${ }^{2}$ E.O. Paton Electric Welding Institute, NASU \\ 11 Bozhenko Str., 03680, Kiev, Ukraine. E-mail: office@paton.kiev.ua
}

\begin{abstract}
Issues of circuit engineering and analysis of processes in electronic voltage boosters of asynchronous type with series switching-in of main and pilot arcs are considered. They have configuration of forming circuit, in which capacitive storage and inductance of primary winding of pulse step-up transformer have series connection, and switching key of the circuit is switched on in parallel to this connection. The first part of work describes circuit engineering solutions for imbedded asynchronous exciters and stabilizers of arcing process for charging devices based on key scheme with dosing reactor and diode-capacitor voltage multiplier. Analysis of arcing process in circuits of these functional assemblies of asynchronous exciters and stabilizers was performed using equations known in theoretical electric engineering. Engineering procedure of design of main components of charging devices for asynchronous exciters and stabilizers of arcing process as well as recommendations on selection of their element base are proposed based on equation solutions. 28 Ref., 3 Tables, 9 Figures.
\end{abstract}

Ke $\boldsymbol{y} \boldsymbol{w} \boldsymbol{o r} \boldsymbol{d} \boldsymbol{s}:$ arc and plasma welding, initial arc ex citation, repeated arc ignitions, electronic arc exciters, spark discharge, series connection, design procedure, recommendations

In recent years, asynchronous-type devices with series connection of main or pilot arc receive more and more distribution among the electronic voltage boosters, which are called exciters and stabilizers of arc and designed for initiation of stationary arc discharge by means of ionizing of inter-electrode gap due to injection of high-voltage pulses in it. The peculiarities of such devices are:

- consistency of energy and amplitude of output high-voltage pulses independent on periods of connection of switching key of device generator part;

- configuration of forming circuit according to which switching semi-conductor key has in parallel connection to series inductance $L$ and circuit capacity $C$;

- in number of cases separate circuits of pulse aperiodic charge of capacity $C$ using increased (in relation to device supply voltage) voltage of direct current and charge (recharge) of this capacity, accompanied by transient attenuating process at each connection of forming circuit switching key;

- obviously higher efficiency than in exciters and stabilizers of arc, in which forming circuit

represents itself series connection of switching key and reactive elements ( $L$ and $C$ );

- possibility of providing of versatility on supply voltage mode (input voltage) in series of cases.

Significant number of works is dedicated to pulse devices, principle of operation of which is based on charge-discharge cycles of capacitive storages of electric energy. Fundamental work [1] provides for the most complete and detailed consideration of theoretical fundamentals of charging circuits of such storages. However, several works, for example [2-4], dedicated to asynchronous exciters and stabilizers of arc (AESA), give piecewise and not enough for practical application consideration to the issues of analysis and electromagnetic processes in the devices of this group, their circuit engineering and calculation. This results in some difficulties in development and designing of AESA.

Aim of the present work lies in consideration and analysis of processes AESA using known theoretical electric engineering methods of investigation of linear circuits and development of recommendations on design and selection of device components of this group, based on results of their analysis and experience of designing, manufacture and practical application.

Peculiarities of circuit engineering, analysis and calculation of AESA functional assemblies. AESA refer to pulse devices providing accumulation of electric energy in periodic mode and its 
further consumption through electric discharge for development or retention of plasma.

Capacitive storages are used in AESA for accumulation of electric energy as in number of devices with pulse consumption of energy. Their advantages lie in easy switching of their charging and discharging as well as possibility of controlled dosing of accumulated energy by means of charge voltage level stabilizing [1].

Application of capacitive storages makes for mandatory presence of charging device (CD) in AESA structure. In addition to CD, basic AESA structure includes generator of increased voltage pulses (GVP) with regulation scheme and device for input of high-voltage pulses (DIHVP) in circuit of main or pilot arcs (Figure 1).

Variety of existing at present time engineering solutions of $\mathrm{CD}$ and processes taking place in them give grounds to assume that the following can be used for desining of CD in AESA:

- pulse transformation of direct current voltage with the help of semiconductor inverters, DC-DC converters of step-up type, converters based on Polikarpov scheme (often called Cook's scheme), Luo-converters, key schemes with dosing reactors;

- rectification and increase (multiplication) of input voltage of single-phase alternating current to required level of charge voltage of GVP capacitive storage with the help of devices, which are made based on scheme of diode-capacitor voltage multipliers, for example, by Cockcroft -Walton scheme;

- method of resonance pumping.

Processes in $\mathrm{CD}$ with inverters are studied in works [1, 5, 6 etc.), analysis and basics of calculation of semiconductor DC-DC converters and converters based on Polikarpov (Cook's) scheme are given in works [5-8] and Luo-converters - in [9]. The most important and general topological indication of all without exception pulse converters of direct current is presence in their structure of one or several inductive storage units as well as regulated semiconductor keys and their controllers, providing formation of control signals of pulse-width or pulse-frequency modulation considering feedback signals on output voltage or current. This provokes for specific engineering difficulty of such converters and application of significant number of necessary components, that inevitably effect safety and cost of $\mathrm{CD}$ and AESA in whole.

$C D$ based on key schemes with dosing reactors. CDs based on key schemes with dosing reactors are the simplest ones and have the smallest quantity of elements and, respectively, the lowest cost among known semiconductor pulse con-

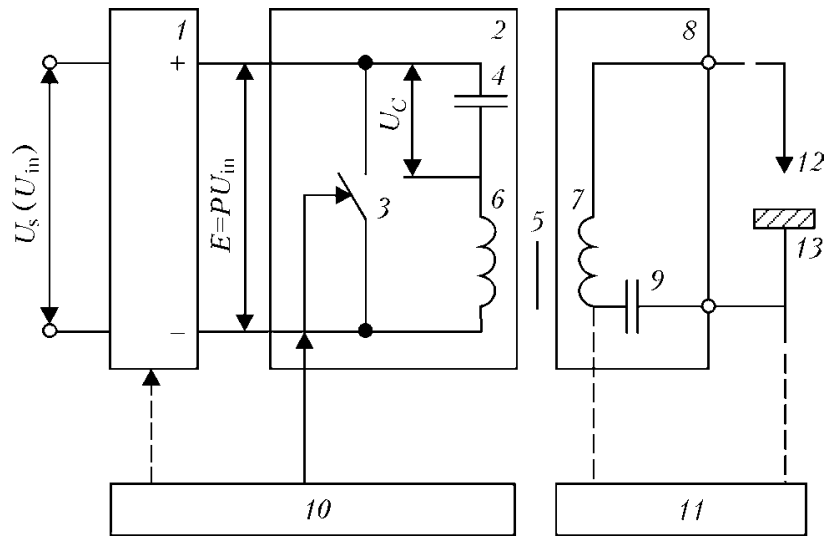

Figure 1. Structural diagram of AESA: 1 - CD of step-up type; 2 - GVP; 3 - semiconductor switching key included in GVP; 4 - capacitor of GVP forming circuit; 5 - pulse step-up transformer with primary winding 6 and secondary winding $7 ; 8-$ DIHVP in arc circuit; $9-$ protective (bypass) capacitor of DIHVP; 10 - AESA control scheme; 11 - arc supply source; 12 - electrode; 13 - part to be welded

verters of direct current voltage. It should be noted that one of the advantages of such CDs lies in constant amount of consumed energy under conditions of providing complete discharge of dosing reactors [1].

Somewhat simplified electric schematic diagram of AESA with CD, which is built based on key scheme with dosing reactor, is given in $\mathrm{Fi}^{-}$ gure 2, $a$. Charge of capacitive storage in such $\mathrm{CD}$ (condenser $\mathrm{C} 2$ ) of GVP forming circuit is carried out for several two-phase cycles of switching of transistor key $V T 1$.

Accumulation of energy in inductive storage (choke) $L 1$ takes place during the first stage of each cycle, in course of which transistor key $V T 1$ is in open (on) condition. Scheme of CD replacement for this stage of its operation is given in Figure 2, $b$. Building up of current $i_{L}$ through reactor (choke) $L 1$ and current $i_{T}$ through transistor key $V T 1$ take place from zero to amplitude value $I_{m}$, and process of charging of choke $L 1$ at current $i_{L}$ and voltage $u_{L}$ are described by equations [10], solutions of which are

$$
i_{L}=i_{T}=\frac{U_{\text {in }}}{R}\left(1-e^{-\frac{R}{L} t}\right), \quad u_{L}=U_{\text {in }} e^{-\frac{R}{L} t},
$$

where $U_{\text {in }}$ is the direct current power voltage (voltage at $C 1$ capacitor); $R=R_{L}+E S R_{C 1}+$ $+R_{\text {c.e }}+R_{\text {add }}$ is the pure resistance of choke charge circuit $L 1 ; R_{L}$ is the choke pure resistance; $E S R_{C 1}$ is the equivalent active series resistance of capacitor $C 1 ; R_{\text {c. }}$ is the pure resistance of collector-emitter of $V T 1$ transistor in on condition; $R_{\text {add }}$ is the pure resistance of additional current-limiting resistor $(R 2) ; L$ is the reactor (choke) inductance $L 1$. 

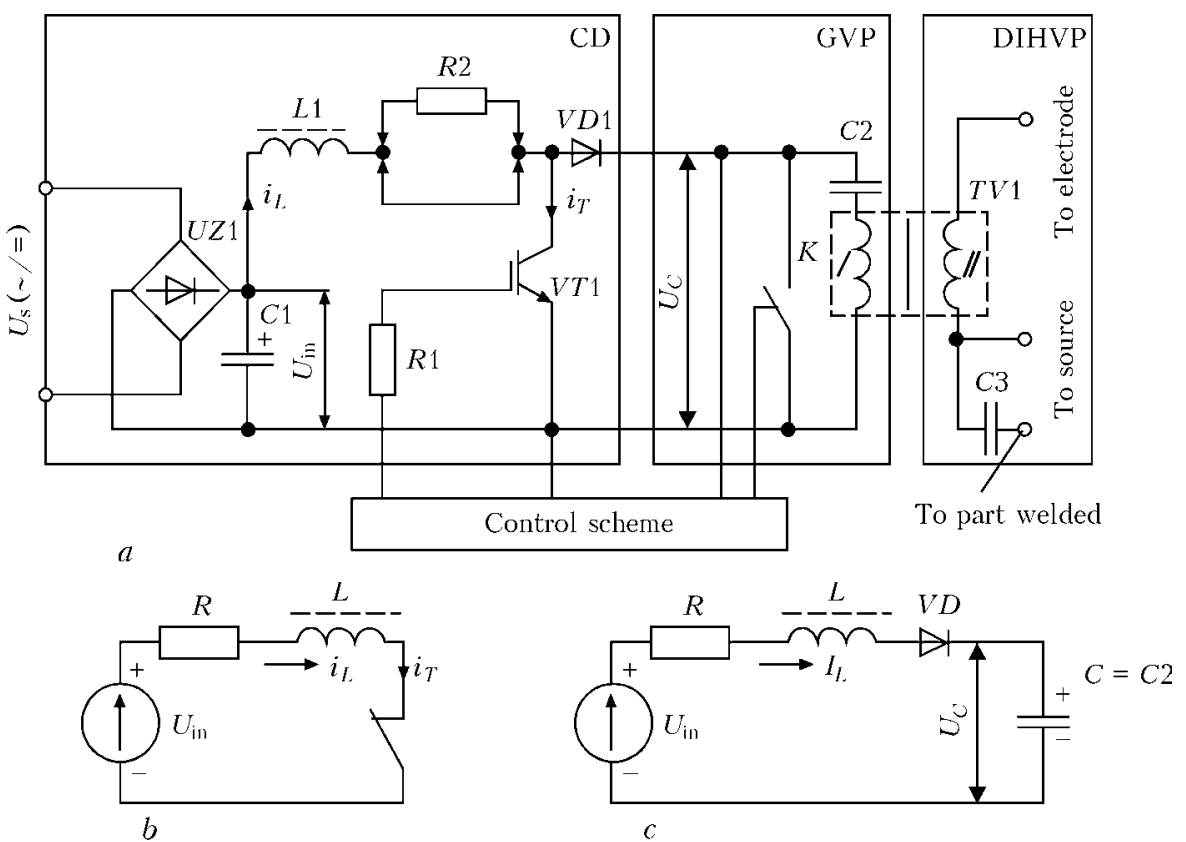

Figure 2. Electrical schematic diagram of AESA with CD based on key scheme with dosing reactor $(a)$ and schemes of $\mathrm{CD}$ replacement for time interval, corresponding to duration of on- $(b)$ and off- $(c)$ condition of CD transistor key

Necessity of introduction of additional current-limiting resistor $R_{\text {add }}$ (Figure 2, $a, R 2$ ) lies in the fact that its presence provides for stability of consumed power for the first moment of charge of capacitive storage (capacitor $C 2$ ). Besides, as long as values of $R_{L}$ and differential diode resistance $V D 1$ in its on condition (conductivity condition) are very small, then it is impossible to provide limitation of charge current of capacitive storage of GVP forming circuit in considered AESA scheme by means of influence on control inlet of transistor key $V T 1$. Moreover, it is obvious that introduction of additional current-limiting resistor $R_{\text {add }}$ somewhat deteriorates CD energy indices.

The largest (amplitude) value of current $I_{m}$, which is achieved in passing of current $i_{L}=i_{T}$ in time interval, corresponding to on condition of $\mathrm{CD}$ transistor key, is determined by relationship

$$
I_{m}=\frac{U_{\mathrm{in}} D}{L f_{\mathrm{t} . \mathrm{k}}},
$$

where $D$ is the relative duration of on condition of CD transistor key during $T_{\text {t.k }}$ of each switching cycle; $f_{\mathrm{t} . \mathrm{k}}=1 / T_{\mathrm{t} . \mathrm{k}}$ is the frequency of switching cycles of $\mathrm{CD}$ transistor key.

Transistor key VT1 (Figure 2,a) is transformed in off condition at the beginning of second stage of each cycle, and dose of energy accumulated in inductive storage $L 1$ is

$$
\Delta W=\int_{0}^{\tau_{\mathrm{a}}}\left(u_{L} i_{L}\right) d t=L I_{m}^{2} / 2=\text { const },
$$

where $\tau_{\mathrm{a}}$ is the pulse duration, in course of which choke $L 1$ accumulates energy and this energy starts proceeding in GVP capacitive storage (capacitor $C 2$ ). Scheme of $C D$ replacement for the second stage of charging-discharging cycle of inductive storage $L$ is given in Figure 2, $c$.

Below condition, grounded in work [1], is applied to CD transistor key switching frequency $f_{t . k}$ for accumulation of energy on inductive storage $L$ and its complete discharge during the second stage of each cycle:

$$
f_{\mathrm{t} . \mathrm{k}} \leq \frac{1}{1.57 \sqrt{L C}+L I_{m} / U_{\mathrm{in}}},
$$

where $C$ is the capacitor (capacitive storage) capacity of GVP forming circuit.

Considering the fact that AESA as a rule, in addition to value of pulse energy, includes set values of charge voltage $U_{C 0}$ of GVP capacitive storage (Figure 2, $a, C 2$ ) and duration of its charge $t_{\mathrm{ch}}$, which should fulfill the condition

$$
t_{\mathrm{ch}} \leq \frac{1}{f_{\mathrm{sw}}}
$$

then energy value $W_{C}$, accumulation of which should be provided for $t_{\mathrm{ch}}$ time interval, makes

$$
W_{C}=\frac{C U_{C 0}^{2}}{2}=n \Delta W=\frac{L I_{m}^{2}}{2} t_{\mathrm{ch}} f_{\mathrm{t} . \mathrm{k}},
$$

where $f_{\mathrm{sw}}$ is the frequency of connection of GVP switching key (Figure $2, a, K) ; n=t_{\mathrm{ch}} / T_{\mathrm{t} . \mathrm{k}}=$ $=t_{\mathrm{ch}} f_{\mathrm{t} . \mathrm{k}}$ is the amount of cycles of CD transistor key switching (Figure 2, $a, V T 1$ ) for $t_{\mathrm{ch}}$ time interval.

Solutions of known equations with non-zero initial conditions $[10,11]$ for replacement 
scheme, given in Figure 2, $c$, show that $u_{L}$ voltage at the storage in the second part of cycle in course of complete discharge $\tau_{\mathrm{d}} n$th CD inductive storage in the moment of $n$th pulse beginning is determined as

$$
-u_{L}=-\left(U_{C_{n-1}}+U_{\text {in }}\right),
$$

where $U_{C n-1}$ is the GVP capacitive storage voltage before $n$th pulse beginning, and in the moment of $n$th pulse ending the following formula is used:

$$
-u_{L}=-\left(U_{C_{n-1}}+U_{\text {in }}\right) / e^{-\frac{R}{L} \tau_{d}} .
$$

According to work [1] $U_{C_{n-1}}$ voltage can be determined by expression

$$
U_{C_{n-1}}=\sqrt{\frac{L}{C(n-1)}},
$$

momentary value of charge current $i_{C}$ of GVP capacitive storage for $n$th pulse is determined by formulae

$$
i_{C}(\tau)_{n}=I_{m}\left(\cos \omega_{0} \tau-\sqrt{n-1} \sin \omega_{0} \tau\right),
$$

and $\tau_{\mathrm{d}}$ duration - by expression

$$
\tau_{\mathrm{d}}=\sqrt{L C}(1.57-\operatorname{arctg} \sqrt{n-1}) .
$$

Here $\tau$ is the time taken from the moment of $n$th pulse beginning; $\omega_{0}=1 / \sqrt{L C}$ is the own frequency of $L R C$-circuit of charge of GVP capacitive storage.

Figure 3 shows diagrams of $i_{L}$ and $i_{V T}$ currents, passing through inductive storage and CD transistor key, respectively, charge current $i_{C}$ of GVP capacitive storage $\left(i_{V D}\right.$ current passing through gate-type diode) and $u_{C}$ voltage at this storage. It follows from expressions (7)-(11) and Figure 3 that increase of $u_{C}$ voltage at GVP capacitive storage provides for gradual reduction of $\tau_{\mathrm{d}}$ duration of pulses of charge current $i_{C}$ and $\Delta U_{C}=U_{C_{n}}-U_{C_{n-1}}$ voltage difference. Processes of energy accumulation in CD inductive storage and its complete discharge, repeating with $f_{\text {t.k }}$ frequency, take place up to the moment of GVP capacitive storage voltage reaching set $U_{C 0}$ value, after which discharge (re-charging) of the latter without switching off of its charge circuit is performed in GVP. In order to prevent charging of GVP capacitive storage to $U_{C}$ voltage values, exceeding allowable ones, it is necessary to switch off supply voltage or $U_{\text {in }}$ voltage at the moment of stop of AESA output pulse generation.

Active value of current $I_{\mathrm{c}}$, consumed by such AESA, for CD scheme, given in Figure 2, $a$, can be determined by relationship

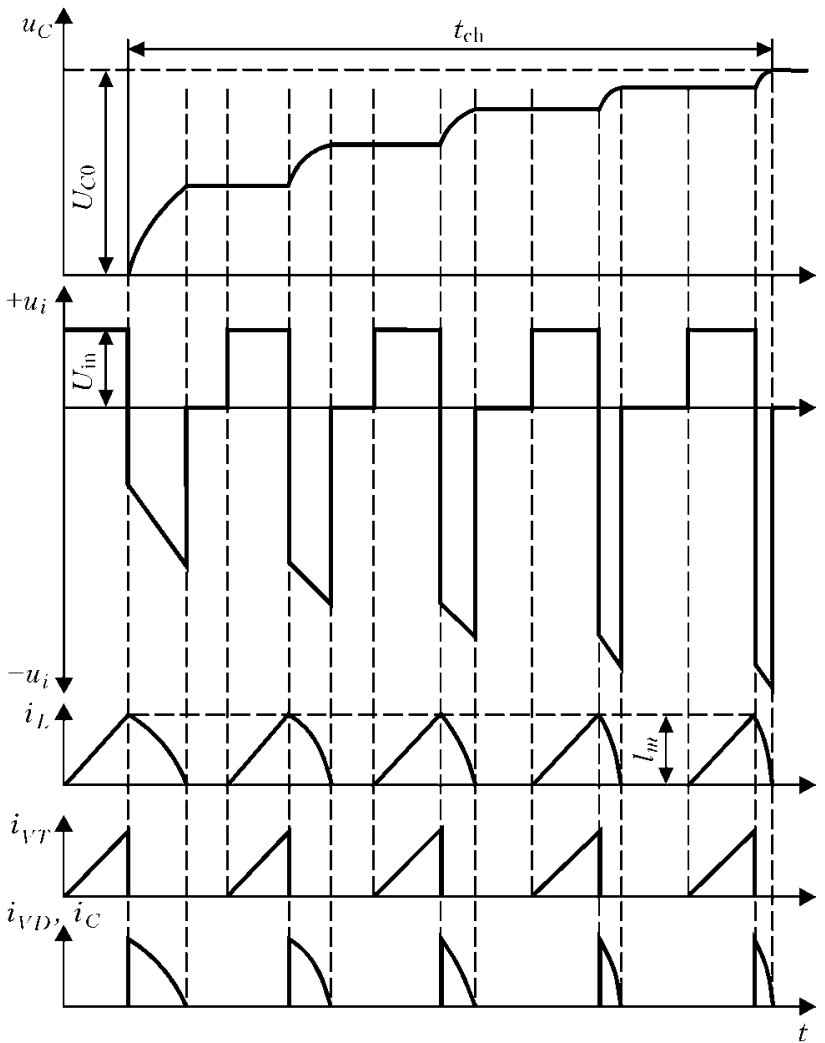

Figure 3. Diagrams of voltages and currents in CD circuits based on key scheme with dosing reactor

$$
I_{\mathrm{c}}=\frac{U_{\mathrm{in}}}{4.9 L f_{\mathrm{t} . \mathrm{k}}},
$$

and amplitude value of current $I_{m}$ necessary for charging of GVP capacitive storage (at set values of $U_{C 0}$ and $\left.t_{\mathrm{ch}}\right)-$ by expression

$$
I_{m}=\sqrt{\frac{C}{L t_{\mathrm{ch}} f_{\mathrm{t} . \mathrm{k}}} U_{C 0}}=\sqrt{\frac{C}{L n} U_{C 0}} .
$$

Advantages of CD, constructed on key scheme with dosing reactor (see Figure 2, $a$ ), are practical absence of limitations on the level of input voltage $U_{\text {in }}$ (making in most cases from 50 to $350 \mathrm{~V}$ ) as well as invariance of such CD by kind of AESA supply voltage. At that standard functioning of CD in AESA supplied by alternating current voltage does not depend on its frequency. If only direct current voltage is provided for AESA supply, then presence of $U Z 1$ rectifier and $C 1$ buffer capacitor in the scheme, given in Figure 2, $a$, is not mandatory.

However, practice shows that CDs based on key scheme with dosing reactor have some limitations on the level of complete charge voltage $U_{C 0}$ of GVP capacitive storage. This is provoked by the fact that rise of $U_{C 0}$ inevitably determines and tightens the requirements on maximum allowable values of transistor key $V T 1$ collectoremitter $\left(U_{\text {c.e max }}\right)$ voltage (see Figure $\left.2, a\right)$ and voltage on switching key $K$ of GVP forming cir- 
SCIENTIFIC AND TECHNICAL

Table 1. Calculation value of pulse stored energy $(\mathrm{J})$ depending on capacity of GVP forming circuit

\begin{tabular}{|c|c|c|c|c|c|c|c|c|c|c|c|}
\hline \multirow{2}{*}{$C_{C 0}, \mathrm{~V}$} & \multicolumn{11}{|c|}{$C, \mu \mathrm{F}$} \\
\hline & 0.05 & 0.10 & 0.15 & 0.20 & 0.25 & 0.30 & 0.40 & 0.50 & 0.60 & 0.70 & 0.80 \\
\hline 600 & 0.278 & 0.556 & 0.833 & 1.111 & 1.389 & 1.667 & 2.222 & 2.778 & 3.333 & 3.889 & 4.444 \\
\hline 650 & 0.237 & 0.473 & 0.710 & 0.997 & 1.183 & 1.420 & 1.893 & 2.367 & 2.840 & 3.314 & 3.787 \\
\hline 700 & 0.204 & 0.408 & 0.612 & 0.816 & 1.020 & 1.224 & 1.633 & 2.041 & 2.449 & 2.857 & 3.265 \\
\hline 750 & 0.178 & 0.356 & 0.533 & 0.711 & 0.889 & 1.067 & 1.422 & 1.778 & 2.133 & 2.489 & 2.844 \\
\hline 800 & 0.156 & 0.313 & 0.469 & 0.625 & 0.781 & 0.938 & 1.250 & 1.563 & 1.875 & 2.188 & 2.500 \\
\hline
\end{tabular}

cuit in off condition of these keys, back voltage of diode $V D 1$ and voltages on AESA passive elements. Regardless the basic possibility of achievement of high levels of $U_{C 0}$, its recommended values make from 600 to $800 \mathrm{~V}$ based on experience of development and application of AESA, available range of key semiconductor devices and their costs.

Engineering calculation of basic components of $\mathrm{CD}$, constructed on the basis of key scheme with dosing reactor at set value of stored energy of $W_{C}$ pulses, $U_{\text {in }}$ and $U_{C 0}$ voltages, frequency $f_{\mathrm{sw}}$ or $T_{\mathrm{sw}}=\left(f_{\mathrm{sw}}=1 / T_{\mathrm{sw}}\right)$ period of connection of GVP switching key can be carried out in the following way:

1. Minimum necessary value of capacity $C$ of GVP forming circuit (see Figure 2, $a, C 2$ ) is determined with the help of relationship (6) and values, given in Table 1 :

$$
C \geq \frac{2 W_{C}}{U_{C 0}^{2}}
$$

In accordance to the earlier carried investigations and obtained experimental data the recommended values of pulse stored energy $W_{C}$ depending on AESA value are $0.05-0.50 \mathrm{~J}$ for arc exciters and that for pulse stabilization of process of burning of alternating current arc make 0.20 and $0.80 \mathrm{~J}[2,3,12]$.

The closest value (with rounding to larger side) from $0.10,0.15,0.22,0.33,0.47,0.68,1.00$, $1.50 \mu \mathrm{F}$ series is taken as calculation value of capacitor capacity $C 2$ (see Figure 2,a) based on determined according to (14) or Table 1. At that necessary $C$ value can be received due to dissipative (parallel) switching of two-four capacitors with polyethylene or polycarbonate dielectric, characteristics and parameters of which correspond to the recommendations, given in [13] (for example, capacitors of PPA or PPB series of ICEL company).

2 . The value of figure $n$ is taken according to condition (4) and depending on values of frequency $f_{\mathrm{sw}}$ or $T_{\mathrm{sw}}\left(f_{\mathrm{sw}}=1 / T_{\mathrm{sw}}\right)$ period of connection of GVP switching key (frequency or period of passing of AESA output pulses) and energy of $W_{C}$ pulses. This figure based on expression (7) determines number of $\Delta W_{C}$ energy doses, accumulation of which provide for complete charge of GVP capacitive storage to $U_{C 0}$ level for $t_{\mathrm{ch}}$ time interval. Table 2 shows recommended values of $n$.

3. Amplitude value of $I_{m}$ current passing through reactor and relative duration $D$ of on condition of CD transistor key are determined based on expressions (2), (5) and (6) and figure $n=W_{C} / W_{C}=t_{\mathrm{ch}} / T_{\mathrm{t} . \mathrm{k}}=t_{\mathrm{ch}} f_{\mathrm{t} . \mathrm{k}}$ taken according to Table 2. Recommended $I_{m}$ values following the results of carried investigations and experimental data and depending on set values of $W_{C}$, $W_{\text {in }}$ or $U_{C 0} ; f_{\text {ch }}$ make from 2.2 to $3.2 \mathrm{~A}$ and $D$ value is from 0.24 to 0.30 . At that values being selected in indicated ranges of $I_{m}$ and $D$ should increase with rise of $U_{\text {in }}$ values or decrease of $n$ figure values.

4. $L$ is determined by expression below assuming that inductance of dosing reactor $L 1$ (see Figure $2, a$ ) is linear and does not depend on current $i_{L}$ passing through reactor, and using calculated and selected values of $I_{m}, n$ and $D$ as well as set $U_{\text {in }}$ and $W_{C}$ values considering (2)

Table 2. Recommended $n$ values depending on $f_{\mathrm{sw}}$ and $W_{C}$

\begin{tabular}{|c|c|c|c|c|c|c|c|c|c|c|c|}
\hline \multirow{2}{*}{$f_{\mathrm{sw}}, \mathrm{Hz}$} & \multicolumn{11}{|c|}{$W_{C}, \mathrm{~J}$} \\
\hline & 0.05 & 0.10 & 0.15 & 0.20 & 0.25 & 0.30 & 0.40 & 0.50 & 0.60 & 0.70 & 0.80 \\
\hline From 50 to 100 & 1 & 2 & 3 & 4 & 5 & 6 & 8 & 8 & 9 & 10 & 10 \\
\hline Over 100 to 120 & 1 & 2 & 3 & 4 & 5 & 6 & $6 ; 7$ & 8 & 8 & 8 & 8 \\
\hline Over 120 to 200 & 1 & 2 & 2 & 3 & 3 & $3 ; 4$ & $4 ; 5$ & 5 & 5 & 5 & 5 \\
\hline
\end{tabular}




$$
L=\frac{U_{\text {in }} D}{I_{m}^{2} f_{\mathrm{t} . \mathrm{k}}}
$$

and considering (6)

$$
L=\frac{2 W_{C}}{I_{m}^{2} n} .
$$

Diagrams of $L=f\left(U_{\text {in }}, I_{m}, D, f_{\mathrm{t} . \mathrm{k}}\right)$ dependence is illustrated by Figure 4 .

Figure 5 gives the recommended values of dosing reactor inductance $L 1$, following from Table 2, range of $I_{m}$ recommended values, expressions (15) and (16) as well as experience of development and application of AESA CD based on key scheme with dosing reactor.

Many works, for example [14-17], are dedicated to theoretical fundamentals, analysis of processes and procedures of electromagnetic calculations and design of inductive elements with ferromagnetic cores, including chokes of ultralow, low and average frequencies. These works indicate that shell-type structure is the most efficient for CD dosing reactor on the basis of electromagnetic and weight-dimension indices. Such a structure can be built on the basis of cores from E-type plates or strip magnetic conductors from sheet cold-rolled anisotropic electrical steel of 3411-3412 grades. At that, length of total diamagnetic gap in a core of dosing reactor should make $1.05-1.50 \mathrm{~mm}$.

5. After inductance of dosing reactor $L 1$ is determined, it is necessary to specify calculation amplitude value of current $I_{m}$. Expressions (2) or (13) can be used for this.

6 . Determining resistance $R$ of $R 2$ resistor (see Figure $2, a$ ) requires consideration of the next facts, namely, first of all, since $R_{\text {add }}>R_{L}+$ $+E S R_{C 1}+R_{T 0}$, then $R \approx R_{\text {add }}$ and, for the second, obtaining of linear dependence $i_{L}=f(t)$ through application of initial (virtually linear) part of exponent during charging of dosing reactor $L 1$ necessitates fulfilment of condition

$$
L / R>\tau_{\mathrm{ch}} .
$$

Recommended values of $R 2$ resistor resistance make from 6 to $22 \mathrm{Ohm}$ assuming that $L / R>>$ $>>1 / f_{\text {sw }}$ and considering results of calculation, experimental data and recommended values of $f_{\text {t.k }}, I_{m}, U_{C 0}$ and $L$. They increase with rise of $U_{\text {in }}$ values or reduction of $f_{\text {t.k }}$ values.

Lager value of dissipation power $P_{R 2 \max }$, emitted in resistor $R 2$ during two first cycles of charging-discharging of dosing reactor $L 1$, can be determined by expression

$$
P_{R 2 \max }=I_{\text {c. } \mathrm{a}}^{2} R 2=I_{m}^{2} D R 2,
$$

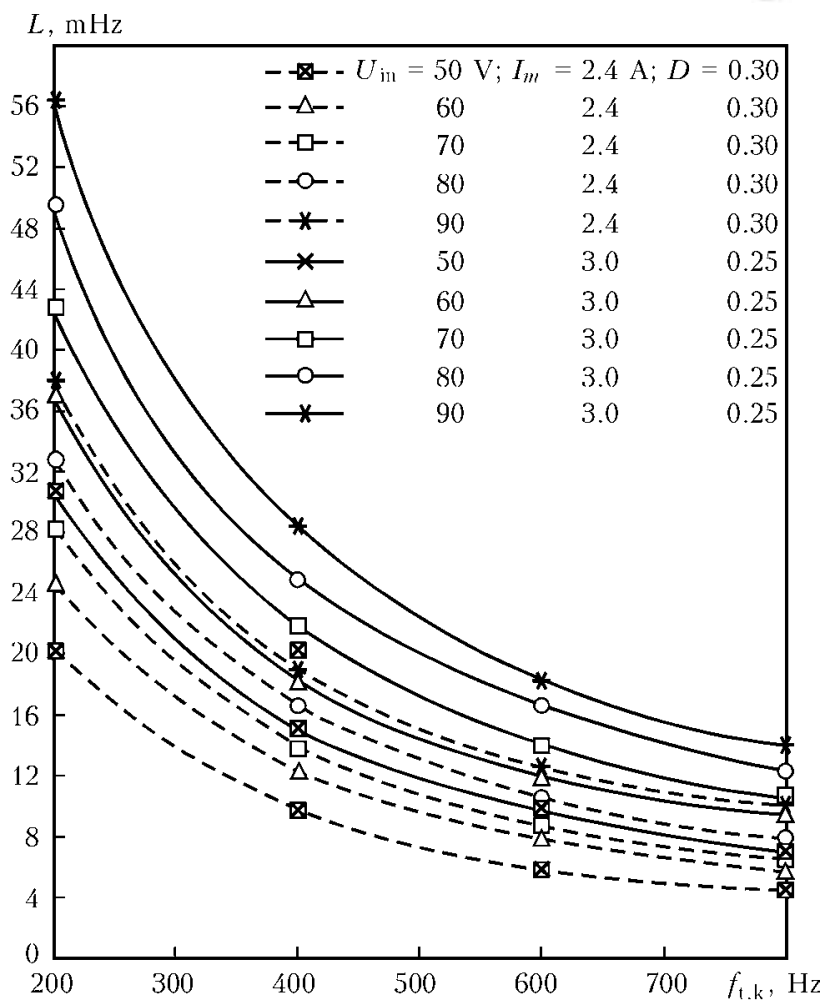

Figure 4. Diagrams of dependence of dosing reactor inductance $L=f\left(U_{\mathrm{in}}, I_{m}, D, f_{\mathrm{t} . \mathrm{k}}\right)$

where $I_{\text {c.a }}=I_{\mathrm{c}} / \sqrt{1 / D}$ is the active value of current $i_{L}$, passing through resistor $R 2$. Since rise of $U_{C}$ (see Figure 3) provides for reduction of discharge current of dosing reactor $L 1$ in each next cycle, then up to the moment of ending of GVP capacitive storage charge the power $P_{R 2 \text { min }}$ emitted in resistor $R 2$ is determined as

$$
P_{R 2 \min } \approx 0.5 I_{m}^{2} D R 2 \text {. }
$$

It follows from (18) and (19) that average value of power $P_{R 2}$, emitted in resistor $R 2$, is

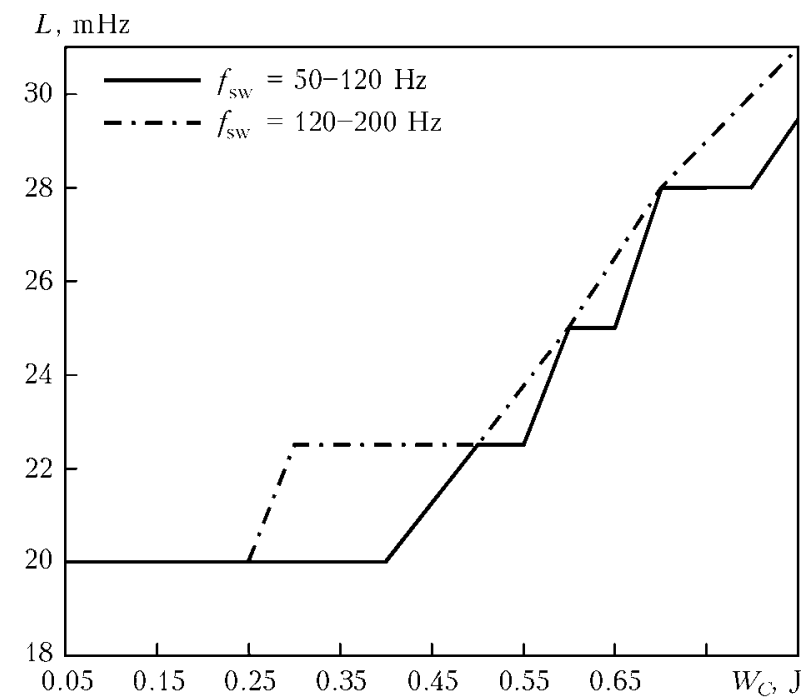

Figure 5. Recommended values of choke inductance of $\mathrm{CD}$ based on key scheme with dosing reactor at $U_{C 0}=(700 \pm$ $\pm 100) \mathrm{V}$ 


$$
P_{R 2} \approx 0.75 I_{m}^{2} D R 2 .
$$

If AESA is designed for stabilizing of process of alternating current arc burning, then nominal power $P_{R 2 \text { nom }}$ of resistor $R 2$ is taken from condition

$$
P_{R 2 \text { nom }} \geq 1.67 P_{R 2}
$$

in the case of AESA application only for initial excitation of direct current arc, the value of nominal power of resistor $R 2$ can be significantly reduced in comparison with the value, calculated according to (21), and should make $6-10 \mathrm{~W}$.

Power resistors of C5-C35 series or SPS, SQZ, SQHG [18] series are good to be used as $R 2$ resistor.

7. Maximum value of voltage of collector-emitter is $U_{\text {c.e }} \approx U_{C 0}$, and maximum value of current of collector makes $I_{\mathrm{c}} \approx I_{m}$ during selection of CD transistor key (see Figure 2, $a, V T 1$ ), proceeding from the fact that according to (5) and Table 2 switching frequency $f_{t . k}$ of this key does not exceed $1000 \mathrm{~Hz}$. It can be assumed based on this that the most appropriate for application as CD transistor key are IGBT-transistors, which have

$$
\begin{gathered}
U_{\text {c.e } \max } \geq 1.2 U_{C 0}, \quad I_{\mathrm{c} \max } \geq 1.5 I_{m}, \\
I_{\text {c, p } \max } \geq 1.15\left(U_{\mathrm{in}} / R\right),
\end{gathered}
$$

where $U_{\text {c.e } \max }$ is the maximum allowable voltage of collector-emitter in off condition; $I_{\mathrm{c} \text { max }}$ and $I_{\mathrm{c}, \mathrm{p} \text { max }}$ are, respectively, the maximum allowable direct and pulse current of collector in on condition. Taking into account (22) IRG4BH20K, IRG4PN30R, IRG4PH40KD IGBT-transistors and similar to them of «International Rectifier» [19] or IGW08T120 of «Infineon» companies can be recommend as example for application in CD key, at that resistor resistance $R 1$ (see Figure 2, a) in gate circuit of such transistors should make 8-12 Ohm.

8. The main parameters for selection of diode $V D 1$ (see Figure 2, a) are maximum allowable values of average direct current $I_{F}$ and back voltage $U_{R}$ as well as maximum value of forward drop $U_{F}$ and time of reverse recovery $t_{r r}$. At that, parameters of diode VD1 should fulfill the conditions

$$
U_{R \text { max }} \geq 1.2 U_{C 0}, \quad I_{F \text { max }} \geq 1.2 I_{\text {av. } \max },
$$

where $I_{\mathrm{av} \text { max }}$ is the maximum average value of charge current of GVP capacitive storage, which can be determined with the help of expression

$$
I_{\text {av. } \max }=0.5 I_{\text {a.c }} \text {. }
$$

Diode BYV26E of Vishay Semiconductors Company [20] can be used, for example, in CD according to combination of parameters and characteristics.
$C D$ based on diode-capacitor voltage multipliers. In comparison with earlier considered the CDs based on voltage multiplies (VM) are characterized by absence of inductive and controlled semi-conductor elements, significantly lower values of weight-dimension indices, and, respectively, higher specific power as well as significantly lower cost. Regardless the fact that VMs have been already known from the 30th of the last century and are still used in television and medical equipment, measurement equipment, night vision equipment and many other fields of engineering [21], this class of devices is not studied enough, and works, dedicated to analysis and procedure of VM design, are not numerous. For example, [22, 23] mainly reflect aspects of VM work with supply from sine-wave voltage sources of commercial frequency. At the same time, there is a tendency in recent decade to intensive development of investigations and designs as well as spread of VM application with high frequency pulse supply from inverters operating in switching mode. Series of last works, for example [6, 24-26], provide for sufficiently strict and detailed considerations and analysis of aspects of circuit engineering, transition processes and dynamic characteristics of such VM. Taking into account mentioned above, present work will be restricted by issues of design and selection of VM elements being used in AESA CD construction, in particular, for providing of initial and repeated arc excitations in inverters for nonconsumableelectrode inert-gas (TIG) welding, for example, in Master Tig 2500, Master Tig 3500 and other models of KEMPPI company [27].

Devices, built by Cockcroft-Walton scheme (scheme of asymmetric single-phase half-wave $\mathrm{VM}$ ), were the most widespread among the known diode-capacitor VM in AESA. Simplicity of this scheme realizing and possibility of its application at any stage (of cascades) of voltage multipliers with direct current operating voltage, not exceeding peak-to-peak value of direct current input voltage (AESA supply voltage) can be refereed to its advantages. Among the disadvantages are limited load-carrying capacity due to dropping external volt-ampere characteristic typical for all diode-capacitor VM (and, respectively, significant output resistance) and voltage drop in VM depending on voltage current and number of multiplying stages, high sensitivity to oscillations of values of input current and its frequency as well as fundamental necessity in exclusive application of alternating current voltage of sine-wave and rectangular-wave forms as input one. 


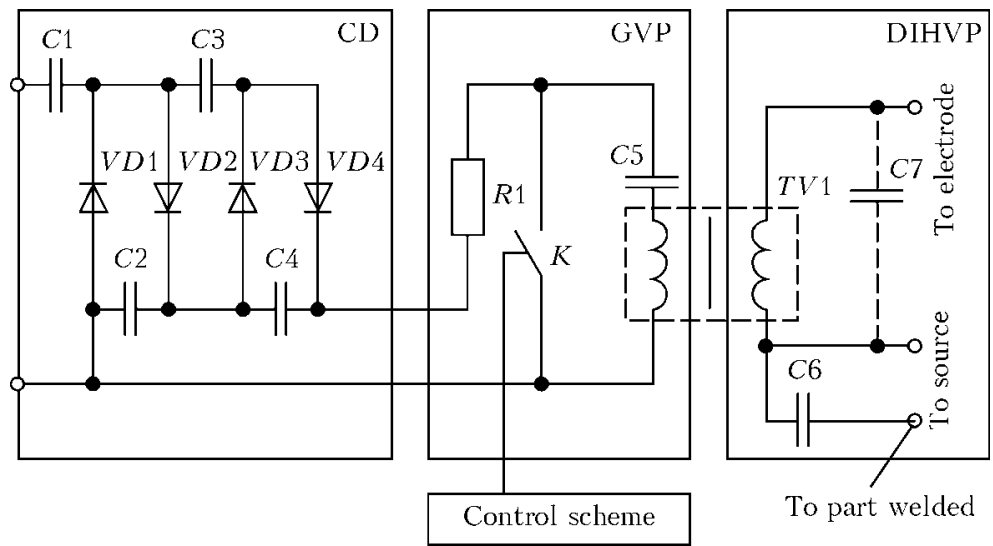

Figure 6. Typical electric schematic diagram of AESA with CD based on VM built on four-stage Cockcroft-Walton scheme

The following was determined as a result of carried investigations of VM based on CockcroftWalton scheme [23-26], namely values of direct current output voltage $U_{\text {out }}$ virtually do not depend on form of alternating current input voltage; VM characteristics are improved with increase of input voltage frequency $f_{\text {in }}$, values of which should be in the limits of $5-50 \mathrm{kHz}$, at that the most optimum values are $15-40 \mathrm{kHz}$; VM power for providing acceptable characteristics of its load-carrying capacity should be not lower than $50 \mathrm{~W}$ and multiplication factor (number of multiplication stages $N$ ) makes from 3 to 6 ; rectangular-wave input voltage is the most heavy current operation mode for diodes in VM cascades, therefore, their designing requires stipulation of measures for limitation of diode starting current.

Example of typical fundamental electric scheme of AESA, CD of which is built based on four-cascade VM and performed by CockcroftWalton scheme, is given in Figure 6.

Capacitor $C 1$ will charge to amplitude value of this voltage $U_{\text {in. } m}$ during negative half-wave of input voltage through open diode $V D 1$. Capacitor $C 2$ will charge to $2 U_{\text {in. } m}$ level during positive half-wave after negative one through open diode $V D 2$, and capacitor $C 3$ will charge to $2 U_{\text {in.m }}$ level in course of following after this negative half-wave through open diode $V D 3$, and capacitor $C 4$ will charge to $2 U_{\text {in.m }}$ level in the next positive half-period of input voltage through open diode $V D 4$. Thus, direct current input voltage in VM open-circuit mode represents itself sum of voltages based on series and stationary re-charging capacitors $C 2$ and $C 4$ and makes

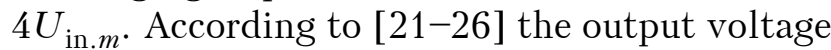
$U_{\text {out }}$ in load mode under condition of time stability of values of input voltage $U_{\text {in. } m}$ and its frequency $f_{\text {in }}$ is determined by formulae

$$
U_{\text {out }}=N U_{\text {in. } m}-\frac{I_{\text {l.c }}\left(N^{3}+9 N^{2} / 4+N / 2\right)}{12 f_{\text {in }} C_{\text {st }}},
$$

where $I_{1 . c}$ is the largest value of VM load current; $C_{\text {st }}$ is the capacitor capacity of each stage of multiplication under $C_{\text {st }}=C 1=C 2=C 3=C 4$ condition. Formulae (25) at $N=4$ (see Figure 6) can be represented as

$$
U_{\text {out }}=4 U_{\text {in. } m}-\frac{8.5 I_{1 . \mathrm{c}}}{f_{\text {in }} C_{\text {st }}} .
$$

Deduction in expression (25) and (26) is a drop of voltage $\Delta U=r_{\text {out }} I_{1 . c}$ of multiplier, from which value of output resistance $r_{\text {out }}$ can be determined by expression

$$
r_{\text {out }}=\frac{N^{3}+9 N^{2} / 4+N / 2}{12 f_{\text {in }} C_{\text {st }}},
$$

and at $N=4$

$$
r_{\text {out }}=\frac{8.5}{f_{\text {in }} C_{\text {st }}} .
$$

Considering that $f_{\text {in }}>>f_{\text {sw }}$ and charge of GVP capacitive storage (Figure 6, C5) is performed for number of full cycles of formation of multiplier output voltage $U_{\text {out }}$, it can be assumed that to a first approximation $i_{C}(t)$ current and $u_{C}(t)$ voltage of charge of capacitive storage in course of this charge duration $\tau_{\mathrm{ch}} \approx 1 / f_{\mathrm{sw}}$ are changed by expressions [10]

$$
i_{C}(t)=I_{m} e^{-\frac{t}{R C}}, \quad u_{C}(t)=U_{\text {out }}\left(1-e^{-\frac{t}{R C}}\right) .
$$

Here the largest (amplitude) $I_{\text {amp }}$ value of charge current $i_{C}(t)$ corresponds to charge initial moment $t=0$ (in which $\left.u_{C}(t)=0\right) ; R=R_{\text {lim }}+$ $+E S R_{C}+R_{L 1} \approx R_{\text {lim }}$ is the sum of pure resistances of current-limiting resistor $R 1$ (see Figure 6), equivalent series resistance of capacitor (capacitive storage), forming GVP circuit and pure resistance of primary winding of pulse transformer 


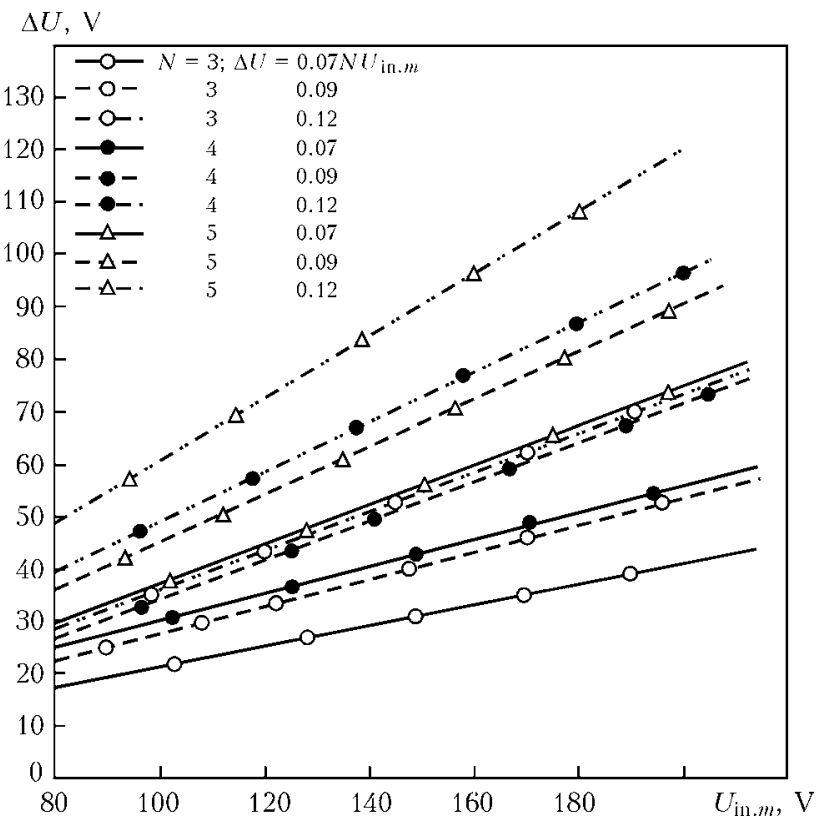

Figure 7. Diagrams of dependence of voltage drop $\Delta U=$ $=f\left(N, U_{\text {in. } m}\right)$ in $\mathrm{VM}$ built by Cockcroft-Walton scheme

$T V 1$. When charging of GVP capacitive storage by voltage formed with the help of VM, current of its charge $i_{C}(t)$ is reduced with increase of $u_{C}(t)$ voltage in this storage, the same as in variant of CD based on key scheme with dosing reactor. Therefore, $I_{1 . c}=I_{m}=\Delta U / r_{\text {out }}=$ $=N U_{\text {in. } m} / r_{\text {out }}+R_{\text {lim }}$ value is the maximum and typical only for the first cycle of charge of GVP capacitive storage, and $\Delta U$ voltage drop is reduced synchronously with charge current $i_{C}(t)$ reduction.

If $\Delta U=(0.07-0.10) N U_{\text {in. } m}$ is set, that can be fulfilled in practice, as shown by calculation and measurement results (diagrams of dependence

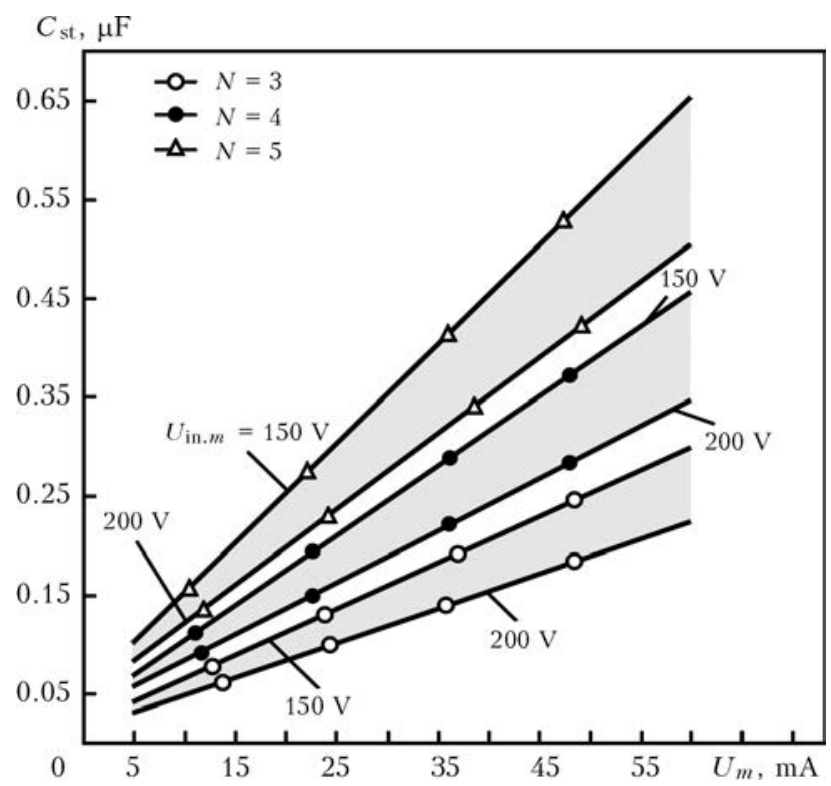

Figure 8. Dependence diagrams of $C_{\mathrm{st}}=f\left(I_{\mathrm{amp}}, U_{\text {in. } m}, N\right)$ capacity of each stage of $\mathrm{VM}$ at $f_{\text {in }}=20 \mathrm{kHz}$ and $\Delta U=$ $=0.01 N U_{\text {in. } m}$
$\Delta U=f\left(N, U_{\text {in. } m}\right)$ are given in Figure 7$)$, then $I_{m}$ according to (25) and (27) can be determined by formulae

$$
I_{m}=\frac{(0.07-0.10) N U_{\text {in. } m} 12 f_{\text {in }} C_{\text {st }}}{N^{3}+9 N^{2} / 4+N / 2},
$$

and $C_{\text {st }}-$ by formulae

$$
C_{\text {st }}=\frac{I_{\text {amp }}\left(N^{3}+9 N^{2} / 4+N / 2\right)}{(0.07-0.10) N U_{\text {in. } m} 12 f_{\text {in }}} .
$$

$C_{\text {st }}=f\left(I_{m}, U_{\text {in. } m}\right)$ dependence diagrams at $\Delta U=$ $=0.1 N U_{\text {in. } . m}$ and $f_{\text {in }}=20 \mathrm{kHz}$ are given in Figure 8 , and $C_{\text {st }}=f\left(f_{\text {in }}, I_{m}\right)$ dependence diagrams at $\Delta U=0.1 N U_{\text {in. } m}$ and $N=4 \div 5-$ in Figure 9 .

In the case of sine-wave input voltage of $\mathrm{VM}$ (AESA supply voltage) and assuming that pure resistance of capacitor charge circuit of each VM stage is negligibly small, the largest (peak) value of $I_{F S M}$ and the largest average $I_{F A V}$ value of direct current through diode of this multiplying stage can be determined with accuracy sufficient for practice as

$$
I_{F S M}=12.56 U_{\mathrm{in} .} f_{\mathrm{in}} C_{\mathrm{st}}, \quad I_{F A V}=0.318 I_{F S M},
$$

$I_{F S M}$ parameter in the case of rectangular VM input voltage can be determined based on the fact that $i_{C_{\mathrm{st}}}=d U_{C_{\mathrm{st}}} / d t$. Considering that $d t=$ $=\tau_{f}$ (where $\tau_{f}$ is the duration of growth of front for VM input peak-to-peak voltage), and assuming $\tau_{\mathrm{f}}=0.04 T_{\text {in }}$ (that is typical for most welding inverters), $I_{F S M}$ and $I_{F A V}$ values can be determined as

$$
I_{F S M}=100 U_{\text {in. } m} f_{\text {in }} C_{\text {st }} . \quad I_{F A V}=U_{\text {in. } m} f_{\text {in }} C_{\text {st }},
$$

It was experimentally determined that the following condition should be fulfilled in use of VM in each cycle of charge of GVP capacitive storage:

$$
0.5 N T_{\text {in }}<\tau_{\mathrm{ch}}<0.9 T_{\mathrm{sw}},
$$

where $\tau_{\mathrm{ch}}=\left(R_{\text {lim }}+r_{\text {out }}\right) C=R_{\mathrm{ch}} C$, from which

$$
R_{\mathrm{ch}} \leq 0.9 T_{\mathrm{sw}} / C \text {. }
$$

Based on (27) and (35) resistance of currentlimiting resistor $R_{\text {lim }}$ (see Figure $6, R 1$ ) can be determined by formulae

$$
R_{\mathrm{lim}} \leq \frac{0.9 T_{\mathrm{sw}}}{C}-\frac{N^{3}+9 N^{2} / 4+N / 2}{12 f_{\mathrm{in}} C_{\mathrm{st}}} .
$$

Calculation of VM-based CD, built by Cockcroft-Walton scheme, at set values of pulse energy $W_{C}$, frequency $f_{\text {in }}$ or period $T_{\text {in }}$ of input voltage $U_{\text {in }}\left(f_{\text {in }}=1 / T_{\text {in }}\right)$ and frequency $f_{\text {sw }}$ or period $T_{\text {sw }}$ of connection of GVP switching key $\left(f_{\mathrm{sw}}=\right.$ $\left.=1 / T_{\mathrm{sw}}\right)$, is carried out in the following way: 
Table 3. Calculation values of $I_{m}$ and $R_{\mathrm{ch}}$ for VM-based CD

\begin{tabular}{|c|c|c|c|c|c|}
\hline$f_{\mathrm{sw}}, \mathrm{Hz}$ & $0.9 T_{\mathrm{sw}} \cdot 10^{2}, \mathrm{~s}$ & $U_{\text {out }}, \mathrm{V}$ & $C, \mu \mathrm{F}$ & $R_{\mathrm{ch}}, \mathrm{kOhm}$ & $I_{m}, \mathrm{~A}$ \\
\hline \multirow[t]{12}{*}{50} & \multirow[t]{12}{*}{1.80} & \multirow[t]{4}{*}{600} & $0.5-1.5$ & 12 & 0.050 \\
\hline & & & $1.5-2.0$ & 9 & 0.056 \\
\hline & & & 3.0 & 6 & 0.100 \\
\hline & & & 4.0 & 4.5 & 0.133 \\
\hline & & \multirow[t]{4}{*}{650} & $0.5-1.5$ & 12 & 0.054 \\
\hline & & & $1.5-2.0$ & 9 & 0.062 \\
\hline & & & 3.0 & 6 & 0.108 \\
\hline & & & 4.0 & 4.5 & 0.144 \\
\hline & & \multirow[t]{4}{*}{700} & $0.5-1.5$ & 12 & 0.058 \\
\hline & & & $1.5-2.0$ & 9 & 0.066 \\
\hline & & & 3.0 & 6 & 0.117 \\
\hline & & & 4.0 & 4.5 & 0.177 \\
\hline \multirow[t]{12}{*}{100} & \multirow[t]{12}{*}{0.90} & \multirow[t]{4}{*}{600} & $0.5-1.5$ & 9 & 0.056 \\
\hline & & & $1.5-2.0$ & 4.5 & 0.133 \\
\hline & & & 3.0 & 3 & 0.200 \\
\hline & & & 4.0 & 2.25 & 0.266 \\
\hline & & \multirow[t]{4}{*}{650} & $0.5-1.5$ & 9 & 0.062 \\
\hline & & & $1.5-2.0$ & 4.5 & 0.144 \\
\hline & & & 3.0 & 3 & 0.217 \\
\hline & & & 4.0 & 2.25 & 0.290 \\
\hline & & \multirow[t]{4}{*}{700} & $0.5-1.5$ & 9 & 0.066 \\
\hline & & & $1.5-2.0$ & 4.5 & 0.156 \\
\hline & & & 3.0 & 3 & 0.233 \\
\hline & & & 4.0 & 2.25 & 0.311 \\
\hline \multirow[t]{12}{*}{200} & \multirow[t]{12}{*}{0.45} & \multirow[t]{4}{*}{600} & $0.5-1.5$ & 12 & 0.133 \\
\hline & & & $1.5-2.0$ & 9 & 0.266 \\
\hline & & & 3.0 & 6 & 0.400 \\
\hline & & & 4.0 & 4.5 & 0.530 \\
\hline & & \multirow[t]{4}{*}{650} & $0.5-1.5$ & 12 & 0.144 \\
\hline & & & $1.5-2.0$ & 9 & 0.290 \\
\hline & & & 3.0 & 6 & 0.433 \\
\hline & & & 4.0 & 4.5 & 0.575 \\
\hline & & \multirow[t]{4}{*}{700} & $0.5-1.5$ & 12 & 0.156 \\
\hline & & & $1.5-2.0$ & 9 & 0.311 \\
\hline & & & 3.0 & 6 & 0.467 \\
\hline & & & 4.0 & 4.5 & 0.620 \\
\hline
\end{tabular}

1. Level of VM output voltage is selected, recommended values of which usually make $U_{\text {out }}=U_{C 0}=(650 \pm 50) \mathrm{V}$.

2. Capacity $C$ of GVP forming circuit, amount and specific type of capacitors forming this capacity (see Figure 6, C5) are determined using expression (14) and value, given in Table 1, as well as recommendations for CD based on key scheme with dosing reactor.
$C_{\mathrm{st}}, \mu \mathrm{F}$
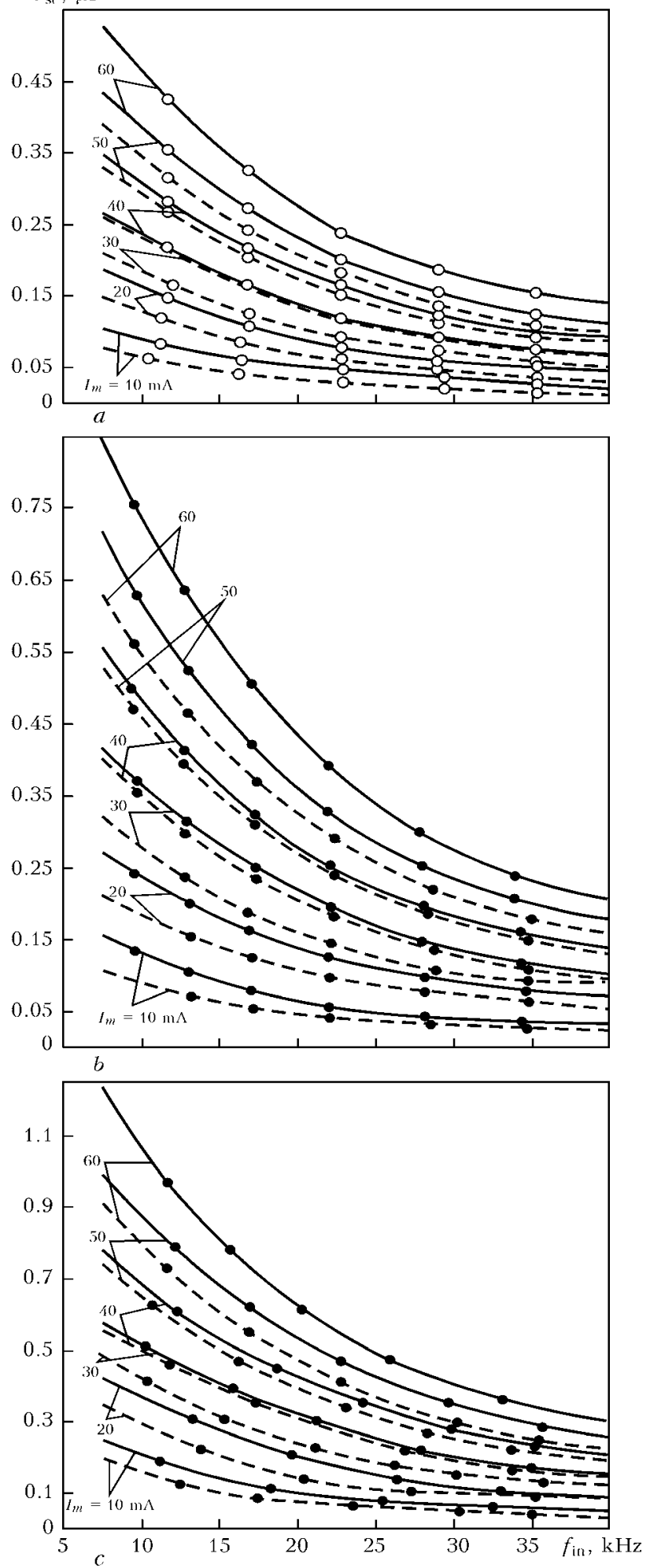

Figure 9. Dependence diagrams of $C_{\text {st }}=f\left(f_{\text {in }}, U_{\text {in. } m}\right)$ capacity of each stage of VM at $N=3(a), 4(b)$ and 5 (c) and $U_{\text {in. } m}=150$ (solid) and 200 (dashed curve) $\mathrm{V}$

3. Number of multiplying stages $N$, amplitude of input voltage $U_{\text {in. } m}$ and maximum allowable voltage drop $\Delta U=k_{\mathrm{s}} N U_{\text {in.m }}$ are determined considering that $U_{C 0}=U_{\text {out }}=N U_{\text {in. } m}-\Delta U$ and using diagrams given in Figure 7. Assuming rational values of electric and weight-dimension parameters of $\mathrm{VM}$, recommended values make: 
$N=4, U_{\text {in. } m}=160-190 \mathrm{~V}, k_{\mathrm{S}}=0.07-0.10$. If circuit or structural peculiarities of welding inverter do not allow realizing recommended values of $N$ and $U_{\text {in. } m}$, then their other values can be used with the help of given in Figure 7 dependence diagrams $\Delta U=f\left(U_{\text {in }}\right)$ or expression

$$
U_{\text {out }}=N U_{\text {in. } m}\left(1-k_{\mathrm{s}}\right) \text {. }
$$

4. Approximate value of capacitor capacity $C_{\mathrm{st}}$ of each VM stage are determined at recommended largest value of charge current $I_{m}$ of GVP capacitive storage, being equal to $50-60 \mathrm{~mA}$, assuming $N=3 \div 5, U_{\text {in. } m}=160-190 \mathrm{~V}, \Delta U=$ $=0.1 N U_{\text {in. } m}$ with the help of diagrams, given in Figure 8. If $N$ or $f_{\text {in }}$ values differ from indicated in Figure 8, then formulae (31) is used for value determination as well as data of Table 3 , which provides for recommended values of $I_{m}$ and $R_{\mathrm{ch}}$, calculated considering their dependence on $U_{\text {out }}$, $T_{\text {sw }}=1 / f_{\text {sw }}$ values and capacity $C$ of GVP forming circuit as well as expressions (14), (34) and (35) and values, indicated in Table 1.

5. $C_{\text {st }}$ value is specified using diagrams given in Figure 9 at $N=3 \div 5$ depending on input voltage frequency $f_{\text {in }}$, which makes $18-40 \mathrm{kHz}$ in the most cases. Received values of capacity $C_{\text {st }}$ (capacity of each of VM capacitors) are used for selection of the closest (with rounding to the largest side) value from $0.047,0.068,0.1,0.15$, $0.22,0.33,0.47,0.68,1.0 \mu \mathrm{F}$ series, at that the largest allowable value of direct current $U_{V D C}$ for all VM capacitors should fulfill $U_{V D C} \geq 2.2 U_{\text {in. } m}$ condition. Metal-film capacitors with polypropylene or polyethylene dielectric, for example, MPR or PPN type or MER of HITANO Company are desirable.

6. $I_{m}$ calculation value is specified by formulae (30) considering specific value of $C_{\text {st }}$ and selected corresponding to it capacitor part-type. In the case when $I_{m}$ values exceed recommended ones, VM capacitor part-type with larger capacity is selected.

7. Selection of VM diodes is carried out using such main parameters as allowable values of average direct current $I_{F A V \text { max }}$ and back voltage $U_{R \text { max }}$ as well as maximum values of forward voltage drop $U_{F}$ and reverse recovery time $t_{r r}$. At that diode parameters should fulfill the conditions

$$
I_{F A V \max } \geq 1.2 I_{F A V},
$$

where $I_{F A V}$ is the largest average value of direct current via diode, calculated on expressions (32) and (33) depending on form of input voltage, and

$$
U_{R \max } \geq 2.2 U_{\text {in. } m},
$$

as well as $U_{F} \leq 1.6 \mathrm{~V}$ and $t_{r r} \leq 100 \mathrm{~ns}$.

VS-20ETF04FPPbF or VS-20ETF06FPPbF diodes of «Vishay Semiconductors» [20] or MURF1660CTG diode of «ON Semiconductor» companies [28] can be used, for example, in AESA VM according to combination of parameters and characteristics.

8. Formulae (36) is used for calculation of resistance of current-limiting resistor $R_{\text {lim }}$ (see Figure $6, R 1)$. The largest value of power dissipation $P_{R_{\text {lim max }}}$, emitted in $R_{\text {lim }}$ resistor during first one-two cycles of charge of GVP capacitive storage, can be calculated by expression

$$
P_{R_{\lim \max }}=\left(I_{C R M S}\right)^{2} R_{\lim }=0.25 I_{m}^{2} R_{\lim },
$$

where $I_{C \text { RMS }}=\sqrt{1 / T_{\mathrm{sw}} \int_{0}^{T} i_{C}(t)^{2} d t=0.5 I_{m}}$ is the root-mean-square (acting) value of charge current at approximation of exponential video pulse of charge current via video pulse of triangle form. Based on the fact that increase of $u_{C}(t)$ voltage on GVP capacitive storage provides for reduction of its charge current $i_{C}(t)$ and it equals zero up to the moment of charge end, then average value of power $P_{R_{\text {lim }}}$, emitted in resistor $R_{\text {lim }}$ in course of charge duration of GVP capacitive storage, can be determined as

$$
P_{R_{\text {lim }}} \approx 0.5 P_{R_{\text {lim max }}}
$$

If AESA is designed for stabilizing of burning of alternating arc, then minimum power $P_{R_{\text {lim nom }}}$ of resistor $R_{\text {lim }}$ should be taken from condition

$$
P_{R_{\text {lim nom }}} \geq 1.43 P_{R_{\text {lim }}},
$$

and if AESA is designed only for direct current arc excitation, then $P_{R_{\text {lim nom }}}$ value can be significantly reduced in comparison with calculation one and make $2-8 \mathrm{~W}$

C2-22-2 or C2-33-2 series resistors can be used as $R_{\text {lim }}$ resistor at $P_{R_{\text {lim }}} \leq 3 \mathrm{~W}$, or SPS, SQZ, SQHG series [18] at $P_{R_{\text {lim }}} \geq 3 \mathrm{~W}$.

\section{Conclusions}

1. Application of VM-based CD is seemed to be sufficiently effective for AESA, imbedded in welding power sources, which include element of high-frequency transformation, and, respectively, high-frequency transformer. They are simple in realizing and have small values of weightdimension and cost indices for such devices in comparison with other type CD. However, ap- 
plication of $\mathrm{CD}$ based on $\mathrm{VM}$ is reasonable at AESA pulse energy levels do not exceeding $0.25 \mathrm{~J}$, not more than $700 \mathrm{~V}$ of voltage charge of GVP capacitive storage and 150-200 V amplitude values of input voltage (AESA supply voltage) of $18-40 \mathrm{kHz}$ frequency.

Peculiarity of CD based on VM lies in the fact that their functioning requires application of supply voltage of alternating current. At that, form of input voltage (AESA supply voltage) virtually has no effect on output characteristics and parameters of $\mathrm{CD}$, however, significantly effects diode passing currents. Area of application of AESA with CD based on VM is limited by inverter power supplies, mainly for TIG welding.

2. CD based on key scheme with dosing reactor are inferior to $\mathrm{CD}$ based on VM in weight-dimension and cost characteristics, but, at the same time, have series of important advantages in comparison with the letter. CDs based on key scheme with dosing reactor do not depend on supply voltage type and can operate at supply voltage from direct as well as alternating current of sineor rectangular-wave or close to this forms of frequency from tens of hertz (including $50 \mathrm{~Hz}$ ) to tens of kilohertz. There are virtually no limitations for such CDs on level of input voltage, which can lie in the range of several to hundred of volts as well as on technically grounded levels of AESA pulse energy, which can make from 0.01 to $1 \mathrm{~J}$ and more, at that there is a possibility of stabilizing of set values of charge voltage of GVP capacitive storage. They have wide area of application in arc and plasma welding and can be used in traditional power supplies and welding systems and power supplies of inverter type. Such AESA can be efficiently used in manual arc and plasma methods and in automatic welding machines, in particular, single- and multi-station systems of automatic orbital TIG welding of pipeline joints [29].

3. Results of carried analysis and consideration of experience of development, designing, manufacture and operation of AESA allowed development of engineering procedure for calculation of $\mathrm{CD}$ based on key scheme with dosing reactor and $\mathrm{CD}$ based on $\mathrm{VM}$ as well as elaborating practical recommendations on selection of their element base, that can be useful not only for AESA development, but other similar devices, designed for application in different branches of science and technology.

1. Pentegov, I.V. (1982) Principles of theory of charge circuits of capacitor storage. Kiev: Naukova Dumka.

2. (1986) Arc welding equipment: Refer. Book. Ed. by V.V. Smirnov. Leningrad: Energoatomizdat.
3. Temkin, B.Ya. (1981) Theory and calculation of welding arc exciters: Syn. of Thesis for Cand. of Techn. Sci. Degree. Leningrad.

4. Balakin, S.V. Method of excitation of oscillations in electric circuit and device for its realization. Pat. 2127482 RU. Publ. 10.03.1999.

5. Moin, V.S., Laptev, N.N. (1972) Stabilized transistor converters. Moscow: Energiya.

6. Gottlieb, I.M. (2002) Power supplies, switching requlators, inverters and converters. Moscow: Postmarket.

7. Severns, R., Bloom, G. (1988) Pulse converters of direct voltage for systems of secondary power supply. Moscow: Energoatomizdat.

8. Polikarpov, A.G. (1975) Pulse controllers of direct voltage for secondary power supplies. Trydu MEI, Issue 275, 69-75.

9. He, Y., Luo, F.L. (2005) Analysis of Luo converters with voltage-lift circuit. IEE Proc. on Electr. Power Appl., 152(5), 1239-1252.

10. (2008) Theoretical principles of electrical engineering: Refer. Book on theory of electric circuits. Ed. by Yu.A. Bychkov et al. St.-Petersburg: Piter.

11. Levinshtejn, L.M. (1972) Operational calculus in problems of electrical engineering. Leningrad: Energiya.

12. Paton, B.E., Zaruba, I.I., Dymenko, V.V. et al. (2007) Welding power sources with pulse stabilization of arcing. Kiev: Ekotekhnologiya.

13. Makhlin, N.M., Korotynsky, A.E. (2014) Analysis and procedure of calculation of series connection electronic devices for contactless arc excitation. The $\mathrm{Pa}^{-}$ ton Welding J., 1, 30-40.

14. Baev, E.F., Fomenko, L.A., Tsymbalyuk, V.S. (1976) Inductive elements with ferromagnetic cores. Moscow: Sov. Radio.

15. (1985) Portable transformers and chokes: Refer. Book. Ed. by I.N. Sidorov et al. Moscow: Radio i Svyaz.

16. Kalantarov, P.L., Tsejtlin, L.A. (1986) Calculation of inductances: Refer. Book. Leningrad: Energoatomizdat.

17. (1988) Reference book on electrotechnical materials. Ed. by Yu.V. Koritsky et al. 3rd ed. Leningrad: Energoatomizdat.

18. http://www.dart.ru/cataloguenewresistors / ty / ht $\mathrm{ml} /$ cement.shtml

19. http:/ / www.irf.com

20. http://www.vishay.com

21. Sadchenkov, D. (2000) Voltage multipliers. Radio, 10, 31-33.

22. Balabukh, A.I. (1984) Power sources with voltage multipliers for electron beam technology. Izvestiya Vuzov SSSR. Elektromechanika, 9, 113-117.

23. Kostikov, V.G., Nikitin, I.E. (1986) High-voltage power sources of radioelectronics. Moscow: Radio i Svyaz.

24. Blinov, Yu.I., Balabukh, A.I., Vasiliev, A.G. (2004) Effect of voltage shape of input source on operating conditions of voltage multiplier. Izvestiya St.-P. GETU LETI, Issue 1, 54-56.

25. Khrechkov, N.G. (2006) Dynamic characteristics of voltage multipliers of high-voltage electrical engineering systems: Syn. of Thesis for Cand. of Techn. Sci. Degree. Saratov.

26. Tsariashvili, A.A. (2014) Peculiarities of operation of voltage multipliers in supply by various shape voltage and frequency. URL:http://www.online-electri c.ru/articles

27. http: / www.onsemi.com

28. Makhlin, N.M., Korotynsky, A.E., Bogdanovsky, V.A et al. (2011) Single- and multioperator systems for automatic welding of position butt joints of nuclear power plant piping. The Paton Welding J., 11, 28-36. 


\title{
EXPERIMENTAL INVESTIGATION OF PROCESS OF PLASMA-ARC WIRE SPRAYING
}

\author{
I.P. GULYAEV ${ }^{1,2}$, P.Yu. GULYAEV ${ }^{2}$, V.N. KORZHIK ${ }^{3}$, A.V. DOLMATOV ${ }^{2}$, V.I. IORDAN $^{1,4}$, \\ I.V. KRIVTSUN ${ }^{3}$, M.Yu. KHARLAMOV ${ }^{3}$ and A.I. DEMIANOV ${ }^{3}$ \\ ${ }^{1}$ S.A. Khristianovich Institute of Theoretical and Applied Mechanics, SB RAS \\ 4/1 Institutskaya Str., 630090, Novosibirsk, RF \\ E-mail: admin@utam.nsc.ru \\ ${ }^{2}$ State University, Yugra \\ 16 Chekhov Str., 628012, Khanty-Mansiysk, Tyumen region, RF \\ E-mail: ugrasu@ugrasu.ru \\ ${ }^{3}$ E.O. Paton Electric Welding Institute, NASU \\ 11 Bozhenko Str., 03680, Kiev, Ukraine. E-mail: office@paton.kiev.ua \\ ${ }^{4}$ Altai State University \\ 61 Lenin Ave., 656049, Barnaul, Altai region, RF
}

\begin{abstract}
Application of current diagnostic systems becomes very important in development of fundamental concepts in area of thermal spraying and obtaining of new experimental data, in particular, on plasma-arc wire spraying. Firmware complex based on machine vision camera and digital spectrometer was proposed for experimental study of process of plasma-arc wire spraying of coatings. Procedure for experimental investigations of given process was developed. Results of measurements of velocity and temperature of dispersed phase particles as well as video of the most typical steps of plasma-arc spraying, including detachment of droplets from wire being sprayed and their breaking in plasma flow, were represented. Distribution of particles being sprayed in size was investigated and its effect on possibilities of temperature changes was analyzed. Experimental data obtained verified theoretical representations on types of flow and decomposition of jet of wire molten metal as well as droplet breaking in plasma jet. 18 Ref., 11 Figures.
\end{abstract}

$\boldsymbol{K} \boldsymbol{e} \boldsymbol{y} \boldsymbol{w} \boldsymbol{O} \boldsymbol{r} \boldsymbol{d} \boldsymbol{s}:$ thermal spraying, plasma-arc wire spraying, firmware complex, plasma flow, dispersed phase, for mation of drops of liquid metal, measurement of particle temperature, process visualization, spectral analysis

Development of methods for thermal spraying of coating is directly related with comprehensive investigations of physical and chemical processes, taking place in spraying. At that, namely experimental methods of investigations are of particular importance. They are the source of qualitative and quantitative data, promote development of fundamental ideas of thermal spraying processes as well as can be used as method for verification of theoretical approaches and mathematical models. The experiments receive particular importance in investigation of new, not enough studied methods, such as, for example, plasma-arc wire spraying [1] (PAWS).

Key peculiarity of this method is the fact that completely molten metal particles are entered into plasma flow, for example, in contrast to the processes of powder spraying, at which solidstate powder particles are entered in gas or plasma flow [2]. Obviously, that heat and dynamic interaction of dispersed phase with bearing flow is significantly different in cases of wire and powder spraying that has direct effect on structure and properties of produced coatings. In particular, large droplets of molten metal, moving in high-velocity plasma flow, are deformed; internal movement takes place in them, resulting in their breaking with formation of finer fragments [3]. It is sufficiently detailed information on phenomenology of processes of powder spraying, but there are virtually no experimental data on PAWS up to now. This is the basis for present work relevance.

All the systems widely used at present time for measurement of temperature and velocity of particles in thermal flows, namely DPV, Accuraspray (Tecnar, Canada), Spectraviz (Stratonics, USA), SprayWatch (Oseir, Finland), are based on realizing the methods of bichromatic pyrometery and time-of-flight method in that or another form [4, 5]. Besides, PIV (Particle Image Velocimetry) [6] and LDA (Laser-Doppler Anemometry) [7] methods are often used for velocity measurement. Cameras based on high-sensitive CCD and CMOS - matrices have good potential for development of the diagnostics systems. They allow registration of spatial distribution of particles with simultaneous measurement 
of their velocity and temperature. Such a system equipped with channel for registration of spectrum of optical radiation of hetero-phase flow allows increasing safety and accuracy of temperature measurements.

The matter of this work was development and testing of measurement complex, which, first of all, allows visualizing the process of formation and breaking of liquid metal droplets under conditions of PAWS, and, for the second, performing measurement of velocity and temperature characteristics of condensed phase particles [8, 9].

The investigations were carried out using machine for plasma-arc spraying of coatings PLAZER 30-PL-W with current-carrying wire. This machine is designed for deposition of wearresistant, corrosion-resistant and special coatings, repair of worn parts of machines by means of spraying of current-carrying materials in form of powder and compact wires of 1.6-2.0 $\mathrm{mm}$ diameter [1]. Appearance and scheme of experimental complex are presented in Figure 1.

Argon was used as plasma gas and compressed air was applied for plasma jet compression. Spraying of solid wire SV-08 from low-alloy steel was carried out in the following mode: arc current $220 \mathrm{~A}$, arc voltage $65-70 \mathrm{~V}$, argon consumption $28 \mathrm{l} / \mathrm{min}$, air consumption $330 \mathrm{l} / \mathrm{min}$, wire feed rate $14.7 \mathrm{~m} / \mathrm{min}$, wire diameter $1.6 \mathrm{~mm}$, and distance between the electrodes was $9 \mathrm{~mm}$. Plasmatron and wire feeder were located in spraying box (see Figure 1, $a$ ) close by which measurement equipment was mounted.

HD1-1312-1082-G2 camera (Photon Focus, Switzerland) and LR1-T digital spectrometer (ASEQ Instruments, Canada) were integrated in the experimental complex for investigation of dynamics and heat characteristics of the condensed phase at plasma-arc spraying. MATLAB media, having powerful means for transformation of multidimensional signals based on parallel computation technology, was used for data processing. Monochrome digital camera HD1-13121082-G2 is built on CMOS-matrix of $1312 \times 1082$ photo elements size with spectral sensitivity of 400-1000 nm range. Signal of its sensor is represented by 12-digit code and interface allows on-line transmitting full data into computer with 55 frames per second rate. Duration of frame exposure was varied from $10 \mu$ s to $10 \mathrm{~ms}$ range. Driver of the camera supports a standard interface of MATLAB media and gives the possibility of its application as a source at pipelined processing. Addition of SL-575-50 band filter ( $\mathrm{Fo}^{-}$ tooptic Ltd., Obninsk, RF) with central wavelength $575 \mathrm{~nm}$ and band width $50 \mathrm{~nm}$ (FWHM) to optical channel of HD1-1312-1082-G2 camera was necessary for performance of thermal imaging investigations. Moreover, correction of signal inhomogeneity of its sensor and calibration at automated bench, structure and functioning procedure of which are described in work [10], were also performed.

Digital spectrometer LR1-T is built on Czerny-Turner diagram, has linear CCD-probe with 3648 photo elements of $8 \times 200 \mu \mathrm{m}$ size and thermoelectric cooler for cooling to $-35{ }^{\circ} \mathrm{C}$ temperature, and can provide measurements in 200$1100 \mathrm{~nm}$ spectral range. Digital spectrometer data are represented by 16-digit code and they are transferred into computer via USB 2.0 interface. Receiving lens performed focusing of jet image at fiber optics endface of $200 \mu \mathrm{m}$ diameter, through which radiation was entered into device entrance slit. Time of spectrometer exposure varied in 10-100 ms range. M-class of aSpectr objects was developed for spectrometer integration in MATLAB media, which represents it in a form of virtual device with set of properties and methods. Measurement of temperature using spectral
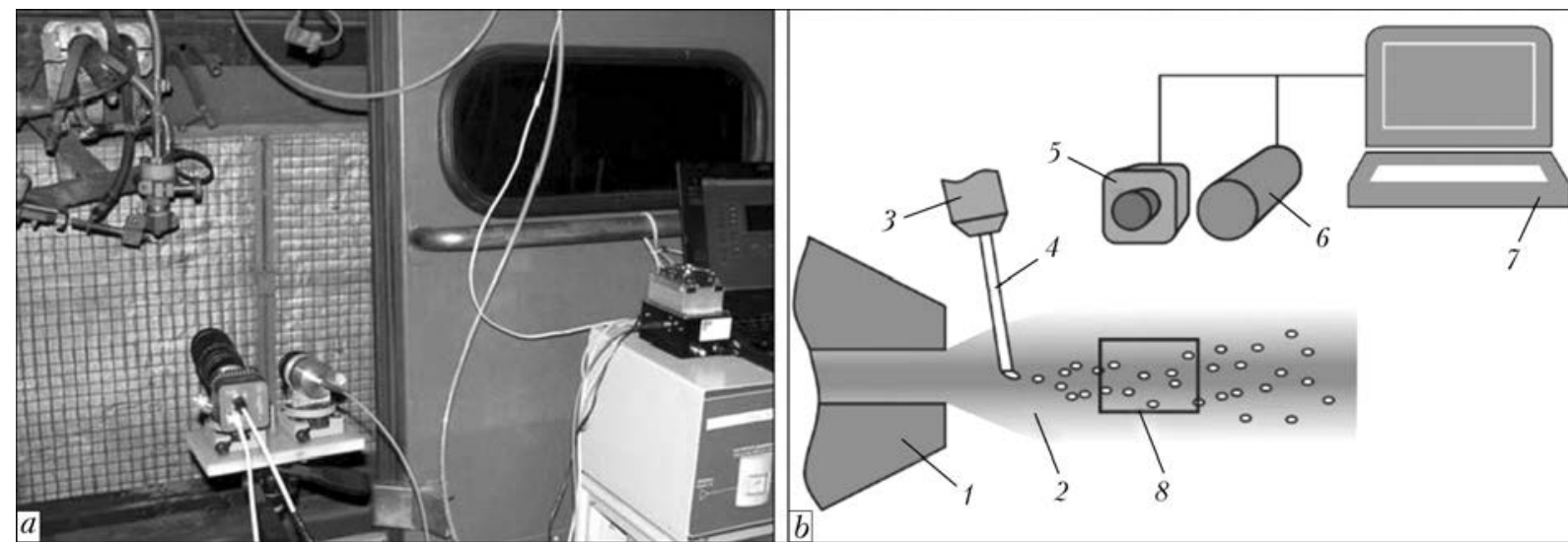

Figure 1. View $(a)$ and structure $(b)$ of diagnostic complex for investigation of process of PAWS: 1 - plasmatron; 2 - plasma jet; 3 - nozzle; 4 - wire being sprayed; 5 - camera; 6 - photospectrometer; 7 - computer; 8 test volume 


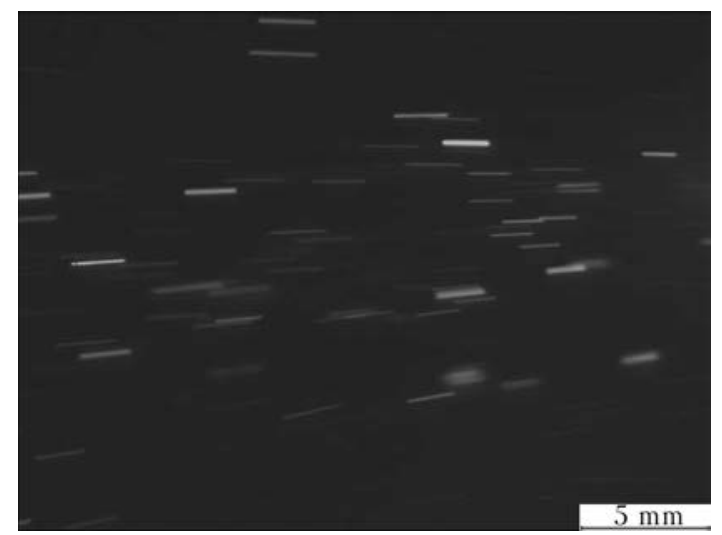

Figure 2. Initial frame showing tracks of particles of material being sprayed in jet sections $z=40-70 \mathrm{~mm}$ from nozzle edge

method was carried out by continuous (thermal) component of spectrum, free of line and banded radiation of atoms and molecules, in 550-600 nm range. For this preliminary correction of inhomogeneity of probe signal with the help of automated bench and procedure, described in work [11], was carried out.

Camera and receiving lens of the spectrometer were fastened to platform in such a way that their mutual positioning was constant (see Figure 1), and jet was in focus plane of both optical systems. Camera vision area covered part of the jet (test volume), size of which varied from $29 \times$ $\times 24$ to $68 \times 56 \mathrm{~mm}^{2}$. Area of spectrometer vision represented a circle of $10 \mathrm{~mm}$ diameter, located in the center of camera frame. Registration of wire melting, detachment and breaking of molten metal droplets in plasma flow was carried out in the initial imaging area not far from place of electric arc attachment to wire being sprayed. Measurement of temperature in this area was not carried out due to strong plasma radiation. Further the platform with camera and lens was moved along plasma jet, providing successive overlapping of areas of temperature and particle velocity measurement.

Figure 2 shows initial (unprocessed) frame of plasma jet with particle tracks. A mask was made for each frame of video stream, and morphological analysis was carried out. During analysis the frame was divided in objects, corresponding to separate possible tracks. Each separated object

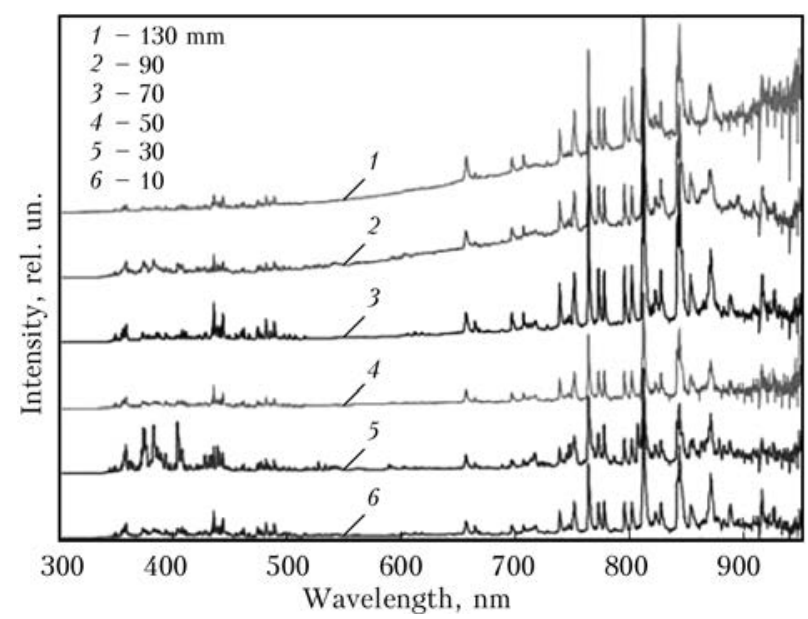

Figure 3. Spectra of radiation of plasma jet at different distances from nozzle edge

was analyzed from point of view of determination of visible diameter of the particle, track length, coordinates of its center, orientation and brightness. In order to eliminate objects corresponding to «splicing» of tracks, filtering on length, diameter and relationship of maximum to average brightness were carried out [12].

Figure 3 shows the spectra of plasma jet radiation registered at $z=10-130 \mathrm{~mm}$ distance from plasmatron nozzle edge. Spectrum range of $550-600 \mathrm{~nm}$, free of own radiation of plasma, was selected, based on obtained data, for temperature measurement by brightness (camera) and spectrum methods. A new approach was used for determination of particle temperature distribution. It lies in registration by photo-spectrometer of total radiation of ensemble of particles, which passed the test volume during device exposure time, and further reconstruction of particle temperature distribution using mathematical method [13, 14].

Visualizing the process of melt formation and droplet detachment from the end of wire being sprayed as well as movement and breaking of particles at the initial part of jet are still one of the main investigation tasks.

Earlier mathematical modelling [15] determined that plasma-arc spraying can have three types of flow and decomposition of jet of wire molten metal, namely, jet metal flow, formation

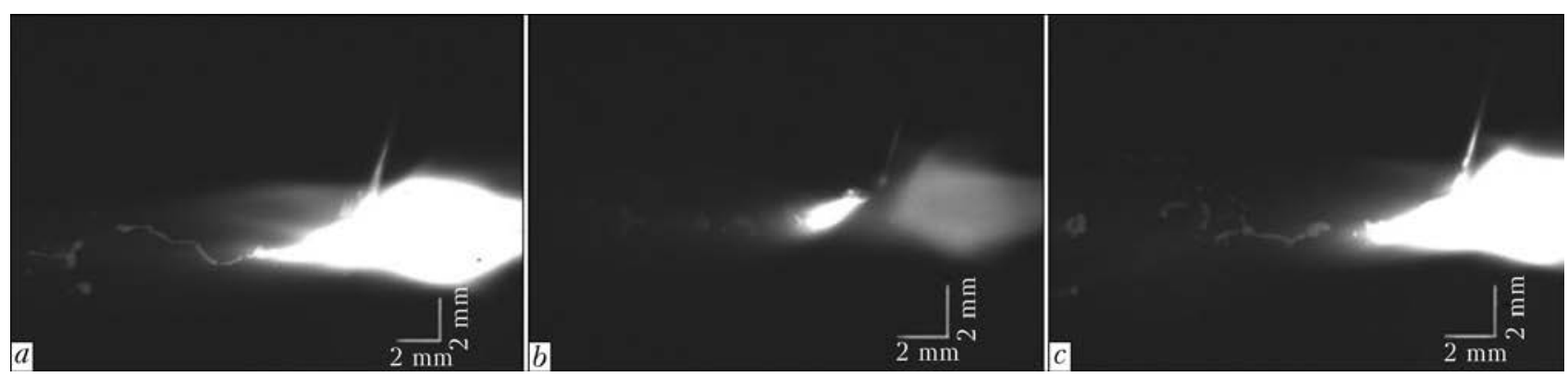

Figure 4. Visualizing droplet detachment from end of wire being sprayed; $a$ - jet metal flow; $b-$ formation of droplets similar in size; $c$ - formation of droplets having significant differences in size 
of droplets of virtually similar size, and, at least, formation of droplets having significant difference in size. Images, represented in Figure 4, completely correspond to given conclusions.

Thus, analysis of images shows (Figure $4, b$ ) that melt, formed at the end of spray wire at optimum spraying mode, is stretched in 3-4 mm length filament, which is decomposed on virtually similar droplets of $650-700 \mu \mathrm{m}$ diameter. Transfer modes of machine operation (switching on, adjustment of arc current, gas consumption or rate of wire feed) can show jet flow of molten metal without actual spraying, as represented in Figure 4, $a$, where filament length makes 11$12 \mathrm{~mm}$. And, finally, Figure 4, $c$ shows spraying mode with droplet formation having significant difference in size, which can be observed at wrong selection of wire feed rate. In this case, periodic change of length of formed metal filament and, respectively, size of detached droplets take place. At that, detachment of large droplets $(\sim 900 \mu \mathrm{m}$ and more) is accompanied by formation of finer droplet-satellites $(\sim 100 \mu \mathrm{m})$.

Obtained experimental results show that initial droplets start intensive breaking virtually at once after detachment from the wire end. This process takes place in area of 50-60 $\mathrm{mm}$ from the end of wire being sprayed. At that, the following types of droplet breaking are typical under conditions of plasma-arc spraying (Figure 5), namely, breaking for several large droplets, breaking by «parachute» type, and «parachute» with filament [3]. In particular, Figure 5, $a$ shows the moment preceding breaking of large droplet for two smaller fragments. Figure 5, $b$ illustrates the moment of fragments spread in breaking by «parachute» mode, i.e. number of fine droplets is formed at breaking of blown «pocket» as well as larger dropletsat - edge breaking.

Quenching of particles being sprayed was carried out in a basin with water at $200 \mathrm{~mm}$ distance from plasmatron nozzle for measurement of their size. Produced powder was investigated using laser-diffraction particle size analyzer LS13 320 (Beckman Coulter, USA). The results are represented in Figure 6. Spectrum of material particle size is very wide, i.e. from $400 \mathrm{~nm}$ to $400 \mu \mathrm{m}$, that can be explained by active breaking and evaporation of liquid particles in the initial area of plasma jet. Overwhelming majority of the particles are of small (no more than 2-3 $\mu \mathrm{m}$ ) size, and, at the same time, their mass fraction is negligibly small. Two significant facts should be noted from practical point of view: first, droplets of $50-400 \mu \mathrm{m}$ size represent the main mass of material particles, forming the coating; second, total area of surface of particles is uniformly distributed among droplets of $500 \mathrm{~nm}$ to $200 \mu \mathrm{m}$ size, therefore, particles of fine fractions, having the highest temperature, will
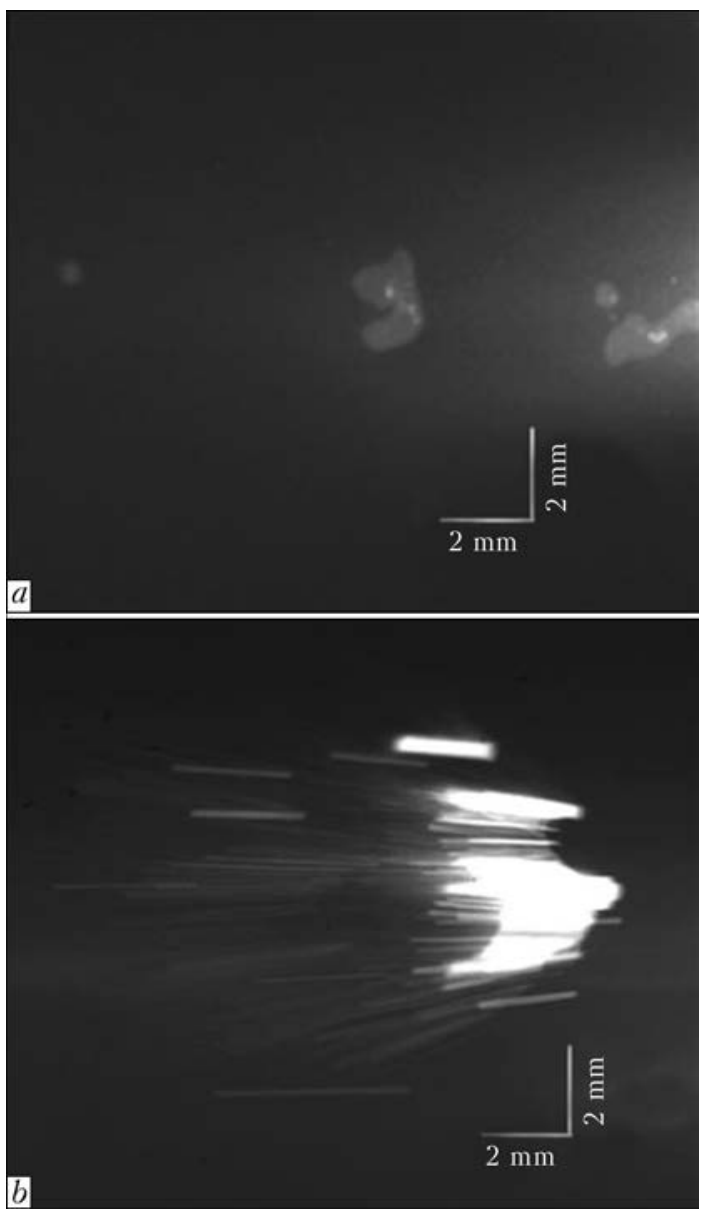

Figure 5. Breaking of droplets of molten metal in plasma flow: $a$ - breaking for several large droplets; $b-$ «parachute» type of breaking

make the main contribution in general spectrum of heat emission of particles.

Local distributions of given parameters in the jet volume were reconstructed based on results of measurement of velocity and temperature of separate particles. The whole volume of sampling made 60,000 of identified objects. For example, Figures 7 and 8 show statistical histograms of distribution of particle velocity and temperature in jet section $z=160 \mathrm{~mm}$ from nozzle edge. Dashed lines indicate average $V_{\mathrm{av}}$ and $T_{\mathrm{av}}$ values

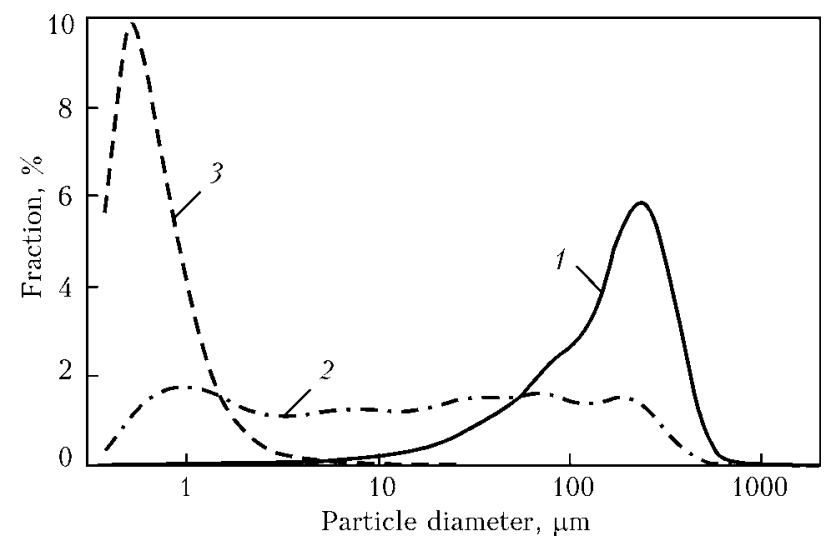

Figure 6. Size distribution of particles of spray material: 1 - mass; 2 - area; 3 - number of particles 


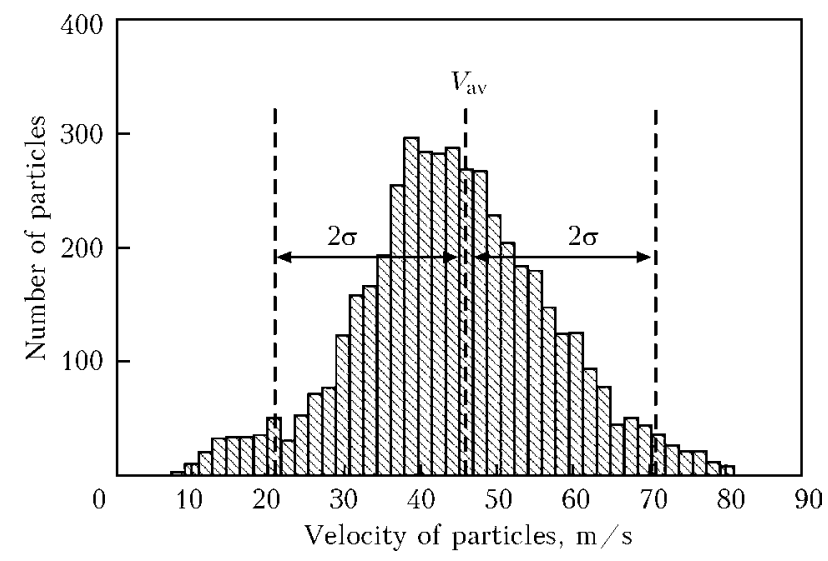

Figure 7. Distribution of particle velocities in jet section $z=160 \mathrm{~mm}$

as well as boundaries of $V_{\mathrm{av}} \pm 2 \sigma$ and $T_{\mathrm{av}} \pm 2 \sigma$ ranges, where $\sigma$ is the standard deviation from corresponding average value.

Figure 9 shows a change of average particle velocity $V_{\text {av }}$ in movement along the jet. It can be indicated that $V_{\mathrm{av}}$ value reaches fixed level of $45-50 \mathrm{~m} / \mathrm{s}$ at $100-160 \mathrm{~mm}$ distance from the nozzle. At that, spread of particle velocities is sufficiently large, i.e. $2 \sigma=22-25 \mathrm{~m} / \mathrm{s}$, that is a half of $V_{\text {av }}$ value. This is related with wide range of sizes of the particles, formed under conditions of PAWS.

Figure 10 gives the results of measurement of particle temperature in different sections of the jet, received by brightness (camera) and spectral methods. As can be seen, obtained temperature values have significant difference that can be explained in the following way. Algorithm applied for processing of still images does not include recognizing the particles, image of which has subpixel size. This means that only particles of more than $50 \mu \mathrm{m}$ size are identified using selected $51.9 \mu \mathrm{m} /$ pixel spatial resolution of video system. Therefore, temperatures of dispersed phase, measured by brightness method, correspond exactly to that large particles, from which the coating is mainly formed. As can be seen, average

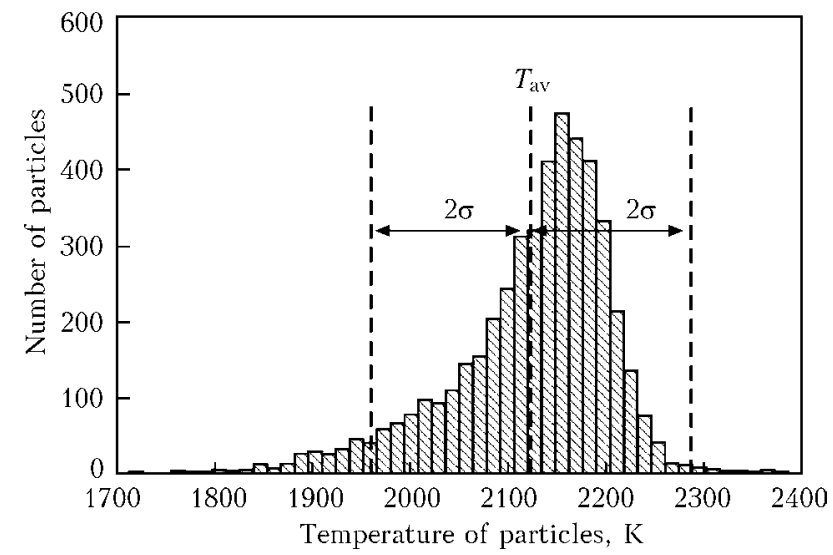

Figure 8. Distribution of particle temperatures in section $z=160 \mathrm{~mm}$

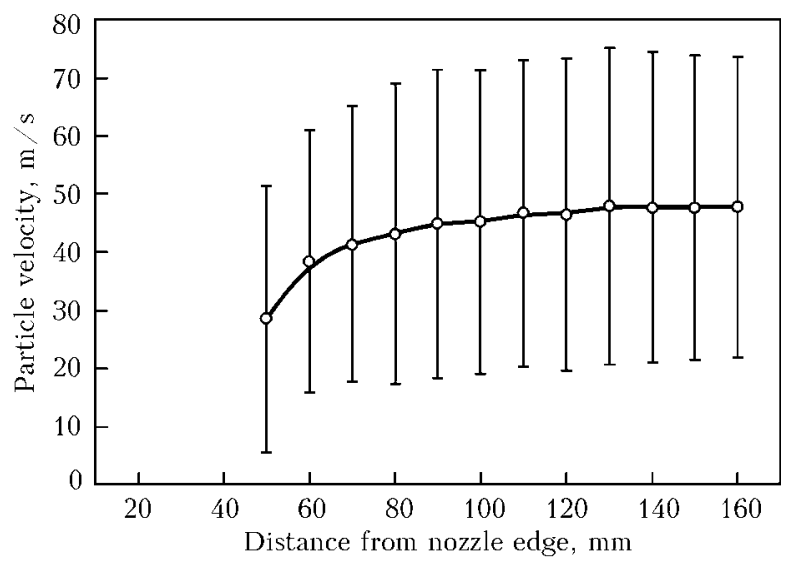

Figure 9. Value of average velocity of particles in different jet sections

temperature of particles gradually increases (from 2000 to $2130 \mathrm{~K}$ ) along the spraying distance. This is related with the fact that initial temperature of droplets at once exceeds melting temperature and makes $1700-1800 \mathrm{~K}$ in contrast to powder spraying.

On the other hand, spectral method always provides for the result close to maximum distribution temperature [16] in the case of presence of inhomogeneous temperature field in area of observation. It is obvious fact that the particles of the smallest size, which are quickly heated by bearing plasma flow, will have the maximum temperature in the initial jet area. Typical time of particle heating-up is of $\tau \sim d^{2} / a$ order (where $d$ is its diameter, $a$ is the temperature conductivity of its material), that, for steel droplet of $1 \mu \mathrm{m}$ diameter, for example, provides for $1 \mu \mathrm{s}$ value. Considering the fact that such fine particles move with $V \approx 100 \mathrm{~m} / \mathrm{s}$ velocity, they can be assumed as «heat markers», temperature of which equals local temperature of plasma flow in area of $\delta=\tau V$, i.e. around $100 \mu \mathrm{m}$. It should be mentioned here that such an approach is used for measurement of temperature of flame, in which superdispersed soot particles being a heat radiation source are formed [17, 18].

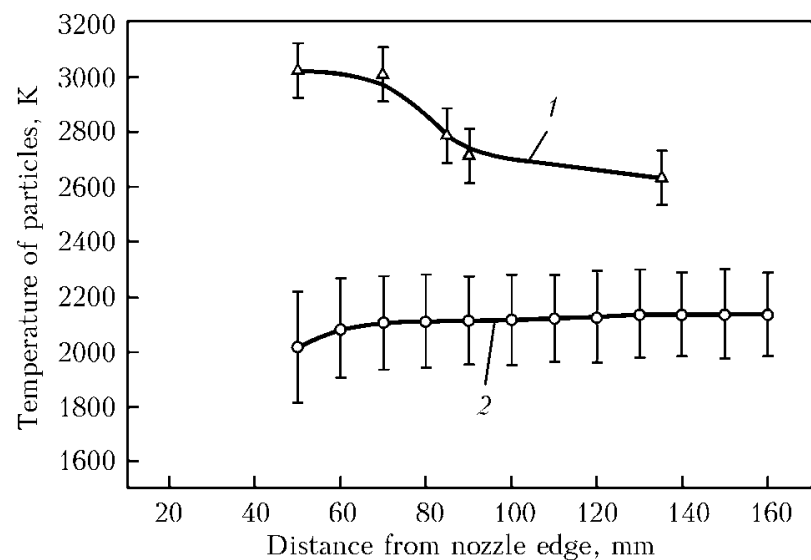

Figure 10. Value of average temperature of particles in different jet sections: 1 - spectral measurements; 2 brightness measurements 
It can be seen in Figure 10 that temperature of the particles measured by spectral method is monotonously reduced in removal from plasmatron nozzle edge. Its maximum values in initial area do not exceed temperature of steel boiling (3000-3100 K), since further metal overheating requires larger heat input. Ultra-fine particles due to their small mass are taken out of the limits of jet core by expanding plasma flow, where plasma temperature is reduced.

Plasma own intensive radiation did not allow measuring temperature of dispersed phase by spectral and brightness methods in area of electric arc attachment to wire being sprayed. However, results of this area visualizing, given in $\mathrm{Fi}$ gure 11, are interesting. Bright radiation of plasma flow, the most heated area of steel wire, i.e. anode spot, as well as separate droplet of melt, flowed by high-velocity plasma jet, can be observed. Clear aerodynamic path is noted down the flow following the droplet, which is, possibly, visualized due to material evaporation. Thus, intensive heating of particles up to material melting temperature takes place already at $\sim 8 \mathrm{~mm}$ distances from wire being sprayed $(\sim 15 \mathrm{~mm}$ from plasmatron nozzle edge).

Experimental complex was developed for investigation of processes of heat and dynamic interaction of liquid particles with plasma flow under conditions of PAWS of coatings. HD11312-1082-G2 camera and LR1-T spectrometer make a basis of complex measurement equipment. Thermal imagining system allowed visualizing processes of melt formation, detachment of metallic droplets and their further breaking as well as carrying out measurements of velocity and temperature of particles along the spraying distance. Using channel for registration of radiation spectrum of heterophase jet allowed making grounded selection of working spectral range of the camera. Analysis of distribution of material particles by size showed that measurements of temperature by spectral method reflected local temperature of bearing plasma flow. Experimental data verified obtained earlier theoretical formulations on types of flow and decomposition of molten wire metal as well as variants of droplet breaking in the plasma jet.

The work is carried out in scope of joint project RFFI (No. 14-08-90428) and NAS of Ukraine (No. 06-08-14).

1. Korzhik, V.N., Kharlamov, M.Yu., Petrov, S.V. et al. (2011) Technology and equipment of plasma-arc spraying for repair of critical parts of railway transport. Vestnik V. Dal VUNU, 14, 76-82.

2. Pawlowski, L. (2008) Science and engineering of thermal spray coatings. 2nd ed. John Wiley \& Sons.

3. Nigmatulin, R.I. (1987) Dynamics of multiphase me dia. Pt 1. Moscow: Nauka.

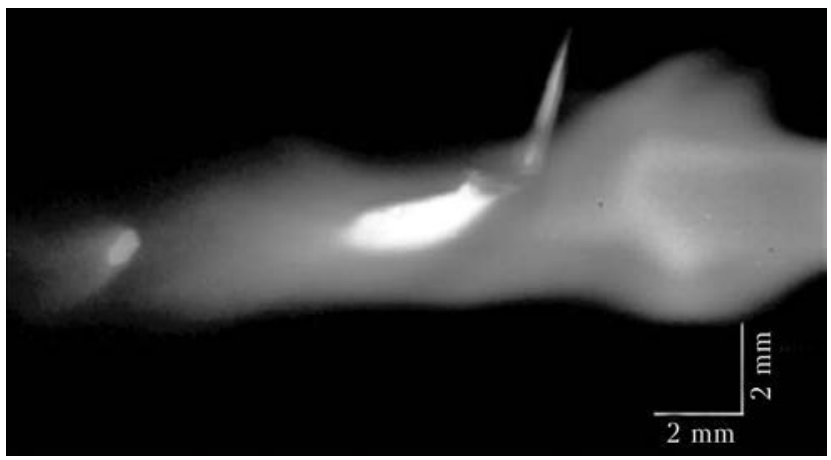

Figure 11. Visualizing the process of material evaporation from surface of droplets detached from wire being sprayed

4. Mauer, G., Vassen, R., Stoever, D. (2007) Comparison and applications of DPV-2000 and accura-sprayg3 diagnostic systems. J. Thermal Spray Technology, $16(3), 414-424$

5. Schwenk, A., Wank, A., Wallendorf, T. et al. (2010) NIR (Near-Infra-Red) sensor - An alternative diagnostic tool for the online process control of thermal spray processes. In: Proc. of Int. Thermal Spray Conf. (Singapore, 2010), 120-123.

6. Marchand, O., Bertrand, G., Planche, M.P. (2009) Particle image velocimetry diagnostics for suspension plasma spraying. In: Proc. of Int. Thermal Spray Conf. (4-5 May, 2009, Las Vegas, USA), 855-860.

7. Zimmermann, S., Vogli, E., Kauffeldt, M. et al. (2010) Supervision and measuring of particle parameters during the wire-arc spraying process with the diagnostic systems Accuraspray-g3 and LDA. (LaserDoppler-Anemometry). J. Thermal Spray Technology, 19(4), 745-755.

8. Boronenko, M.P., Gulyaev, I.P., Gulyaev, P.Yu. et al. (2013) Methods of control of temperature and velocity of condensed phase particle during plasma-arc spraying. Fundament. Issledovan., 10(6), 1194-1199.

9. Gulyaev, P.Yu., Dolmatov, A.V., Popov, V.A. et al. (2012) Methods of optical diagnostics of particles in hightemperature flows. Polzunozsky Vestnik, 1/2, 4--7.

10. Dolmatov, A.V., Ermakov, K.A., Lavrikov, V.V. et al. (2012) Complex of automated calibration of thermal image system on the base of MATLAB. Vestnik YugorskGU, 25(2), 59-63.

11. Dolmatov, A.V., Gulyaev, I.P., Imamov, R.R. (2014) Spectral pyrometer for control of temperature in process of thermosynthesis. Ibid., 33(2), 32-42.

12. Boronenko, M.P., Gulyaev, I.P., Gulyaev, P.Yu. et al. (2014) Evaluation of velocity and temperature of dispersed phase in plasma-arc spraving jets. Fundament. Issledovan., 10(11), 2135-2140.

13. Gulyaev, I.P., Solonenko, O.P., Smirnov, A.V. et al. Method for determination of temperature distribution of condensed phase particles in two-phase plasma flow. Pat. $2383873 \mathrm{RF}$. Int. Cl.G01J $3 / 30$. Publ. 10.03.2010.

14. Gulyaev, I.P. Ermakov, K.A., Gulyaev, P.Yu. (2014) New high-speed combination of spectroscopic and brightness pyrometry for studying particles temperature distribution in plasma jets. Europ. Researcher, 71(3/2), 564-570.

15. Kharlamov, M.Yu., Krivtsun, I.V., Korzhyk, V.N. (2014) Dynamic model of the wire dispersion process in plasma-arc spraying. J. Thermal Spray Technology, 23(3), 420-430.

16. Magunov, A.N. (2010) Spectral pyrometry of objects with inhomogeneous temperature. Zhurnal Tekhnich. Fiziki, 80(7), 78-82.

17. Zhao, H., Ladommatos, N. (1998) Optical diagnostics for soot and temperature measurement in diesel engines. Progress in Energy and Combustion Sci., 24(3), 221-255.

18. Lu, G., Yan, Y. (2006) Temperature profiling of pulverized' coal flames using multicolor pyrometric and digital imaging techniques. IEEE Transact. on Instrumentation and Measurement, 55(4), 1303-1308. 


\title{
LASER WELDING OF COMMERCIAL ARC SLAG REMELTED TITANIUM VT1-0 HARDENED BY NITROGEN
}

\author{
V.D. SHELYAGIN, V.Ya. SAENKO, A.A. POLISHKO, V.A. RYABININ, A.V. BERNATSKY, \\ S.N. STEPANYUK and I.N. KLOCHKOV \\ E.O. Paton Electric Welding Institute, NASU
}

11 Bozhenko Str., 03680, Kiev, Ukraine. E-mail: office@paton.kiev.ua

\begin{abstract}
The possibility of producing the full-strength butt joint of sheet rolled titanium VT1-0 of $12 \mathrm{~mm}$ thickness, preliminary hardened by nitrogen $(0.098 \mathrm{wt} . \%)$ from the gas phase in the process of arc slag remelting, using laser welding was shown. In the course of experimental investigations double-sided welding of butt joints applying Nd:YAG-laser radiation was performed. The results of macro- and microinvestigations, measurements of distribution of microhardness $H V$, mechanical properties in testing on static tension and impact bending proved a high quality of welded joints. The homogeneity of the structure, absence of cracks, pores and other defects evidence of the challenging development of technology of laser welding of commercial titanium VT1-0 hardened by nitrogen (up to 0.1 wt.\%) in ASR. 9 Ref., 4 Tables, 11 Figures.
\end{abstract}

Keywords: laser welding, commercial titanium, hardening by nitrogen from gas phase, weldability, butt joint, micro-, macrostructure, microhardness, mechanical properties

Widening of production and application of titanium and its alloys in different branches of engineering caused, in the first turn, by their increased specific strength (relation of tensile strength to density). High corrosion resistance of titanium under the atmospheric conditions, sea water and a number of high-aggressive environments predetermines its efficient use for manufacture of welded structures operating in the most severe conditions. The volumes of industrial use of these structures depend greatly on modernization of technological processes of their manufacture and, first of all, welding. The main problems of titanium welding include serious difficulties caused by its high chemical activity at elevated temperatures. In welding a reliable protection of weld pool from surrounding environment is required to eliminate interaction with gases of atmosphere, otherwise the welded joints loose their ductility, the defects are formed in welds, in particular, pores. To provide a good weldability of titanium and its alloys the content of harmful impurities, such as gases (oxygen, nitrogen, hydrogen) and carbon is restricted. Thus, commercial titanium VT1-0 contains, wt. $\%$ : $0.12 \mathrm{O}_{2}, 0.04 \mathrm{~N}_{2}, 0.01 \mathrm{H}_{2}, 0.07 \mathrm{C}$ [1].

As a result of complex of investigations carried out at the E.O. Paton Electric Welding Institute
[2-4] the possibility of more than 1.5 times increase of level of strength characteristics of commercial titanium of VT1-0 grade (GOST 2375579) was established by its alloying with nitrogen up to $0.1 \mathrm{wt} . \%$ from gas phase in the process of melting ingots using method of arc slag remelting (ASR). Moreover, in spite of the real content of nitrogen (0.069 and 0.098 wt.\%), in hardened titanium VT1-0 of 14-152 and 5-35 mm thickness in ASR, the values of elongation and reduction in area are at the high level $-\delta=14-27 \%$ and $\psi=32.5-47 \%$.

One of the main tasks of investigation of metallurgical quality and technological properties of sheet rolled titanium VT1-0, hardened by nitrogen, as a new structural material is its weldability.

Earlier [5], the efficiency of application of electron beam welding to produce welded joints of full-strength with base metal (BM) of sheet commercial titanium VT1-0 of $35 \mathrm{~mm}$ thickness, hardened by nitrogen up to $0.1 \%$ from gas phase in ASR process, was shown. Metallographic investigations proved the production of the quality welded joint without cracks, pores and other defects, in spite of the fact that the real content of nitrogen $(0.098 \%)$ in BM almost 2.5 times exceeds the admissible $(\leq 0.04 \%)$ content in VT1-0 titanium according to GOST 19807-74. Weld metal and BM are characterized by the homogeneous structure.

\footnotetext{
${ }^{*}$ In this work A.V. Siora and A.Yu. Tunik participated. 
New capabilities in the production of critical welded structures of titanium and its alloys are opened as a result of application of laser and hybrid laser-arc welding for this purpose [6, 7]. The important is also the fact that laser welding is one of the challenging methods allowing producing high-quality and long-life welded joints almost without residual deformations [8].

The aim of this work is the investigation of weldability of butt joints of sheet rolled titanium VT1-0 of up to $12 \mathrm{~mm}$ thickness, hardened by nitrogen $(0.098 \%)$ from gas phase in ASR, with evaluation of possibility of producing welded joint of full strength using laser radiation.

To achieve the put aim, the experiments on laser welding of double-sided butt joints were carried out.

The chemical composition of sheet rolled titanium VT1-0 ASR $12 \mathrm{~mm}$ thick, used for welded specimens, is given in Table 1 , and its mechanical properties - in Table 2 .

The experiments were carried out in laboratory stand mounted on the base of three-coordinate manipulator «Lastochka-1» of the PWI production. For experiments ROFIN-SINAR Nd:YAG-laser DY044 (Germany) was used with radiation wave length $\lambda=1.06 \mu \mathrm{m}$. Laser radiation was transmitted along the optic fiber manufactured of quartz glass of $600 \mu \mathrm{m}$ diameter and $20 \mathrm{~m}$ length. From the optic fiber the laser radiation got to the collimator, where it was transformed by means of the optic elements system,

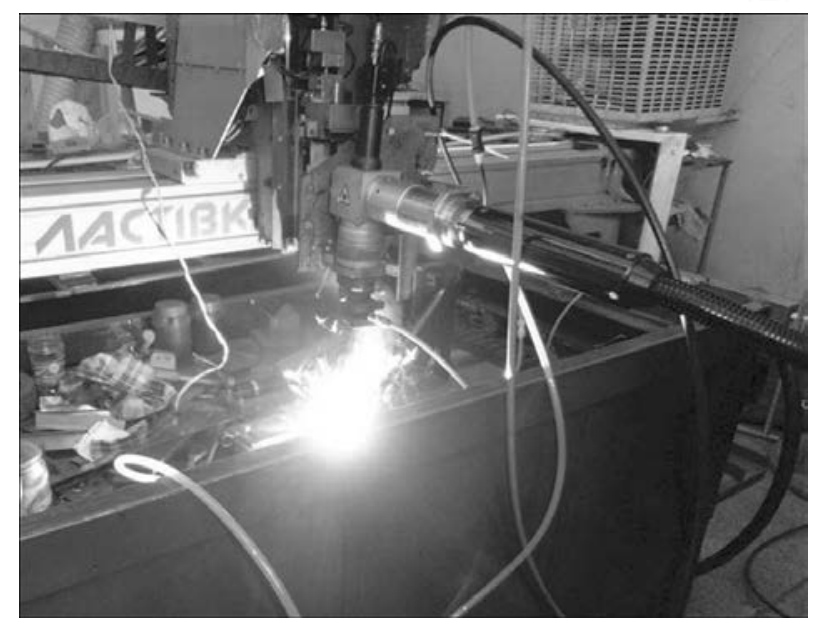

Figure 1. Process of laser welding of double-sided butt joint of sheet rolled titanium VT1-0 $12 \mathrm{~mm}$ thick, hardened by nitrogen (0.098 wt.\%) from gas phase in the ASR process

acquired the necessary geometric sizes and then got to the focusing quartz lens of $50 \mathrm{~mm}$ diameter with focus distance $F=300 \mathrm{~mm}$. The experiments were carried out according to the scheme given in work [6]. The specimens were fixed in the screw clamp, positioned on the object sample table, and laser head was fastened on the movable carriage of manipulator as it is shown in Figure 1. The welding was performed in the atmosphere of active $\left(\mathrm{N}_{2}\right)$ and inert $(\mathrm{Ar}, \mathrm{He})$ gases. Technological modes of welding of plates of alloy VT1-0 ASR $12 \mathrm{~mm}$ thick, hardened by nitrogen $(0.098 \%)$, are given in Table 3 .

The produced welded joints were subjected to macro- and microstructure examinations and also

Table 1. Comparison of chemical composition (wt.\%) of sheet rolled titanium of VT1-0 grade and VT1-0 ASR

\begin{tabular}{|c|c|c|c|c|c|c|}
\hline Material & $\mathrm{Al}$ & $\mathrm{Fe}$ & $\mathrm{C}$ & {$[\mathrm{N}]$} & [O] & {$[\mathrm{H}]$} \\
\hline VT1-0 ASR & 0.23 & 0.09 & 0.02 & 0.098 & 0.09 & 0.002 \\
\hline VT1-0 (GOST 19807-74) & $\leq 0.30$ & $\leq 0.30$ & $\leq 0.07$ & $\leq 0.04$ & $\leq 0.12$ & $\leq 0.01$ \\
\hline
\end{tabular}

Table 2. Mechanical properties of sheet rolled titanium VT1-0 and VT1-0 ASR 12 mm thick

\begin{tabular}{|c|c|c|c|c|c|}
\hline Material & $\sigma_{y}, \mathrm{MPa}$ & $\sigma_{\mathrm{t}}, \mathrm{MPa}$ & $\delta, \%$ & $\psi, \%$ & $K C U_{+20}, \mathrm{~J} / \mathrm{cm}^{2}$ \\
\hline VT1-0 ASR & 625 & 705 & 23 & 40.5 & 61 \\
\hline VT1-0 (GOST 23755-79) & - & $375-570$ & $10-13$ & $24-27$ & - \\
\hline
\end{tabular}

Table 3. Technological modes* of laser welding of plates of commercial titanium VT1-0 ASR hardened by nitrogen (0.098 wt.\%)

\begin{tabular}{|c|c|c|}
\hline $\begin{array}{l}\text { Number of } \\
\text { specimen }\end{array}$ & Size of specimen, mm & Gas atmosphere (gas consumption) \\
\hline 1 & $198 \times 194 \times 12$ & $\begin{array}{c}\text { He }- \text { weld pool }(201 / \mathrm{min}), \mathrm{Ar}-\text { tail side of pool }(141 / \mathrm{min}) \text {, } \\
\text { Ar }- \text { back side of weld }(101 / \mathrm{min})\end{array}$ \\
\hline 2 & $207 \times 197 \times 12$ & $\begin{array}{c}\text { He - weld pool }(201 / \mathrm{min}), \mathrm{N}_{2}-\text { tail side of pool }(141 / \mathrm{min}) \text {, } \\
\text { Ar }- \text { back side of weld }(101 / \mathrm{min})\end{array}$ \\
\hline
\end{tabular}




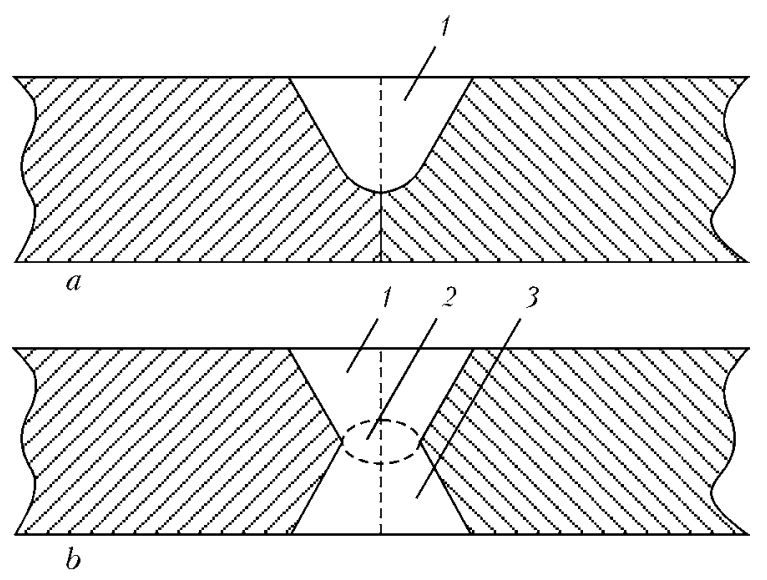

Figure 2. Schematic reproduction of stages of formation of double-sided butt joint in laser welding: $a$ - laser path on one side; $b$ - overlapping of laser path on the other side; 1 - weld $1 ; 2-$ weld root; 3 - weld 2

their mechanical characteristics during testing on static tension and impact bending in the aswelded state were determined.

The schematic reproduction of stages of formation of double-sided butt welds using laser welding is shown in Figure 2.

The appearance of welded plates and technological modes of laser welding on the both sides are given in Figures 3, 4 and in Table 3.
The double-sided butt welds on the both plates are characterized by a good formation, any surface defects in weld or HAZ metal were not detected.

Metallographic macro- and microexaminations (Figures 5 and 6) showed that the quality laser-welded butt joints without cracks, pores and other defects were produced according to both technological variants.

In specimen $1(\mathrm{He}+\mathrm{Ar}+\mathrm{Ar})$ the width of weld 1 amounts to $6.5 \mathrm{~mm}$, of weld 2 is $6.6 \mathrm{~mm}$, of weld root is $2.4 \mathrm{~mm}$ (see Figure 2), and width of HAZ is $0.3-0.5 \mathrm{~mm}$. In the whole volume of double-sided butt weld of specimen 1 the microstructure is composed of acicular martensite $\alpha$ phase. In weld 1 the needles are of different length $(10-15 \mu \mathrm{m})$. The size of grains at this area amounts to $250-450 \mu \mathrm{m}$, and the grains of $100-$ $150 \mu \mathrm{m}$ size can be found. The plate precipitates of $\alpha$-phase are observed, mainly along the boundaries of grains. In the weld root the size of grains amounts to $50-100 \mu \mathrm{m}$, they have innergranular acicular structure with the size of needles of $10 \mu \mathrm{m}$. Weld 2 has also acicular martensite structure. The size of grains is somewhat smaller - from 150 to $250 \mu \mathrm{m}$. In the HAZ metal the transition from finer grains in weld metal to
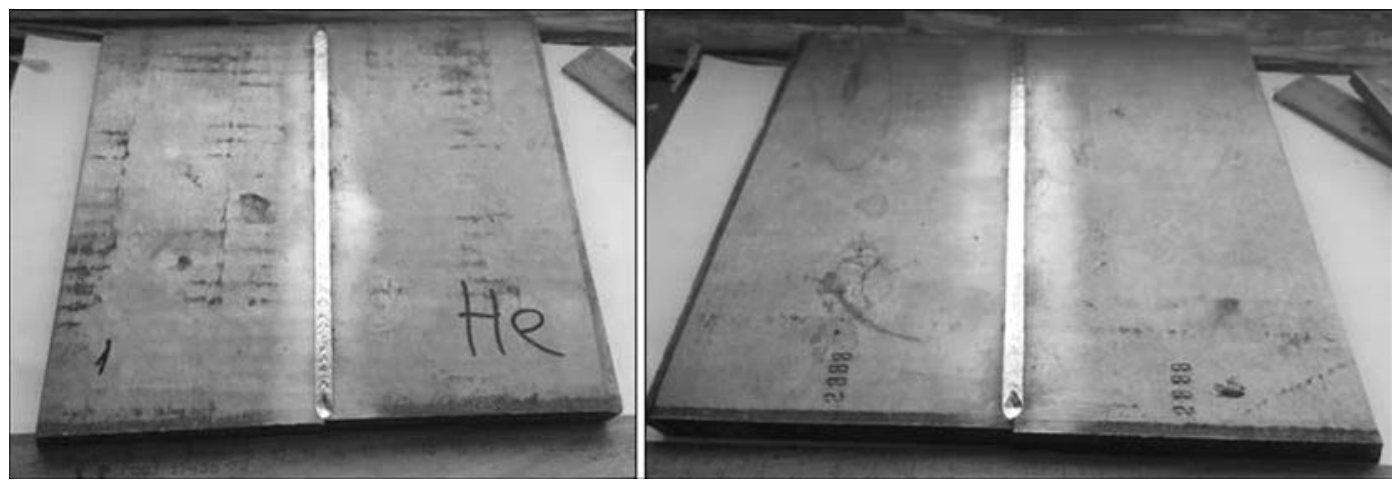

Figure 3. Appearance of plates of commercial titanium VT1-0 ASR $12 \mathrm{~mm}$ thick, hardened by nitrogen (0.098 wt.\%), welded in $\mathrm{He}+\mathrm{Ar}+\mathrm{Ar}$ atmosphere on both sides
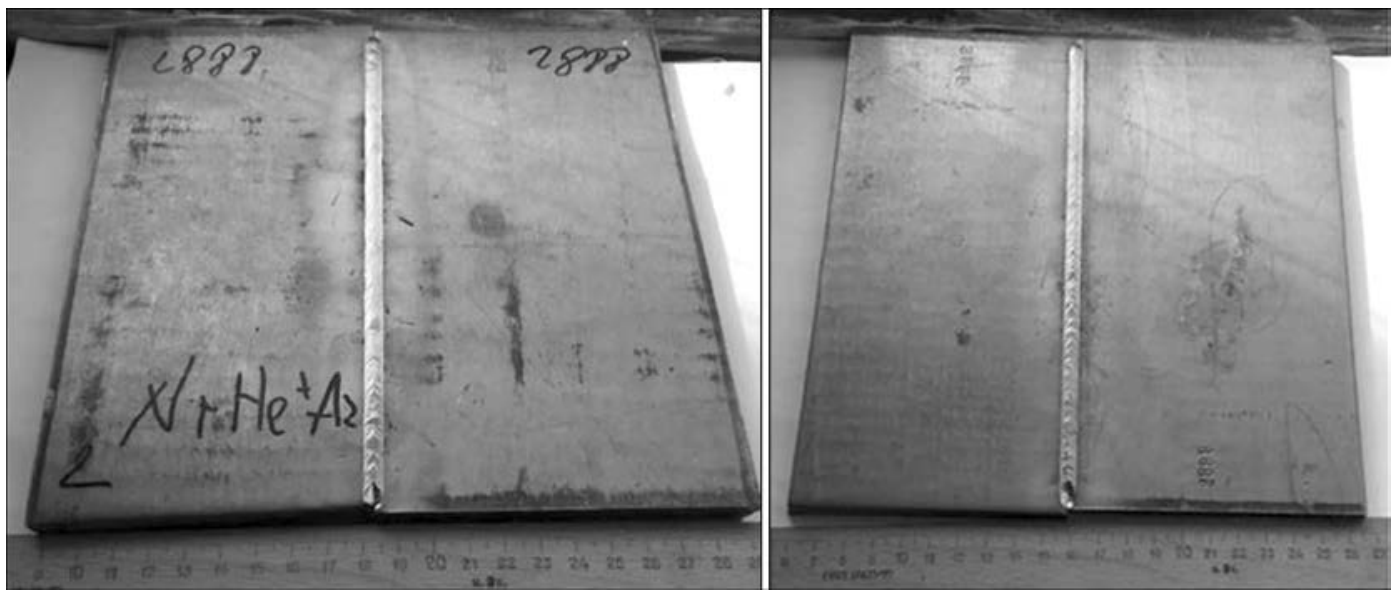

Figure 4. Appearance of plates of commercial titanium VT1-0 ASR $12 \mathrm{~mm}$ thick, hardened by nitrogen (0.098 wt.\%), welded in $\mathrm{He}+\mathrm{N}_{2}+\mathrm{Ar}$ atmosphere on both sides 


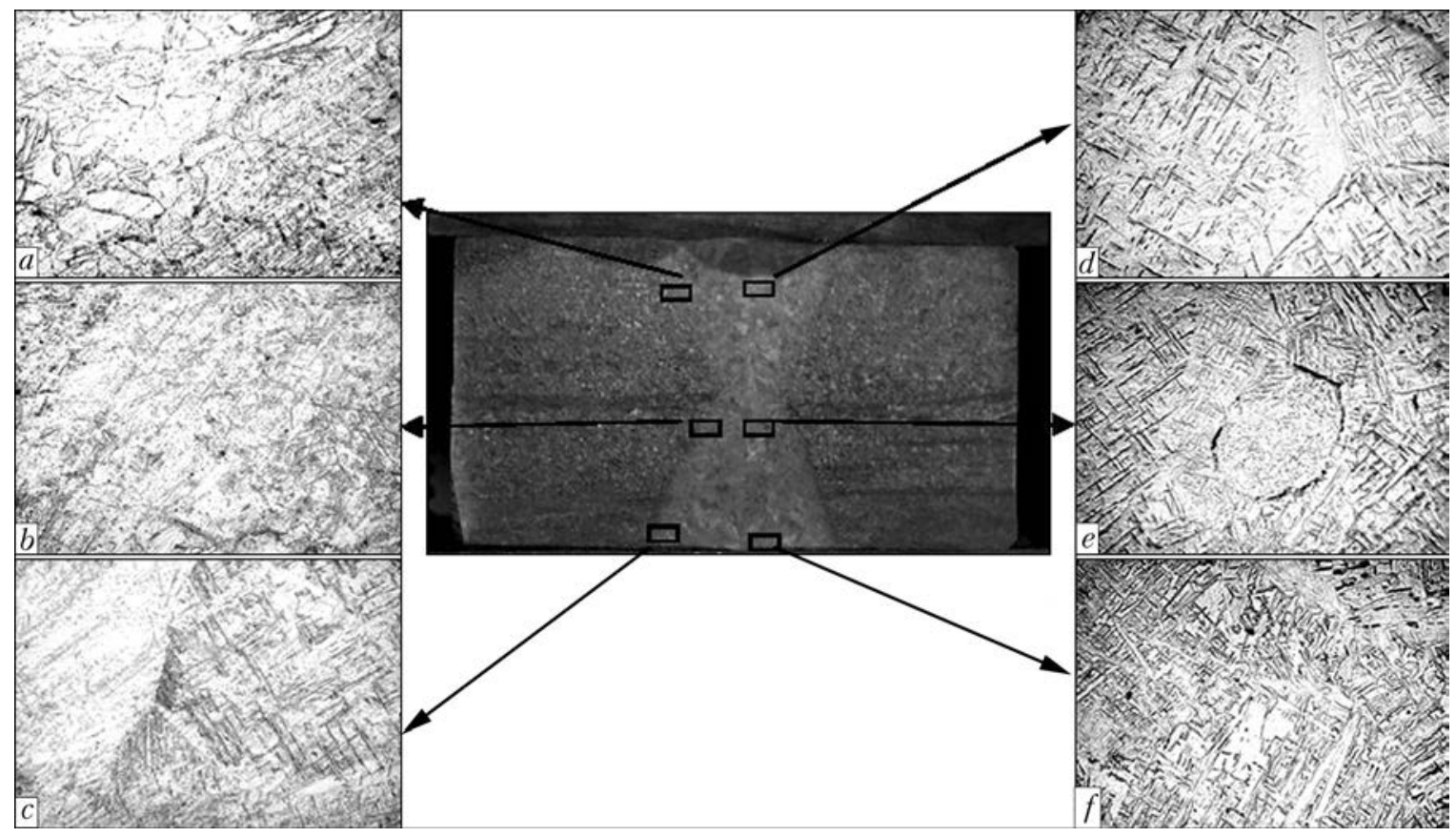

Figure 5. Macro- $(\times 2.5)$ and microstructure $(\times 500)$ of double-sided butt welded joint (specimen 1$)$ of commercial titanium VT1-0 ASR $12 \mathrm{~mm}$ thick, hardened by nitrogen (0.098 wt.\%), produced in $\mathrm{He}+\mathrm{Ar}+\mathrm{Ar}$ atmosphere: $a-\mathrm{HAZ}$ of weld $1 ; b$ - of weld root; $c$ - of weld $2 ; d$ - weld $1 ; e$ - weld root; $f$ - weld 2

coarser grains in $\mathrm{BM}$ is observed. In the HAZ no defects are observed (Figure 5).

In specimen $2\left(\mathrm{He}+\mathrm{N}_{2}+\mathrm{Ar}\right)$ the weld 1 width amounts to $6.8 \mathrm{~mm}$, weld $2-7.3 \mathrm{~mm}$, weld root $-2.6 \mathrm{~mm}$, and HAZ width amounts to $0.4-0.6 \mathrm{~mm}$. Throughout the whole volume of double-sided butt joint of specimen 2 the microstructure is composed of acicular martensite $\alpha$ phase. In weld 1 the needles are of different (5$15 \mu \mathrm{m})$ length. The size of grains at this area is from 150 to $250 \mu \mathrm{m}$. The plate precipitates of $\alpha$-phase are observed, mainly, along the boundaries of grains. In the overlapping zone the size of grains amounts to $40-100 \mu \mathrm{m}$, they have an innergranular acicular structure with the size of needles of $5-10 \mu \mathrm{m}$. The lower part of weld has also the acicular martensite structure. The size of grains is somewhat smaller - from 100 to $200 \mu \mathrm{m}$. In the HAZ metal the transition from finer grains in the weld metal to coarser grains in the $\mathrm{BM}$ is observed. In the HAZ metal no defects are observed (Figure 6).

Microhardness was measured on transverse microsections applying LECO hardness meter M400 at loading of $50 \mathrm{~g}$ with pitch of $100 \mu \mathrm{m}$ in different zones of welded joints: weld 1, weld

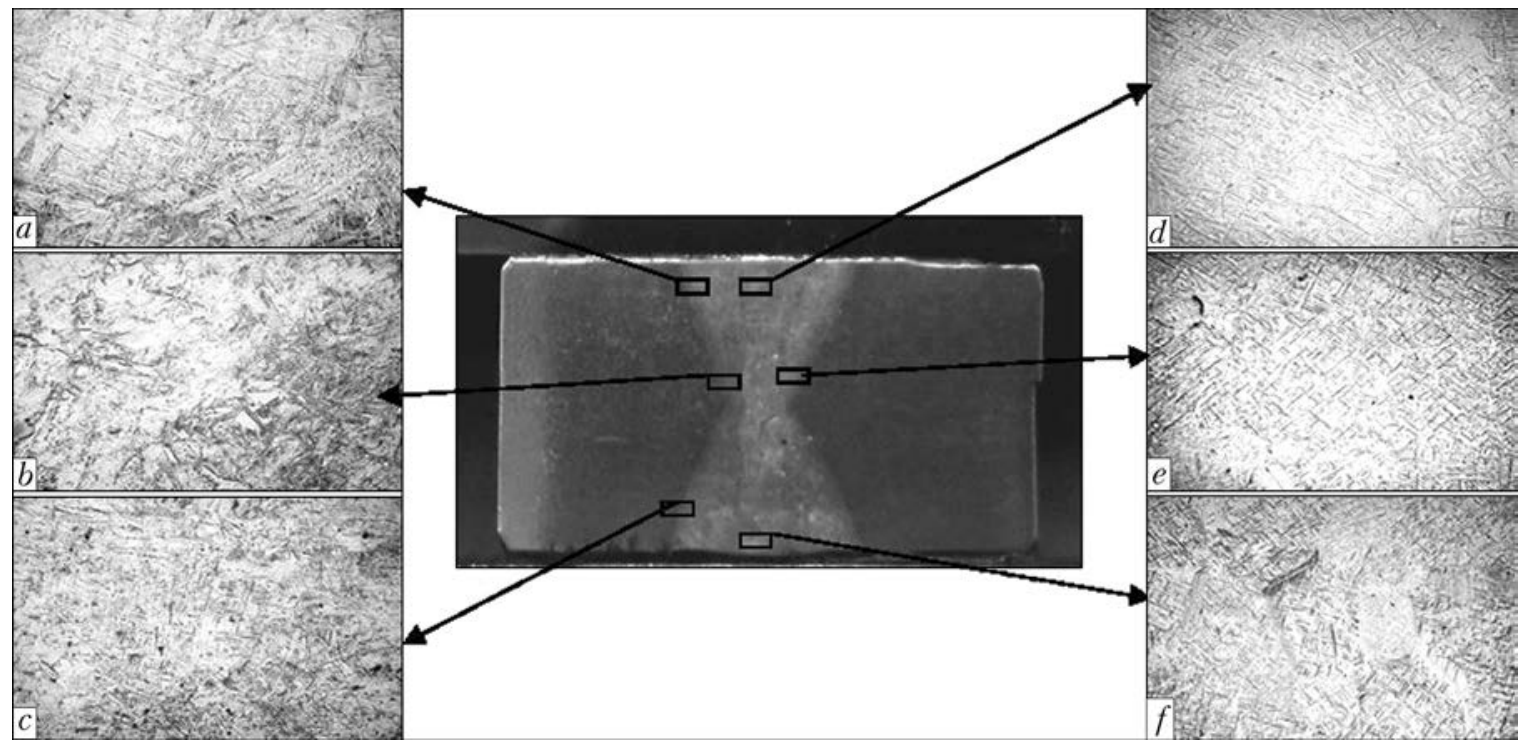

Figure 6. Macro- $(\times 2.5)$ and microstructure $(\times 500)$ of double-sided butt welded joint (specimen 2$)$ of commercial titanium VT1-0 ASR $12 \mathrm{~mm}$ thick, hardened by nitrogen (0.098 wt.\%), produced in $\mathrm{He}+\mathrm{N}_{2}+\operatorname{Ar}$ atmosphere $(a-f$ are the same as in Figure 6) 

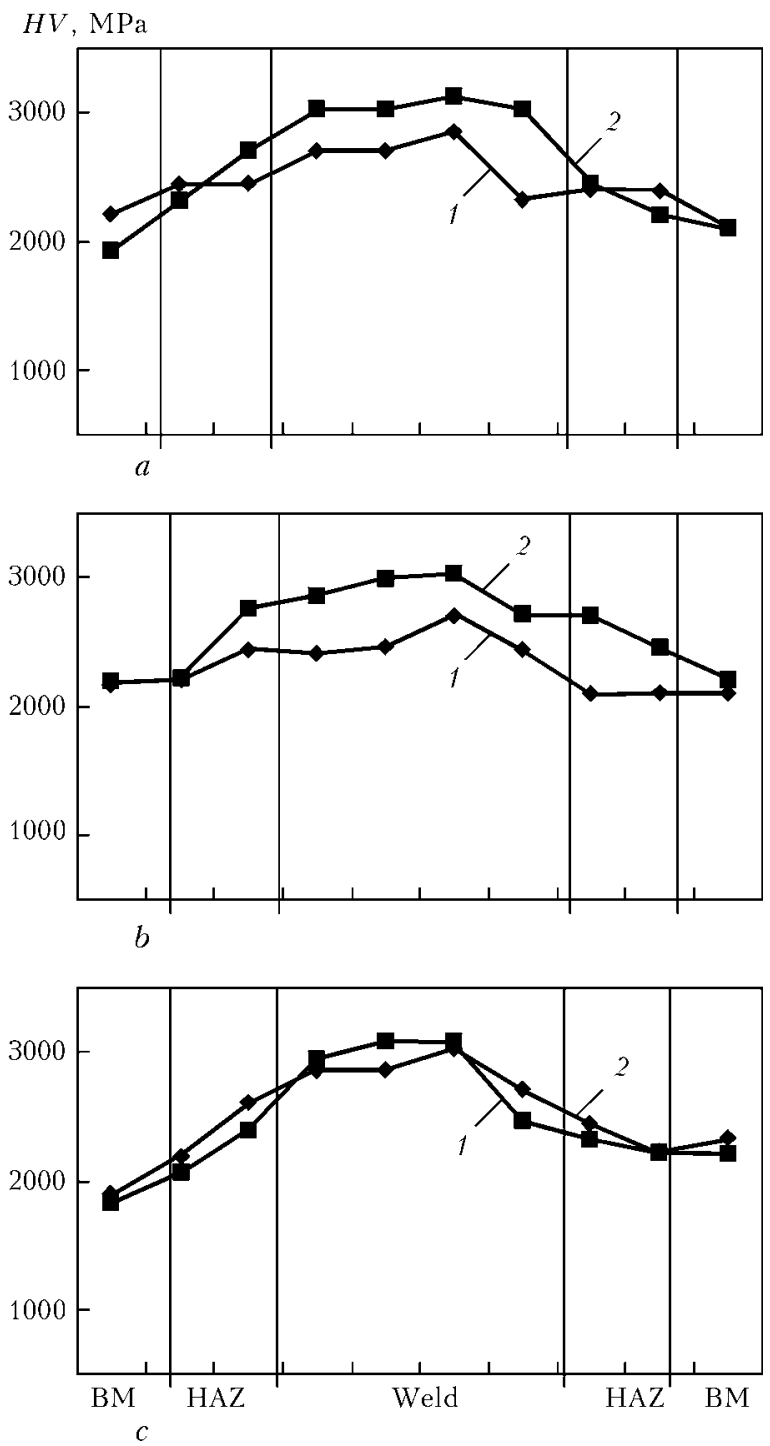

Figure 7. Distribution of microhardness along the height of welded joint, HAZ and BM of specimens of commercial titanium VT1-0 ASR $12 \mathrm{~mm}$ thick, hardened by nitrogen (0.098 wt.\%) in $\mathrm{He}+\mathrm{Ar}+\mathrm{Ar}$ (1) and $\mathrm{He}+\mathrm{N}_{2}+\mathrm{Ar}$ (2) atmosphere: $a$ - weld $1 ; b$ - weld root; $c$ - weld 2 (see Figure 2)

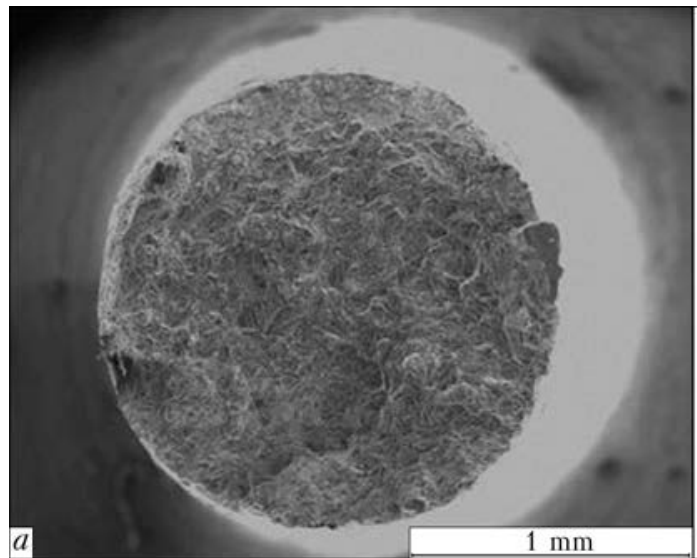

Table 4. Mechanical properties of double-sided butt welded joint of commercial titanium VT1-0 ASR $12 \mathrm{~mm}$ thick, hardened by nitrogen (0.098 wt.\%)

\begin{tabular}{|c|c|c|c|c|c|c||}
\hline \multirow{2}{*}{$\begin{array}{c}\text { Test } \\
\text { specimens }\end{array}$} & \multicolumn{5}{|c|}{ Mechanical properties } & \multirow{2}{*}{$\begin{array}{c}\text { Bending } \\
\text { angle, } \\
\text { deg. }\end{array}$} \\
\cline { 2 - 7 } & $\sigma_{\mathrm{t}}, \mathrm{MPa}$ & $\sigma_{\mathrm{y}}, \mathrm{MPa}$ & $\delta, \%$ & $\psi, \%$ & $\begin{array}{c}K C U, \\
\mathrm{~J} / \mathrm{cm}^{2}\end{array}$ & 45 \\
\hline 1 & 656 & 562 & 12 & 22 & 45 & 45 \\
\hline 2 & 677 & 613 & 15 & 37 & 43 & 63 \\
\hline
\end{tabular}

root and weld 2. The increase of values of microhardness from $\mathrm{BM}(H V$ 1830-2210 $\mathrm{MPa})$ to HAZ metal: in specimen $1(\mathrm{He}+\mathrm{Ar}+\mathrm{Ar})$ the average value is $H V 2372 \mathrm{MPa}$; in specimen 2 ( $\left.\mathrm{He}+\mathrm{N}_{2}+\mathrm{Ar}\right) H V 2373 \mathrm{MPa}$ is observed. In weld metal of specimen 1 the average value is $H V 2673$, in specimen 2 it is $2880 \mathrm{MPa}$. In general, the increase in level of microhardness in the weld metal of specimen 2 is observed as compared to the weld metal of specimen 1 at all the investigated levels as to the height. In HAZ metal the distribution of microhardness in the surface layers of weld in the whole volume of the produced joint in both specimens is almost equal. The mechanical tests of butt joints on static (short time) tension in the as-welded state (without heat treatment) were carried out according to the requirements of GOST 1497-84 and GOST 965184 . The tests were carried out in servohydraulic testing machine MTS 318.25 (USA) allowing the loading with maximum force of $250 \mathrm{kN}$ with error of up to \pm 0.5 . The results were processed using MTS software TestWorks 4. The accuracy of obtained results is $\pm 0.5 \%$, and according to GOST $1497-78$ it is up to $1 \%$.

The tests were carried out on the specimens with the middle notch by one shock of pneumatic pendulum hammer of 2130-KM-03 type with rated potential energy of pendulum of $300 \mathrm{~J}$ at

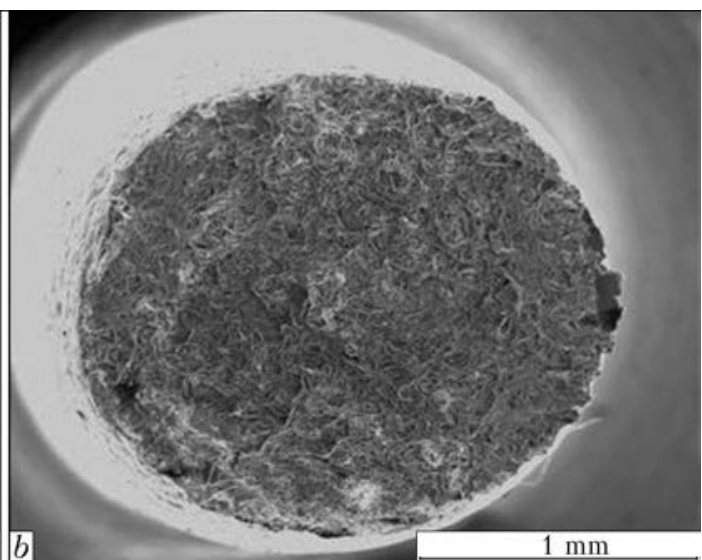

Figure 8. Macrofractograms of fracture surfaces after tests on static tension (here and in Figures 9-11 below: $a-$ specimen of welded joint $1 ; b-$ specimen of welded joint 2 of commercial titanium VT1-0 ASR 12 mm thick, hardened by nitrogen $(0.098$ wt.\%) 

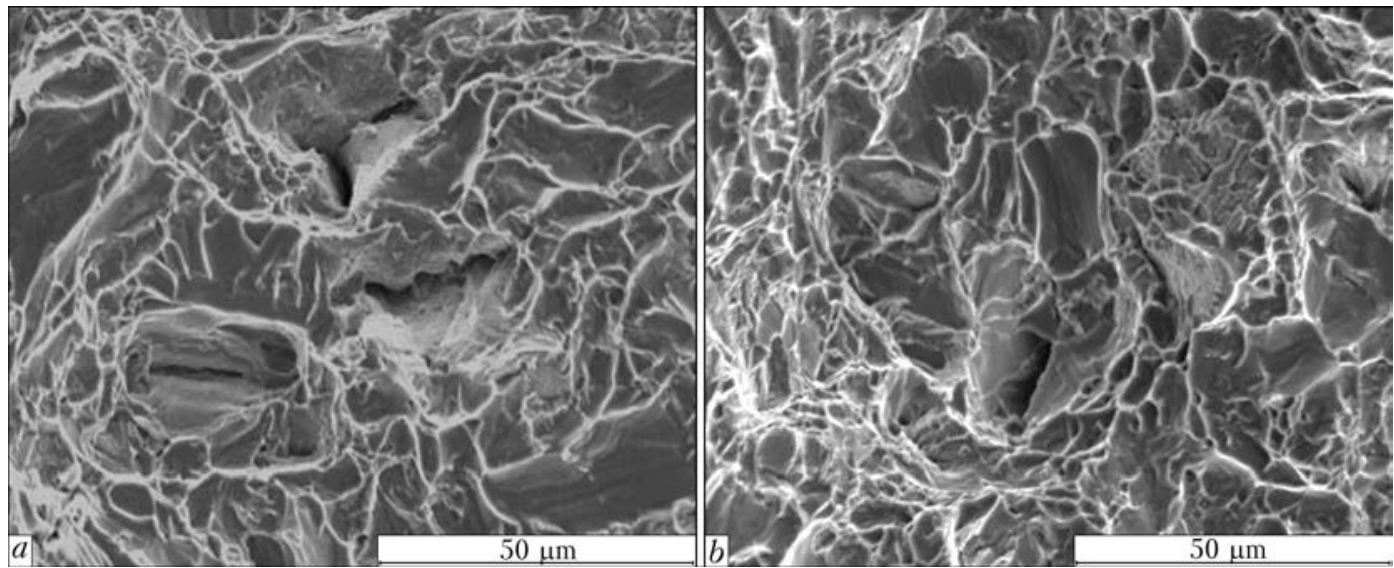

Figure 9. Fractograms of fracture surfaces after tests on static tension

the temperature of $20^{\circ} \mathrm{C}$. The results of mechanical tests are given in Table 4.

The fracture of specimens after tests on static (short time) tension in both cases was occurred along the BM. The notches of specimens for tests on impact bending are made along the weld. The angle of bending for laser weld of variant 1 is $45^{\circ}$, and for the weld of variant 2 is almost 1.5 times larger and equal to $63^{\circ}$ (see Table 4 ).

On macrofractograms of fracture surfaces after tests on static tension in both cases the plane fracture with small traces of shrinkage at the lateral surfaces of specimens is seen (Figure 8).
Fractograms of fracture surfaces after tests on static tension show pitting microrelief with projections. The pits of different sizes from 5-10 to 20-30 $\mu \mathrm{m}$ on the fracture surface of specimen 1 (Figure $9, a$ ), and from $2-5$ to $15-20 \mu \mathrm{m}$ on the fracture surface of specimen 2 (Figure 9, $b$ ) are seen. In both cases the areas of secondary cracking were observed.

Macrofractograms of fracture surfaces after tests on impact bending of specimens are fibrous, on the fracture surface of specimen 1 the projections were observed. The surface of specimen 2 is fibrous and plane (Figure 10).
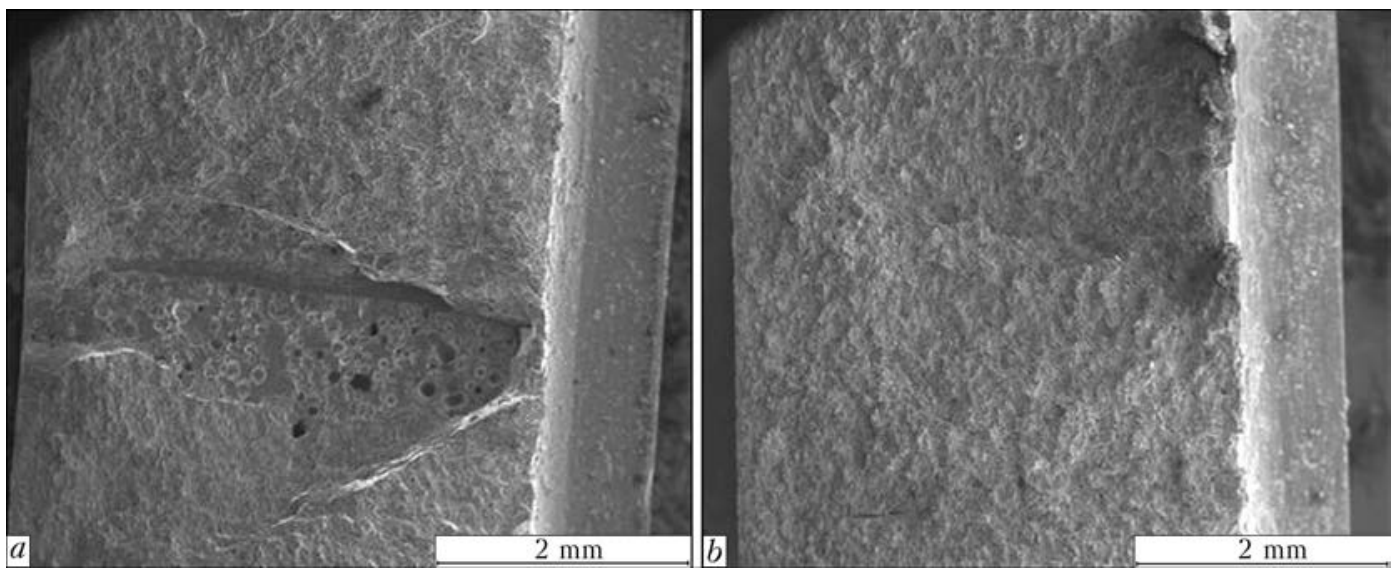

Figure 10. Macrofractograms of fracture surfaces after tests on impact bending
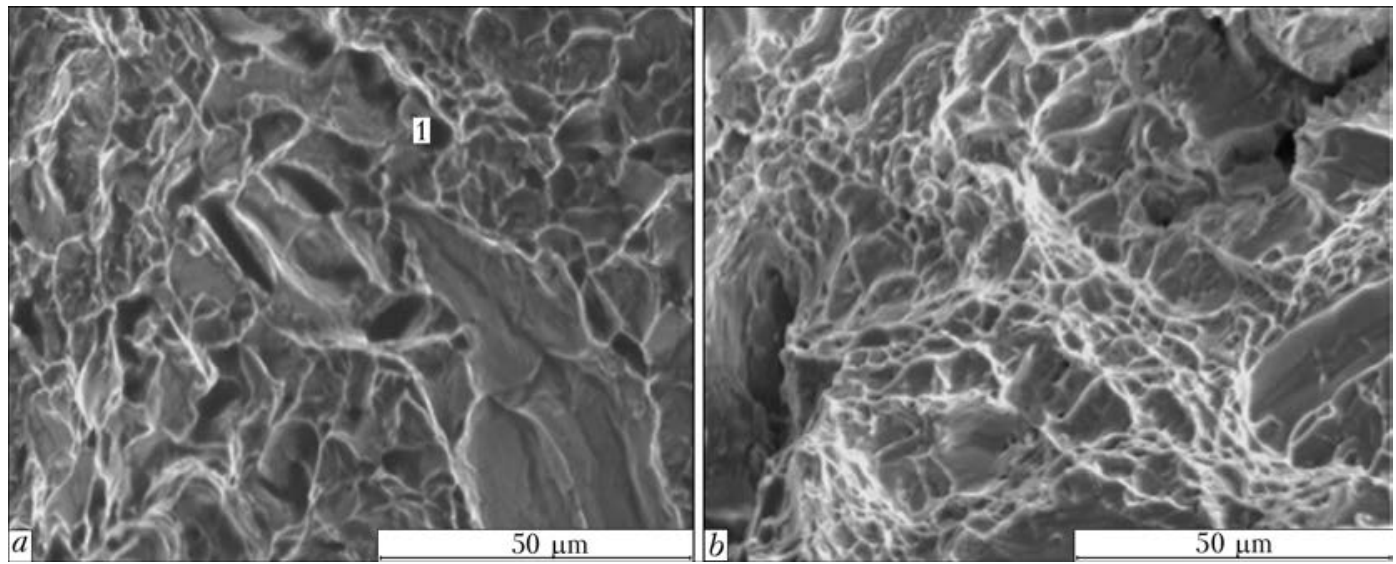

Figure 11. Fractograms of fracture surfaces after tests on impact bending 
During analysis of fractograms of fracture surfaces after tests on impact bending the deep pits with inclusions are observed being the centers of their origination. The mixed mechanism of fracture is observed, i.e. combination of secondary intergranular fracture, and in case 1 (Figure 11, a) there is a small number of pits of the size from $5-10$ to $15-20 \mu \mathrm{m}$ and in case 2 (Figure $11, b$ ) a large number of them of the size from $2-3$ to $5-15 \mu \mathrm{m}$.

In general, fractographic analysis showed the mixed mechanism of fracture: the combination of secondary intergranular fracture and signs of tough pitting character of fracture [9].

\section{Conclusions}

1. The possibility of producing the full-strength butt joint of sheet rolled titanium VT1-0 $12 \mathrm{~mm}$ thick, hardened by nitrogen (0.098 wt.\%) from the gas phase in the ASR process, using laser welding was shown.

2. The results of macro-, microexaminations, measurements of distribution of microhardness $H V$, evaluation of mechanical properties in the tests on static tension and impact bending (values of impact toughness $K C U_{+20}$ are almost at the same level for both cases, and bending angle for butt laser weld $2\left(\mathrm{He}+\mathrm{N}_{2}+\mathrm{Ar}\right)$ is almost 1.5 times larger than that for butt laser weld $1(\mathrm{He}+$ $+\mathrm{Ar}+\mathrm{Ar})$ ) confirm high quality and fullstrength of butt double-sided joint (homogeneity of its structure, absence of cracks, pores and other defects), and evidence of the challenging development of works on application of laser welding of commercial titanium VT1-0 ASR, hardened by nitrogen (up to $0.1 \mathrm{wt} \%$ ).

1. Gurevich, S.M., Zamkov, V.N., Blashchuk, V.E. et al. (1986) Metallurgy and technology of welding of titanium and its alloys. Kiev: Naukova Dumka.

2. Medovar, B.I., Saenko, V.Ya., Kumysh, V.I. et al. (1994) Hardening of titanium by nitrogen alloying from vapor phase during arc slag remelting. Problemy Spets. Elektrometallurgii, 3/4, 12-17.

3. Medovar, B.I., Saenko, V.Ya., Kumysh, V.I. et al. (1995) Properties of thick plates rolled from largetonnage slab ingot of VT1-0 titanium ASR of $4.5 \mathrm{t}$ mass. Ibid., 2, 10-14.

4. Medovar, B.I., Saenko, V.Ja., Grigorenko, G.M. et al. (1996) Arc-slag remelting of steel and alloys. Cambridge: Intern. Sci. Publ.

5. Saenko, V.Ya., Polishko, A.A., Ryabinin, V.A. et al. (2014) Electron beam welding of sheet commercial titanium VT1-0 hardened by nitrogen in the process of arc-slag remelting and properties of produced joints. The Paton Welding J., 11, 46-49.

6. Paton, B.E., Shelyagin, V.D., Akhonin, S.V. et al. (2009) Laser welding of titanium alloys. Ibid., 7, 30-34.

7. Shelyagin, V.D., Akhonin, S.V., Khaskin, V.Yu. et al. (2013) Hybrid welding of titanium alloys with Nd:YAG laser radiation and arc with nonconsumable electrode. In: Proc. of Int. Conf. on Laser Technologies in Welding and Materials Processing, 96-100. Kiev: IAW.

8. Krivtsun, I.V., Shelyagin, V.D., Bushma, A.N. et al. (2013) Ibid , 44-47.

9. Fellouz, J. (1982) Fractography and atlas of fractograms: Refer. Book. Moscow: Metallurgiya.

Received 11.02.2015 


\title{
CONTRIBUTION OF PROFESSOR EVGENY O. PATON TO THE DEVELOPMENT OF WELDING MATERIALS SCIENCE AND PRODUCTION OF HIGH-QUALITY STEEL
}

\author{
A.P. LYUTY \\ Electrometallurgical Works «Dneprospetsstal» \\ 81 Yuzhnoe Shosse, 69008, Zaporozhie, Ukraine. E-mail: info@dss.com.ua
}

\begin{abstract}
The activity of Professor Evgeny O. Paton is analyzed in investigations of metallurgical processes of submerged arc welding, development of welding consumables and improvement of quality of welded joints. The results of these works were used in development of electroslag technologies. 37 Ref.
\end{abstract}

Key words: welding production, metallurgy, special electrometallurgy, Institute of Electric Welding, welding consumables, history of technology

In 1929, Evgeny O. Paton, the famous scientist in the field of bridge construction, academician of the All-Ukranian Academy of Sciences (AUAS, now NASU - the National Academy of Sciences of Ukraine) decided to apply welding in the bridge construction. Over centuries the metal structures were constructed by using riveted or bolted joints. Each of bridges, designed by E.O. Paton, was characterized by unique architecture, optimum costs for materials and construction works. And academician-amateur began to work with a project of the new bridge across the Dnieper river in Kiev. Evgeny Paton decided to create the radically new design of bridge and started the designing and testing of welded subassemblies. During the period of three year a cycle of investigations of service characteristics of welded structures was fulfilled, the comparative tests of a number of full-scale riveted and welded products were made, the recommendations were worked out for designing the welded structures $[1,2]$.

After finding out that the quality of welds is not stable and depends on skill of the worker, welding consumables and condition parameters, he put forward the task to mechanize and automate the arc welding technology. In 1933, the Presidium of the AUAS took a decision about establishment of the Institute of Electric Welding (now the E.O. Paton Electric Welding Institute) approved by the Ukr.SSR government in January 1934 [3-5].

Investigations of factors, influencing the quality of welds, and development of welding consumables were started. By understanding that

(C) A.P. LYUTY, 2015 unlike the other methods of permanent joining the metallurgical processes in welding are proceeding in a molten pool, E.O. Paton started in 1935 to organizer the laboratory of welding technology, headed by V.I. Dyatlov, graduated from the metallurgical faculty of Kiev Politechnic Institute and worked three years at the plant in Zlatoust (RF), where the high-quality armor steels were produced. Investigations in the field of welding materials science started from study of structure peculiarities of low-carbon steel welded joints. At the first stage of development of the welding materials science the main attention was paid to the establishment of interaction between parameters of thermal cycles and weld structure, as well as heat-affected zone [6-8].

At the same time, a welding head for the automatic consumable-electrode arc welding (P.P. Bushtedt) and methods of welding zone protection (V.I. Dyatlov) were developed at the Institute of Electric Welding under supervision of E.O. Paton. The problems of placing mixture on the electrode wire surface were solving for welding zone shielding and current connection to welding heads. In short terms several variants of mixture composition and designs of wires were developed: with grooves, cruciform section with recesses, filled with charge, etc. However, it was not managed to attain the stable good quality [8].

E.O. Paton took a decision to concentrate efforts to investigation of processes of submerged arc welding. Flux for weld pool shielding was earlier developed by N.G. Slavyanov [9], however, the conventional metallurgical fluxes did not guarantee the required quality. His idea was used by associates of the Linde company (USA), who developed the composition of granulated flux for welding of steels and technique of automatic consumable-electrode submerged arc welding $[10,11]$. 
To develop the new domestic type of welding, E.O. Paton organized the group of welding metallurgy, including V.I. Dyatlov, A.M. Lapin, and V.S. Shirin. The main volume of investigations fell at the processes of melting and metallurgical processes proceeding in the weld pool [12].

In 1938-1939, the welding under the flux layer with non-consumable (carbon) electrode of up to $18 \mathrm{~mm}$ thick low-alloy steels was developed at the Institute of Electric Welding. By continuing to attain the achievements in mechanization and automation of arc welding processes, the specialists of the Institute could finalize independently the solution of all the problems remaining on the way of application of welding with consumable electrode under the flux layer [13].

In 1993, the first domestic fused flux (AN-1), electrode wire (10GS type) with increased content of deoxidizers (silicon and manganese), unique designs of welding head and welding transformers were developed. A year later, the highly-manganese flux for welding with lowcarbon wire was suggested. The new method of welding occurred to be 11 times more efficient than the manual welding.

The results of search works were generalized by E.O. Paton in the first in the world monograph on submerged arc welding, published in 1940. In addition to other things it laid the foundations of the new scientific direction - welding materials science [14].

For the first time in the world, E.O. Paton disclosed dependence of microstructure of weld metal and heat-affected zone on welding conditions, systematized the data on peculiar features of microstructure of welded joints. In the third edition of the manuscript on automatic arc welding E.O. Paton outlined: «Weld, produced in submerged arc welding, greatly differed from conventional weld, produced by the open arc. In spite of the columnar structure, the weld metal is characterized by high toughness (elongation up to $25 \%$ and impact toughness up to $150 \mathrm{~J} / \mathrm{cm}^{2}$ ). This result disproved the existing until now theory about the fact that metal brittleness, i.e. low elongation and impact toughness, are caused first of all by the columnar structure. The submerged arc welding proved that the decisive factor, causing the weld metal brittleness, is the contamination with nitrogen and oxygen, penetrating into the molten metal» [15].

All the further development of welding confirmed brilliantly the point of view of E.O. Paton. The effect of these factors was also confirmed in the new process, namely, electroslag casting, developed at the E.O. Paton Electric Welding Institute in the 1960s [16].

The Paton's principle in development of the new technologies was subjected to the severe testing in the years of the World War II. In Nizhny Tagil at the Ural Tank Plant after the name of Comintern (RF) it was managed for the first time in the world to create equipment and technology of automatic welding of tanks and other armored ammunition under the supervision of $\mathrm{Pa}-$ ton E.O. The main problem was the prevention of crack formation in welded joints of armored low-alloy steels.

The causes of weld metal cracking were found (V.I. Dyatlov, T.M. Slutskaya, A.I. Ivanov), fluxes from local raw material were developed (V.I. Dyatlov, T.M. Slutskaya, A.I. Korennoj); the nature of process in the zone of submerged arc welding was studied and the presence of arc discharge here was experimentally proved for the first time in the world (B.E. Paton and A.M. Makara), unique automatic welding heads with constant rate of electrode feeding and control systems, etc. were designed [17, 18]. During the period of 1941-1945 the hardening hypothesis of formation of cold cracks was confirmed in investigations of weld and HAZ metal on the armored steels [18]. During the war years the further development of works of the Institute on study of fundamentals of submerged arc welding (B.E. Paton and A.M. Makara), development of new consumables (fluxes AN-2, ASh, AShMA) and wide implementation of this advanced process in production of defense equipment were progressing [18-21].

One more peak in history of automatic submerged arc welding was the development of devices and technologies for the first time in the world for fulfillment of vertical and horizontal welds. Thus, the task of full-scale application of submerged arc welding was solved in construction of large objects (blast furnaces, gas-holders, thickwalled pipelines) and buildings [19].

In spite of large programs of implementation tasks, work in shops of the restoration enterprises, the research work at the Institute was carried out on 35 subjects. E.O. Paton was the initiator of purposeful fundamental studies. At the end of the 1940s and at the beginning of the 1950s, the theoretical and experimental investigations were carried out, without results of which it was not even possible to develop the new technologies and welding equipment and the results of which became the basis of development of new scientific directions. Specialists of the Electric Welding Institute, N.E. Bauman MVTU, TsNI- 
ITMASh, NIAT and others studied the processes of electrode melting, solidification of weld pool, define the causes of formation of pores, cracks, etc. The metals science of welding, distinguished from the metallurgy of welding into the independent direction, became progressing. In similar directions the investigations were carried out also by specialists of the USA, Great Britain and France. Discussions were organized in journals, recommendations were formulated for improving the weld metal quality, development of welding and surfacing consumables [20-26]. Investigations of primary solidification and microscopic heterogeneity of welds, made in the 1940-50s, had the great importance for improvement of welding consumables and technologies.

In the first post-war years, a number of highsilicon fused fluxes was developed, containing $40-50 \% \mathrm{SiO}_{2}$, and also up to $20 \% \mathrm{MnO}$ (AN-3) or up to 35-40\% MnO (AN-348, AN-348Sh, AN$348 \mathrm{~A}$ ), etc. In welding of carbon steels by lowalloy wire using these fluxes the silicon recovery from flux takes place. At the same time, manganese is recovered from flux into the weld metal.

In the middle of the 1940s at the Electric Welding Institute, it was found (Medovar B.I.) that cracks are initiated in welding of corrosionresistant chrome-nickel steels using electrodes with niobium content of $0.9 \%$ and higher at content of silicon and manganese of more than $1.5 \%$ and carbon of $0.09 \%$. For welding of niobium steel the welding wires of new types, such as EI605 and EI606, EP75, EP87, EI793 and also fluxes AN-26, BKF-5, KhNK-66 were developed [27].

By the beginning of the 1950s, the comprehensive experimental information on the problem of cracking in welds was collected. Studied were physical-chemical properties of molten fluxes and slags at high temperatures (viscosity, electric conductivity, surface properties, thermodynamic activity of oxides). The important process is the interaction of molten slag with solidified weld metal.

As a result of investigations of weldability of the low-alloy steel, carried out under the supervision of E.O. Paton, it was found that the increase in steel tendency to transition into a brittle state in the process of welding thermal cycle depends on chemical composition, method of steel deoxidation in melting and grain size. The lowcarbon steel, killed by silicon and aluminium and rolled at optimum temperature, possesses the lowest threshold of cold brittleness in the heataffected zone [28, 29]. As to the weld metal, then to avoid the cracks it is necessary that the amount of impurities, contributing to crack formation, did not exceed the definite value and were distributed uniformly in the rolled metal section.

The main result of these investigations was the working out of requirements to steels for welded structures. Evgeny O. Paton had a meeting with I.F. Tevosyan, Ministrer of Ferrous Metallurgy, and asked him to assist in making experimental samples of steels according to the technical specifications of the Institute. The request was immediately satisfied and steel, melted in Mariupol (Ukraine), possessed a good weldability at the absence of defects. Metallurgists had to support the point of view of E.O. Paton, such as «in steel production it is necessary to take into account the requirements of welders» (and ten years later the technologies of production of metals and alloys were developed at PWI and implemented by metallurgists in many countries).

In 1948-1949, Voloshkevich G.Z. found during testing of technology of submerged arc welding with forced formation of vertical weld that the electrode wire is melted at arcless discharge in the fused flux, i.e. in slag pool. The new type of welding appeared - electroslag welding (ESW), based on electric conductivity of the molten slag. The problems of providing the stability of electroslag process and also designing of devices for maintaining of metal and slag pools, etc. were solved (B.E. Paton, G.Z. Voloshkevich, V.E. Paton, et al.) [30, 31].

The development of ESW process allowed solving the problems of production of the new class of massive metal structures: cast-welded, forged-welded, and rolled-welded. ESW «opened the way» for technologies, acquiring the general name «electroslag technologies».

In 1952, the first ingot was produced at the PWI and study of ways of application of welding metallurgy, welding physics-chemistry, welding technique in producing of ingots for rolling and forging started. The electroslag remelting (ESR) initiated the beginning of the special electrometallurgy. Due to a number of ESR peculiar features it was necessary to develop special fluxes using the experience of development of fluxes for the ESW of steel [32, 33].

The molten electrically-conductive slag is not only heat source, but also contributes to refining of metal being remelted from harmful impurities (sulphur, non-metallic inclusions), protects the molten metal from the effect of atmosphere.

A laboratory furnace, designed at the PWI in 1956 and put into operation at «Dneprospetsstal» Works in Zaporozhie (Ukraine) in May 1958, was the first in the world industrial electroslag 
furnace. Soon at the same Works the first in the world practice specialized ESR shop was constructed. At the beginning of 1958 the first in the world three-phase furnace for producing 12 $\%$ chromium heat-resistant steel was put into service [34-37] at Novo-Kramatorsk MachineBuilding Works (Ukraine).

1. Paton, E.O., Kozlovsky, N.I. (1931) Comparison of riveted and welded trussed girders: Experiences of studies. Kiev: Elektrosv. Kom.

2. Paton, E.O. (1932) Bridge support parts of welded type. Kiev: VUAN Elektr. Kom.

3. (1930) Reports of AUAS Presidium meetings for 1930. In: Central scientific archive of NASU.

4. (1930) Reports of AUAS Presidium meetings for 1931. Organization of electric welding laboratory (at AUAS). Visnyk VUAN, 6, 14.

5. Paton, E.O. (1930) About organizing of Electric Welding Committee at AUAS. Ibid., 6, 25-28.

6. Dyatlov, V.I., Slutska, T.M. (1938) Producing of thick electrode coatings from synthetic slags. Kyiv: AN Ukr.SSR.

7. Dyatlov, V.I., Frumin, I.I., Slutskaya, T.M. (1941) Electrodes of the Institute of Electric Welding of AS of Ukr.SSR. Ed. by E.O. Paton. Kiev: AN Ukr.SSR.

8. Litvinov, A.P. (2008) V.I. Dyatlov is one of the founders of scientific principles of welding. Visnyk Pryazov. DTU, 18, 158-161.

9. Paton, B.E. (1955) State-of-the-art of automatic submerged arc welding as the result of development of N.G. Slavyanov's ideas. In: Proc. of Sci.-Techn. Conf. of Welders, Dedicated to the 100th Anniversary of N.G. Slavyanov. Kiev: Mashgiz.

10. Paton, E.O. (1951) About priority of Soviet science and technology in the field of submerged arc welding. Kiev: IEW

11. Matijko, M.M. (1960) Development of arc welding in Ukraine. Kyiv: AN Ukr.SSR.

12. Paton, E.O. (1956) Memoirs. Kiev: Khud. Literatura.

13. Chekanov, A.A. (1963) History of automatic electric welding. Moscow: AN USSR.

14. Paton, E.O. (1940) Welding with bare electrode under flux layer. Kharkov: Dom Tekhniki.

15. Paton, E.O. (1942) High-speed automatic submerged arc welding. Moscow; Sverdlovsk: Mashgiz.

16. Kasatkin, B.S. (1981) Metals science of fusion welding. In: Welding in USSR. Vol. 2, 88-107. Moscow: Nauka.

17. Paton, B.E., Makara, A.M. (1944) Experimental study of automatic submerged arc welding process. Kiev: IEW.
18. Paton, B.E. (1945) Development of automatic submerged arc welding during the war years. Elektrichestvo, 3, 3-5.

19. (1948) Collection dedicated to the 75th anniversary and the 50th scientific activity of E.O. Paton. Kiev: AN Ukr.SSR.

20. (1953) Automatic electric arc welding. Ed. by E.O. Paton. Kiev; Moscow: Mashgiz.

21. Paton, E.O. (1950) Development of automatic submerged arc welding during 10 years (1940-1950). Avtogennoe Delo, 2, 1-3.

22. Makara, A.M., Medovar, B.I. (1948) On the nature of primary solidification of weld pool. Ibid., 12, 25-27.

23. Lyubavsky, K.V. (1948) To the problem of interaction of elements and their oxides in weld pool. Ibid., 10, 30-31.

24. Frumin, I.I., Kirdo, I.V., Podgaetsky, V.V. (1949) Formation of pores in welds and effect of flux content on pore susceptibility. Ibid., 10, 1-11.

25. Movchan, B.A. (1953) On some peculiarities of primary solidification of alloyed metal. Avtomatich. Svarka, 3, 3-15

26. Kasatkin, B.S., Rossoshinsky, A.A. (1956) On the effect of alloying elements on development of chemical heterogeneity of welds. Ibid., 6, 104-108.

27. Medovar, B.I. (1966) Welding of heat-resistant austenitic steels and alloys. Moscow: Mashinostroenie.

28. Paton, E.O., Shevernitsky, V.V. (1948) To the problem of welded railway bridges. In: Transact. on automatic submerged arc welding, 1, 7-14.

29. Paton, E.O., Shevernitsky, V.V. (1949) Steel for welded bridges. Ibid., 6, 3-7.

30. (1956) Electroslag welding. Ed. by B.E. Paton. Kiev; Moscow: Mashgiz.

31. (1959) Electroslag welding. Ed. by B.E. Paton. 2nd ed. Kiev; Moscow: Mashgiz.

32. Podgaetsky, V.V. (1984) Fluxes for welding and special electrometallurgy. In: Welding and special electrometallurgy, 188-200. Kiev: Naukova Dumka.

33. Paton, B.E., Medovar, B.I. (1978) Future of electroslag technology. In: Problems of electroslag technologies, 7-26. Kiev: Naukova Dumka.

34. Paton, B.E., Medovar, B.I., Paton, V.E. (1956) New method of electric casting of ingots. Bull. of Tekhn. Inform. of NTO Mashprom, Issue 1, 3-9.

35. Paton, B.E., Medovar, B.I., Latash, Yu.V. (1958) Electroslag remelting of steels and alloys in copper water-cooled mould. Avtomatich. Svarka, 11, 5-15.

36. Lejbenzon, S.A., Tregubenko, A.F. (1963) Steelmaking by electroslag remelting method. Moscow: Metallurgiya.

37. Medovar, B.I., Latash, Yu.V., Maksimovich, B.I. et al. (1965) Electroslag remelting. Moscow: Metallurgizdat. 


\title{
MANUFACTURE OF LONG-LENGTH SEMI-PRODUCTS FROM SINTERED TITANIUM ALLOYS USING FRICTION WELDING
}

\author{
A.E. KAPUSTYAN \\ Zaporozhie National Technical University MESU \\ 64 Zhukovsky Str., 69063, Zaporozhie, Ukraine. E-mail:glotka87@ukr.net
}

\begin{abstract}
Aim of the present stady lies in determination of possibility of application of conventional friction welding for production of quality joints from sintered titanium alloy in manufacture of long-length semi-products. Commercial titanium powder of PT5 grade of Ukrainian manufacture was used as initial material. Billets for rod production were received by powder metallurgy methods and their chemical composition corresponded to commercial purity of VT1-0 grade titanium. Shaping of billets of $12 \mathrm{~mm}$ diameter and $100 \mathrm{~mm}$ length was carried out by pressing. Long-length semi-products were manufactured using friction welding on MF-362 machine. Welding was performed without additional shielding. Weldability of the specimens was evaluated visually, by means of metallographic investigations and mechanical tests. Analysis of macrostructure of welded joints allowed determining absence of defects of metallurgical nature in the weld and thermal-mechanical-affected zone (TMAZ). Average size of pores in TMAZ and weld was smaller then in the base metal, effect of partial and complete «healing» of pores also took place. Micro-X-ray-spectral quality analysis of weld structure showed uniform distribution of main impurity elements. Mechanical tests of examined welded specimens allowed determining that their strength and ductile characteristics are comparable with that of VT1-0 cast titanium. Possibility of realizing the production of semi-products from sintered titanium alloys in production scales was shown. 5 Ref., 2 Tables, 6 Figures.
\end{abstract}

Key words: titanium, powder metallurgy, pressing, sintering, friction welding, semi-product, rod, strength, structure

Necessity of weldability investigation of sintered titanium billets, produced by friction welding [1], was shown earlier.

Aim of the present stady lies in determination of technical possibility of application of conventional friction welding for formation of quality joints from sintered titanium alloy in manufacture of long-length semi-products (rods).

Commercial titanium powder of PT5 grade (TU 14-10-026-98), produced by SEs «State Scientific-Research and Design Institute of Titanium» and «Zaporozhie Metallurgical Pilot-Production Plant», was used as initial material. Billets for rod production were received by powder metallurgy method. Chemical composition of the billets corresponded to commercial purity of VT1-0 grade titanium (GOST 19807-91). Shaping of billets of $12 \mathrm{~mm}$ diameter and $100 \mathrm{~mm}$ length (Figure 1, $a$ ) was carried out by pressing on hydraulic press with $700 \mathrm{MPa}$ force. Sintering was carried out in vacuum chamber SNVE1.3.1/16IZ at $1250 \pm 20{ }^{\circ} \mathrm{C}$ temperature during 3 hours with $13.3 \mathrm{MPa}$ pressure, cooling took place together with furnace. Long-length semiproducts were manufactured using friction welding on MF-362 machine.

Welding was carried out without additional shielding, since it makes no effect on weld metal

(C) A.E. KAPUSTYAN, 2015 structure [2]. Rod semi-products of $12 \mathrm{~mm}$ diameter and 185-190 mm length (Figure 1, b) were produced as a result of welding. Oxidation of metal to $0.5 \mathrm{~mm}$ depth [2] takes place during welding in air, therefore, according to recommendations of work [3], treatment was carried out at turning machine for removal of surface layer being saturated with gas in order to stabilize mechanical properties.

Weldability of specimens was examined visually (by presence and shape of extruded flash), by means of metallographic examinations and mechanical tests. Microstructural investigations were carried out on sections, made in transverse and longitudinal directions of welded billets, using inverted-stage reflection microscope Observer.D1m and electron microscope JSM6360LA, equipped with attachment for perform-

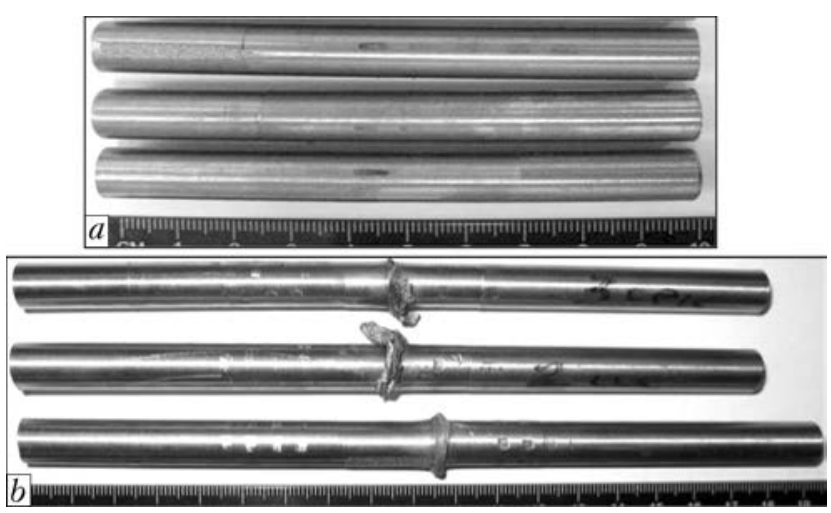

Figure 1. Billets produced based on powder metallurgy method: $a$ - pressed; $b$ - welded (rods) 


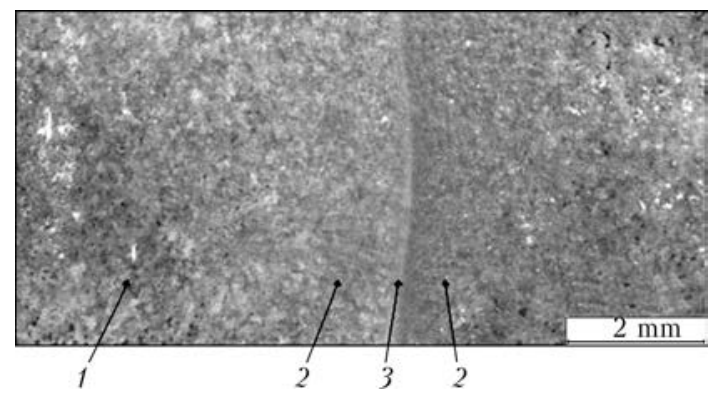

Figure 2. Macrostructure of friction welded joint from sintered titanium VT1-0: 1 - base metal; 2 - near-weld zone 3 - weld

ance of energy-dispersive X-ray microanalysis (XMA). Mechanical tests were carried out on IP-110 machine in accordance with the requirements of GOST 1497-84 using cylinder specimens with $5 \mathrm{~mm}$ diameter test portion.

Visual examination of welded billets showed that extrusion of flash took place all over joint circumference, that indirectly indicates satisfactory weld formation. Each of the billets being joined due to upsetting underwent the similar $5.0-7.5 \mathrm{~mm}$ reduction depending on modes of welding.

Structure was examined on etched sections, manufactured in longitudinal section of welded specimens. Analysis of macrostructure of the welded joints allowed determining presence of thin light weld band of up to $0.3 \mathrm{~mm}$ width along the place of joining of powder billets. A zone, having no clear pores, observed in the base metal of the specimens (Figure 2), is formed in both billets at $2.0-2.5 \mathrm{~mm}$ distance from the weld. No metallurgical defects were found in the weld and thermal-mechanical-affected zone (TMAZ).

Microstructure of pressed billets (base metal of welded specimen) was characterized by presence of disoriented $\alpha$-phase plates, body and boundaries of which included round and sharpcornered pores of up to $70 \mu \mathrm{m}$ size, around $35 \mu \mathrm{m}$ on average (Figure 3, $a$ ).

Examination of welded joint determined ( $\mathrm{Fi}$ gure $3, b$ ) that pores and structural constituents with clearly observed interfaces are virtually absent in weld metal. Microstructure of weld represented itself fragments of $\alpha$-phase grains of up to $5 \mu \mathrm{m}$ size, which were formed as a result of intensive deformation of metal under effect of pressure and friction, at that diameter of found pores does not exceed $3 \mu \mathrm{m}$, that indicated reduction of pores and their possible «healing» under effect of shearing deformation (Figure $3, b$ ).

It should be noted that structure of TMAZ of welded billets had some differences. TMAZ represented itself fine plate-like structure and consisted of radial-oriented $\alpha$-plates of up to $3 \mu \mathrm{m}$ width and up to $150 \mu \mathrm{m}$ length, on interface of which elongated pores of around $15 \mu \mathrm{m}$ were located.
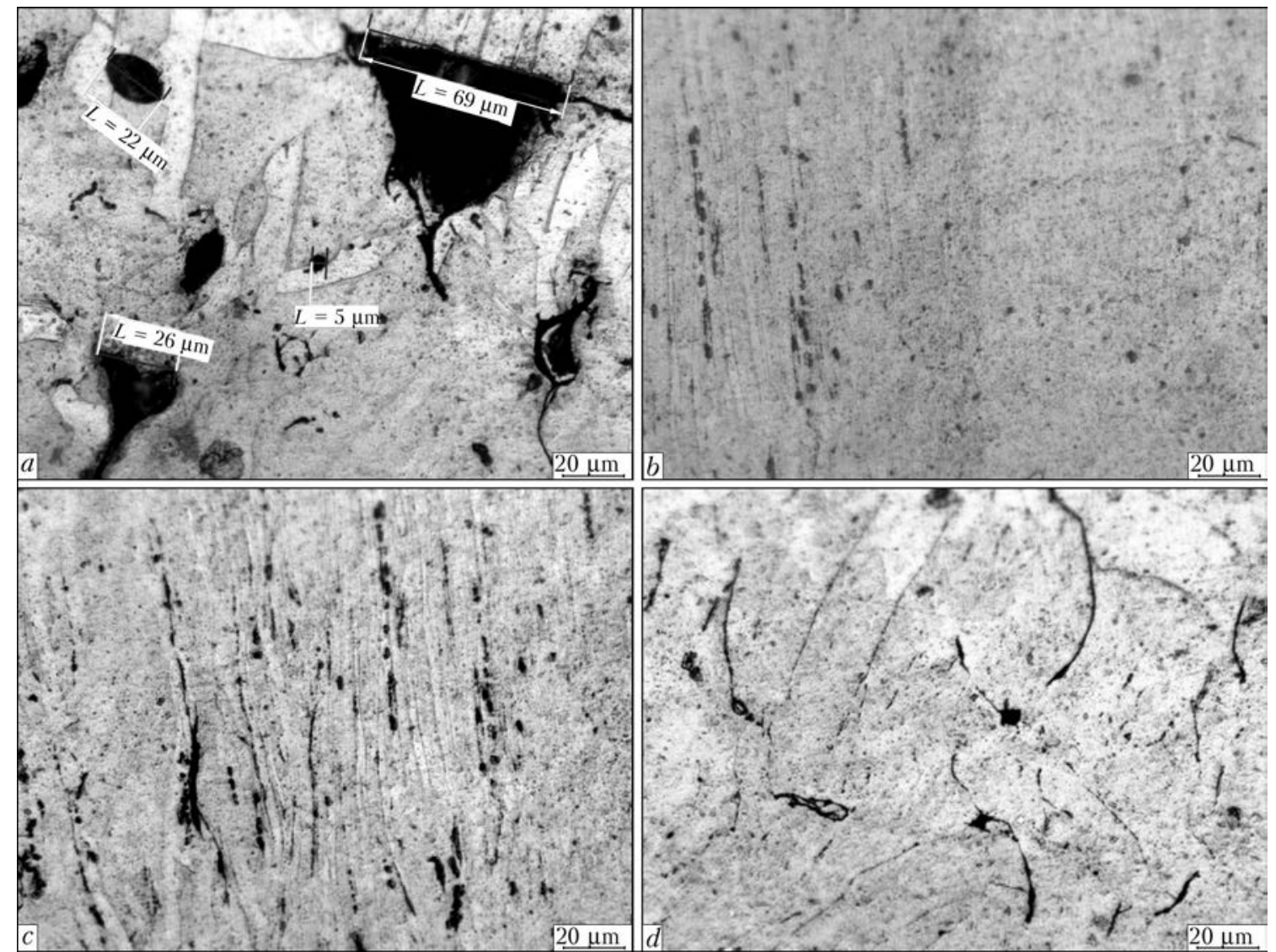

Figure 3. Microstructure of billet from sintered titanium VT1-0 produced by friction welding: $a-$ base metal; $b-$ weld; $c$ - TMAZ located close to weld; $d$ - TMAZ located close to base metal 
Table 1. Amount of some impurities in investigated materials, wt.\%

\begin{tabular}{||l|c|c|c||}
\hline \multicolumn{1}{|c|}{ Material } & $\mathrm{N}$ & $\mathrm{O}$ & $\mathrm{Fe}$ \\
\hline PT5 TU (14-10-026-98) & 0.03 & - & 0.08 \\
\hline $\begin{array}{l}\text { Alloy VT1-0 } \\
\text { (GOST 19807-91) }\end{array}$ & 0.04 & 0.20 & 0.25 \\
\hline
\end{tabular}

Formation of radial orientation and «healing» of pores were promoted by effect of axial force due to upsetting and temperature (Figure 3,c). The same effect is observed in the case of treatment of rods and cast parts from titanium alloys using intensive plastic deformation methods or in gasostat [4].

At the same time, TMAZ located near billet base metal consisted of $\alpha$-phase plates of deformed shape of around $10 \times 50 \mu \mathrm{m}$ size, the pores in this zone had crescent-like shape (Figure 3, d) and were located arbitrarily. Besides single round pores of 4-5 $\mu \mathrm{m}$ diameter were present in its structure.

Thus, the metallographic examination allowed determining that average size of pores in TMAZ metal was smaller than in the base metal as well as partial and complete «healing» of pores took place. Pores were virtually absent in the weld and residual pores were of order smaller then in the base metal.

Micro-X-ray-spectral quality analysis of weld and zones from both sides of the weld showed uniform distribution of main impurity elements (Figure 4). Micro-X-ray-spectral quantity analysis of weld and zones from both sides of the weld (Figure 5) showed that number of main impurity elements does not exceed GOST requirements for VT1-0 alloy (Table 1).

Therefore, non-shielded friction welding of sintered titanium does not result in saturation of weld and TMAZ metal with ambient atmosphere gases.

Mechanical tests of examined welded specimens allowed determining that level of their strength characteristics is comparable with that of cast titanium VT1-0 (Table 2), and lower ductility is promoted by the fact that failure of the specimens takes place in most of the cases out of weld zone, i.e. along the base metal, where larger amount of pores, reducing metal deformation capacity, is observed (Figure 6).

In the whole, values of mechanical properties of weld of sintered VT1-0 titanium billets was at the level of cast titanium properties, and tensile strength of the weld exceeded that of sintered titanium alloy, due to formation of dispersed microstructure with single pores in the weld.

Based on performed investigations, billets of series sizes (40 $\mathrm{mm}$ diameter and $700 \mathrm{~mm}$ length) were produced.

Thus, the possibility is shown for realizing the manufacture of semi-products from sintered titanium alloys in production volumes. This
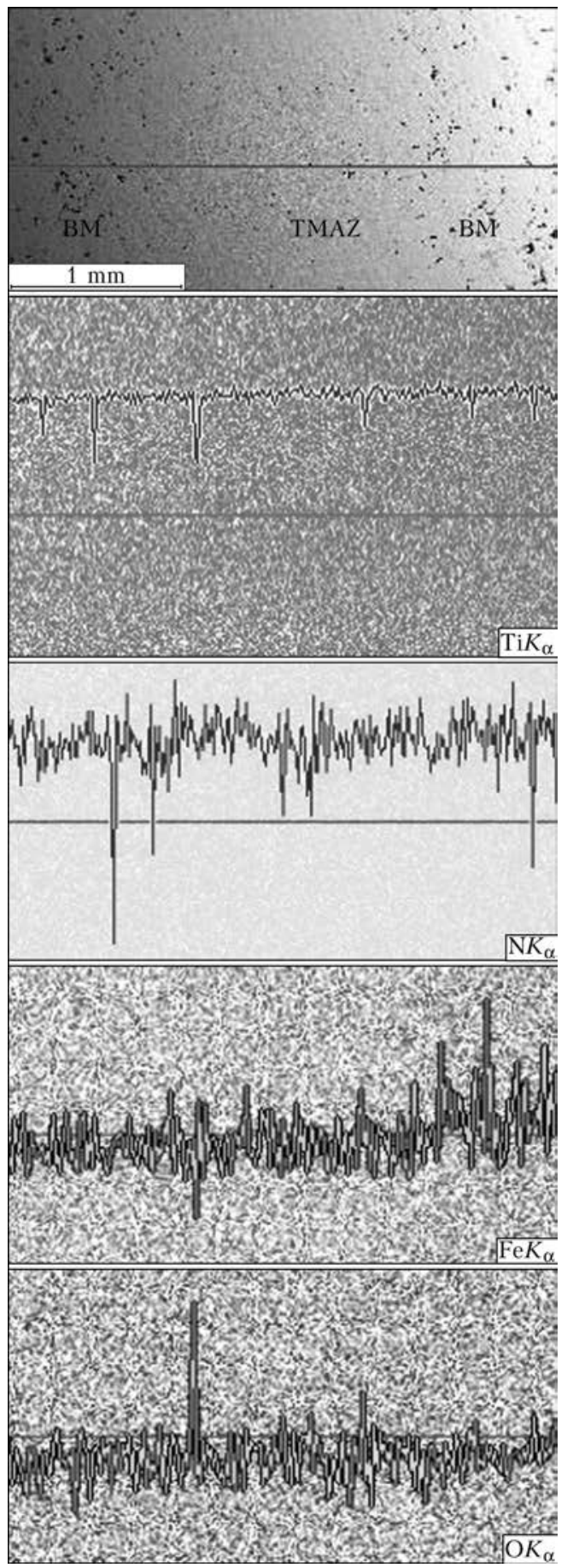

Figure 4. Macrostructure of welded joint from sintered alloy VT1-0 $(a)$, and distribution of elements (Ti, N, Fe, O)

makes a ground for wider application of sintered titanium alloys in form of welded long-length semi-products, providing implementation of titanium in new, large-scale areas of engineering.

Table 2. Mechanical properties of welded billet from VT1-0 titanium alloy produced based on methods of powder metallurgy

\begin{tabular}{||l|c|c|c||}
\hline \multirow{2}{*}{\multicolumn{1}{|c|}{ Material condition }} & \multicolumn{3}{|c||}{ Mechanical properties } \\
\cline { 2 - 4 } & $\sigma_{\mathrm{t}}, \mathrm{MPa}$ & $\delta, \%$ & $\psi, \%$ \\
\hline $\begin{array}{l}\text { Sintered VT1-0 welded billet } \\
\text { (failure out of the weld) }\end{array}$ & $322-338$ & $7-9$ & $14-18$ \\
\hline Cast VT1-0 [5] & $340-390$ & $7-17$ & $33-40$ \\
\hline
\end{tabular}




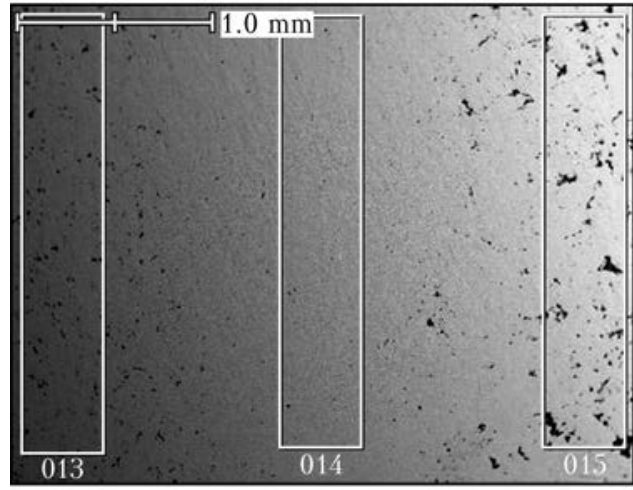

014

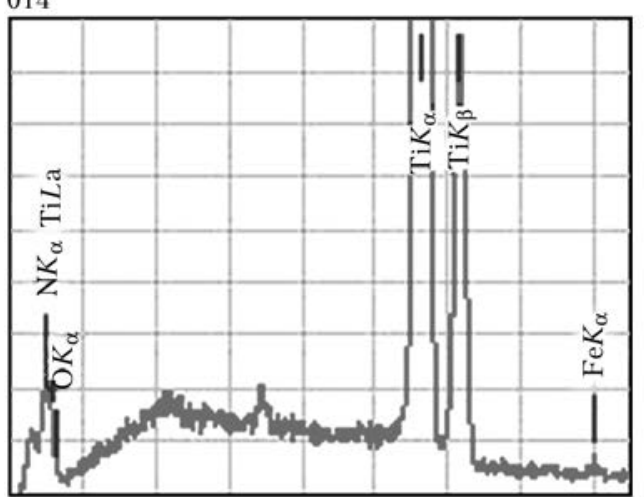

013

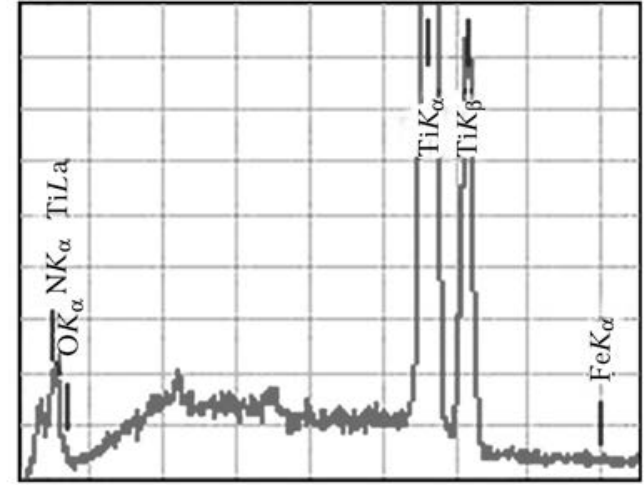

015

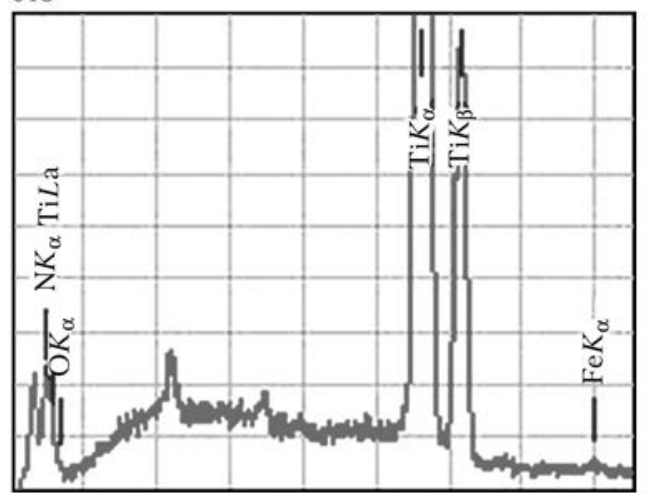

\begin{tabular}{|c|c|c|c|c|}
\hline Number of point & $\mathrm{Ti}$ & $\mathrm{N}$ & $\mathrm{O}$ & $\mathrm{Fe}$ \\
\hline 013 (base metal) & Base & 0.030 & 0.15 & 0.20 \\
\hline 014 (TMAZ) & Same & 0.013 & 0.18 & 0.25 \\
\hline 015 (base metal) & $\Rightarrow$ & 0.035 & 0.15 & 0.28 \\
\hline
\end{tabular}

Figure 5. Quantity distribution of elements in the VT1-0 titanium specimens

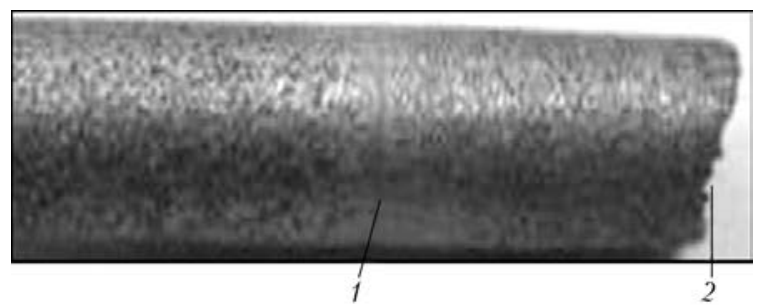

Figure 6. View of specimen after tension testing: 1 - weld; 2 - failure zone

\section{Conclusions}

1. Conventional friction welding of billets from VT1-0 sintered alloy was realized.

2. Technical possibility of application of conventional friction welding is shown for production of quality joints from sintered alloy in manufacture of long-length semi-products.

3 . The results of metallographic examination determined that width of weld made $0.08-0.25 \mathrm{~mm}$ and TMAZ width was $2-2.5 \mathrm{~mm}$. Pores were virtually absent in the weld, diameter of residual pores did not exceed $3 \mu \mathrm{m}$, that in TMAZ was up to 5 $\mu \mathrm{m}$, width of partially closed pores made not more than $3 \mu \mathrm{m}$, whereas maximum diameter of pores in the base metal lied in $70 \mu \mathrm{m}$ limit.

4. Dependencies of distribution of elements (nitrogen, oxygen, iron) in the weld were determined, and the fact is shown that welding with- out additional shielding does not promote auxiliary gas saturation.

5. Effect of structure on mechanical properties of welded joints from porous materials was determined. Relevance of application of conventional friction welding in production of fullstrength joint was grounded. Level of mechanical properties of welded joint from sintered titanium alloys was at the level of cast titanium VT1-0 and made $\sigma_{\mathrm{t}}=322-338 \mathrm{MPa}, \delta=7-9 \%$, and $\psi=14-18 \%$.

6 . The billets can be successfully remelted.

1. Ovchinnikov, A.V. (2014) On possibility to produce the rods from sintered titanium alloys using the welding methods. Avtomatich. Svarka, 1, 50-53.

2. Seliverstov, A.G., Tkachenko, Yu.M., Kulikovsky, R.A. et al. (2013) Effect of friction welding parameters on structure and mechanical properties of joints on titanium alloy VT3-1. The Paton Welding J., 1, 28-33.

3. Bolshakov, M.V., Chernitsyn, A.I. (1974) Structure and properties of titanium alloy OT4 and its friction welded joints. Svarochn. Proizvodstvo, 40-42.

4. Ovchinnikov, A.V. (2012) Application of titanium alloys with submicrocrystalline structure for reconditioning GTE rotor parts. The Paton Welding J., 2, 18-22.

5. Kovalenko, T.A., Ovchinnikov, A.V. (2010) Influence of initial structure on fracture mechanisms and mechanical properties of submicrocrystalline titanium. Novi Mater. $i$ Tekhnol. v Metallurgii ta Mashynobud., 1, 72-80. 


\title{
STRUCTURAL SUPERLIGHT POROUS METALS (Review)
}

\author{
M.A. KHOKHLOV and D.A. ISHCHENKO \\ E.O. Paton Electric Welding Institute, NASU \\ 11 Bozhenko Str., 03680, Kiev, Ukraine. E-mail: office@paton.kiev.ua
}

\begin{abstract}
Porous metals, having many attractive technological properties, have aroused greater interest over the recent years. The paper gives the main technological advantages of porous metals opening up good prospects for their application. Porous metals, while preserving the main advantages of the initial material, have many times lower heat and electric conductivity, while their sound absorption and damping capability are higher. Adhesion bonding, brazing or diffusion welding can be used as methods of joining porous metals. Porous aluminium is capable of providing an unprecedented strength-to-weight ratio that can be actively applied in aerospace technologies, where mass minimizing is highly important. Porous aluminium properties, the most widely applied at present, are damping and maximum absorption of vibrations, waves and impact energy at collisions. In the near future porous alloys, depending on the degree of porosity and manifestation of new unique properties, will become the main structural and protective materials in development of military ammunition, in construction, instrument-making, as well as automotive, railway, aerospace engineering and in ship-building. Porous metals have been intensively manufactured since 2000 in Europe, USA and Japan. In Ukraine porous aluminium manufacturing has been mastered the experimental level, and still is expensive and energy-consuming. 17 Ref., 12 Figures.
\end{abstract}

Key words: superlight materials, aluminium, magnesium, porous aluminium, foam aluminium, damping, specific strength, instrument-making, telecommunications satellite, aerospace industry, weldability

Over the recent years porous metals, which have a lot of attractive technological properties, have aroused increased interest. Porous metal (PM) is metal foam, the cellular structure of which contains a large number of uniformly distributed pores and bridges. There exist several fundamentally different technologies of producing porous metals, one of which is sintering of granulessemi-finished products (Figure 1). Technological differences allow manufacturing PM with different pore configuration that changes their density and technological properties into opposite ones. For instance, PM with closed pores (Figure 2, a) has $50-80 \%$ porosity, and ensures thermo-in- sulating properties, while material with open pores (Figure 2, $b$ ) and 35-95\% porosity enables heat exchange to be performed. PM has low hygroscopicity (1-3\%), that provides frost resistance and absence of cracks at temperature gradients. Metallic foams from aluminium, magnesium, steel, titanium or zinc are readily joined by adhesion bonding, welding, brazing with different materials, have higher corrosion resistance, and lend themselves easily to drilling, sawing and milling.

Porous aluminium (PA) is capable of providing an unprecedented strength-to-weight ratio, that can be actively applied in aerospace technologies, where mass minimizing is highly important. As aluminium fraction in aircraft structures is equal from $2 / 3$ up to $3 / 4$, and in rocket structures it is from $1 / 20$ up to $1 / 2$, the possi-
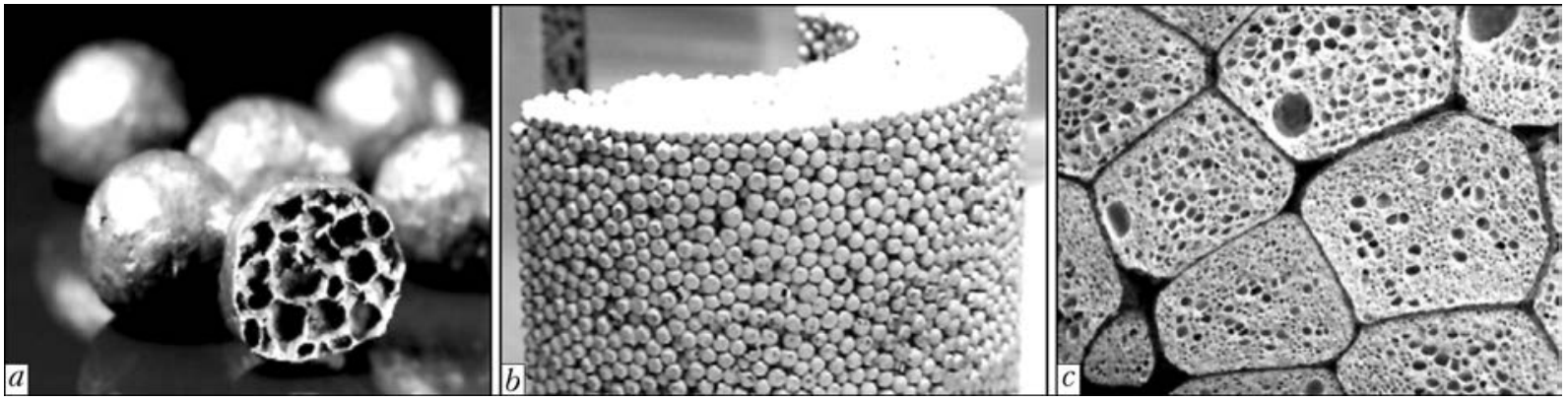

Figure 1. Granules-semi-finished product $(a)$ are placed into a form for sintering $(b)$ in production of porous aluminium $(c)$ 


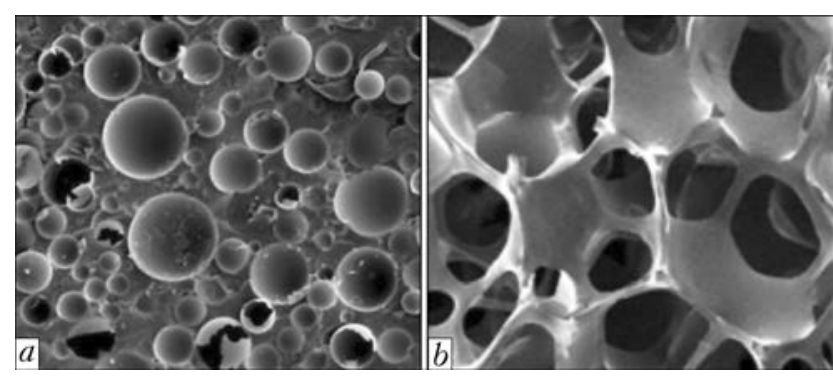

Figure 2. PA with closed $(a)$ and open $(b)$ type of porosity

bility of replacement of monolithic materials by porous ones in large-sized structural elements is an attractive goal (Figure 3 ).

Replacement of expensive honeycomb structures by PA panels [1-3] (Figures 4-6) can essentially reduce the manufacturing cost of telecommunications satellites and other space equipment, where there is a tendency of increase of the ratio of weight of payload (research equipment fastened on the satellite) to total weight of the launched space vehicle (platform) ( $\mathrm{Fi}^{-}$ gure 7).

PMs, while preserving the main advantages of the initial material, have many times lower heat- and electric conductivity, and their sound absorption and damping capacity are higher than those of bridge metal. More over, they are nottoxic, heat- and bio-resistant, do not fail at the impact of combustive-lubricating materials, solvents, ultraviolet and radiation. Under the impact of open flame they gradually soften, if the temperature in the heating zone reaches 650$800{ }^{\circ} \mathrm{C}$.

Mechanical properties of foam material are due to three-dimensional isotropic structure and are determined by behaviour of individual structural elements - bridges. Material compression proceeds in four stages. At the first stage, deformation of the frame weakest elements and edge inhomogeneities occurs at small loads, at the second stage, elastic deformation takes place, and at the third stage, the bridges lose their stability, plastic deformations develop and compressive diagram moves into a flat area (compression plateau). The process is of a cyclic chain nature: loss of stability of one of the bridges involves development of deformation in the adjacent ones and furtheron over the entire layer, material layers gradually collapse to the compactification limit, when the pores close completely and deformed material begins acquiring the properties of compact material. At the fourth stage, the
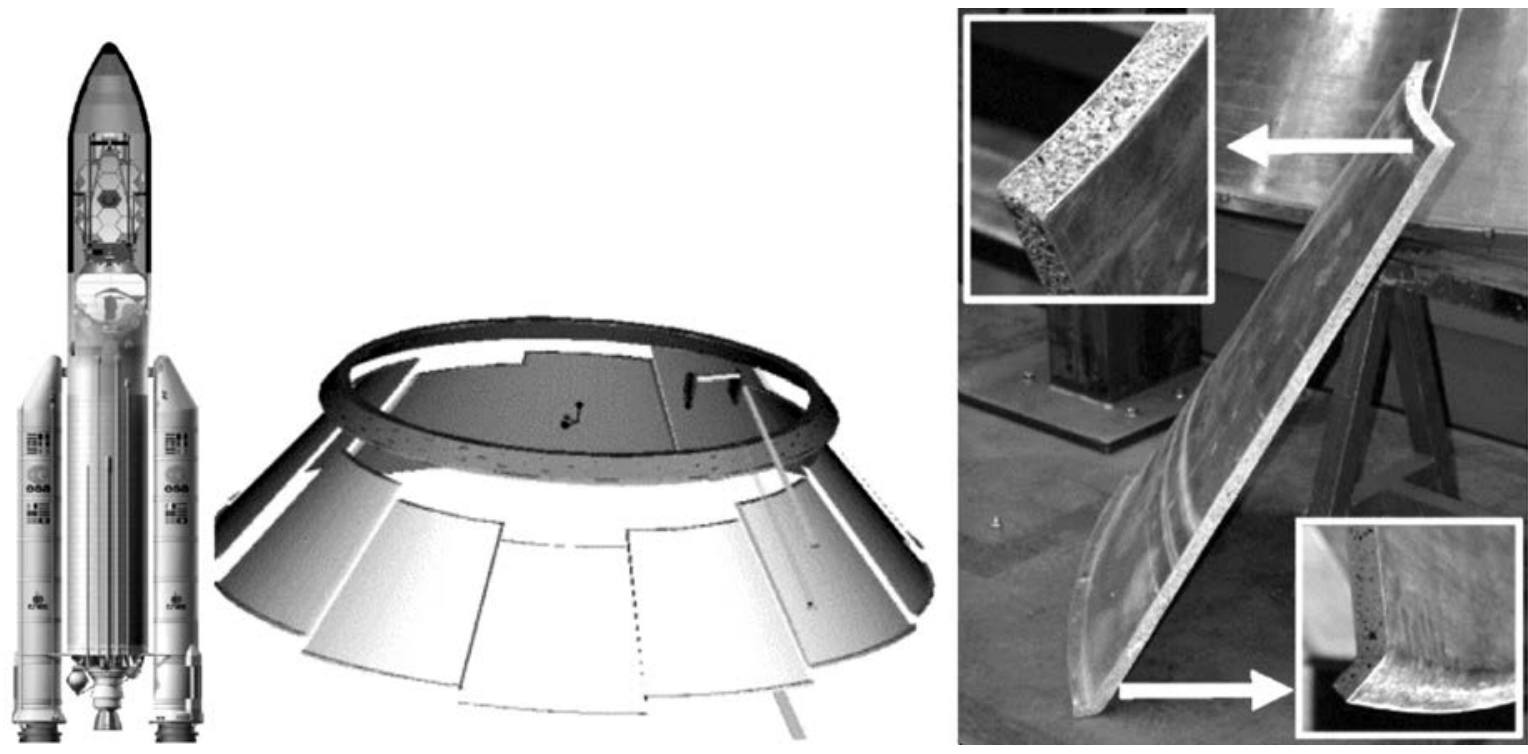

Figure 3. Segments of AFS cone of Arianne missile engines from PA
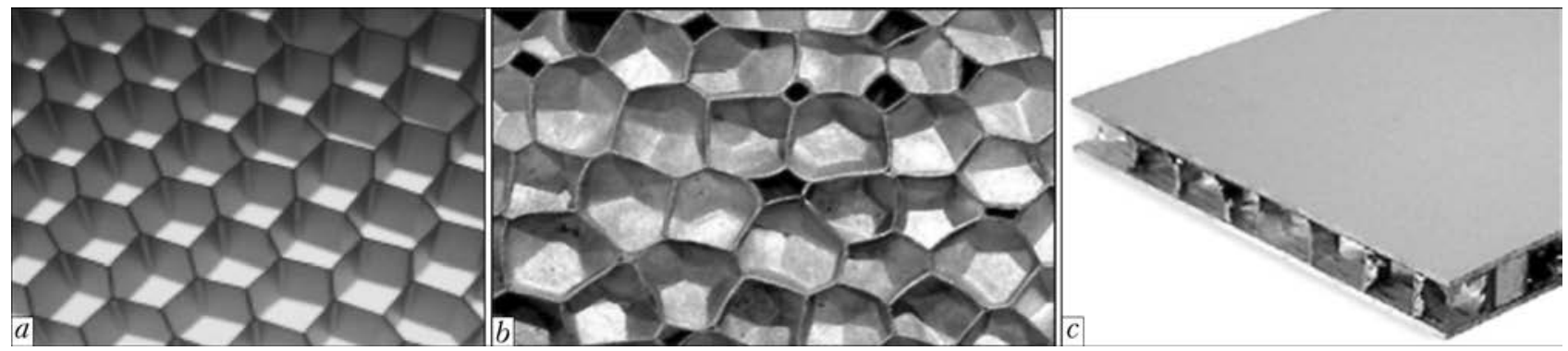

Figure 4. Traditional material for honeycomb panels from foil $(a)$ and porous honeycomb of Fraunhofer (Germany) (b) in honeycomb panel $(c)$ 


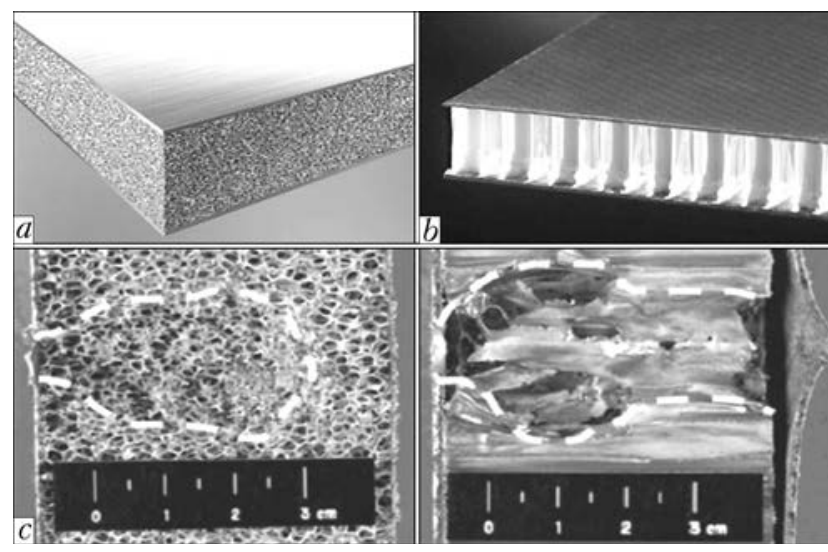

Figure 5. Comparative testing $(c)$ of honeycomb panel from aluminium foil $(b)$ and sandwich panel from highly-porous aluminium $(c)$

stress in the material rises again, and it gradually becomes close to a compact material.

PMs demonstrate nonlinear behaviour at deformation, characteristic of cellular structures. Therefore, PMs are used not only for shock damping, but also for increasing the rigidity of hollow profiles (Figure 8), manufacturing incombustible light-weight flame- and heat-resistant damping materials, as well as reinforcing anchors in concrete walls. PA can be used as mould cores. After casting they remain in the finished shaped casting instead of cavities, which are envisaged to reduce the car weight that yields certain advantages in strength and reduces the expenses for removal of standard sand cores.

Strength of PA products is greatly increased at surface treatment - rolling, forging, stamping $[4,5]$. PA does not melt at the temperature of melting of the initial alloy: at heating in the electric furnace up to $1400{ }^{\circ} \mathrm{C}$ it did not melt; after soaking for $100 \mathrm{~h}$ at $1482{ }^{\circ} \mathrm{C}$ it strongly oxidized, but strength and dimensions of the samples remained the same. Thus, PA can be heated

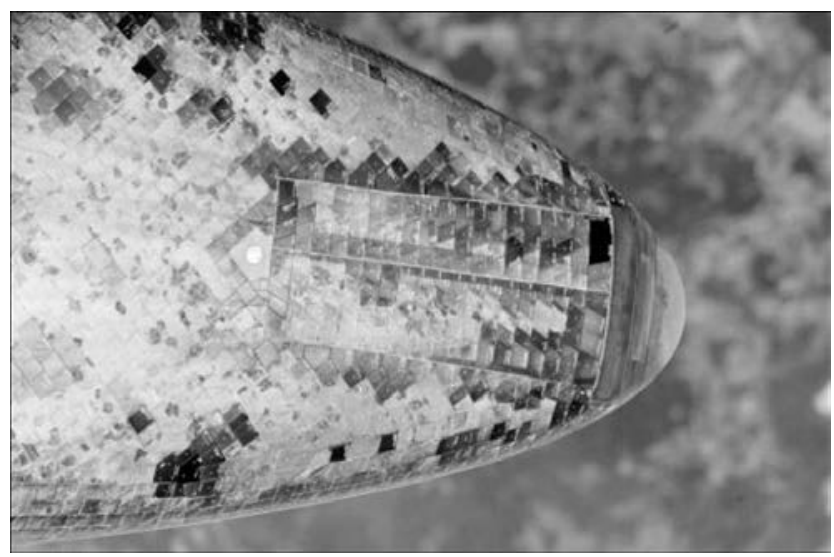

Figure 6. Damage of anti-meteor defense of Space Shuttle Discovery

many times up to high temperatures and rapidly cooled, here its properties change only slightly. To manufacture flexible PA sheets of large dimensions with adjusted values of porosity, air content is brought to $93-98 \%$ by volume, and then the manufactured material is rolled into sheets.

Characteristics of PA structure influence the degree of deformation at its compression [6]. PM from AMg6 alloy of $0.5-0.6 \mathrm{~g} / \mathrm{cm}^{3}$ density is resistant to elastic relaxation before and after plastic deformation, right up to $27 \%$ compression. At $4.5-5.0 \%$ compression this material is elastically deformed; at 5.5-6.0 \% elastic deformation in it develops into plastic deformation. Material strengthening after multiple compression in the elastic and elastic-plastic region for a specimen of $0.6 \mathrm{~g} / \mathrm{cm}^{3}$ density does not exceed $\Delta \sigma=1 \mathrm{MPa}$, and for a specimen of lower density of $0.5 \mathrm{~g} / \mathrm{cm}^{2}$ it reaches $\Delta \sigma=2.7 \mathrm{MPa}$, that may be related to the mechanism of frame evolution. During compression the structure of material of $0.5 \mathrm{~g} / \mathrm{cm}^{3}$ density evolves by the mechanism of pore closure and torsion.
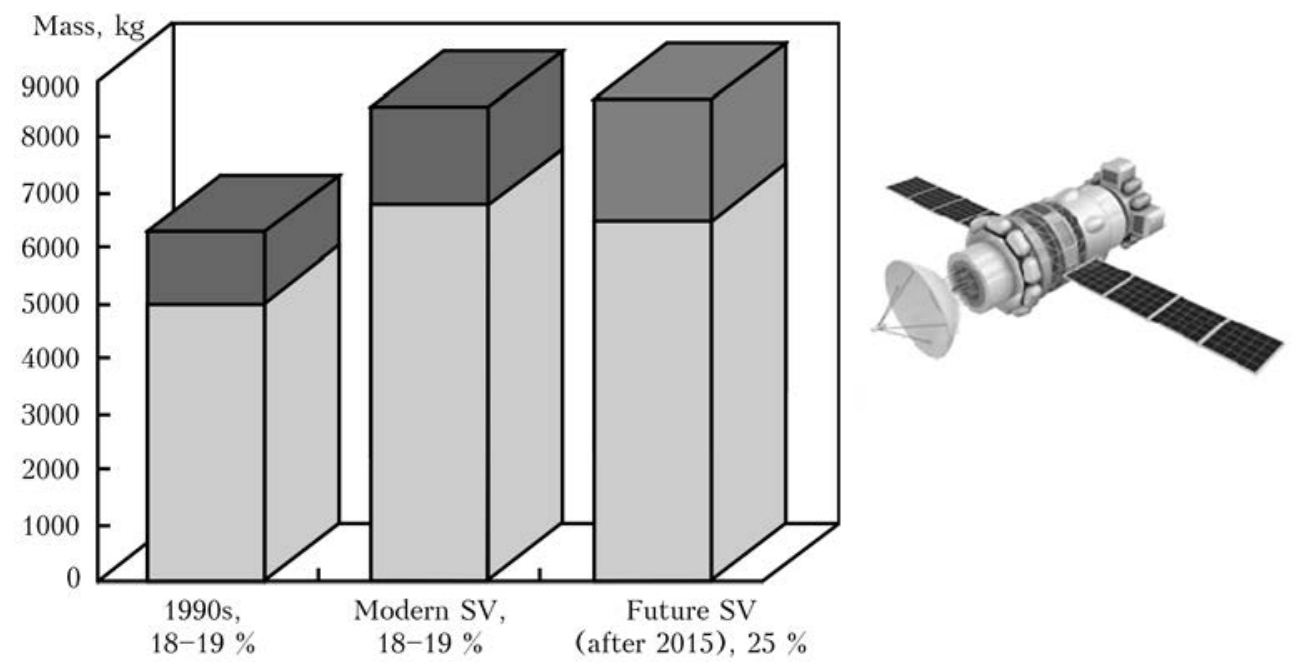

Figure 7. Prospects for increase of ratio of payload weight (dark colour) to the total weight of space vehicle (SV) (light colour) 


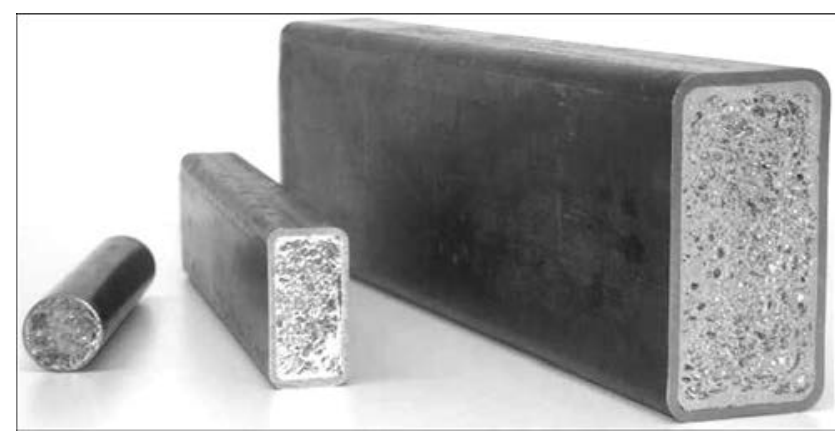

Figure 8. Types of panels with PA filler

«The strongest metal foam in the world» was produced at the University of North Carolina (USA) [7]. Material can be compressed to $80 \%$ of its size under the impact of weight and can preserve its initial form after the load has been relieved. New metal foam is unique due to uniformity of the cells and their walls. This is exactly what gives it strength and elasticity, required for compression without deformation.

Automotive industry is showing the greatest interest to PA. Three-layered aluminium sheets with aluminium foam are used in body manufacture. The low weight of such a structure reduces petrol consumption. The body is by $50 \%$ lighter than the respective steel one, but 10 times more stable. Three-dimensional multilayer structures enhance the frame rigidity. They can be used to make also the body parts - from the doors to a complex group of bottom elements. Such parts are very light and have the rigidity 15 times higher than the regular sheet structures.

PA of Cymat (Canada) in the form of rectangular-shaped profiles is used for car door shockabsorbers and emergency partitions. Unlike the honeycomb structure from aluminium material, PA is isotropic and can resist a shock at any angle.

Application of the technology of foamed magnesium production by filtration through granules of water-soluble salts allows producing items of the porosity of $55-75 \%$, density of $0.7-$ $0.9 \mathrm{~g} / \mathrm{cm}^{3}$, with ultimate compression strength of 5-10 MPa. Foamed magnesium has high damp-

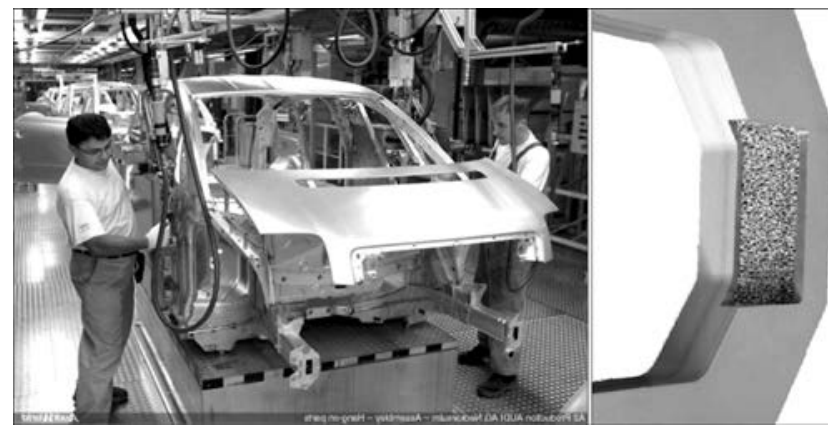

Figure 9. Car body parts from PA ing properties, and its coefficient of elastic and viscous deformation is $2-5$ times smaller than that of PA [8].

Nickel alloys with manganese and hallium, developed by the staff of Boise State University (Idaho, USA) and Northwest University (Illinois, USA) feature a coarse-grained structure.

This makes them light-weight, while the materials preserve an exceptionally high strength. However, the new alloys also have a totally unusual property - they are elongated under the impact of an external magnetic field up to $10 \%$ of their initial length. They also have shape-memory effect - they are preserved in the changed state for any length of time after field removal, but can return to the initial condition at magnetic field rotation through $90^{\circ}$. The new alloy was produced in the form of a polycrystalline material. Such materials are usually characterized by absence of pores, while their elastic properties and deformability, on the whole, are very insignificant.

The new material with the «magnetic shape memory» was produced by pouring the melt into a sample of sodium aluminate salt with inner pores. Then, the sodium aluminate is dissolved with acid, and large pores form in place of fragments filled with it. This material was subjected to various tests, in particular, by a rotating magnetic field. After $10 \mathrm{mnl}$ revolutions in the magnetic field the material preserved its capacity for elastic deformation that makes it quite suitable for application in different magnetic drive systems. Developers believe that there is still room for further improvement of such systems. The porous structure of the material and low density, respectively, and reaction to magnetic fields, will allow it to be applied in the future in such industries as biomedical pumps without moving parts, various devices for slight displacement monitoring.

Neuman Alufoam (Austria) makes from PA unloaded car parts (Figure 9) and lateral shock absorbers, placed into the side doors. Density of parts from PA is $0.5-0.6 \mathrm{~g} / \mathrm{cm}^{3}$. It is noted that the closed external shell, surrounding the porous structure, provides a higher rigidity than that of the structure with open porosity. The company also produces parts of the body and chassis working in bending and torsion, to enhance their rigidity.

Alulight International GmbH (Germany, Austria) proposes PA of 300 up to $1000 \mathrm{~kg} / \mathrm{m}^{3}$ density for manufacturing basic shock-absorbing parts; electromagnetic shields in the form of wall and ceiling plates, protecting from penetration 


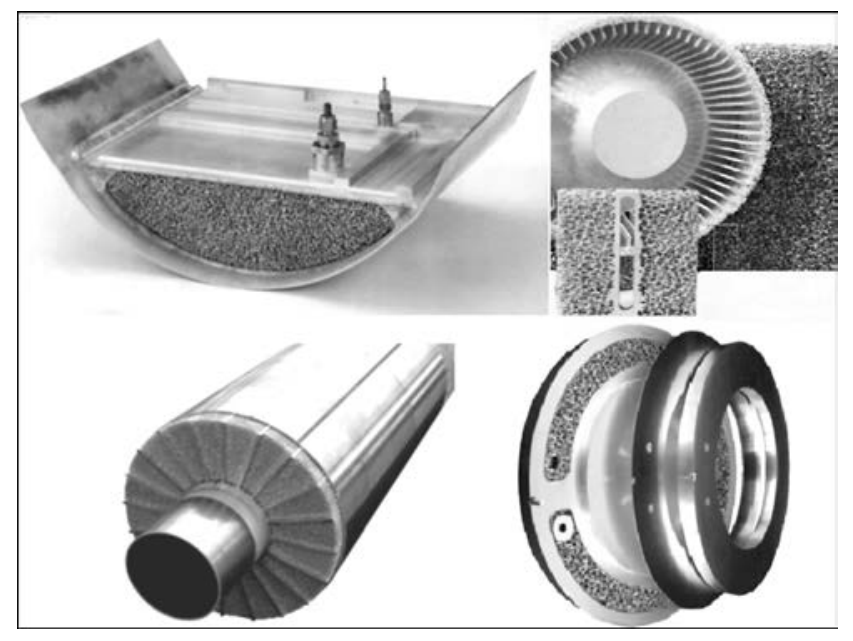

Figure 10. Items with application of PA produced by ERG Aerospace Corporation (USA) [9]

or radiation of electromagnetic waves of the frequency from 0.1 up to $1000 \mathrm{MHz}$, as well as electronic device cases; thermal shields; light construction materials as non-combustible alternative to wood and plastics (can be supplied in the form of plates with maximum dimensions of $625 \times 625 \mathrm{~mm}$, of thickness from 8 up to $25 \mathrm{~mm}$ ); shock-absorbers for motor and rail transport; noise-killers operating under difficult conditions (high temperature, humidity, dust, vibration), in sterile or fire-risk premises.

Method to produce extended PA plates is interesting [10]. PA plates produced by hot rolling of a mixture of aluminium alloy powders with frothing agent into a blank with its subsequent foaming, are successively abutted. A powder interlayer of a mixture of aluminium granules of not less than $200 \mu \mathrm{m}$ size and frothing agent in the quantity exceeding by $50 \%$ the frothing agent quantity in the mixture for producing a blank, is placed between the plate end faces. The assembled plates are fixed to avoid relative displacements and the butt area is heated up to the

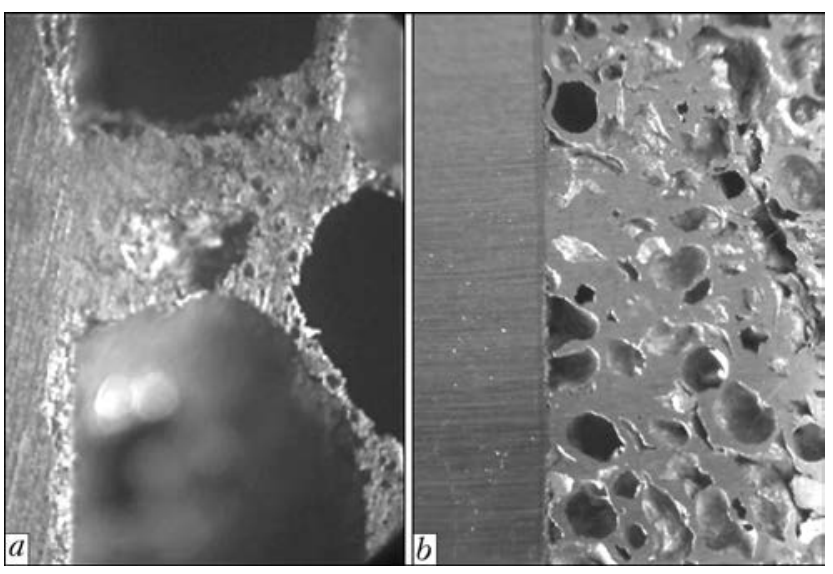

Figure 11. PA joints with monolithic aluminium $(a)$ and magnesium (b) alloys

temperature, ensuring foaming of the powder interlayer at the speed of $150-300{ }^{\circ} \mathrm{C} / \mathrm{min}$. The method allows increasing the strength and quality of the joining areas.

Thus, PM application is possible for the following items: filters; flame arresters; noise-killers (at increased frequencies higher than $800 \mathrm{~Hz}$ ); catalyst carriers; dampers of mechanical, acoustic and electromagnetic pulses; structural elements; sandwich panels; fillers of cavities and tanks (Figure 10).

Brazing, diffusion or electron beam welding and adhesion bonding can be used as methods to join PM.

Department of Physico-Metallurgical Processes of Welding Light Metals and Alloys of the E.O. Paton Electric Welding Institute of the NAS of Ukraine made experimental bimetal joints of PA from V95 and AK7 alloys with monolithic aluminium (AD1, AK12, AMg6) and magnesium (ML4, MA2-1) alloys (Figure 11) by the method of activation of the surfaces being joined at $140-300{ }^{\circ} \mathrm{C}$ for fabrication of superlight blocks for encapsulation of microelectronics for aero-

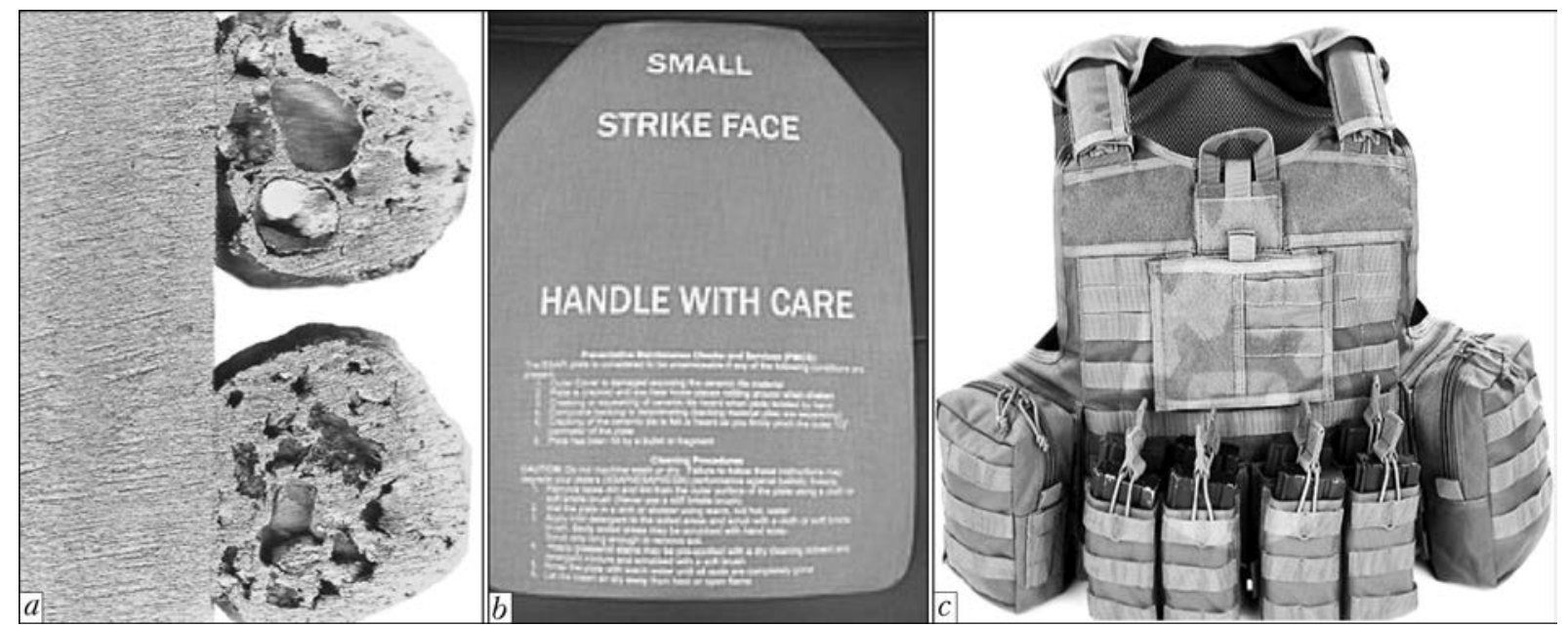

Figure 12. Fastening PA granules $(a)$ for fabrication of panel-insert $(b)$ of combined arms assault bulletproof vest $(c)$ 
space applications [11-17]. Such joints can also be used for fastening the granules-semi-finished product in fabrication of composite armour plates of combined arms assault bulletproof vest ( $\mathrm{Fi}-$ gure 12), built by the modular principle that ensures all-round protection of the torso from fragments, cold and small arms.

The most widely applied at present PA property is damping and maximum absorption of vibrations, waves and shock energy at collisions. In the near future porous alloys, depending on the degree of porosity and manifestation of new unique properties, will become the main structural and protective materials at development of military ammunition, in construction, instrument-making, as well as automotive, railway and aerospace equipment and shipbuilding. PMs have been intensively manufactured in Europe, USA and Japan since 2000. In Ukraine PA manufacturing has been mastered on the experimental level and still is expensive and energy-consuming. Considering the military-political situation in the country, advance of PA manufacturing and fabrication of light and strong structures from it could significantly influence the defense potential of Ukraine.

1. Rvan, S., Christiansen, E.L. Honeycomb vs. foam: evaluating potential upgrades to ISS module shielding. http: / ntrs.nasa.gov / archive/nasa/casi.ntrs.nasa.g ov /20090016347.pdf

2. Rvan, S., Hedman, T., Christiansen, E.L. Honeycomb vs. foam: evaluating a potential upgrade to international space station module shielding for micrometeoroids and orbital debris. http: / stonjsc. nasa.gov / collections / trs / techrep/TM-2009-21479 3.pdf

3. http://www.aviationspectator.com/image/latest-a viation-images? Page $=223$

4. Metal foam. http://msd.com.ua/pena/metalliches kaya-pena

5. Krushenko, G.G. (2013) Some technologies for producing foam metals from metal melts and their application. Tekhnologiya Metallov, 10, 11-16.

6. Martynyuk, A.M., Krupin, Yu.A. (2011) Influence of structure of foam aluminium on material stability in compression. Metallurgiya Mashinostroeniya, 5, 35-37.

7. Bogdanova, A. Metal of the future will be porous. wrw.equipnet.ru/articles/metall/metall_556.html

8. Kovtunov, A.I., Khokhlov, Yu.Yu., Novsky, I.V. (2013) Prospects for application of magnesium for producing foam materials. Metallurgiya Mashinostroeniya, 4, 9-11.

9. Why is duocel aluminum foam so special. http: / www.ergaerospace.com/Aluminum-properties.htm

10. Pasechnik, N.V., Pavlenko, V.V., Orlov, V.K. et al. Method for producing enlarged foam aluminum plates. Pat. 2404020 Russia. Int. Cl. $22 \mathrm{~F} 3 / 10$ (2006.01)B 22 F 3/11 (2006.01). Fil. 23.03.2009. Publ. 20.11.2010.

11. Khokhlova, J. (2014) Intergranular phase formation during reactive diffusion of gallium with $\mathrm{Al}$ alloy. Materials Science Forum. Transact. Tech. Publication. Max Plank Institute for Intelligent Systems, Vol. 768/769, 321-326.

12. Ishchenko, A.Ya., Khokhlova, Yu.A., Khokhlov, M.A. (2013) Low-temperature joining of elements of bimetallic heat-exchange blocks for encapsulation of microelectronics. In: Proc. of 6th Int. Conf. on Space Technologies: Present and Future (17-19 April 2013, Dnepropetrovsk, Ukraine), 107.

13. Khokhlov, M.A., Khokhlova, Yu.A. Method of joining a bimetallic block for thermal insulation of $\mathrm{mi}^{-}$ croelectronics elements. Pat. 69145 UA. Int. Cl. (2012.01) B01B 1/00, B23K, 1/00. Fil. 05.09.2011. Publ. 25.04.2012.

14. Khokhlov, M., Falchenko, Yu., Khokhlova, Yu. et al. (2014) Microstructure transformation of diffusion zone in aluminum foam and monolithic magnesium alloy bimetallic joint. In: Proc. of 5th Int. Conf. on Fracture Mechanics of Materials and Structural Integrity (24-27 June, 2014, Lviv, Ukraine), 551-556.

15. Khokhlov, M., Falchenko, Yu., Khokhlova, Yu. (2014) Peculiarities of forming diffusion bimetallic joints of aluminium foam with a monolithic magnesium alloy. In: Proc. of Cellmat-2014 (22-24 October 2014, Dresden, Germany).

16. Khokhlova, J., Khokhlov, M. (2014) International hi-tech match-making meeting. Int. Depart. of Organizing Committee of CCHTF (April 2014, Chongqing, China).

17. Ishchenko, A., Khokhlova, J., Khokhlov, M. (2011) Low-temperature diffusion joining of dissimilar materials using gallium. In: Proc. of Europ. Conf. on Aluminium Alloys «Aluminium Science and Technology» (5-7 October 2011, Bremen, Germany), 31.

Received 24.10.2014 


\title{
THERMAL PROTECTION TILE STRUCTURES OF SHUTTLECRAFT WITH DIFFERENT EXTERNAL LOAD-CARRYING ELEMENTS
}

\author{
V.G. TIKHY ${ }^{1}$, V.V. GUSEV ${ }^{1}$, A.M. POTAPOV ${ }^{1}$, E.I. SHEVTSOV ${ }^{1}$, I.A. GUSAROVA ${ }^{1}$, \\ T.A. MANKO ${ }^{2}$ and Yu.V. FALCHENKO ${ }^{3}$ \\ ${ }^{1}$ M.K. Yangel DB «Yuzhnoe» \\ 3 Krivorozhskaya Str., 49008, Dnepropetrovsk, Ukraine. E-mail: info@juzhnoye.com \\ ${ }^{2}$ O. Gonchar Dnepropetrovsk National University \\ 72 Yu. Gagarin Ave., 49050, Dnepropetrovsk, Ukraine \\ ${ }^{3}$ E.O. Paton Electric Welding Institute, NASU \\ 11 Bozhenko Str., 03680, Kiev, Ukraine. E-mail: office@paton.kiev.ua
}

\begin{abstract}
Thermal protection tile structures, made from heat-resistant materials, are widely applied for protection of space vehicle bodies. Carbon-carbon composite materials, high-temperature metal alloys and structural ceramics can be used as high-temperature heat-resistant materials for manufacturing thermal protection structure tiles. The presented work gives calculation-theoretical assessment of strength properties of combined tiles of thermal protection structure of returnable space vehicles, having a metal external load-carrying element and body from carbon-carbon composite material, as well as tiles from carbon-carbon and ceramic materials. The advantages and disadvantages of each of the studied thermal protection tile systems are considered. Strength analysis is used to determine the dimensions of load-carrying elements for bodies of thermal protection structures, meeting the requirements of strength, stability and resistance to flutter, and weight of each structure. It is found that thermal protection tiles with a body from carbon-carbon composite materials and tiles with an external three layer honeycomb panel from YuIPM-1200 alloy have the best weight and strength characteristics. 6 Ref., 5 Tables, 9 Figures.
\end{abstract}

$\boldsymbol{K} \boldsymbol{e} \boldsymbol{y} \boldsymbol{w} \boldsymbol{o} \boldsymbol{r} \boldsymbol{d} \boldsymbol{s}:$ returnable space vehicles, thermal protection tile structures, stress-strain state, carbon-carbon composite materials, high-temperature metal alloys

Tiles based on quartz fibers were used in returnable Space Shuttle and Buran vehicles-aircraft for thermal protection of sections, heated up to $1200{ }^{\circ} \mathrm{C}$. A serious drawback of quartz ceramic tiles is their extreme brittleness and low strength, as well as permanent joint of tile thermal protection with airframe skin. More attractive is the concept of removable thermal protection tile structures with the body of resistant materials and internal thermal insulation. Such a structure ensures a more reliable fastening of thermal protection tiles by mechanical means and convenience of their interflight maintenance.

Carbon-carbon composite materials (CCCM), heat-resistant metal alloys and structural ceramics can be used as high-temperature heat-resistant material of tiles of thermal protection structure (TPS). TPSs, the surface density of which does not exceed $10 \mathrm{~kg} / \mathrm{m}^{2}$, are acceptable [1].

Each of heat-resistant materials has its advantages and disadvantages. Metal advantages include the fact that their production is highly standardized and their quality is guaranteed within narrow tolerances. Here extremely important is the fact that extensive experience of transfer of metal sample testing results to full-scale structure parts has been accumulated. The main heat-resistant materials applied for operation in high-temperature structures, are iron- and nickelbased alloys. The main disadvantages of metals are their high specific weight and insufficient corrosion resistance at working temperatures.

Ceramic materials are essentially superior to metals and alloys by many service parameters (thermal stability, hardness, corrosion resistance, density, accessibility and low cost of raw materials). The main problems arising at selection of ceramics for TPS tiles are its inherent brittleness and possibility of catastrophic failure because of development of Griffith cracks [2,3].

CCCM are characterized by low weight, high strength and rigidity, and low coefficient of thermal expansion. Moreover, this material strength rises with temperature. CCCM preserve their mechanical properties at up to $500{ }^{\circ} \mathrm{C}$ temperatures in non-oxidizing media better than any other material. At application in thermal protection structures of space vehicles (SV) all the external surfaces from CCCM structures should be protected 


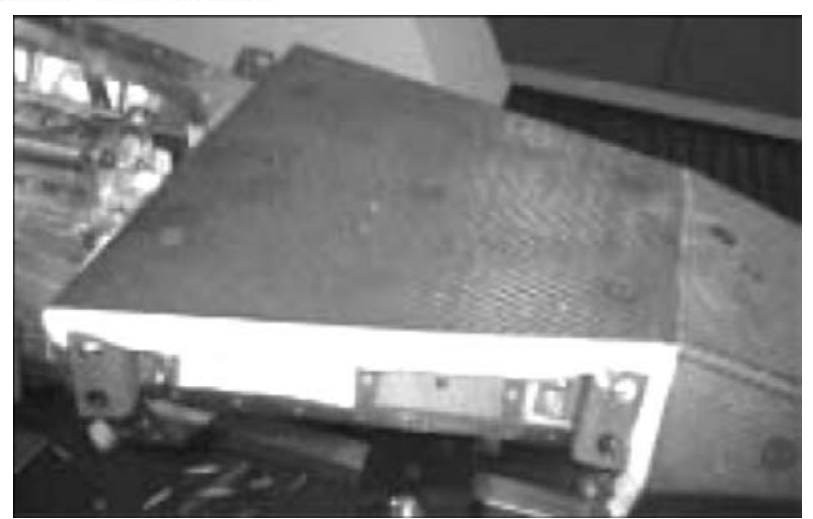

Figure 1. Panels from CCCM-SiC of DRL Company with internal thermal insulation

by heat- and erosion-resistant coating, preventing material loss in the atmospheric section of the flight [1]. DLR developed external heatresistant panels from $\mathrm{CCCM}-\mathrm{SiC}$ composite (Figure 1) [4].

Panels from such materials are used in TPSs of ISV SHEEFEX, PH HIFiRE 8 and IXV demonstrator [5]. Manufacturing CCCM structures is a lengthy and expensive process.

The objective of this work is comparative analysis of thermal protection tiles with an external load-carrying layer from various thermostable materials and internal thermal insulation pack, based on calculation-theoretical evaluation of their strength and weight characteristics.

The object of investigations are TPS tiles of for shuttlecraft with load-carrying element from metal, carbon-carbon and ceramic materials and internal thermal insulation. The studied TPSs should have surface density of not more than $10 \mathrm{~kg} / \mathrm{m}^{2}$, and ensure temperature lowering from $1100{ }^{\circ} \mathrm{C}$ on outer wall to $200{ }^{\circ} \mathrm{C}$ on inner wall within 20 min per one cycle of the vehicle intended use, while withstanding 100-fold repetition of such cycles for 15 years.

Analysis of currently available reusable TPSs showed that the main elements of removable thermal protection tiles are external load-carrying element from heat-resistant material, internal

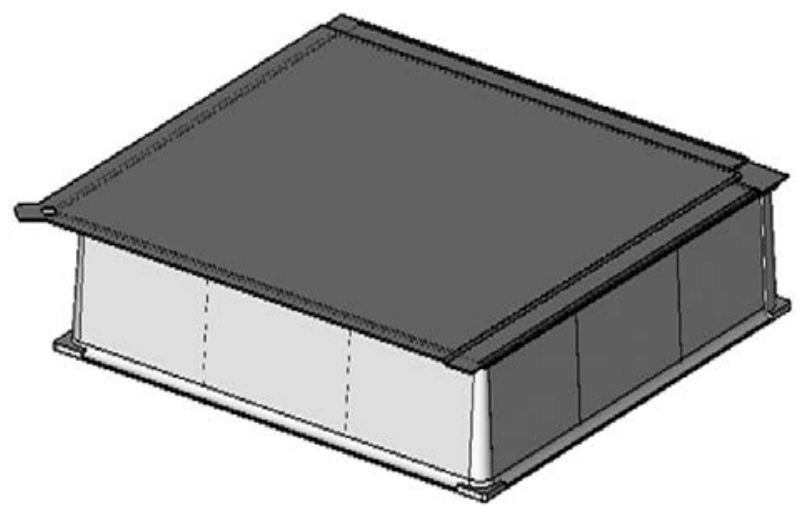

Figure 2. Design of combined thermal protection tile light-weight fibrous thermal insulation and system of fastening thermal protection tiles to SV load-carrying shell. Load-carrying element should have a structure, which develops minimal internal stresses at loading that allows reducing the thicknesses and, therefore, its weight.

In order to analyze the variants of external load-carrying element of various structures from a number of heat-resistant materials, a calculation-theoretical procedure was developed for evaluation of the influence of aerodynamic impacts on removable thermal protection tiles of shuttlecraft, based on MSC Nastran software package. Comparative analysis of structure variants was performed for tiles with in-plane dimensions of $300 \times 300 \mathrm{~mm}$ and $50 \mathrm{~mm}$ height of useful volume for placing the light thermal insulation material. Six different variants of tiles with bodies from CCCM and structural ceramics, with metal sheet, three-layer corrugated and honeycomb loadcarrying elements have been designed and analyzed, as well as combined tile with CCCM body and metal sheet load-carrying element.

Designs of tiles with metal sheet, three-layer corrugated and honeycomb load-carrying elements and results of calculation of their stressstrain state (SSS) are given in work [6].

Combined TPS tile consists of CCCM body and external metal load-carrying element, which is attached in eight points to the body ribs in the points of their intersection with side walls ( $\mathrm{Fi}^{-}$ gure 2).

Bodies of thermal protection tiles from CCCM and ceramics are made by an identical schematic and they are designed in the form of a whole formed box (Figure 3).

Tile body is reinforced by 4 ribs, separating its internal volume into 9 cells with $100 \times 100 \mathrm{~mm}$ in-plane dimensions, and is closed from below by a flat bottom from polished titanium foil, which is connected with the box along the wall and rib end faces by adhesion bonding. The case has flanging for attachment to SV load-carrying shell. As either ceramic or carbon-carbon materials do not allow considerable bending deformations, which arise under the impact of external loads, their fastening is performed through an intermediate element - the damping substrate. The latter should have a certain elasticity and play the role of a soft elastic interlayer (felt), compensating, first of all, all the unevenness of the airframe external metal surface and, secondly, all the bending deformations of the skin, and at the same time, be the emergency thermal protection coating preventing the load-carrying shell from overheating at one tile failure. 


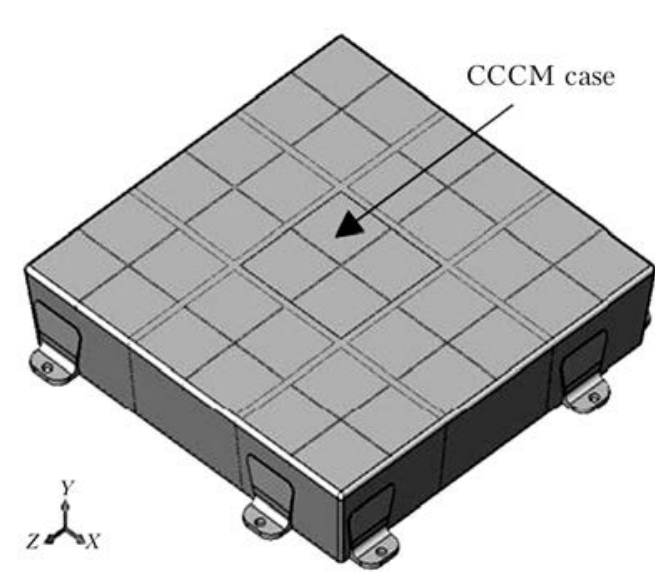

Figure 3. Structure of thermal protection tile with CCCM or ceramic case

The body rests directly on emergency thermal protection coating mounted on SV load-carrying shell, and is fastened in the four corners. Fastening is rigid in one of the corners, and in the other three corners it allows motion in the butt plate in the direction of the straight line connecting this point with the rigidly fastened one. All the fastening points allow rotation in TPS diagonal plane. Tile fastening is performed with screws, which are turned into nuts, fastened on the body of shuttlecraft. Bosses-thermal bridges from glass-reinforced plastic are placed in the zone of screw mounting (Figure 4).

Owing to low coefficients of linear temperature expansion of CCCM and ceramic elements, it is possible to minimize the intertile gaps, in which intertile thermal insulation from quartz fibre, reinforced by quartz cords, is mounted. After that the intertile gaps are closed by a seal from heat-resistant alloy.

Material property values taken for calculation are given in Table 1 . Ni-Cr-based powder alloy - YuIPM-1200 was selected as heat-resistant metal alloy. It was specially developed for application in TPSs of spacecraft. Silicate ceramics with the properties, given in Table 1, was selected for comparison.

External pressure and temperature impact were taken as the main load for design calcula-

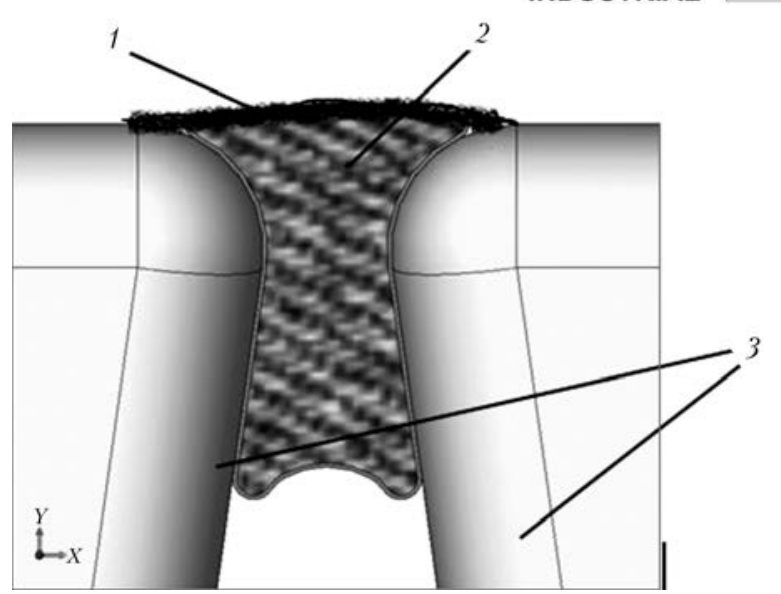

Figure 4. Variant of intertile seal: 1 - seal from heat-resistant alloy; 2 - internal filling of quartz cord type; 3 TPS tile

tions. All the calculations were performed allowing for loading by external calculation pressure of $0.065 \mathrm{MPa}$ at up to $1100{ }^{\circ} \mathrm{C}$ temperatures. In addition, in order to prevent flutter (self-excited non-damping bending and torsional spontaneous vibrations of flying vehicle structural elements, which may lead to its fracture) at maximum dynamic heads in the descent section, the structure was required to have not lower than $100 \mathrm{~Hz}$ frequency of the first tone of spontaneous vibrations.

Selection of the dimensions of the body loadcarrying elements and method of fastening on SV shell was conducted on the basis of analysis of SSS, margins of strength, stability and modal finite element analysis of the respective structure models performed with application of FE packages of Nastran programs.

The load (safety) factor was determined as the ratio of material ultimate strength (critical load for the structure) to maximum stress (calculated load). Structure strength was considered to be sufficient, if the load factor was not less than a unity.

Calculation results are obtained in the form of visualization of each structural element. Results of strength analysis in the case of TPS combined tile are given in Figures 5-9.

Table 1. Physical and mechanical properties of applied materials

\begin{tabular}{|c|c|c|c|c|c|c|}
\hline$T,{ }^{\circ} \mathrm{C}$ & Material & $\rho, \mathrm{g} / \mathrm{cm}^{3}$ & $E, \mathrm{MPa}$ & $\sigma_{\mathrm{b}}, \mathrm{MPa}$ & $\delta, \%$ & $\alpha \cdot 10^{6}, \mathrm{~K}^{-1}$ \\
\hline 20 & \multirow[t]{2}{*}{$\mathrm{CCCM}$} & \multirow[t]{2}{*}{$1.8-2.0$} & \multirow[t]{2}{*}{$24000-45000$} & \multirow{2}{*}{$\frac{90-140}{130-160}$} & \multirow[t]{2}{*}{15} & \multirow[t]{2}{*}{$3.0-4.7$} \\
\hline 1100 & & & & & & \\
\hline 20 & Structure ceramics & 2.4 & 5000 & 50 & - & 5 \\
\hline 20 & \multirow[t]{2}{*}{ YuIPM-1200 alloy } & \multirow[t]{2}{*}{$8.2-8.4$} & & $660-1000$ & 15 & 16 \\
\hline 1100 & & & & 100 & & 21 \\
\hline
\end{tabular}




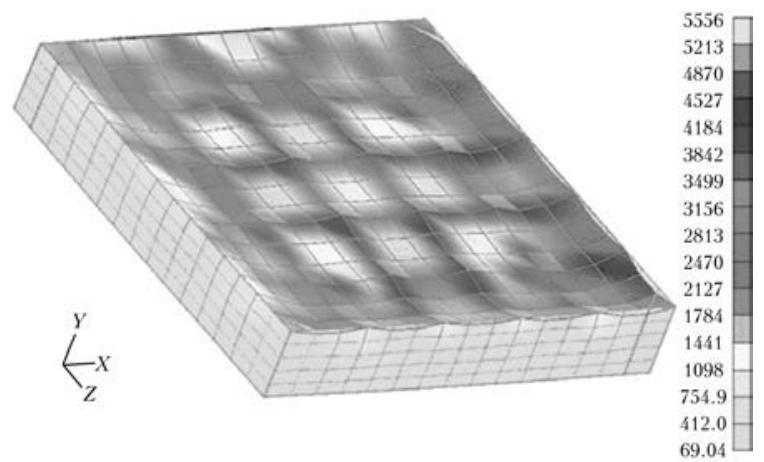

Figure 5. SSS of TPS combined body at loading by $0.065 \mathrm{MPa}$ maximum pressure

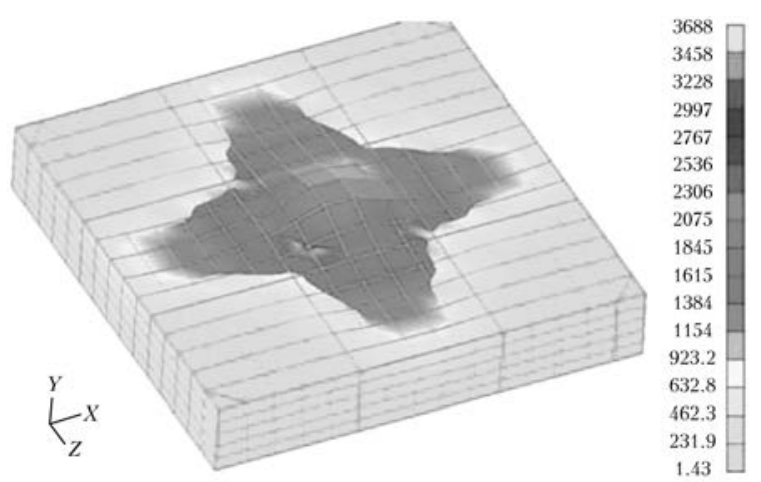

Figure 6. Nature of stability loss of combined body bottom at pressure loading

SSS of TPS tiles at loading by $0.065 \mathrm{MPa}$ pressure is shown in Figures 5 and 6. This structure preserves its stability at loading by external pressure of $0.065 \mathrm{MPa}$, and the external loadcarrying element is the most critical point. Figure 6 gives the nature of stability loss.

Figure 7 shows SSS of TPS tile at temperature loading. Safety factor of the body at temperature loading is equal to 6.12 .

Figure 8 gives the nature of the loss of stability. Frequencies of the first three tones of the body spontaneous vibrations are equal to 294, 302 and $310 \mathrm{~Hz}$ (see Figure 9).

To eliminate flutter, natural frequency should be not lower than $100 \mathrm{~Hz}$, i.e. this structure meets the requirements on flutter resistance. The main results of calculation of the combined tile are given in Table 2 . The structure meets the

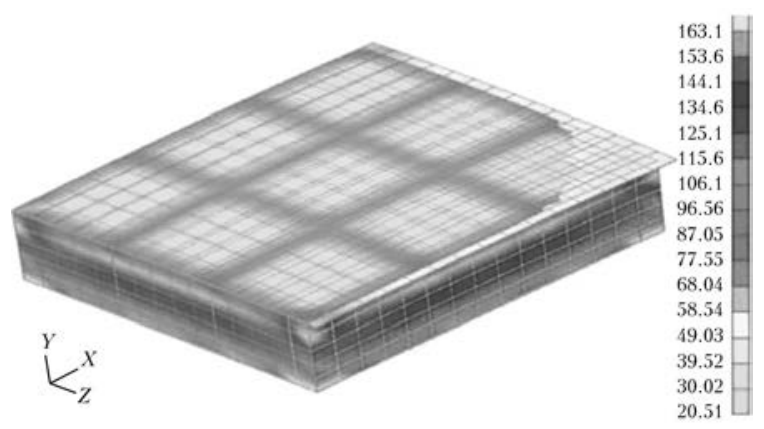

Figure 7. SSS of combined body at temperature loading
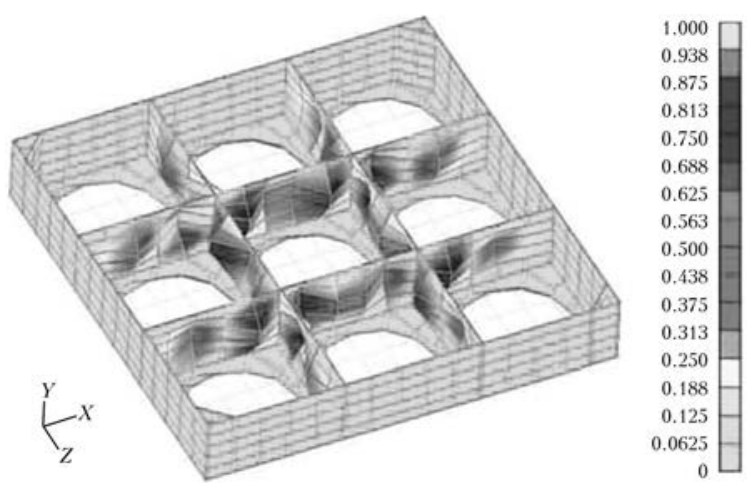

Figure 8. Nature of body stability loss at temperature loading requirements on strength and stability. The mass of this body variant is $670 \mathrm{~g}$. The thickness of the box front sheet contacting RM-1000 plate, is equal to $1 \mathrm{~mm}$, thickness of side walls and ribs is $0.8 \mathrm{~mm}$.

Models of TPS tiles from CCCM and silicate ceramics were analyzed in a similar fashion. The main results of calculations of TPS tiles from CCCM are given in Table 3.

By strength conditions the thickness of box sheet, contacting the environment and directly taking the external loads, is equal to $1.6 \mathrm{~mm}$, thicknesses of side walls and ribs are $0.9 \mathrm{~mm}$. Tile weight is $371 \mathrm{~g}$. Note the quite low deformability of the structure from CCCM, both under the impact of mechanical loads and at heating.

The main results of calculations of TPS tiles from silicate ceramics are given in Table 4. Thickness of box outer sheet, taking up external loads, is equal to $2 \mathrm{~mm}$, thickness of side walls and ribs is $1 \mathrm{~mm}$. Body weight is $920 \mathrm{~g}$.

Analysis of calculation results. Calculation results enable determination of the dimensions of load-carrying elements of TPS combined tiles and CCCM and ceramic tiles, which meet the requirements to strength, stability and flutter resistance, and weight of each structure (Table 5). Thermal protection tile with CCCM body has the best weight and strength characteristics. Body weight is $371 \mathrm{~g}$, load factor is 1.16 , first

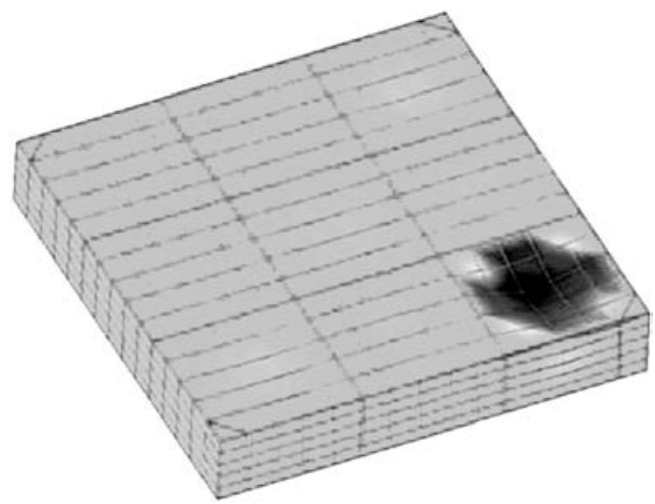

Figure 9. Shape of the first tone of natural vibrations of combined body 
Table 2. Results of combined tile calculations

\begin{tabular}{|c|c|c|c|c|c|c|}
\hline Parameter & Studied factor & $\sigma_{\max }, \mathrm{MPa}$ & $V_{\text {max }}, \mathrm{mm}$ & $W_{\max }, \mathrm{mm}$ & $\eta$ & $F, \mathrm{~Hz}$ \\
\hline \multirow[t]{2}{*}{ Calculated pressure } & $\begin{array}{c}\text { Strength } \\
\text { CCCM } \\
\text { YuIPM-1200 }\end{array}$ & $\begin{array}{c}85.4 \\
215.5\end{array}$ & 0.59 & 2.68 & 1.05 & - \\
\hline & Stability & - & - & - & 1.08 & - \\
\hline \multirow[t]{2}{*}{ Temperature loading } & $\begin{array}{c}\text { Strength } \\
\text { CCCM } \\
\text { YuIPM-1200 }\end{array}$ & $\begin{array}{c}11.1 \\
9 \\
\end{array}$ & 4.73 & 1.50 & $>>1$ & - \\
\hline & Stability & - & - & - & 6.12 & - \\
\hline \multirow[t]{3}{*}{ Frequency analysis } & Sample 1 & - & - & - & - & 294 \\
\hline & Sample 2 & - & - & - & - & 302 \\
\hline & Sample 3 & - & - & - & - & 310 \\
\hline
\end{tabular}

Table 3. Results of CCCM tile calculations

\begin{tabular}{||c|c|c|c|c|c|c|c||}
\hline \hline Parameter & Studied factor & $\sigma_{\mathrm{b}}, \mathrm{MPa}$ & $\sigma_{\max }, \mathrm{MPa}$ & $V_{\max }, \mathrm{mm}$ & $W_{\max }, \mathrm{mm}$ & $\eta$ & $F, \mathrm{~Hz}$ \\
\hline \multirow{2}{*}{ Calculated pressure } & Strength & 90 & 70.3 & 0.40 & 1.40 & 1.28 & - \\
\cline { 2 - 9 } & Stability & - & - & - & - & 1.16 & - \\
\hline \multirow{2}{*}{ Temperature loading } & Strength & 130 & 10.7 & 0.63 & 1.48 & 12.10 & - \\
\cline { 2 - 9 } & Stability & - & - & - & - & 36.60 & - \\
\hline \multirow{2}{*}{ Frequency analysis } & Sample 1 & - & - & - & - & - & 742 \\
\cline { 2 - 9 } & Sample 2 & - & - & - & - & - & 762 \\
\cline { 2 - 9 } & Sample 3 & - & - & - & - & - & 808 \\
\hline
\end{tabular}

Table 4. Main results of calculations of TPS tile from silicate ceramics

\begin{tabular}{||c|c|c|c|c|c|c|c||}
\hline \hline Parameter & Studied factor & $\sigma_{\mathrm{b}}, \mathrm{MPa}$ & $\sigma_{\max }, \mathrm{MPa}$ & $V_{\max }, \mathrm{mm}$ & $W_{\max }, \mathrm{mm}$ & $\eta$ & $F, \mathrm{~Hz}$ \\
\hline \multirow{2}{*}{ Calculated pressure } & Strength & 50 & 27.8 & 0.85 & 4 & 1.80 & - \\
\cline { 2 - 9 } & Stability & - & - & - & - & 2.38 & - \\
\hline \multirow{2}{*}{ Temperature loading } & Strength & 50 & 25.2 & 1.1 & 0.23 & 1.98 & - \\
\cline { 2 - 9 } & Stability & - & - & - & 1.03 & 1.03 & - \\
\hline \multirow{2}{*}{ Frequency analysis } & Sample 1 & - & - & - & - & - & 271 \\
\cline { 2 - 9 } & Sample 2 & - & - & - & - & - & - \\
\cline { 2 - 9 } & Sample 3 & - & - & - & - & -293 \\
\hline
\end{tabular}

Table 5. Calculated values of tile parameters

\begin{tabular}{||l|c|c|c||}
\hline \multicolumn{1}{|c|}{ Material, structure type } & Weight, $\mathrm{g}$ & Load factor & $F, \mathrm{~Hz}$, at $T=20^{\circ} \mathrm{C}\left(1000{ }^{\circ} \mathrm{C}\right)$ \\
\hline CCCM & 371 & 1.16 & $742(742)$ \\
\hline Structure (silicate) ceramics & 920 & 1.03 & $271(271)$ \\
\hline YuIPM-1200, base with sheet load-carrying element & 1100 & 1.03 & $246(54)$ \\
\hline Same, base with three-layer corrugated panel & 760 & 1 & $219(48)$ \\
\hline Same, base with three-layer honeycomb panel & 612 & 1.17 & $428(94)$ \\
\hline Combined tile from CCCM and YuIPM-1200 & 670 & 1.05 & $294(64)$ \\
\hline
\end{tabular}


tone frequency at 20 and $1000{ }^{\circ} \mathrm{C}$ is equal to $742 \mathrm{~Hz}$. However, CCCM tiles require special protection of the external surface from loss at high temperatures, as well as development of cost-effective technologies of manufacturing thin-walled structures, that is practically impossible to implement at the modern level of engineering development.

Weight of thermal protection tile with external three-layer honeycomb panel from YuIPM1200 alloy is equal to $612 \mathrm{~g}$, that, even though it is higher than that of tile with CCCM body, still allows application of this structure for development of TPS of future shuttlecrafts. Here, an extremely important fact is the availability of extensive experience of manufacturing metal structures allowing development of technology of manufacturing tiles with external three-layer honeycomb panel. The main objective is manufacturing heat-resistant three-layer honeycomb panel. Adhesion joints do not ensure reliable operation of the structure in the service temperature range, therefore, it is necessary to develop the technology of manufacturing the honeycomb core by welding and its joining with panel skins.

Experimental studies showed that the honeycomb core can be made by welding the separate strips by passing current. The most complex task is welding the honeycomb core to the skins.

Such technologies for heat-resistant welded structures are developed at PWI.

The variant of thermal protection tiles with the combined body, having an external metal panel from YuIPM-1200 alloy and box made from CCCM, also looks promising. The weight of such a body is $670 \mathrm{~g}$, however, its practical implementation requires development of the technology of manufacturing thin-wall body from CCCM and technology of its welding to metal.

The weight of thermal protection tile with ceramic bodies is higher, and the load factor is lower, so that these structures are not attractive for application in thermal protection of future shuttlecrafts.

\section{Conclusions}

1. Influence of mechanical and thermal loading on thermal protection tiles with different loadcarrying layers from heat-resistant materials and packs of inner thermal insulation has been studied. It is found that thermal protection tiles with the body of CCCM and tiles with external threelayer honeycomb panel from YuIPM-1200 alloy have the best weight and strength characteristics.

2. Thermal protection tiles of CCCM require special protection of external surface from loss at high temperatures, as well as development of technologies of manufacturing thin-walled structures that makes them not cost-effective at present. Therefore, the most promising are the TPSs with external three-layer honeycomb panel from YuIPM-1200 alloy, which is resistant in oxidizing medium at service temperatures. Available experience of manufacturing metal products and their joining by various welding, as well as costeffectiveness of such technologies, should be also taken into account.

1. Gofin, M.Ya. (2003) Heat-resistant and thermal protection structures of shuttlecrafts. Moscow: Mir.

2. Koleda, V.V., Polozhaj, S.G., Potapov, A.M. et al. (2007) Thermal protection elements for shuttlecrafts. In: Proc. of 1st Int. Conf. on Advanced Space Technologies for Benefit of Mankind (18-20 April 2007, Dnepropetrovsk, Ukraine).

3. Tretiakov, Yu.D. Ceramics in the past, present and future. http:// www.pereplet.ru

4. Krenkel, W. (2008) Ceramic matrix composites. Weinheim: Wiley-VCH.

5. Glass, D.E., Capriotti, D.P., Reimer, T. et al. (2013) Testing of DLR C/C-SiC for HIFiRE \& Scramjet Combustor. In: Proc. of 7th Europ. Workshop on Thermal Protection Systems and Hot Structures (8-10 April 2013, Noordwijk, The Netherlands).

6. Tikhy, V.G., Gusev, V.V., Potapov, A.M. et al. (2014) Prospective thermal protection structure of shuttlecrafts with metal load-carrying element. In: Transact. of N.E. Zhukovsky NAU on Problems of Design and Production of Flying Vehicles, 28-43. Kharkov: KhAI.

Received 05.02.2015 


\title{
MANUFACTURE OF COAXIAL COPPER-ALUMINIUM RODS USING EXPLOSION WELDING AND DRAWING
}

\author{
A.G. BRYZGALIN ${ }^{1}$, L.D. DOBRUSHIN ${ }^{1}$, P.S. SHLENSKY ${ }^{1}$, I.G. LAVRENKO ${ }^{2}$ and I.M. ROMASHKO ${ }^{2}$ \\ ${ }^{1}$ E.O. Paton Electric Welding Institute, NASU \\ 11 Bozhenko Str., 03680, Kiev, Ukraine. E-mail: office@paton.kiev.ua \\ ${ }^{2} \mathrm{SE}$ «Antonov» \\ 1 Tupolev Str., 03082, Kiev, Ukraine. E-mail: info@antonov.com
}

\begin{abstract}
Replacement of copper during production of current-conducting busbars by aluminium clad with a thin layer of copper allows reducing metal intensity of products preserving the high electric conductivity. The technology of manufacture of coaxial copper-aluminium current-conducting rods using explosion welding and drawing was offered. The modes of heat treatment of rods after drawing were experimentally selected providing the required mechanical properties at a minimum number of forming intermetallics. The methods of calculation of sizes of initial billets providing obtaining the required geometric parameters of a product were described. The possibility of application of explosion reduction of billets instead of explosion welding is shown. 5 Ref., 2 Tables, 7 Figures.
\end{abstract}

$\boldsymbol{K} \boldsymbol{e} \boldsymbol{y} \boldsymbol{w} \boldsymbol{o} \boldsymbol{r} \boldsymbol{d} \boldsymbol{s}:$ copper-aluminium rods, electric conductivity, explosion welding, drawing, bimetal

The current-conducting busbars of electric equipment of critical purpose are produced of copper, having a high electric conductivity and, at the same time, a high density [1]. The replacement of solid copper busbars by aluminium ones with the thin copper layer provides a considerable decrease of mass of products preserving their electric conductivity. However, the existing technologies, which would allow producing bimetal billets admitting the further rolling and bending at big angles without violations of mechanical integrity and reliable electric contact, suppose using of the rather expensive import equipment.

To produce $\mathrm{Cu}-\mathrm{Al}$ bimetal in Ukraine and abroad the explosion welding is widely applied. This material finds application in power-consuming fields of industry as current-conducting and transition elements due to the transition resistance of a joint close to zero. In spite of the fact that both materials are characterized by high ductile properties, which is necessary to produce quality welded joint, the providing of full strength and zero defects in explosion welding is problematic by a number of reasons connected with considerable differences in physical and mechanical properties of metals and also rather unfavorable type of metallurgy interaction from the position of weldability with formation of a number of intermetallics of the $\mathrm{Al}_{2} \mathrm{Cu}, \mathrm{AlCu}, \mathrm{AlCu}_{2}$, $\mathrm{Al}_{2} \mathrm{Cu}_{3}$ type [2].

At the E.O. Paton Electric Welding Institute the technology of manufacture of bimetal $\mathrm{Cu}-\mathrm{Al}$ rods using explosion joining of copper shell with aluminium rod and further drawing was developed. According to the technical assignment (TA) it was necessary to manufacture the bimetal rods of 8 and $9 \mathrm{~mm}$ diameter with thickness of copper coating of not less than $0.3 \mathrm{~mm}$ and required level of mechanical properties: ultimate tensile strength of rod of not less than $90 \mathrm{MPa}$ and elongation of not less than $25 \%$.

Bimetal billet was manufactured by weldingon of copper tube with outer diameter of $28 \mathrm{~mm}$ and wall thickness of $1 \mathrm{~mm}$ to aluminium rod of $24 \mathrm{~mm}$ diameter. The given geometric parameters were selected basing on assumption about conservation of mass and volume of applied materials during drawing, conditions of providing the required finite sizes of rod and optimum modes of explosion welding. Aluminium rod 2 (Figure 1) was grinded to render it the shape, setting a welding gap and shaping of stem for the further

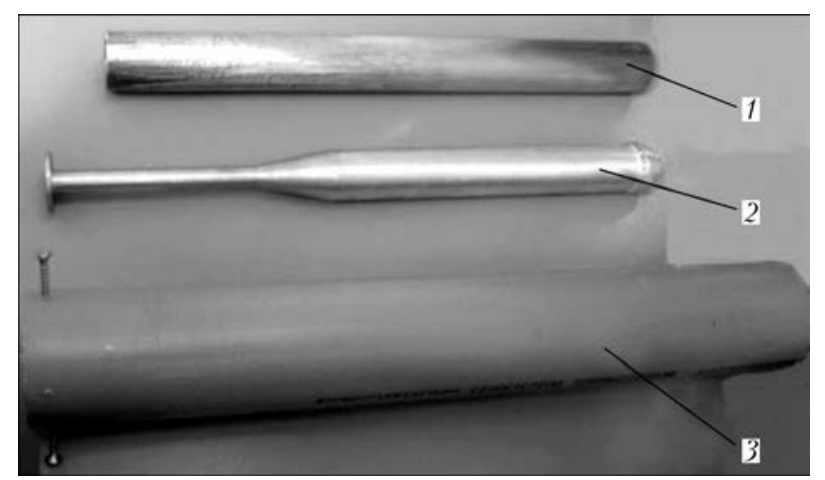

Figure 1. Basic composing elements for explosion welding of bimetal rod: 1 - copper tube; 2 - aluminium rod; 3 polyethylene pipe serving as a container for explosive 
Figure 2. Billet for drawing of bimetallic rod produced using explosion welding

drawing. The assembly for explosion welding was performed by positioning of aluminium rod inside the copper tube 1 with welding gap of $1 \mathrm{~mm}$. The copper tube in its turn was maximum inserted to the polyethylene pipe with inner diameter of $47 \mathrm{~mm}$, which served as a container for explosive 3.

The thickness of charge, representing a mixture of ammonite $6 \mathrm{ZhV}$ with ammonia niter, amounted to $9.5 \mathrm{~mm}$. The selected mode of welding provided producing of quality billets for the further drawing (Figure 2).

The joint boundary did not have a wave formation, characteristic of explosion welding, which evidences of performing welding at the lower limit of admissible modes, i.e. with minimum energy input [3]. It allowed minimizing the number of intermetallics formed in welding (about $10 \%$ along the length of the joint) ( $\mathrm{Fi}-$ gure $3, a)$.

The drawing of bimetal rods was performed in the equipment of the PWI Research Center «Explosion Treatment of Materials». It was found that optimum decrease of diameter of bimetal billet per one pass amounts to $0.5 \mathrm{~mm}$. Here it is not required to conduct heat treatment of billets at all the stages of drawing operation.

The investigation of mechanical properties of bimetal rods after drawing showed that they met the requirements specified by the customer. In this connection the rods were subjected to heat treatment at the modes given in Table 1. Figure 3 shows photos of microstructure of the joint in initial as-welded and as-drawn condition and after heat treatment at some of the mentioned modes. In the initial state the intermetallics are almost absent, after heat treatment at mode 2 (see Table 1) the intermetallics appeared, heat
Table 1. Mechanical properties of bimetal rods produced using explosion welding and drawing

\begin{tabular}{|c|c|c|c|c|}
\hline $\begin{array}{l}\text { Number } \\
\text { of mode }\end{array}$ & State of specimen & $\sigma_{\mathrm{y}}, \mathrm{MPa}$ & $\sigma_{\mathrm{t}}, \mathrm{MPa}$ & $\delta, \%$ \\
\hline 1 & Initial & 121 & 150 & 12 \\
\hline 2 & HT at $180{ }^{\circ} \mathrm{C}$ for $30 \mathrm{~min}$ & 143 & 150 & 13 \\
\hline 3 & HT at $250{ }^{\circ} \mathrm{C}$ for $60 \mathrm{~min}$ & 171 & 187 & 18 \\
\hline 4 & HT at $300{ }^{\circ} \mathrm{C}$ for $40 \mathrm{~min}$ & 127 & 149 & 28 \\
\hline 5 & $\mathrm{HT}$ at $350{ }^{\circ} \mathrm{C}$ for $60 \mathrm{~min}$ & 44 & 113 & 57 \\
\hline 6 & $\begin{array}{c}\text { «Copperweld» } \\
\text { bimetal rod (USA) }\end{array}$ & 186 & - & 11 \\
\hline
\end{tabular}

treatment at mode 5 resulted in increase of their number and sizes.

Mechanical properties of bimetal rods of $9 \mathrm{~mm}$ diameter, produced using explosion welding and drawing, and also bimetal rods, produced in the Copperweld installation (USA) of $8 \mathrm{~mm}$ diameter, and TA requirements are also given in $\mathrm{Ta}^{-}$ ble 1 .

The bimetal rods subjected to heat treatment at $300{ }^{\circ} \mathrm{C}$ for $40 \mathrm{~min}$, meet also TA requirements. Such products revealed a sufficiently high ability to deformation both at standard tests for bending (Figure 4) [4, 5], as well as at formation of contact areas of current-conducting busbars.

At the bending tests the rods without heat treatment withstood three bends at $180^{\circ}$ and had a fracture with separation of copper layer from aluminium base, the rods which passed heat treatment at mode 4 withstood 24 bends, and fracture had no delaminations.

The measurement of specific electric resistance $R$ of annealed bimetal rod (mode 4) to direct current in recalculation for temperature of $20{ }^{\circ} \mathrm{C}$, amounted to $0.027 \cdot 10^{-6} \mathrm{Ohm} \cdot \mathrm{m}$, which corresponds to TA requirements.

Achievement of the quality explosion welding of billets requires thorough keeping of welding parameters, that predetermines a high labor in-
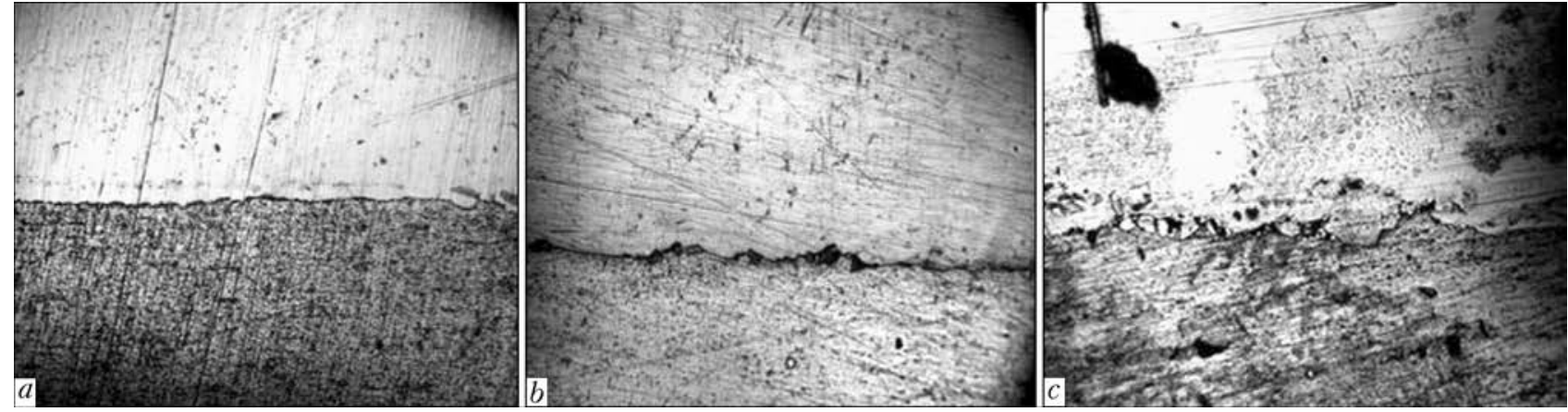

Figure 3. Microstructure $(\times 200)$ of $\mathrm{Cu}-\mathrm{Al}$ joint: $a-$ in initial state after welding and drawing; $b-$ after heat treatment at $180{ }^{\circ} \mathrm{C}$ for $30 \mathrm{~min} ; c$ - after heat treatment at $350{ }^{\circ} \mathrm{C}$ for $60 \mathrm{~min}$ 

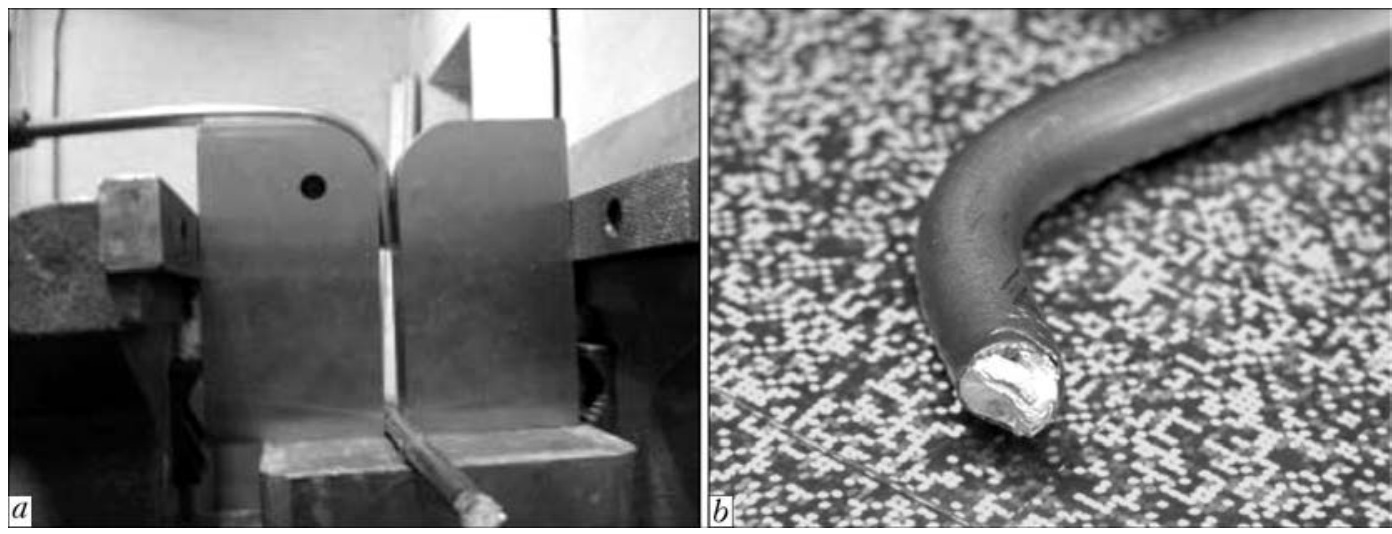

Figure 4. General view of bend test $(a)$, and appearance of rod fracture $(b)$

tensity of preparation operations. In this connection the peculiar interest is represented by a possibility of production of coaxial rods according to the explosion reduction + drawing scheme.

The joining of bimetal billet using reduction without forced formation of welded joint has a number of advantages:

- less severe requirements to the modes of explosion treatment as compared to explosion welding and, respectively, increase in efficiency and decrease in cost effectiveness;

- decrease in mass of the applied explosive charge;

- possibility of using explosives with any detonation rate.

Here, the explosion reduction provides cumulative cleaning of the surfaces being joined, that gives grounds to expect a possibility of diffusion welding, the process of which is accelerated during drawing and heat treatment of billets.

To manufacture coaxial bimetal rods according to the reduction + drawing scheme, the following billets were used:

- aluminium rod of AD1 grade of $15 \mathrm{~mm}$ diameter and $300 \mathrm{~mm}$ length;

- copper tube (M2) with outer diameter of $20 \mathrm{~mm}, 1 \mathrm{~mm}$ wall thickness and $300 \mathrm{~mm}$ length.

After explosion reduction the bimetal billet with variable diameter of $17.5-18.0 \mathrm{~mm}$ was produced. The difference in diameter along the billet length is explained by presence of air gaps between the layer of copper and aluminium rod. The volume of bubbles relatively to the volume of primary billets amounted to $10 \%$ (the volume of bubbles was calculated as a difference of volume of initial billets and bimetal billet after explosion reduction).

The bimetal rod was produced using drawing with a pitch of decrease of $0.5 \mathrm{~mm}$ diameter without intermediate heat treatment. The length of produced rod considering the technological losses on manufacture of stems for clamping of billet during drawing amounted to $930 \mathrm{~mm}$. The length of rod with quality coating after removal of beginning and end of the rod with a rejected coating amounted to $845 \mathrm{~mm}$, the visual inspection showed the absence of air bubbles and surface defects. The diameter of rod produced after drawing amounted to $8.91-8.94 \mathrm{~mm}$, the average value (according to 10 measurements) was $8.92 \mathrm{~mm}$. The thickness of copper layer was $0.535-0.6 \mathrm{~mm}$, the average value $-0.587 \mathrm{~mm}$.

Mechanical properties of bimetal specimens were determined directly after drawing and also after reduction according to mode $1\left(180{ }^{\circ} \mathrm{C}\right.$ for $0.5 \mathrm{~h})$ and mode $2\left(350{ }^{\circ} \mathrm{C}, 1 \mathrm{~h}\right)$. The data of tensile tests are given in Table 2 .

The examination of microstructure was carried out on sections in the initial state and after heat treatment at modes 1 and 2 (Figure 5).

For evaluation of influence of heat treatment on state of intermetallics the area of section in the initial state after reduction and drawing was selected (Figure 5, $a$ ). The same area of section with characteristic intermetallic inclusions is presented in Figure 5, $b$ and $c$ after heat treatment in the beginning at mode 1 and then at mode 2 . Mode 1 did not result in formation of intermetallic interlayer and growth of the existing intermetallics. During tempering at mode 2 the intermetallic interlayer of about $10 \mu \mathrm{m}$ thickness was formed.

The line of $\mathrm{Cu}-\mathrm{Al}$ joint has no delaminations and other defects of discontinuities. The areas with characteristic wave formation deformed after drawing are observed. On some waveless areas

Table 2. Mechanical properties of bimetal rods produced using explosion welding and drawing

\begin{tabular}{|c|c|c|c|c||}
\hline $\begin{array}{c}\text { Number } \\
\text { of mode }\end{array}$ & Type of specimen & $\sigma_{\mathrm{y}}, \mathrm{MPa}$ & $\sigma_{\mathrm{t}}, \mathrm{MPa}$ & $\delta, \%$ \\
\hline 1 & Initial & 144 & 150 & 12 \\
\hline 2 & $\mathrm{HT}$ at $180^{\circ} \mathrm{C}$ for $30 \mathrm{~min}$ & 143 & 150 & 13 \\
\hline 3 & $\mathrm{HT}$ at $350^{\circ} \mathrm{C}$ for $60 \mathrm{~min}$ & 44 & 113 & 57 \\
\hline
\end{tabular}




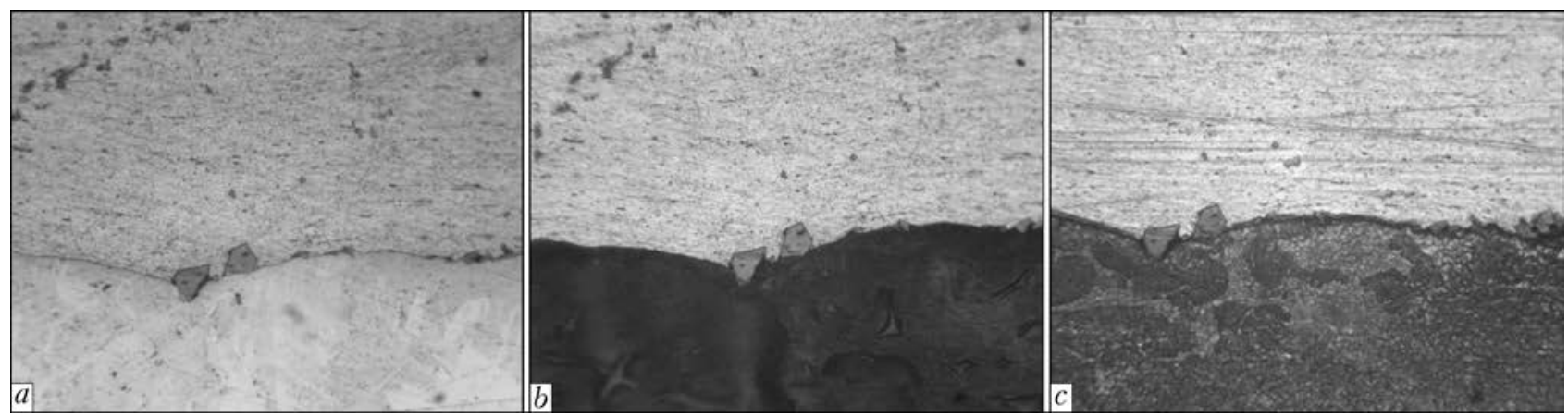

Figure 5. Microstructure $(\times 200)$ of joint: $a$ - in initial state after reduction and drawing; $b$ - after heat treatment at $180{ }^{\circ} \mathrm{C}$ for $30 \mathrm{~min} ; \mathrm{c}-$ after heat treatment at $350{ }^{\circ} \mathrm{C}$ for $60 \mathrm{~min}$

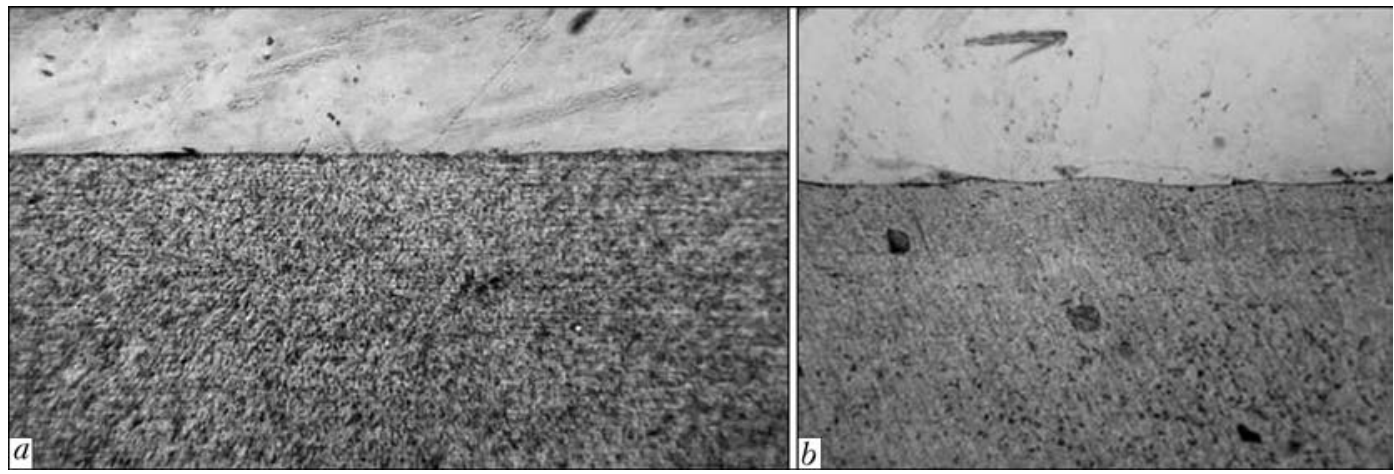

Figure 6. Microstructure $(\times 200)$ of a $\mathrm{Cu}-\mathrm{Al}$ joint after explosion reduction and drawing: $a-$ waveless joint; $b-$ introduction of aluminium particles to the copper base

along the line of joining in the zone of welding the chains of aluminium inclusions into the copper base are noted. Most obviously, in these spots the waves from explosion welding were broken during drawing, that resulted in introduction of aluminium particles to the copper base ( $\mathrm{Fi}^{-}$ gure 6).

The formation of intermetallics in the form of a chain of grains along the joining line was also revealed in some areas. The total length of areas with intermetallics amounts to about $20-25 \%$. Providing the required mechanical and electric parameters of the rod needs selection of optimal modes of explosion reduction (in the given case

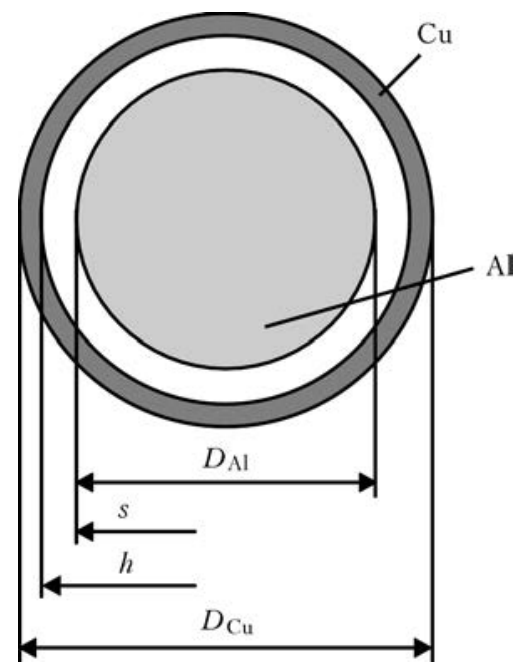

Figure 7. Parameters of coaxial billet for explosion welding decrease in the charge energy and decrease in the gap) and heat treatment.

For selection of optimum type and size of the initial billets of aluminium rod and copper tube (Figure 7) the method of calculation evaluation of their geometry parameters was proposed. Here it is supposed that welding gap between copper and aluminium is equal to thickness of wall of copper tube (that corresponds to the practical modes of welding) and calculation values of the second order of smallness are neglected.

The customer preset the diameter of $\operatorname{rod} d$, which should be manufactured and the admissible thickness of copper layer $h_{\mathrm{i}}$ in it. During manufacture of billets they are oriented to the purchased copper tube with the standard type and size determined by its outer diameter $D_{\mathrm{Cu}}$ and thickness of wall $h$. To increase the efficiency, $D_{\mathrm{Cu}}$ should be as high as it can and limited by the capabilities of drawing equipment. Basing on these assumptions the standard diameter of the copper tube is selected and the calculation thickness of its wall is determined according to the expression

$$
h_{\mathrm{c}}=h_{\mathrm{i}} D_{\mathrm{Cu}} / d .
$$

The value $h$ is determined by the approximation $h_{\mathrm{c}}$ up to the highest standard one. The thickness of copper layer in the product is calculated by the expression 


$$
h_{\mathrm{i}}=h d / D_{\mathrm{Cu}}
$$

and will be deliberately higher than that determined by the customer. Varying the standard diameter of copper tube, one can select its most optimum type and size considering the requirements to the value $h_{\mathrm{i}}$ and efficiency of the process of manufacture of the rod.

The diameter of aluminium $\operatorname{rod} D_{\mathrm{Al}}$ is calculated in the following way:

$$
D_{\mathrm{Al}}=D_{\mathrm{Cu}}-2 h-2 s,
$$

where $s$ is the welding gap.

The coefficient of elongation is determined during drawing:

$$
K=\left(D_{\mathrm{Cu}}^{2}-4 D_{\mathrm{Al}} h\right) / d^{2} .
$$

The length of cylindrical part of billets $L_{\mathrm{b}}$ is determined basing on the minimum length of rod $L_{\mathrm{r}}$ preset by the customer:

$$
L_{\mathrm{b}} \geq L_{\mathrm{r}} / K+L_{\mathrm{st}},
$$

where $L_{\text {st }}$ is the length of billet considering the manufacture of intermediate stems and is determined by the drawing technology.

According to the results of $\mathrm{R} \& \mathrm{D}$ the batch of $\mathrm{Cu}-\mathrm{Al}$ rods of 8 and $9 \mathrm{~mm}$ diameter was manufactured allowing practicing the technology of manufacture of current-conducting busbars and carrying out their tests.

\section{Conclusions}

1. The technology of manufacture of $\mathrm{Cu}-\mathrm{Al}$ rods for electric engineering purposes using explosion welding and drawing providing their high ductile and electric conducting properties was developed.

2. The principal possibility of manufacture of a rod using explosion reduction and drawing was shown.

3. The technical specifications «Aluminiumcopper electrotechnical rod of the PAM grade» on manufacture and delivery of copper-aluminium rods of $8-10 \mathrm{~mm}$ diameter were worked out.

1. GOST 434-78: Wire of rectangular section and copper busbars for electric engineering purposes. Technical assignment

2. Kudinov, V.M., Koroteev, A.Ya. (1978) Explosion welding in metallurgy. Moscow: Metallurgiya.

3. Lysak, V.I., Kuzmin, S.V. (2005) Explosion welding. Moscow: Mashinostroenie.

4. GOST 1579-93: Wire. Overbending tests

5. GOST 7229-76: Cables, wires and cords. Method for determination of electric resistance of conductive cores and conductors.

Received 26.01.2015 


\title{
INDUCTOR FOR CONTINUOUS HEATING IN HARDENING OF RAILWAY RAIL HEAD
}

\author{
E.A. PANTELEJMONOV and A.A. PISMENNY \\ E.O. Paton Electric Welding Institute, NASU \\ 11 Bozhenko Str., 03680, Kiev, Ukraine. E-mail: office@paton.kiev.ua
}

\begin{abstract}
Heat treatment of railway rails using HF current heating should be carried out considering the energy consumption for heating equipment service. The increase of efficiency of heat treatment process can be provided by improvement of the inductor design. The peculiarities of distribution of temperature field in the head of rail of R65 type at induction heating with current of $2.4 \mathrm{kHz}$ frequency under the conditions of stationary position of inductor relative to the rail were investigated. The models of inductors with different design of coils of inductive wire of magnetic core were used. It is shown that to achieve primary heating of rolling surface, as compared to side edges of the rail head, and to decrease the capacity of power source is possible by design of the inductor where windings of inductive wire are located across the rolling surface, along the rolling surface and along the lower part of side edges, and magnetic core embraces a part of windings of inductive wire over the rolling surface. The application of additional magnetic cores embracing the part of windings of inductive wire along the side edge of rail head, results in leveling of heating of a fillet, side edges and lower part of side edges. 6 Ref., 1 Table, 4 Figures.
\end{abstract}

$\boldsymbol{K} \boldsymbol{e} \boldsymbol{y} \boldsymbol{w} \boldsymbol{o} \boldsymbol{r} \boldsymbol{d} \boldsymbol{s}:$ rails, heat treatment of rails, induction HF current heating, inductors

The surface heat treatment (HT) of railway rail head with application of induction heating using HF currents is directed to improvement of physical and mechanical properties of rails and decrease of their stressed state. The concentration of energy in surface layer of metal, characteristic of $\mathrm{HF}$ current heating, provides high rates of heating across the thickness of head surface, allows controlling the level of dispersity of structure and size of austenite grain [1, 2]. At the same time HT with HF current heating is a sufficiently complex and power consuming process.

The HT technology of head of rails using continuously successive method in rail hardening machine (RHM) includes heating of rail head in three sections of inductors. After passing of the first and second sections of inductors the rail head is heated with considerable gradient of temperatures of surface and deep layers of metal. The exceeding in heating temperature of side edges is observed as compared to rolling surface. With the purpose of leveling the temperature field across the head section, the rail gets to the zone free from heating. The further heating of the rail head up to the preset temperature occurs in the third section of inductors. According to the requirements of technological instruction on production of railway rails of R65 type in RHM, HF current heating should provide the temperature at the head surface in range of $920-970{ }^{\circ} \mathrm{C}$ and depth of hardened layer of not less than $11 \mathrm{~mm}$. To reach such parameters of heating at the speed of movement of rails of $42-46 \mathrm{~mm} / \mathrm{s}$ and frequency of current of $2.4 \mathrm{kHz}$

(C) E.A. PANTELEJMONOV and A.A. PISMENNY, 2015 a total capacity of inductors of $1120-1220 \mathrm{~kW}$ is required $[3,4]$.

Under the conditions of high power capacity of HT with HF current heating the very urgent and important task is the decrease of power consumptions at operation of induction heating equipment. One of the ways of increasing its efficiency is improvement of design of inductors to attain the redistribution of temperature field in the rail head in the direction of primary heating of rolling surface as compared to side edges.

At the present work the influence of design of inductors on formation of temperature field in R65 rail head in stationary position of inductors relative to the rail was investigated. The inductors with different configuration of coils of inductive wire and magnetic cores were used.

In the design of inductor 1 (Figure 1,a) the coil of inductive wire repeats the shape and sizes of coils of inductors of the first and second sections of RHM. The coil of $\Pi$-shape consists of two windings of inductive wire, which embrace the rail head across the rolling surface and along the lower part of side edges of the head, closer to the rail neck. The instant direction of current in the windings of inductive wire is concordant. The length of coil along the rail head is $160 \mathrm{~mm}$. The size of air gap between the windings of inductive wire and rail head surface is $10 \mathrm{~mm}$. Magnetic core of plates of transformer steel of E-shape embraces windings of inductive wire in the places of their location across the rolling surface. Magnetic core is designed for increase of concentration of induced current under the windings of inductive wire and surface of head after the loss of the magnetic properties by the latter $[5,6]$. 

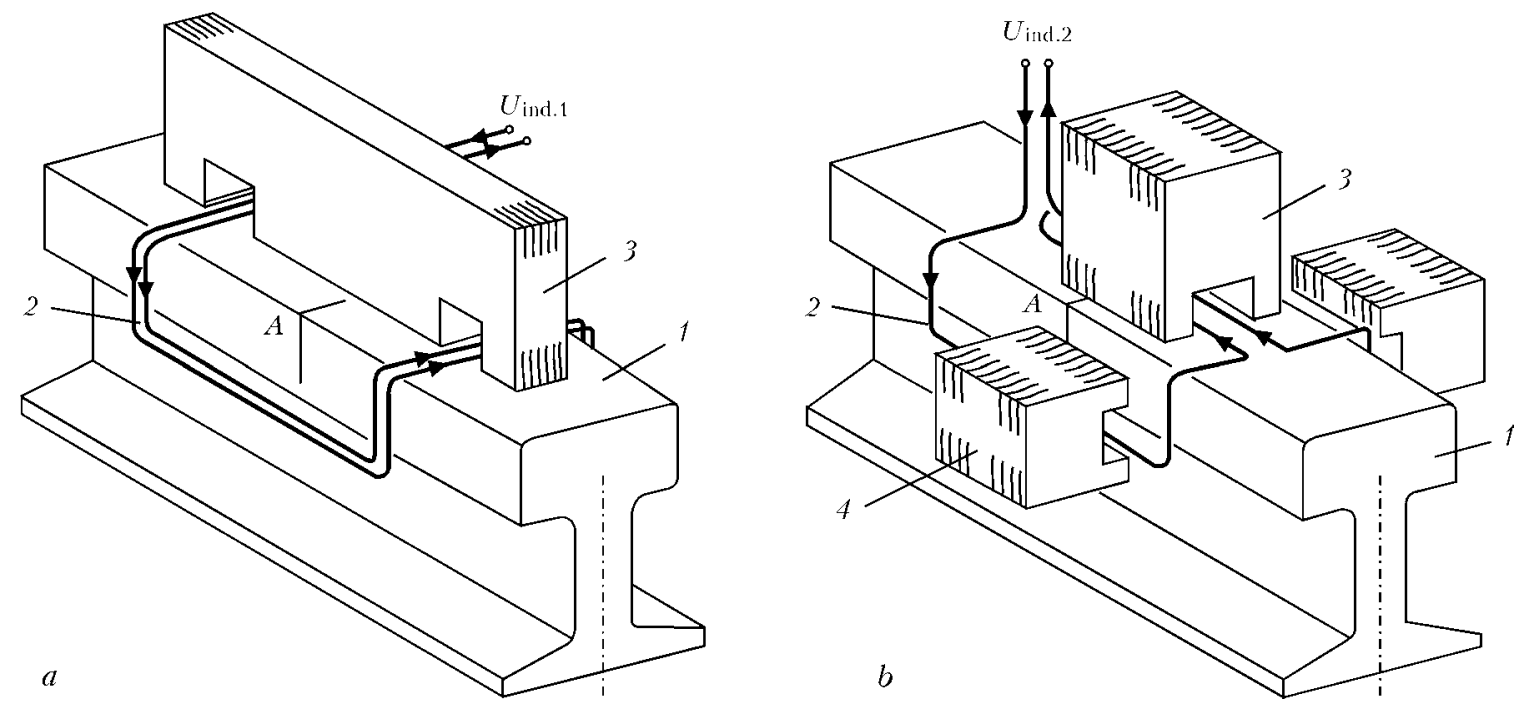

Figure 1. Design of inductors $1(a)$ and $2(b)$ for rail head heating: 1 - rail of R65 type; 2 - inductive wire; 3 main magnetic core; 4 - additional magnetic cores

The design of inductor 2 (Figure $1, b$ ) is characterized by that the part of windings of inductive wire is located along the rolling surface. The instant direction of current in this part of windings is concordant. The length of coil is $160 \mathrm{~mm}$, the size of air gap is $10 \mathrm{~mm}$. The main magnetic core embraces a part of windings of inductive wire over the rolling surface. Along the head side edges the additional magnetic cores installed. The plates of main and additional magnetic cores of П-shape are oriented across the rolling surface and across the side edges of rail head.

As a power source of inductors the thyristor frequency converter was applied connected according to the scheme to the matching transformer. The rated frequency of current was $2.4 \mathrm{kHz}$. For measurement of temperature of rail head heating the chromel-alumel thermal electric transducers were positioned in the points of cross section $A$ (see Figure 1), equidistant from edges of the coil of inductive wire along the length of the rail. The scheme of positioning of transducers is given in Figure 2.

The rail head heating was performed at the modes given in the Table. The capacity of power source in switching on of inductor 2 , as compared to inductor 1 , is lower, and coefficient of power is higher. The ratio of voltages and currents of

Electric parameters of modes of the rail head heating

\begin{tabular}{||l|c|c|c||}
\hline \multirow{2}{*}{ Parameter } & Inductor 1 & $\begin{array}{c}\text { Main } \\
\text { magnetic } \\
\text { core }\end{array}$ & $\begin{array}{c}\text { Main and } \\
\text { additional } \\
\text { magnetic } \\
\text { cores }\end{array}$ \\
\hline Power source capacity, kW & 44.8 & 36.4 & 27.5 \\
\hline Voltage of inductor $U_{\text {ind }}, \mathrm{V}$ & 56 & 26 & 26 \\
\hline $\begin{array}{l}\text { Current of inductor } I_{\text {ind }}, \\
\text { rel. un. }\end{array}$ & 4.5 & 3.0 & 2.3 \\
\hline $\begin{array}{l}\text { Power coefficient of induc- } \\
\text { tor cos } \varphi_{\text {ind }}\end{array}$ & 0.122 & 0.240 & 0.260 \\
\hline
\end{tabular}

inductors (Rogowski coil) is $U_{\text {ind.1 }}>U_{\text {ind.2 }}$ and $I_{\text {ind.1 }}>I_{\text {ind.2. }}$. The application of additional magnetic cores in the design of inductor 2 resulted in decrease of capacity of power source from 36.4 to $27.5 \mathrm{~kW}$ at the voltage $U_{\text {ind } .2}=26 \mathrm{~V}$.

The appropriate distribution of temperature field in the rail head is characterized by temporary dependencies of temperature in the points $1-6$ of the rail head, given in Figures 3 and 4. During switching on of inductor 1 (Figure $3, a$ ), the rate of heating of the lower part of side edges of rail head $\left(6.5^{\circ} \mathrm{C} / \mathrm{s}\right.$, points 5 and 6$)$ is higher than that of the fillet $\left(4.9{ }^{\circ} \mathrm{C} / \mathrm{s}\right.$, point 4$)$ and rolling surface $\left(4.5^{\circ} \mathrm{C} / \mathrm{s}\right.$, point 2$)$.

Here the action of induced current in the rail head is appeared, which passes across the rolling surface and along the side edges, closer to the rail neck. The close values of heating rate in points 1,2 and 3 of rail head are predetermined

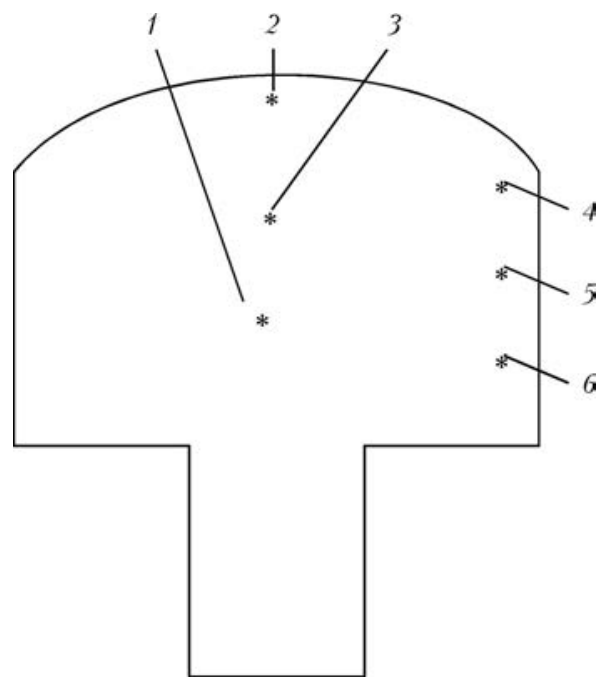

Figure 2. Scheme of positioning of thermal electric transducers in points $1-6$ of cross section of rail head: along the axis of symmetry of rail at depth of 20 (1), 5 (2) and 13 (3) $\mathrm{mm}$ from the rolling surface; at depth of $5 \mathrm{~mm}$, respectively, along the fillet (4), along the centre of side edges (5) and in the lower part of side edges (6) 

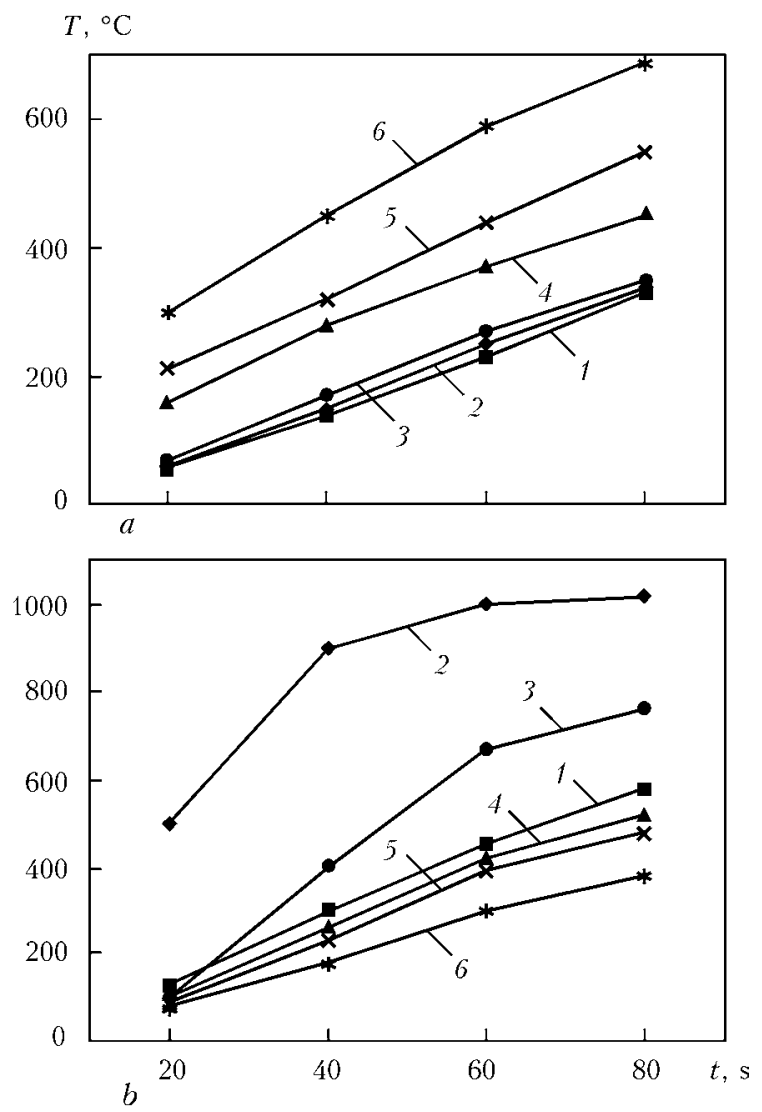

Figure 3. Temporary dependencies of temperature of heating in points $1-6$ of rail head: $a-$ inductor $1 ; b-$ inductor 2 (main magnetic core)

by spreading of temperature field from the side edges to head centre. Within $80 \mathrm{~s}$ of heating (Figure 4) temperature of the lower part of side edges $\left(690^{\circ} \mathrm{C}\right.$, point 6$)$ is higher than that of the fillet $\left(450{ }^{\circ} \mathrm{C}\right.$, point 4$)$ and rolling surface $\left(340{ }^{\circ} \mathrm{C}\right.$, point 2$)$.

During heating of rail head using inductor 2, in design of which the main magnetic core was used, induced current passes along the rolling surface, across the rolling surface and along the side edges. It results in sharp increase of rates of heating in points 1,2 and 3 of rail head (see Figure $3, b$ ) till the moment of reaching of Curie point (about $750{ }^{\circ} \mathrm{C}$ ). In point 2 of rolling surface the rate of heating is $20^{\circ} \mathrm{C} / \mathrm{s}$. The rate of heating of fillet increased $\left(7^{\circ} \mathrm{C} / \mathrm{s}\right.$, point 4$)$, but it decreased in the lower part of side edges $\left(4.2^{\circ} \mathrm{C} / \mathrm{s}\right.$, point 6 ). After $80 \mathrm{~s}$ of heating (see Figure 4), the temperature of rolling surface amounted to 1020 (point 2), of fillet - 520 (point 4) and of side edges $-480{ }^{\circ} \mathrm{C}$ (point 5). The heating temperature at depth of $13 \mathrm{~mm}$ from the rolling surface reached $760{ }^{\circ} \mathrm{C}$ (point 3), and at the depth of $20 \mathrm{~mm}-580{ }^{\circ} \mathrm{C}$ (point 1). The gradient of temperatures at depth of 5-20 $\mathrm{mm}$ from the rolling surface is $260{ }^{\circ} \mathrm{C}$ (points 2 and 3 ). The application of additional magnetic cores in the design of inductor 2 resulted in leveling of heating of the fillet (point 4), side edges (point 5) and

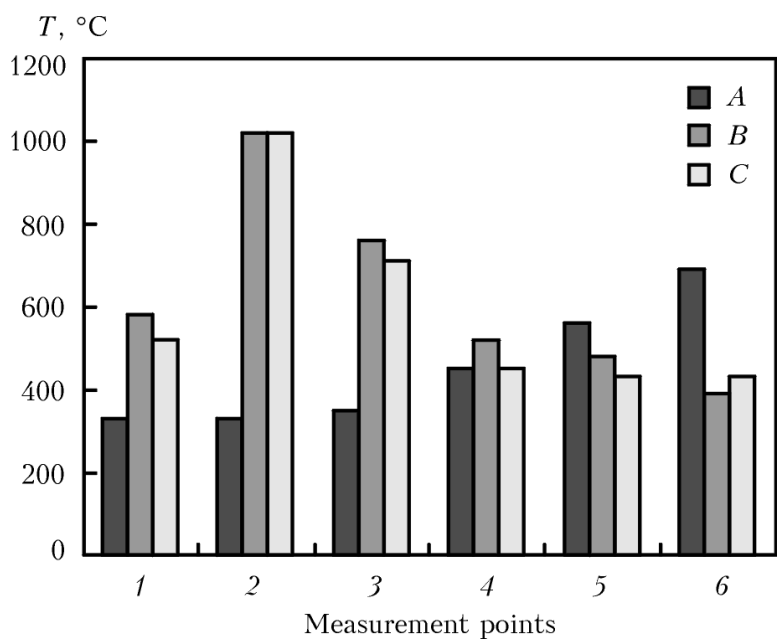

Figure 4. Finite values of temperature in points $1-6$ of rail head through $80 \mathrm{~s}$ of heating: $A-$ inductor $1 ; B-$ inductor 2 (main magnetic core); $C$ - inductor 2 (main and additional magnetic cores)

lower part of side edges. The temperature in those points was $430-450{ }^{\circ} \mathrm{C}$.

\section{Conclusions}

1. To reach the primary heating of rolling surface, as compared to the side edges of rail head, and considerable decrease of capacity of power source is possible by the design of inductor where windings of inductive wire are positioned across the rolling surface, along the rolling surface and along the lower part of side edges, and magnetic core embraces the part of windings of inductive wire over the rolling surface.

2. Application of additional magnetic cores embracing the part of windings of induced current along the side edges of rail head, results in leveling of heating of the fillet, side edges and lower part of side edges.

3 . The carried out investigations allow recommending the design of inductor for application in one of the sections of RHM with the purpose of primary heating of rolling surface as compared to the side edges.

1. Nesterov, D.K. Sapozhkov, V.E., Levchenko, N.F. et al. (1990) Heat treatment of rail steel using the induction heating. Metallovedenie $i$ Term. Obrab. Metallov, 8, 30-34.

2. Golovin, G.F., Zimin, N.V. (1979) Technology of heat treatment of metals using the induction heating. Leningrad: Mashinostroenie.

3. Firstov, S.O., Trotsan, A.P., Kaverinsky, V.V. et al. Method of heat treatment of rails. 'Pat. 76555 Ukraine. Int. Cl. S21D 9/04. Publ. 10.01.2013.

4. Chervinsky, V.I., Shevchenko, V.G. (2010) Application of induction heating in manufacturing and strengthening of products designed for railway transport. Indukts. Nagrev, 4, 18-20.

5. Taras, P., Fireteanu, B. (2010) Inductors for continuous induction heating of rails. Ibid., 4, 21-26.

6. Slukhotsky, A.E., Ryskin, S.G. (1974) Inductors for induction heating. Leningrad: Energiya.

Received 12.01.2015 


\section{MEETING OF BORIS E. PATON, PRESIDENT OF THE NAS OF UKRAINE, WITH CARLOS MOEDAS, EU COMMISSIONER}

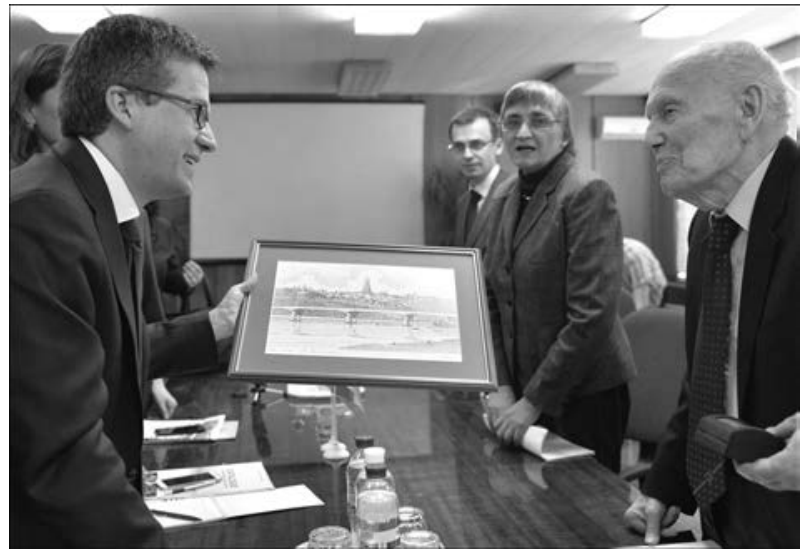

Presentation of «E.O. Paton Bridge» engraving to Carlos Moedas

On March 20, 2015, a meeting of Prof. B.E. Paton, President of the National Academy of Sciences of Ukraine, with EU delegation led by Carlos Moedas, EU Commissioner on Science, Research and Innovation, was held at the E.O. Paton Electric Welding Institute.

The meeting was connected with a significant event in the academic life of our country - signing of the Agreement on Ukraine's participation in «Horizon 2020», EU Program on research and innovations.

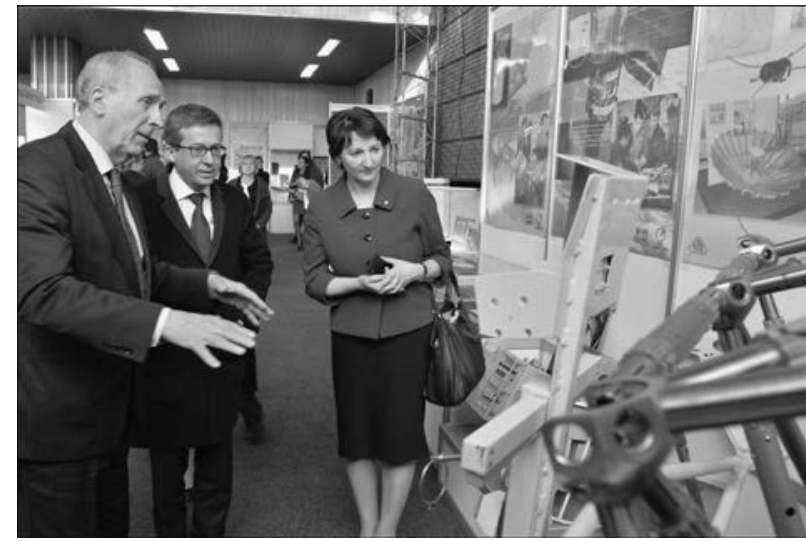

Visit to PWI demonstration hall

«Horizon 2020» is the EU 8th Framework Program on research and innovations. It started in 2014 and is designed for 7 years. This Program aimed at support of research and innovative activity in all the spheres of public life and unites all EU programs on funding research and innovations. Its overall budget is equal to about 80 bln Euros.

Having signed the Agreement, Ukraine gained access to the entire range of events, funded under the Program. Scientists can use modern scientific resources, electronic databases, and compete for

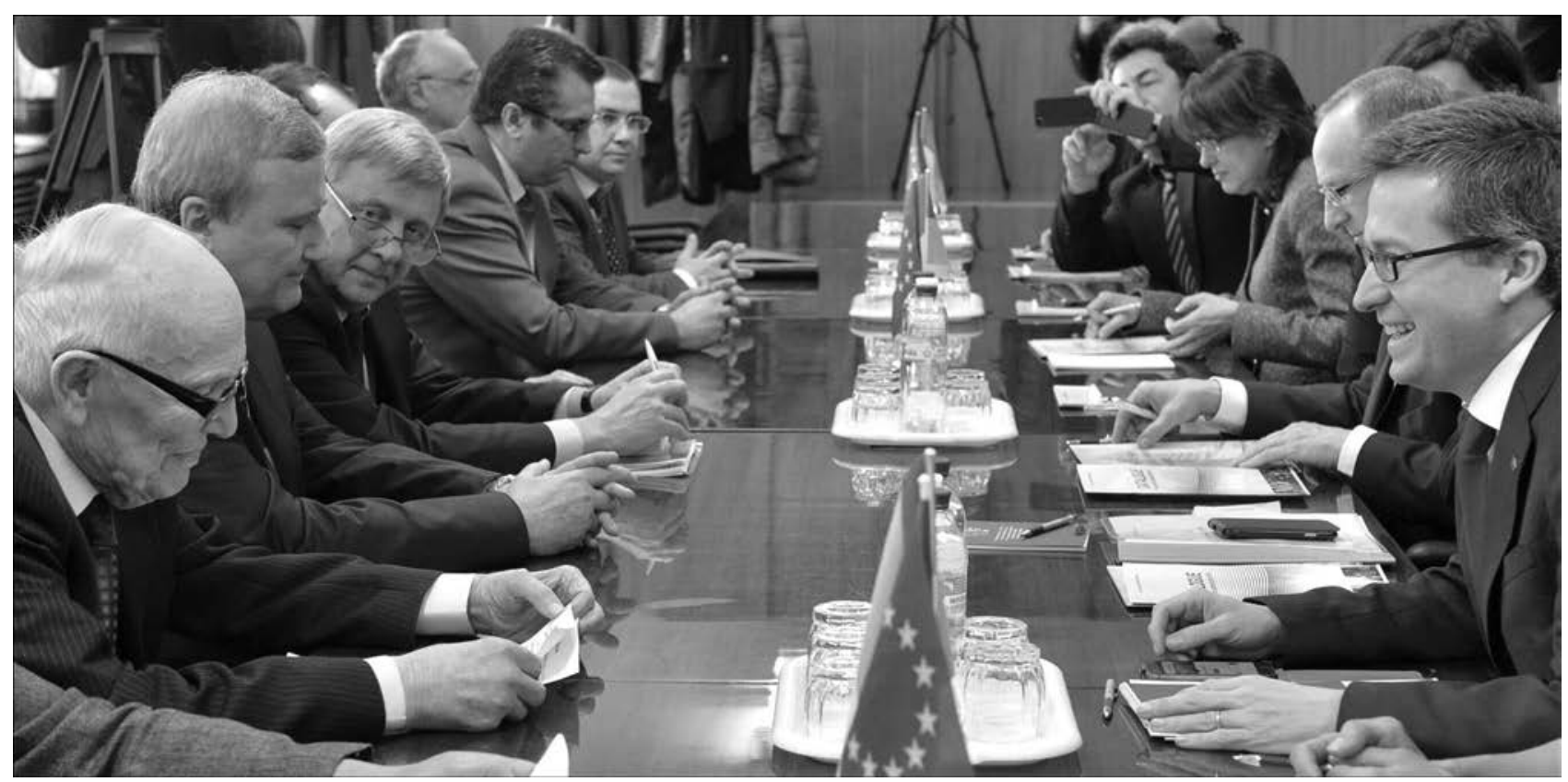

Meeting with EU delegation at PWI 


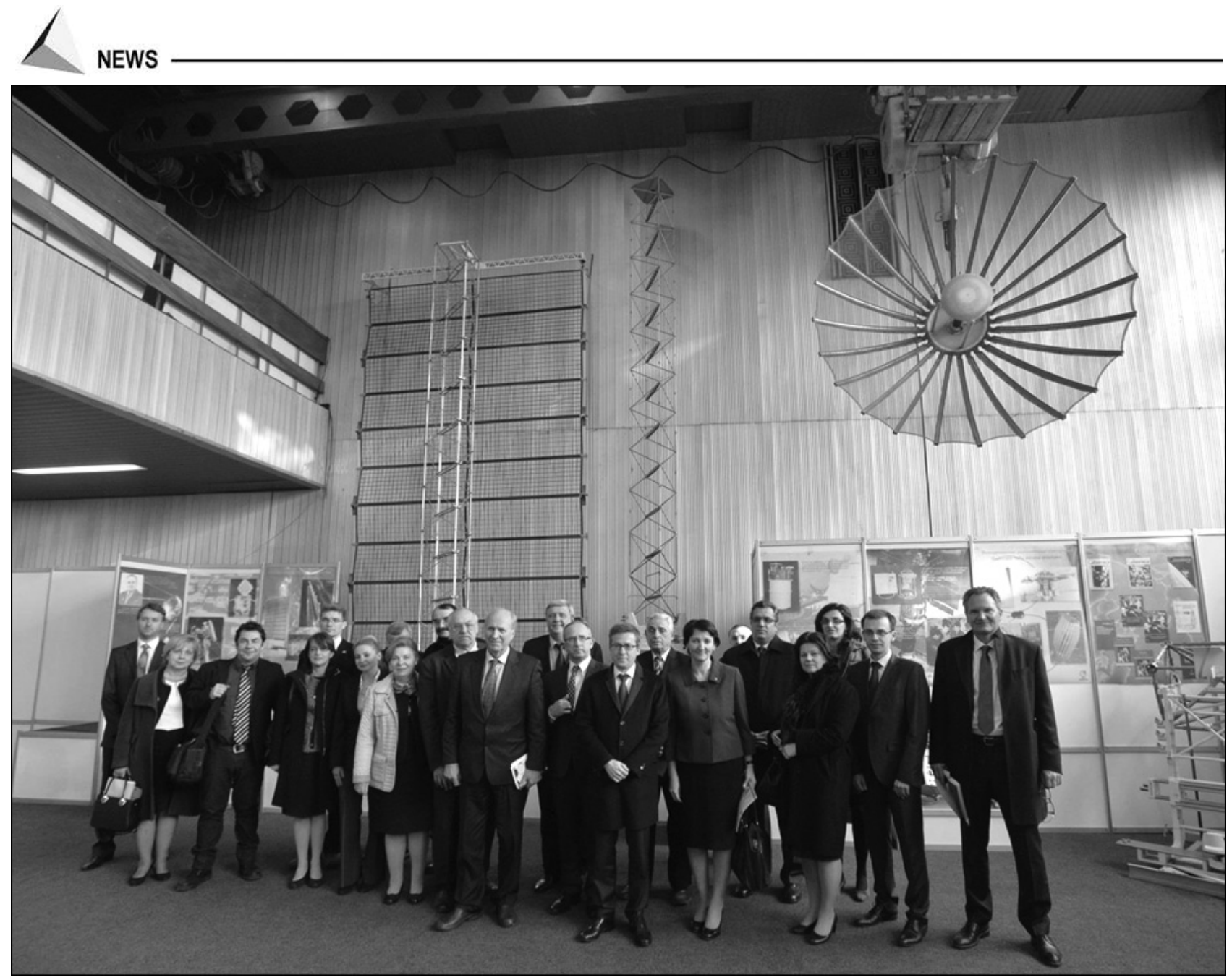

Meeting participants in PWI demonstration hall

grants with European colleagues. «Horizon 2020» program participants can be academic institutes, research centers, higher educational establishments, science and production enterprises or small and medium businesses. Ukraine received from EU the unprecedented $95 \%$ discount and annual postponement of the first fee for participation in the Program.

During the meeting Boris E. Paton welcomed signing of the agreement and thanked Carlos Moedas for supporting Ukrainian science and the possibility provided to Ukrainian scientists of open access to the European research space, and expressed his confidence that participation in the Program will promote widening of cooperation of the NAS of Ukraine with its numerous European partners.

Boris E. Paton noted the extensive positive experience of international cooperation. Just within the EU 7th Framework Program the institutes of the NASU fulfilled 92 joint projects with their colleagues from all the European countries. President of the NASU particularly emphasized the many-year participation of PWI in fulfillment of international programs, including the
EU 7th Framework Program. The subjects of these projects are related to fundamental research in the field of welding technologies, materials science and new materials.

In his reply, Carlos Moedas expressed his deep gratitude to Boris Paton, and emphasized the special significance of PWI joint projects under EU Programs and noted the wide possibilities opened up by «Horizon 2020» for Ukrainian science.

Marite Seile, Minister of Education and Science of Latvia, delegation participant, also thanked Prof. Paton and welcomed the signing of the Agreement. She noted the special role of PWI in combining fundamental research with applied developments, and expressed her confidence that signing of the Agreement on Ukraine's participation in «Horizon 2020» Program will be a new stage in development of Ukrainian science that will provide an impetus for new innovative developments.

After the meeting, EU delegation visited PWI demonstration hall and was familiarized with PWI most recent developments.

From materials of the NASU press-service 